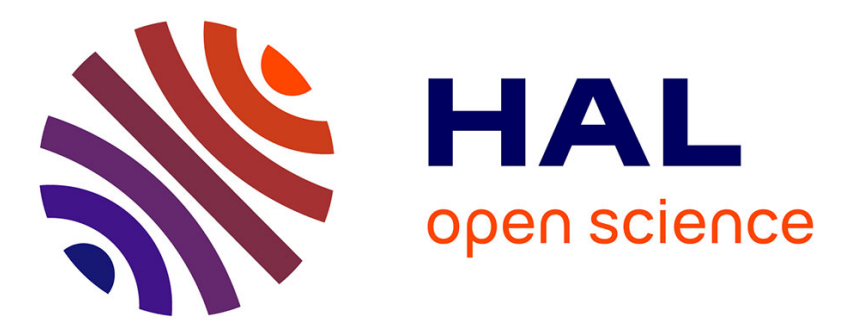

\title{
CALL and professionalisation: short papers from EUROCALL 2021
}

Naouel Zoghlami, Cédric Brudermann, Cédric Sarré, Muriel Grosbois, Linda Bradley, Sylvie Thouësny

\section{- To cite this version:}

Naouel Zoghlami, Cédric Brudermann, Cédric Sarré, Muriel Grosbois, Linda Bradley, et al.. CALL and professionalisation: short papers from EUROCALL 2021. 1, Research-publishing.net, 336 p., 2021, 978-2-490057-97-9. 10.14705/rpnet.2021.54.9782490057979 . hal-03909201

\section{HAL Id: hal-03909201 \\ https://hal.science/hal-03909201}

Submitted on 22 Dec 2022

HAL is a multi-disciplinary open access archive for the deposit and dissemination of scientific research documents, whether they are published or not. The documents may come from teaching and research institutions in France or abroad, or from public or private research centers.
L'archive ouverte pluridisciplinaire HAL, est destinée au dépôt et à la diffusion de documents scientifiques de niveau recherche, publiés ou non, émanant des établissements d'enseignement et de recherche français ou étrangers, des laboratoires publics ou privés.

\section{(ㅇ)(1) $\$$}

Distributed under a Creative Commons Attribution - NonCommercial - NoDerivatives $\mid 4.0$ 



\section{CALL and professionalisation: short papers from EUROCALL 2021}

Edited by Naouel Zoghlami, Cédric Brudermann, Cedric Sarré, Muriel Grosbois, Linda Bradley, and Sylvie Thouësny 


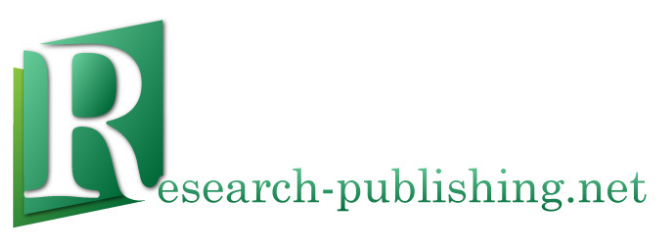

Published by Research-publishing.net, a not-for-profit association Contact: info@research-publishing.net

(C) 2021 by Editors (collective work)

(C) 2021 by Authors (individual work)

CALL and professionalisation: short papers from EUROCALL 2021

Edited by Naouel Zoghlami, Cédric Brudermann, Cedric Sarré, Muriel Grosbois, Linda Bradley, and Sylvie Thouësny

Publication date: 2021/12/13

Rights: the whole volume is published under the Attribution-NonCommercial-NoDerivatives International (CC BY-NCND) licence; individual articles may have a different licence. Under the CC BY-NC-ND licence, the volume is freely available online (https://doi.org/10.14705/rpnet.2021.54.9782490057979) for anybody to read, download, copy, and redistribute provided that the author(s), editorial team, and publisher are properly cited. Commercial use and derivative works are, however, not permitted.

Disclaimer: Research-publishing.net does not take any responsibility for the content of the pages written by the authors of this book. The authors have recognised that the work described was not published before, or that it was not under consideration for publication elsewhere. While the information in this book is believed to be true and accurate on the date of its going to press, neither the editorial team nor the publisher can accept any legal responsibility for any errors or omissions. The publisher makes no warranty, expressed or implied, with respect to the material contained herein. While Researchpublishing.net is committed to publishing works of integrity, the words are the authors' alone.

Trademark notice: product or corporate names may be trademarks or registered trademarks, and are used only for identification and explanation without intent to infringe.

Copyrighted material: every effort has been made by the editorial team to trace copyright holders and to obtain their permission for the use of copyrighted material in this book. In the event of errors or omissions, please notify the publisher of any corrections that will need to be incorporated in future editions of this book.

Typeset by Research-publishing.net

Cover Theme by (C) 2021 DIRCOM CNAM; Graphiste : Thomas Veniant

Cover Photo by (C) 2021 Léo Andres, Sorbonne Université

Cover Photo by (C) 2021 Sandrine Villain, Le Cnam

Cover Layout by (C) 2021 Raphaël Savina (raphael@savina.net)

Fonts used are licensed under a SIL Open Font License

ISBN13: 978-2-490057-97-9 (PDF, colour)

British Library Cataloguing-in-Publication Data.

A cataloguing record for this book is available from the British Library.

Legal deposit, France: Bibliothèque Nationale de France - Dépôt légal: décembre 2021. 


\section{Table of contents}

ix Peer-review committee

xiii Preface

Naouel Zoghlami, Cédric Brudermann, Cédric Sarré, and Muriel Grosbois

1 Assessing the quality of TTS audio in the LARA learning-by-reading platform

Elham Akhlaghi, Anna Baczkowska, Harald Berthelsen, Branislav Bédi,

Cathy Chua, Catia Cucchiarini, Hanieh Habibi, Ivana Horváthová, Pernille Hvalsøe, Roy Lotz, Christèle Maizonniaux, Neasa Ní Chiaráin, Manny Rayner, Nikos Tsourakis, and Chunlin Yao

6 TextMix: using NLP and APIs to generate chunked sentence scramble tasks Brendon Albertson

12 Is it a blessing? The impact of Covid-19 on non-traditional language learners' satisfaction at Saudi Electronic University Amera Alharbi, Vicky Wright, and Kate Borthwick

18 Intercultural exchanges among pre-service teachers in Israel and Sweden as a path of introduction into the epistemology and practice of teaching Christopher Allen, Stella Hadjistassou, David Richardson, and Tina Waldman

23 Online translators for L2 writing: a comparison of student and teacher perspectives

Antonie Alm and Yuki Watanabe

29 Assessing attitudes of university students toward online classes of Icelandic as a foreign and second language during COVID-19

Branislav Bédi and Lara Roje

35 Constructing meaning in a different language: the case of doctoral students in a French University

Albana Canollari-Baze and Gaby David 
41 Interaction games to boost students' engagement in foreign language virtual exchanges: the case of virtual worlds and video-communication Silvia Canto and Kristi Jauregi-Ondarra

46 The mediating effects of teacher-student power relations in a blended English course for academic purposes

Li Cheng

52 Context, method, and theory in CALL research articles Yazdan Choubsaz, Alireza Jalilifar, and Alex Boulton

57 The affective benefits of speech recognition systems on pronunciation monitoring Junko Chujo

63 A needs survey of overseas Irish language learners Ronan Connolly

69 The challenges of dynamic teacher training for a short English for academic purposes course when using multimodal digital platforms: a case study

Karla K. de Lima Guedes and Vanessa Mar-Molinero

75 Collaborative skills in language courses: how to support pupils?

Carole Delforge

80 Machine translation literacy: a panorama of practices at Swiss universities and implications for language teaching Alice Delorme Benites, Sara Cotelli Kureth, Caroline Lehr, and Elizabeth Steele

88 Facilitating reflection in teletandem through automatically generated conversation metrics and playback video

Aparajita Dey-Plissonneau, Hyowon Lee, Michael Scriney, Alan F. Smeaton, Vincent Pradier, and Hamza Riaz

94 Helping aerospace engineering students develop their intercultural communicative competence

Sofia Di Sarno-García 
100 Using virtual reality and peer feedback to reduce L2 speaking anxiety: an exploratory study

Isabelle Godefridi, Ferran Suñer, Cécile Leblanc, and Fanny Meunier

106 Design-based research as a framework for developing and deploying augmented reality applications and scenarios for intercultural exchange Stella Hadjistassou, Petros Louca, Shaunna Joannidou, and Pedro Jesus Molina Muñoz

112 Internationalisation at home through virtual exchange: an encounter between distance language learners and trainee language teachers Xavière Hassan, Annie Eardley, and Christelle Combe

119 Student evaluation of teachers' pedagogical skills during the first COVID-19 period

Çiler Hatipoğlu, Elżbieta Gajek, Lina Milosewska, and Nihada Delibegović Džanić

126 Can online translators and their speech capabilities help English learners improve their pronunciation?

Yue He and Walcir Cardoso

132 Participation, inclusion, and success in emergency remote online teaching and learning

Sandra Healy

137 Immersive virtual reality versus webcam in an online language course Borja Herrera

143 Immigrant families' home use of electronic and online Icelandic L2 materials for children

Kelsey P. Hopkins and Branislav Bédi

149 Effects of repeating after stimuli sounds during computer assisted HVPT on Japanese learners' perception and production of English fricatives Atsushi Iino and Brian Wistner

155 Pedagogical experiences in a virtual exchange project using high-immersion virtual reality for intercultural language learning Kristi Jauregi-Ondarra, Alice Gruber, and Silvia Canto 
161 Comics for inclusive English language learning: the CIELL app, supporting dyslexic English language learners

Shaunna Joannidou and Julie-Ann Sime

167 Speaking to write: examining language learners' acceptance of automatic speech recognition as a writing tool

Carol Johnson and Walcir Cardoso

172 OFLEBO, an online teacher-training programme for teachers of French in Botswana as an example of professionalisation Boingotlo Winnie Kaome and Anne-Laure Foucher

177 Students' perceptions of digital storytelling in primarily asynchronous EFL classes at a Japanese university

Naoko Kasami

184 Independent learner strategies to improve second language academic writing in an online course

Olivia Kennedy

189 The use of MS Teams in ESP instruction during the COVID-19 pandemic: students' attitudes towards the e-learning environment Ivana M. Krsmanović and Vesna M. Petrović

194 Experiences of using Unicam for asynchronous video assessment of the Irish language

Rob Lowney, Gearóidín Ui Laighléis, Seán Mac Risteaird, and Éadaoin Ní Mhuircheartaigh

200 Developing intercultural communicative competence in the ClerKing telecollaborative project

Oneil Madden and Soyini Ashby

207 Capturing potential learning sequences in intercultural interactions through telecollaboration

Oneil Madden, Trishana Nelson, and Rona Barnett-Passard

214 Facilitating L2 listening through automatic detection of speech and lexical difficulties

Maryam Sadat Mirzaei and Kourosh Meshgi 
220 Promoting common ground building in L2 cross-cultural conversations Maryam Sadat Mirzaei, Kourosh Meshgi, and Toyoaki Nishida

226 Intelligent personal assistants and L2 pronunciation development: focus on English past -ed

Souheila Moussalli and Walcir Cardoso

232 Promoting informal learning by integrating smartphones into the language classroom

Martin Mullen

238 EFL learners and English email writing: developing a computerised diagnostic language assessment Allan Nicholas, John Blake, and Maxim Mozgovoy

243 Using Moodle Quiz to respond to emergency: a case study with a tertiary L2 French teacher

Salomi Papadima-Sophocleous and Savvi Antoniou

248 Face issues in second language teaching via videoconferencing: the role of the smile as a co-verbal semiotic resource Agnès Pétillat, Anne-Laure Foucher, and Ciara R. Wigham

255 To Zoom or not to Zoom: Japanese and Ukrainian students' attitudes towards online language learning Jaime Selwood and Kateryna Nykytchenko

261 A world of differences: the role of individual differences in L2 vocabulary learning with clickers Anne-Marie Sénécal and Walcir Cardoso

267 Assessing learners' needs for practising spoken Icelandic L2 with the mobile app TALAĐU!

Fanny Sissoko and Branislav Bédi

273 The HERO project: language training for migrants' professional career as caregivers through blended learning

María-Victoria Soulé, Kostas Stylianou, Christina Yerou, Eftychia Xerou, Theologia Tsitsi, and Andreas Charalambous 
279 Students' intercultural sensitivity development through telecollaborative Chinese language learning on Zoom: a case study of Irish students at the beginning-level of Chinese language Mengdi Wang, Ann Devitt, Garreth Hodgins, and Ciarán Bauer

285 Less commonly taught languages at EUROCALL: what has changed over the years?

Monica Ward

290 Reflections on 21 st century skill development using interactive posters and virtual reality presentations

Andrew Warrick and Heather Woodward

296 Digital language teaching after COVID-19: what can we learn from the crisis?

Sina Werner and Can Küplüce

302 Professionalization tools: impact of the game-based website 'Check your Smile' on specialized terminology acquisition Nadia Yassine-Diab, Laura M. Hartwell, and Sébastien Dejean

307 Addressing the impact of informal language learning practices in digital wilds on the development of L2 digital literacies Artem Zadorozhnyy and Baohua Yu

312 Developing pedagogically appropriate language corpora through crowdsourcing and gamification

Rina Zviel-Girshin, Tanara Zingano Kuhn, Ana R. Luís, Kristina Koppel, Branislava Šandrih Todorović, Špela Arhar Holdt, Carole Tiberius, and Iztok Kosem

318 Author index 


\section{Peer-review committee}

- Alharbi, Amera; Saudi Electronic University, Dammam, Saudi Arabia

- Anker, Kirsten; Independent scholar, Canberra, Australia

- Antoniou, Savvi; Cyprus University of Technology, Limassol, Cyprus

- Bédi, Branislav; The Árni Magnússon Institute for Icelandic Studies, Reykjavik, Iceland

- Blake, John; University of Aizu, Aizu-wakamatsu, Japan

- Boulton, Alex; ATILF, CNRS \& University of Lorraine, Nancy, France

- Cardoso, Walcir; Concordia University, Montreal, Canada

- Carloni, Giovanna; University of Urbino, Urbino, Italy

- Cheng, Li; Beijing University of Posts and Telecommunications, Beijing, China

- Choubsaz, Yazdan; Shahid Chamran University of Ahvaz, Ahvaz, Iran / Sultan Qaboos University, Muscat, Oman

- Christoforou, Maria; Cyprus University of Technology, Limassol, Cyprus

- Chujo, Junko; Tokyo City University, Yokohama, Japan

- David, Gaby; TransCrit, Paris 8 and IRCAV, Sorbonne Nouvelle, Paris, France

- De Lima Guedes, Karla K.; University of Southampton, Southampton, United Kingdom

- Delibegović Džanić, Nihada; University of Tuzla, Tuzla, Bosnia and Herzegovina

- Delorme Benites, Alice; ZHAW Zurich University of Applied Sciences, Winterthur, Switzerland

- Dey-Plissonneau, Aparajita; Dublin City University, Dublin, Ireland

- Di Sarno-García, Sofia; Universitat Politècnica de València, Valencia, Spain

- Godefridi, Isabelle; Université catholique de Louvain, Louvain-la-Neuve, Belgium

- Gruber, Alice; Heilbronn University of Applied Sciences, Heilbronn, Germany

- Guerda Rodríguez, Eva; Université de Paris, Paris, France

- Hadjistassou, Stella; KIOS Research and Innovation Center of Excellence, Nicosia, Cyprus

- Hartwell, Laura M.; Université Toulouse Capitole, Toulouse, France 
- Hassan, Xavière; The Open University, Milton Keynes, United Kingdom

- Hatipoğlu, Çiler; Middle East Technical University, Ankara, Turkey

- Hopkins, Kelsey P.; University of Iceland, Reykjavik, Iceland

- Iino, Atsushi; Hosei University, Tokyo, Japan

- Iso, Tatsuo; Tokyo Denki University, Tokyo, Japan

- Jauregi-Ondarra, Kristi; Utrecht University, Utrecht, the Netherlands

- Joannidou, Shaunna; University of Cyprus, Nicosia, Cyprus

- Johnson, Carol; Concordia University, Montreal, Canada

- Kalyaniwala, Carmenne; University of Lorraine, Nancy, France

- Kaome, Boingotlo Winnie; Université Clermont Auvergne, ClermontFerrand, France

- Kasami, Naoko; J. F. Oberlin University, Tokyo, Japan

- Kennedy, Olivia; Nagahama Institute of Bioscience and Technology, Shiga, Japan

- Krsmanović, Ivana M.; University of Kragujevac, Kragujevac, Serbia

- Küplüce, Can; Ruhr-University, Bochum, Germany

- Lee, Hyowon; Dublin City University, Dublin, Ireland

- Louca, Petros; University of Cyprus, Nicosia, Cyprus

- Luís, Ana R.; CELGA-ILTEC/University of Coimbra, Coimbra, Portugal

- Madden, Oneil; Université Clermont Auvergne, Clermont-Ferrand, France

- Mar-Molinero, Vanessa; University of Southampton, Southampton, United Kingdom

- Milosewska, Lina; University of Information Science and Technology "St. Paul the Apostle", Ohrid, Republic of North Macedonia

- Molle, Nicolas; University of Lorraine, Nancy, France

- Mullen, Martin; University of Limerick, Limerick, Ireland

- Nadasdy, Paul; Tokyo Denki University, Tokyo, Japan

- Nicholas, Allan; University of Aizu, Aizu-wakamatsu, Japan

- Nykytchenko, Kateryna; Kyiv National Linguistic University, Kyiv, Ukraine

- Perifanou, Maria; University of Macedonia / Aristotle University of Thessaloniki / Hellenic Open University, Greece

- Pradier, Vincent; Paris Sciences et Lettres University, Paris, France

- Raheb, Chadi; University of Guilan, Rasht, Iran

- Rayner, Manny; University of Geneva, Geneva, Switzerland

- Selwood, Jaime; Hiroshima University, Hiroshima, Japan

- Sénécal, Anne-Marie; Concordia University, Montreal, Canada

- Sime, Julie-Ann; Lancaster University, Lancaster, United Kingdom

- Smeaton, Alan F.; Dublin City University, Dublin, Ireland

- Soulé, María Victoria; Cyprus University of Technology, Limassol, Cyprus 
- Suñer, Ferran; Université catholique de Louvain, Louvain-la-Neuve, Belgium

- Vassiliou, Skevi; Cyprus University of Technology, Limassol, Cyprus

- Ward, Monica; Dublin City University, Dublin, Ireland

- Warrick, Andrew; Rikkyo University, Tokyo, Japan

- Werner, Sina; Ruhr-University, Bochum, Germany

- Wistner, Brian; Hosei University, Tokyo, Japan

- Woodward, Heather; Rikkyo University, Tokyo, Japan

- $\mathrm{Wu}$, Guanzhen; Beijing University of Posts and Telecommunications, Beijing, China

- Xerou, Eftychia; Cyprus University of Technology, Limassol, Cyprus

- Yang, Jing; Beijing University of Posts and Telecommunications, Beijing, China

- Yerou, Christina; Cyprus University of Technology, Limassol, Cyprus

- Zadorozhnyy, Artem; The Education University of Hong Kong, Hong Kong SAR, China

- Zingano Kuhn, Tanara; University of Coimbra, Coimbra, Portugal 


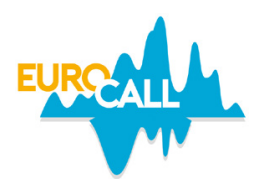

\section{Preface}

\section{Naouel Zoghlami ${ }^{1}$, Cédric Brudermann ${ }^{2}$, Cédric Sarré ${ }^{3}$, and Muriel Grosbois ${ }^{4}$}

The 2021 EUROCALL conference was held in Paris on 26-27 August 2021 as a fully online event hosted by Cnam Paris. It was preceded by an online project event, the CATAPULT Symposium on 25 August 2021 hosted by Sorbonne Université.

The conference theme was CALL and Professionalisation.

Technology - the new mediator of learning - has both revolutionised the way we learn languages and created a sense of urgency in the need to modernise the initial and ongoing training of today's and tomorrow's professionals. As a result, by focusing on research, technological development, and innovation, this conference set out to explore the potential of technology and of the expansion of educational opportunities in foreign languages to provide a basis for addressing the current issues both higher education and the job market are facing in the 21 st century.

A key aspect of the current socio-economic reality is to support learners in increasing their foreign language skills and other competencies required in today's technology mediated society (team work, project management or the use of digital technologies for example) and help them enhance their employability on the job market. To address these issues, the following subthemes were identified and proposed in the conference call for papers: professional development, teacher education, assessment, multimodality, interculturality, soft skills, internationalisation, and translation (tools).

\footnotetext{
1. Conservatoire National des Arts et Métiers, FoAP (Laboratoire Formation et Apprentissages Professionnels); naouel. zoghlamiterrien@lecnam.net; https://orcid.org/0000-0002-0181-6306

2. Sorbonne Université, CeLiSo (Centre de Linguistique en Sorbonne); cedric.brudermann@sorbonne-universite.fr; http:// orcid.org/0000-0003-2645-007X

3. Sorbonne Université - INSPE de l'académie de Paris, CeLiSo (Centre de Linguistique en Sorbonne); cedric.sarre@sorbonneuniversite.fr; https://orcid.org/0000-0002-8548-2824

4. Conservatoire National des Arts et Métiers, FoAP (Laboratoire Formation et Apprentissages Professionnels); muriel. grosbois@lecnam.net; https://orcid.org/0000-0003-2258-8733
}

How to cite this article: Zoghlami, N., Brudermann, C., Sarré, C., \& Grosbois, M. (2021). Preface. In N. Zoghlami, C. Brudermann, C. Sarré, M. Grosbois, L. Bradley, \& S. Thouësny (Eds), CALL and professionalisation: short papers from EUROCALL 2021 (pp. xiii-xvi). Research-publishing.net. https://doi.org/10.14705/rpnet.2021.54.1298 
The 2021 EUROCALL conference engaged just under 250 speakers from 40 different countries. Cnam Paris and Sorbonne Université joined forces to host and organise the event despite the challenging context due to the Covid-19 pandemic. Originally programmed to be held on site in the heart of Paris, France, the EUROCALL organising team and executive committee agreed to opt for a blended and then for a fully online conference. Thanks to sustained combined efforts and to the outstanding customer service provided by the Whova ${ }^{\circledR}$ team which provided the platform, a totally new and innovative format emerged combining a diversity of livestreamed events in six parallel strands:

- 4 plenary sessions;

- 8 group sessions in which 3 presenters gave a five-minute lightning talk with a total of 131 presentations;

- 6 individual sessions in which each presenter gave a twenty-minute presentation, totalling 35 presentations;

- 36 poster presentations in the artefact centre;

- 9 special interest group meetings and symposia; and

- an editors' workshop.

To sustain the EUROCALL community, the participants were asked to upload their pre-recorded presentations or posters on the Whova platform by mid-July, thus allowing for exploration of content, scientific exchanges around the conference themes, socialisation, and interactions with presenters as well as with the plenary speakers prior to the conference.

The four outstanding keynote presentations were given by the professors as follows.

Professor Laurent Filliettaz, from the University of Geneva (Switzerland), who focused on the linguistic demands of workplace learning: power and miscommunication in vocational training interactions. The purpose of his talk was to reflect on the complex literacy practices of a specific category of learning workers. Based on a social and situated approach to literacy, Prof. Filliettaz proposed to identify and discuss some of the challenges that apprentices from different cultural backgrounds are facing when entering the workplace and when applying new knowledge and skills in professional settings. He provided empirical 
material for addressing the issue of discourse and interaction in the workplace and discussed some practical implications regarding the role of language and interactional competences in initial vocational education programmes.

Professor Greg Kessler, from Ohio University (USA), dealt with disruptive CALL: anticipated innovations in technology, pedagogy, and language learning. The presenter shared his thoughts about the changing nature of language teaching and learning in relation to technological and pedagogical innovations, including emerging trends in artificial intelligence, automation, assessment, data driven learning, automated speech interfaces, and a variety of forms of natural language processing and artificial intelligence. Some of the tools and resources associated with these developments have found their way into language teaching and learning while others certainly will in the near future. Prof. Kessler discussed creative ways to focus on communication while designing instructional experiences which should harness the potential of these emerging innovations in a thoughtful manner.

Professor Rudy Loock, from Université de Lille (France), delivered a keynote presentation entitled no more rage against the machine: developing students' 'Machine Translation Literacy'. He discussed the use of machine translation tools by both undergraduate students in languages and master's students in translation. If teaching these tools and post-editing is no issue in a master's translation programme as such skills are often necessary to join today's translation market, the use of machine translation in language classes with undergraduate students is still controversial. However, Prof. Loock reported on a study that shows that such students do massively use it but fail to correct its errors, hence the need to help them develop their machine translation literacy.

Professors Denyze Toffoli and Geoffrey Sockett, respectively from Université de Toulouse and Université de Paris (France), explored teaching English for specific purposes online, blending formal, non-formal, and informal contexts, examples from online courses in undergraduate social Sciences. In their talk, they argued for a big-picture view that "CALL means learners learning language in any context with, through, and around computer technologies" (Egbert, 2005). Profs Toffoli and Sockett claimed that "this means that much CALL is informal learning through the host of leisure activities which now involve English, as young people get their daily fix of vlogs, series, and multiplayer games". They further explained what this means in our day-to-day work when designing English for Specific Purposes courses for students in French Universities from a microscopic point of view. 
We would like to address our warmest thanks to all the participants, keynote speakers, presenters, special interest groups, and workshop contributors. We are also very grateful to our institutional sponsors, namely the Cnam, Sorbonne Université, INSPE de Paris, FoAP, CeLiSo, LabEx haStec, and Erasmus+.

Of course, we would like to extend our gratitude to the EUROCALL executive committee, the scientific committee, the organising team, and the English teaching fellows from the Cnam language department, who served as moderators. This new and unique experience has allowed us to develop new skills in terms of conference organisation, and we believe the format we initiated might serve as a basis for future conferences, given its great success.

As for this volume, it is a selection of 54 short papers by some of the EUROCALL 2021 presenters and it offers a combination of research studies as well as practical examples fairly representative of the eight subthemes of the conference. They are ordered alphabetically. We would like to thank the authors as well as the reviewers for their time and efforts in ensuring the highest scientific standards expected for and from the EUROCALL community. Finally, we would like to warmly thank Sylvie Thouësny and Linda Bradley in particular for their support in the publication process of this volume of short papers. We hope you will enjoy reading it! 


\title{
Assessing the quality of TTS audio in the LARA learning-by-reading platform
}

\author{
Elham Akhlaghi ${ }^{1}$, Anna Bączkowska ${ }^{2}$, Harald Berthelsen ${ }^{3}$, \\ Branislav Bédi ${ }^{4}$, Cathy Chua ${ }^{5}$, Catia Cucchiarini 6 , \\ Hanieh Habibi ${ }^{7}$, Ivana Horváthová ${ }^{8}$, Pernille Hvalsøe 9 , \\ Roy Lotz ${ }^{10}$, Christèle Maizonniaux ${ }^{11}$, Neasa Ní Chiaráin ${ }^{12}$, \\ Manny Rayner ${ }^{13}$, Nikos Tsourakis ${ }^{14}$, and Chunlin Yao ${ }^{15}$
}

\begin{abstract}
A popular idea in Computer Assisted Language Learning (CALL) is to use multimodal annotated texts, with annotations typically including embedded audio and translations, to support L2 learning through reading. An important question is how to create the audio, which can be done either through human recording or by a Text-To-Speech (TTS) synthesis engine. We may reasonably expect TTS to be quicker and easier, but humans to be of higher quality. Here, we report a study using the open-source LARA platform and ten languages. Samples of LARA audio totaling about three and a half minutes were provided for each language in both human and TTS form; subjects used a web form to compare different versions of the same item and rate the voices as a whole. Although human voice was more often preferred, TTS achieved higher ratings in some languages and was close in others.
\end{abstract}

Keywords: reading, multimodality, TTS, evaluation.

\footnotetext{
1. Ferdowsi University of Mashhad, Mashhad, Iran; elham.akhlaghi@mail.um.ac.ir

2. University of Gdansk, Gdansk, Poland; anna.baczkowska@ug.edu.pl

3. Trinity College, Dublin, Ireland; berthelh@tcd.ie

4. The Árni Magnússon Institute for Icelandic Studies, Reykjavík, Iceland; branislav.bedi@arnastofnun.is

5. Independent scholar, Adelaide, Australia; cathyc@pioneerbooks.com.au

6. Radboud University, Nijmegen, The Netherlands; c.cucchiarini@let.ru.nl

7. University of Geneva, Geneva, Switzerland; hanieh.habibi@unige.ch

8. Univerzita Konstantina Filozofa, Nitra, Slovakia; ihorvathova@ukf.sk

9. University of Copenhagen, Copenhagen, Denmark; phv@hum.ku.dk

10. Independent scholar, Madrid, Spain; roylotz09@hotmail.com

11. Flinders University, Adelaide, Australia; christele.maizonniaux@flinders.edu.au

12. Trinity College, Dublin Ireland; neasa.nichiarain@tcd.ie

13. University of Geneva, Geneva, Switzerland; emmanuel.rayner@unige.ch

14. University of Geneva, Geneva, Switzerland; nikolaos.tsourakis@unige.ch

15. Tianjin Chengjian University, Tianjin, China; yao_chunlin@126.com
}

How to cite this article: Akhlaghi, E., Baczkowska, A., Berthelsen, H., Bédi, B., Chua, C., Cucchiarini, C., Habibi, H., Horváthová, I., Hvalsøe, P., Lotz, R., Maizonniaux, C., Ní Chiaráin, N., Rayner, M., Tsourakis, N., \& Yao, C. (2021). Assessing the quality of TTS audio in the LARA learning-by-reading platform. In N. Zoghlami, C. Brudermann, C. Sarré, M. Grosbois, L. Bradley, \& S. Thouësny (Eds), CALL and professionalisation: short papers from EUROCALL 2021 (pp. 1-5). Researchpublishing.net. https://doi.org/10.14705/rpnet.2021.54.1299 


\section{Introduction}

An increasingly popular idea over the last decade is to help L2 learners improve their reading skills in non-native languages by creating annotated multimedia texts that contain integrated help, most commonly word translations and/or audio. High profile examples include LingQ ${ }^{16}$ and Learning With Texts ${ }^{17}$.

In this study, our focus is the audio, created either by recording human voice or through a TTS engine. Using TTS is faster, but despite on-going improvements in TTS technology, human-recorded audio is still of higher voice quality. It is less clear how large the difference is, or how important it is in practice when TTS is used in L2 teaching. Our study addresses these questions.

\section{Method}

The experiments were performed using LARA ${ }^{18}$ (Akhlaghi et al., 2020), a learning-by-reading platform under development by an international open-source consortium since 2018. So far, most LARA texts have used human-recorded audio, though the Irish LARA group has consistently used TTS. In our study, we selected existing LARA texts in Danish, English, Farsi, French, Icelandic, Irish, Italian, Mandarin, Spanish, and Swedish, creating a version using the other method so that it was available in both human and TTS voice. For each language, a single human voice was used and TTS audio was created using the best TTS engine available to us for that language: ABAIR ${ }^{19}$ for Irish, Google TTS $^{20}$ for Mandarin, Nuance Vocalizer $^{21}$ for Farsi, and ReadSpeaker ${ }^{22}$ for the other languages.

We randomly selected contiguous passages from the texts so that the total audio for each language was about three and a half minutes; for some languages, we also included individual words. The material was presented on an openly available anonymous web form consisting of three portions: demographic data; item-by-item comparison of the audio; and overall impressions of the two voices. In the item-by-item comparison, subjects chose between 'both acceptable and roughly equal', 'both acceptable but one clearly better', 'one acceptable, one not acceptable', and 'neither acceptable'. In the overall impressions part,

\footnotetext{
16. https://www.lingq.com/

17. https://sourceforge.net/projects/lwt/

18. https://www.unige.ch/callector/lara/

19. http://www.abair.ie/

20. https://cloud.google.com/text-to-speech

21. https://www.nuance.com/en-au/omni-channel-customer-engagement/voice-and-ivr/text-to-speech/vocalizer.html

22. https://www.readspeaker.com/
} 
subjects gave Likert scale scores for quality of individual words, quality of whole sentences, speed, naturalness, pleasantness, suitability for teaching, suitability for imitating, and a freeform response. Full details are posted in the supplementary materials.

\section{Results}

Responses were logged for 130 subjects and collated using a script. There were large differences between languages, between responses for sentences and words, and between native and non-native judgments. Table 1, Table 2, Table 3, and Table 4 show results for the portions of the data we considered most informative. Full details are posted in the supplementary materials.

Table 1. Overall impressions of voices, five-point Likert scale; ratings from native/near-native speakers only. In each cell, human rating above and TTS rating below. Yellow=TTS equal or better than human, orange $=$ TTS within 0.5 of human

\begin{tabular}{|l|l|l|l|l|l|l|l|l|l|l|}
\hline Language & DA & EN & FA & FR & IS & IE & IT & ZH & SP & SW \\
\hline (\#raters) & $(7)$ & $(13)$ & $(27)$ & $(3)$ & $(6)$ & $(6)$ & $(7)$ & $(2)$ & $(2)$ & $(3)$ \\
\hline Words & 3.86 & 3.77 & 4.74 & 4.0 & 4.17 & 4.5 & 3.43 & 4.0 & 4.5 & 4.67 \\
& 3.71 & 4.08 & 3.19 & 5.0 & 3.17 & 4.5 & 4.43 & 5.0 & 2.5 & 4.33 \\
\hline Sentences & 4.29 & 3.77 & 4.78 & 4.33 & 3.83 & 4.67 & 4.14 & 4.5 & 4.5 & 4.33 \\
& 2.57 & 3.77 & 2.74 & 4.67 & 3.17 & 4.33 & 3.29 & 3.5 & 2.0 & 4.33 \\
\hline Speed & 4.14 & 3.62 & 4.78 & 5.0 & 3.83 & 4.67 & 4.14 & 4.5 & 4.5 & 4.67 \\
& 2.57 & 3.92 & 3.3 & 4.67 & 3.67 & 3.67 & 3.71 & 3.5 & 3.5 & 4.33 \\
\hline Natural & 4.29 & 3.85 & 4.85 & 5.0 & 4.5 & 4.83 & 4.86 & 5.0 & 3.5 & 4.67 \\
& 1.86 & 3.46 & 2.22 & 4.0 & 3.0 & 3.5 & 1.86 & 3.0 & 1.5 & 4.33 \\
\hline Pleasant & 4.14 & 3.46 & 4.63 & 4.33 & 4.33 & 4.83 & 4.14 & 5.0 & 3.5 & 4.33 \\
& 2.43 & 3.62 & 2.41 & 4.33 & 3.33 & 3.33 & 2.43 & 3.5 & 2.5 & 4.33 \\
\hline Teaching & 4.43 & 3.54 & 4.78 & 4.0 & 4.33 & 4.33 & 3.43 & 5.0 & 4.5 & 4.0 \\
& 2.43 & 3.62 & 2.33 & 4.33 & 3.5 & 3.5 & 3.14 & 3.5 & 2.0 & 4.33 \\
\hline Imitating & 4.43 & 3.0 & 4.7 & 4.33 & 3.83 & 4.67 & 3.57 & 5.0 & 4.5 & 4.0 \\
& 2.14 & 3.54 & 2.19 & 4.67 & 2.83 & 3.17 & 2.29 & 3.5 & 1.5 & 4.0 \\
\hline
\end{tabular}

Table 2. Item-by-item comparison averages; percentage ratings from native/ near-native speakers only, sentences only. Yellow=TTS equal or better than human, orange=TTS within $10 \%$ of human

\begin{tabular}{|l|l|l|l|l|l|l|l|l|l|l|}
\hline Language & DA & EN & FA & FR & IS & IE & IT & ZH & SP & SW \\
\hline (\#raters) & $(7)$ & $(13)$ & $(27)$ & $(3)$ & $(6)$ & $(6)$ & $(7)$ & $(2)$ & $(2)$ & $(3)$ \\
\hline (\#items) & $(14)$ & $(8)$ & $(20)$ & $(22)$ & $(15)$ & $(39)$ & $(23)$ & $(17)$ & $(16)$ & $(14)$ \\
\hline
\end{tabular}


Elham Akhlaghi et al.

\begin{tabular}{|l|l|l|l|l|l|l|l|l|l|l|}
\hline $\begin{array}{l}\text { Human } \\
\text { acceptable }\end{array}$ & 98.0 & 100.0 & 98.3 & 84.8 & 94.4 & 97.9 & 88.8 & 100.0 & 100.0 & 97.6 \\
\hline $\begin{array}{l}\text { TTS } \\
\text { acceptable }\end{array}$ & 41.8 & 88.5 & 66.5 & 97.0 & 81.1 & 99.6 & 85.1 & 58.8 & 40.6 & 97.6 \\
\hline $\begin{array}{l}\text { Human } \\
\text { better }\end{array}$ & 81.6 & 43.3 & 70.9 & 6.1 & 53.3 & 47.0 & 31.7 & 47.1 & 100.0 & 40.5 \\
\hline TTS better & 3.1 & 20.2 & 6.1 & 27.3 & 14.4 & 7.7 & 25.5 & 2.9 & 0.0 & 7.1 \\
\hline (same) & $(15.3)$ & $(36.5)$ & $(23.0)$ & $(66.7)$ & $(32.2)$ & $(45.3)$ & $(42.9)$ & $(50.0)$ & $(0.0)$ & $(52.4)$ \\
\hline
\end{tabular}

Table 3. Overall impressions of voices; teachers/trainee teachers only (conventions as in Table 1)

\begin{tabular}{|l|l|l|l|l|l|l|l|l|l|l|}
\hline Language & DA & EN & FA & FR & IS & IE & IT & ZH & SP & SW \\
\hline (\#raters) & $(7)$ & $(16)$ & $(13)$ & $(4)$ & $(9)$ & $(25)$ & $(2)$ & $(2)$ & $(1)$ & $(1)$ \\
\hline Words & 3.86 & 3.62 & 4.69 & 4.5 & 4.33 & 4.2 & 3.5 & 4.0 & 5.0 & 5.0 \\
& 3.71 & 4.25 & 3.15 & 5.0 & 3.22 & 3.8 & 4.0 & 5.0 & 2.0 & 3.0 \\
\hline Sentences & 4.29 & 3.5 & 4.85 & 4.5 & 4.22 & 4.24 & 3.0 & 4.5 & 5.0 & 5.0 \\
& 2.57 & 4.0 & 2.92 & 4.5 & 3.22 & 3.76 & 3.5 & 3.5 & 2.0 & 3.0 \\
\hline Speed & 4.14 & 3.25 & 4.85 & 4.25 & 4.22 & 4.2 & 3.5 & 4.5 & 5.0 & 4.0 \\
& 2.57 & 4.0 & 3.15 & 4.25 & 3.67 & 3.2 & 3.5 & 3.5 & 4.0 & 4.0 \\
\hline Natural & 4.29 & 3.25 & 5.0 & 5.0 & 4.67 & 4.2 & 4.5 & 5.0 & 5.0 & 5.0 \\
& 1.86 & 3.94 & 2.46 & 3.5 & 2.78 & 4.0 & 1.5 & 3.0 & 1.0 & 3.0 \\
\hline Pleasant & 4.14 & 2.88 & 4.77 & 5.0 & 4.44 & 4.28 & 3.5 & 5.0 & 5.0 & 4.0 \\
& 2.43 & 3.88 & 2.85 & 3.0 & 3.22 & 3.16 & 2.5 & 3.5 & 2.0 & 4.0 \\
\hline Teaching & 4.43 & 3.12 & 4.92 & 3.75 & 4.56 & 4.08 & 2.5 & 5.0 & 5.0 & 4.0 \\
& 2.43 & 3.94 & 2.31 & 4.0 & 3.22 & 3.12 & 3.5 & 3.5 & 1.0 & 3.0 \\
\hline Imitating & 4.43 & 2.69 & 4.69 & 4.0 & 4.11 & 4.24 & 2.5 & 5.0 & 5.0 & 4.0 \\
& 2.14 & 3.88 & 2.38 & 3.75 & 2.67 & 2.92 & 3.0 & 3.5 & 1.0 & 2.0 \\
\hline
\end{tabular}

Table 4. Item-by-item comparison averages; teachers only, sentences only (conventions as in Table 2)

\begin{tabular}{|l|l|l|l|l|l|l|l|l|l|l|}
\hline Language & DA & EN & FA & FR & IS & IE & IT & ZH & SP & SW \\
\hline (\#raters) & $(7)$ & $(16)$ & $(13)$ & $(4)$ & $(9)$ & $(25)$ & $(2)$ & $(2)$ & $(1)$ & $(1)$ \\
\hline (\#items) & $(14)$ & $(8)$ & $(20)$ & $(22)$ & $(15)$ & $(39)$ & $(23)$ & $(17)$ & $(16)$ & $(14)$ \\
\hline $\begin{array}{l}\text { Human } \\
\text { acceptable }\end{array}$ & 98.0 & 100.0 & 97.3 & 93.2 & 94.8 & 97.9 & 84.8 & 100.0 & 100.0 & 100.0 \\
\hline $\begin{array}{l}\text { TTS } \\
\text { acceptable }\end{array}$ & 41.8 & 92.2 & 55.0 & 97.7 & 81.5 & 98.5 & 76.1 & 58.8 & 0.0 & 100.0 \\
\hline $\begin{array}{l}\text { Human } \\
\text { better }\end{array}$ & 81.6 & 31.2 & 78.1 & 14.8 & 60.0 & 33.2 & 30.4 & 47.1 & 100.0 & 85.7 \\
\hline TTS better & 3.1 & 32.8 & 4.2 & 28.4 & 15.6 & 11.8 & 30.4 & 2.9 & 0.0 & 0.0 \\
\hline (same) & $(15.3)$ & $(35.9)$ & $(17.7)$ & $(56.8)$ & $(24.4)$ & $(55.0)$ & $(39.1)$ & $(50.0)$ & $(0.0)$ & $(14.3)$ \\
\hline
\end{tabular}




\section{Discussion and conclusions}

This is a preliminary study in a rapidly evolving field, mostly using only one text per language, with genres ranging from simple children's stories to literary novels. The human voices were a mixture of male and female ranging from experienced teachers to a twelve-year-old child, while all but one of the TTS voices were young females.

With the above caveats, human audio was more often preferred than TTS, but this was by no means always the case; the gap was surprisingly close. Some TTS engines are better than others: the English, Irish, and Italian speech engines used clearly outperform the Danish and Farsi ones. TTS engines did very well on pronunciation (high scores in the 'Words' rows), but less well on sentence-level phenomena such as prosody, coarticulation processes, speed, etc. (lower scores in the 'Sentences' rows). Teachers rated TTS more highly than native speakers did (comparing Table 1 and Table 2 with Table 3 and Table 4). Non-native speakers and non-teachers rated TTS even more highly (see supplementary materials).

We are planning an extended study using a larger sample of texts and voices.

\section{Supplementary materials}

Relevant LARA texts, data collection form, and full results: https:/www.issco. unige.ch/en/research/projects/callector/EUROCALL_2021_data.html

\section{Acknowledgments}

We would like to thank Hossein, Matilde, and Rebe for recording the French, Italian, and Spanish audio respectively.

\section{References}

Akhlaghi, E., Bédi, B., Bektas, F., Berthelsen, H., Butterweck, M., Chua, C., Cucchiarini, C., Eryigit, G., Gerlach, J., Habibi, H., Ní Chiaráin, N., Rayner, M., Steingrímsson, S., \& Strik, H. (2020). Constructing multimodal language learner texts using LARA: experiences with nine languages. Proceedings of the 12th Language Resources and Evaluation Conference. https://aclanthology.org/2020.1rec-1.40 


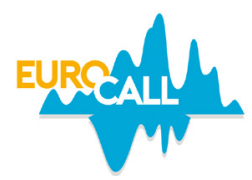

\title{
TextMix: using NLP and APIs to generate chunked sentence scramble tasks
}

\author{
Brendon Albertson ${ }^{1}$
}

\begin{abstract}
A Computer-Assisted Language Learning (CALL) application, TextMix, was developed as a proof-of-concept for applying Natural Language Processing (NLP) sentence chunking techniques to creating 'sentence scramble' learning tasks. TextMix addresses limitations of existing applications for creating sentence scrambles by using NLP to parse and scramble syntactic components of sentences, while connecting with Application Programming Interfaces (APIs) to provide repeated exposure to authentic sentences in the context of texts such as Wikipedia articles. In addition to identifying a novel application of NLP and APIs in CALL, this project highlights the need for teacher-friendly interfaces that prioritize pedagogically useful ways of chunking text.
\end{abstract}

Keywords: NLP, chunking, collocations, syntactic awareness.

\section{Introduction}

This paper describes the rationale, development, and implications of a CALL application, TextMix. It was developed on several premises. First, it served to explore the feasibility of using NLP sentence chunking techniques to generate 'sentence scramble' activities as a method for enhancing input to raise syntactic and collocational awareness. Second, it sought to demonstrate the viability of using APIs to import authentic online text, such as Wikipedia articles and news headlines, for generating learning activities. TextMix aims to serve as a model for developing other CALL tools that use such features.

1. Pine Manor College, Chestnut Hill, USA; albertsonbrendon@gmail.com; https://orcid.org/0000-0001-8932-835X

How to cite this article: Albertson, B. (2021). TextMix: using NLP and APIs to generate chunked sentence scramble tasks. In N. Zoghlami, C. Brudermann, C. Sarré, M. Grosbois, L. Bradley, \& S. Thouësny (Eds), CALL and professionalisation: short papers from EUROCALL 2021 (pp. 6-11). Research-publishing.net. https://doi.org/10.14705/rpnet.2021.54.1300 


\section{Background}

\subsection{Input enhancement and chunking}

Textual input enhancement involves methods for drawing attention to target language such as underlining vocabulary or highlighting grammar structures. It aims to promote noticing as a prerequisite for learning and can be effective in tandem with other learning activities (Kim, 2010). Specifically, drawing attention to formulaic sequences may compensate for impoverished input and improve retention (Nguyen, 2014), while syntactic highlighting has been correlated with higher reading scores among low-proficiency learners (Park \& Warschauer, 2016).

Chunking, or dividing, sentences can also serve as a form of input enhancement. Chunking complex sentences into clauses, for example, may help learners process their structure, while smaller chunks like adjective-preposition pairs can raise awareness of collocations such as interested in. Eye-tracking research by Pulido (2021) has demonstrated that L2 readers who chunked while reading were more efficient readers. However, chunking alone is not likely to improve comprehension; it is necessary to accurately connect and parse the relationships between chunks to form meaning (Nishida, 2013). A task that involves assembling chunks in the correct order would promote focusing on such semantic relationships. Chunking can be performed using NLP algorithms based on parts of speech. While NLP has several educational applications (Litman, 2016), chunking methods in NLP have not been examined for their potential to teach sentence structure or collocations.

\subsection{The sentence scramble task}

The sentence scramble task involves arranging the mixed parts of a sentence into the correct order. By requiring a focus on word order, sentence scrambles may improve understanding of sentence structure and noticing of grammar features (Murasawa \& Brine, 2010), and provide an accurate measure of syntactic awareness (Chu \& Ellefson, 2020). They also represent what Bjork (1994) terms a 'desirable difficulty', an additional processing demand that can aid learning.

An existing CALL system for generating sentence scrambles is FLAX (Murasawa \& Brine, 2010), which rearranges several target words (e.g. prepositions) in each 
sentence. The only other existing CALL tool for creating sentence scrambles is the J-Mix feature of the Hot Potatoes software suite (Half-baked Software, 2020), which requires manual sentence entry and scrambles either by every word or manually specified divisions. These tools have potential for enhancement by scrambling via chunks rather than words, connecting with larger sources of text, and making it easier to generate and share activities.

\subsection{Design question}

The design of the TextMix application was driven by three areas with potential: (1) chunking as a method for raising awareness of sentence structure and collocations, (2) the sentence scramble as a way for learners to work with chunks, and (3) the usefulness of applying NLP chunking techniques and large sources of online text to CALL applications.

The following three-part design question was posed. Can a web-based CALL tool:

- be designed to scramble sentences by meaningful chunks instead of words using NLP;

- be made compatible with large, existing sources of text including APIs;

- enable saving and sharing the generated activities via URL?

\section{Design}

\subsection{The TextMix application}

The online TextMix application generates a sentence scramble for each sentence in a text, performed by dividing the sentence into chunks via NLP and randomly reordering them (Figure 1).

When one sentence is unscrambled by the user, the application proceeds to the next. The source of text is specified by the user; options include news headlines via the News API, Wikipedia articles via the Wikimedia API, pasted text, a preloaded collection of open-source texts, and example dictionary sentences. Users can choose whether chunks should be combined to make the activity less difficult and can generate a URL to the saved activity. 
Figure 1. A sentence scramble activity in TextMix

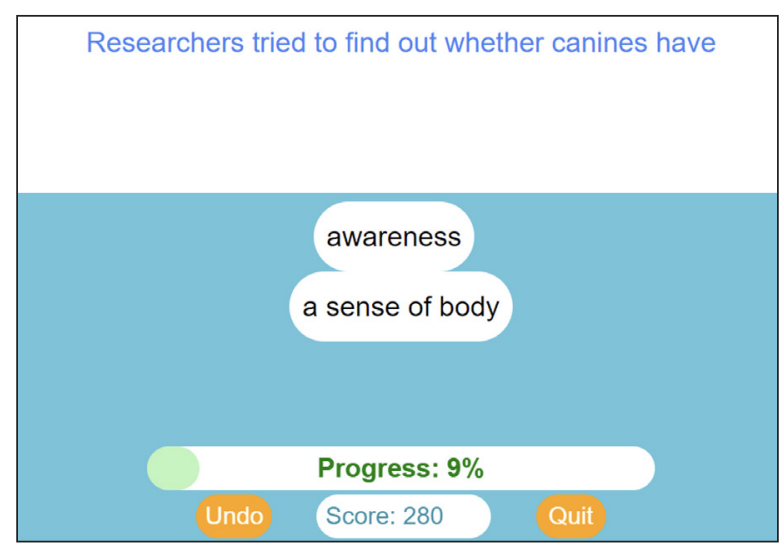

\subsection{Chunking in TextMix}

TextMix uses the Python Natural Language Toolkit, a software library that chunks sentences via a rule-based method using adjustable definitions for each type of chunk. The algorithm is not completely accurate and must prioritize one chunk type over another. For example, if a chunk is defined as a verb plus preposition, it would capture phrasal verbs but also other combinations (e.g. think about). Conversely, defining another type of chunk as a prepositional phrase would capture about the decision but would disrupt the former chunk type from capturing think about. Thus, the algorithm's usefulness depends on defining chunks appropriately for different learning focuses.

For this project, two types of chunks were assumed most useful to learners: collocations and meaningful syntactic units such as noun phrases or compound verbs. In some cases, a chunk would represent both. Consequently, six chunk types were defined: noun phrases, verb phrases, prepositional phrases, compound verbs, infinitive phrases, and relative clauses. These were programmed using the definitions shown in Table 1. The NLP flow of the application is shown in Figure 2.

Table 1. Definitions of chunks

\begin{tabular}{|l|l|}
\hline Type of chunk & Definition \\
\hline Prepositional or noun phrase & $\mathrm{P}^{*}(\mathrm{DET})$ ADJ* N+ \\
\hline Compound verb or infinitive & (to) V+ \\
\hline Relative clause & RP V+ \\
\hline
\end{tabular}

Note: Plus sign = 'one or more'; asterisk = 'zero or more'; parentheses = 'zero or one' 
Figure 2. TextMix programmatic flow

\begin{tabular}{|c|c|c|c|c|}
\hline $\begin{array}{ll}\text { - } & \text { Pasted Text } \\
\text { - } & \text { Wikipedia/News API } \\
\text { - } & \text { Text from Database }\end{array}$ & & & & \\
\hline $\begin{array}{l}\text { Sentence } \\
\text { tokenization }\end{array}$ & $\begin{array}{c}\text { Word } \\
\text { tokenization }\end{array}$ & POS Tagging & Chunking & Scrambling \\
\hline $\begin{array}{l}\text { The torch relay } \\
\text { for the Tokyo } \\
\text { Olympics is finally } \\
\text { under way }\end{array}$ & $\begin{array}{l}\text { The, torch, relay, } \\
\text { for, the, Tokyo, } \\
\text { olymics, is, } \\
\text { finally, under, } \\
\text { way }\end{array}$ & 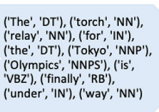 & $\begin{array}{l}\text { The torch relay } \\
\text { for the Tokyo } \\
\text { olympics } \\
\text { is finally } \\
\text { under way }\end{array}$ & $\begin{array}{l}\text { for the Tokyo } \\
\text { Olympics is } \\
\text { The torch relay } \\
\text { under way } \\
\text { finally }\end{array}$ \\
\hline
\end{tabular}

\section{Discussion}

TextMix responds to the design question by automating the creation of chunkbased sentence scramble tasks using NLP and by importing sentences from APIs, while allowing users to save and share activities via URLs. The project revealed two implications of using NLP chunking in CALL. First, due to overlap, not every meaningful chunk can be captured at once, and choosing which chunks to prioritize depends on the learning focus and level. For example, chunking sentences into subject-predicate pairs may be suitable for beginners learning basic sentence structure, while chunking smaller units such as noun phrases and prepositional phrases would be more appropriate for learners with greater syntactic awareness. Adjusting the chunking method, however, is not quite teacher-friendly as it requires changing regular expression definitions in Python code. A possible solution is to provide predefined options for which chunks to prioritize, such as phrasal verbs. Another possibility is to directly identify and extract collocations as chunks using lists such as the Academic Collocations List (Lei \& Liu, 2018). Second, because traditional NLP chunking algorithms aim to extract only semantic data from text, they may not be ideal for creating syntax or grammar-focused learning tasks. A teacher might wish, for example, to focus on infinitives; for these purposes new chunking algorithms must be defined.

\section{Conclusion}

TextMix demonstrates the feasibility of applying NLP chunking techniques and APIs to CALL by separating and drawing attention to meaningful units of sentences drawn from online text sources. The sentence scramble tasks may help 
raise syntactic awareness and sentence processing ability by requiring learners to analyze the relationships between chunks. Furthermore, they may promote collocational awareness by drawing attention to words commonly found together. However, these possible learning benefits still require assessment. Finally, adjusting the learning focus by devising additional chunking methods and making these accessible to teachers remain areas worth exploring.

\section{References}

Bjork, R. A. (1994). Memory and metamemory considerations in the training of human beings. In J. Metcalfe \& A. Shimamura (Eds), Metacognition: knowing about knowing (pp. 185-205). MIT Press. https://doi.org/10.7551/mitpress/4561.003.0011

Chu, C. P., \& Ellefson, M. (2020). The development of a syntactic awareness task using the word-order correction paradigm. Cambridge Open Engage. https://doi.org/10.33774/coe2020-5qdgd

Half-baked Software. (2020). Hot potatoes (Version 7.0) [Computer software]. http://hotpot. uvic.cal

Kim, E. C. (2010). Textual input enhancement: applications in teaching. ORTESOL Journal, 28. https:/ortesol.wildapricot.org/resources/Documents/Publications/Journals/2010/Textual\%20 Input $\% 20$ Enhancement-\%20Applications\%20in\%20Teaching\%20p22.pdf

Lei, L., \& Liu, D. (2018). The academic English collocation list: a corpus-driven study. International Journal of Corpus Linguistics, 23(2), 216-243. https://doi.org/10.1075/ ijcl.16135.lei

Litman, D. (2016). Natural language processing for enhancing teaching and learning. Proceedings of the Thirtieth AAAI Conference on Artificial Intelligence (AAAI-16) (pp. 4170-4176). Association for the Advancement of Artificial Intelligence.

Murasawa, F., \& Brine, J. (2010). Focus-on-form using computer-generated scrambled sentences. International Transactions on eLearning \& Usability, 1(1).

Nguyen, H. (2014). The acquisition of formulaic sequences in high-intermediate ESL learners. Publicly Accessible Penn Dissertations, 1385. http://repository.upenn.edu/ edissertations $/ 1385$

Nishida, H. (2013). The influence of chunking on reading comprehension: investigating the acquisition of chunking skill. Journal of Asia TEFL, 10(4), 163-183.

Park, Y., \& Warschauer, M. (2016). Syntactic enhancement and second language literacy: an experimental study. Language Learning \& Technology, 20(3), 180-199. https://www. 1ltjournal.org/item/2974

Pulido, M. F. (2021). Individual chunking ability predicts efficient or shallow L2 processing: eye-tracking evidence from multiword units in relative clauses. Frontiers in Psychology, 11, 1-18. https://doi.org/10.3389/fpsyg.2020.607621 


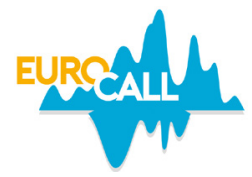

\title{
Is it a blessing? The impact of Covid-19 on non-traditional language learners' satisfaction at Saudi Electronic University
}

\author{
Amera Alharbi ${ }^{1}$, Vicky Wright ${ }^{2}$, and Kate Borthwick ${ }^{3}$
}

\begin{abstract}
This study examines non-traditional language learners' interactions and satisfaction with online learning in the Saudi context during the pandemic. Saudi Electronic University (SEU) is unique in Saudi Arabia as it has adopted a blended mode of teaching and students' completion of both online and class-based materials is mandatory. It enables non-traditional students to further their studies. In a quantitative study, 732 students completed a questionnaire which examines the online learning experiences of these learners. The survey assessed learners' self-efficacy for completing an online course, interactions with content, instructor, other students, and overall satisfaction. The paper examines whether moving to entirely online learning during the pandemic has affected their life and study positively or negatively.
\end{abstract}

Keywords: non-traditional learners, Covid-19, EFL.

\section{Introduction}

With Covid-19, 2020 was an unusual year and education worldwide was shifted to online learning. Despite the fact that some research reflects the effectiveness of online instruction (Markova, Glazkova, \& Zaborova, 2017), this approach might be challenging for non-traditional learners who had to monitor their children's online learning during the pandemic. Non-traditional learners in the Saudi context are either mature learners or those who either took gap years after high school or have many responsibilities. In order to assess the learning outcomes of such non-

\footnotetext{
1. University of Southampton, Southampton, United Kingdom; a.a.alharbi@soton.ac.uk; https:/orcid.org/0000-0002-3799-8543 2. University of Southampton, Southampton, United Kingdom; v.m.wright@soton.ac.uk

3. University of Southampton, Southampton, United Kingdom; k.borthwick@soton.ac.uk; https://orcid.org/0000-0003-2251-7898

How to cite this article: Alharbi, A., Wright, V., \& Borthwick, K. (2021). Is it a blessing? The impact of Covid-19 on non-traditional language learners' satisfaction at Saudi Electronic University. In N. Zoghlami, C. Brudermann, C. Sarré, M. Grosbois, L. Bradley, \& S. Thouësny (Eds), CALL and professionalisation: short papers from EUROCALL 2021 (pp. 12-17). Research-publishing.net. https://doi.org/10.14705/rpnet.2021.54.1301
} 
traditional learners, more research is needed, particularly because the pandemic added extra pressure to the other commitments these learners have. Besides, studies show that language learners prefer face to face classes (Tosun, 2015) or blended learning (Bueno-Alastuey \& López Pérez, 2014). Harrington (2010) highlighted that online education might not be a suitable option for some language learners, in particular those who are lacking the academic skills for success in online learning. Eventually, this situation might be further complicated for first year students enrolled in degree programmes provided in a foreign language, such as English in the case of SEU. Thus, the ultimate goal for this paper is to explore non-traditional language learners' online learning experiences in the foundation year at SEU - which is called the 'First Common Year' (FCY) - by focusing on the following questions.

RQ1. How did Covid-19 affect non-traditional learners' experiences at SEU?

RQ2. What is the preferred learning environment for non-traditional learners?

RQ3. Were non-traditional learners satisfied with their online learning experiences at SEU during the pandemic?

\section{Method}

\subsection{Participants}

Seven hundred and thirty-two students of different proficiency levels in English enrolled in their FCY at SEU participated in the study. The participants were 318 females and 414 males from different regions in Saudi Arabia (37.3\% were over 30 years of age while $34.6 \%$ were 24 to 29 ), and $51 \%$ of the participants were full-time employees and $51.8 \%$ were married.

\subsection{Materials and procedure}

The survey sought to address five learning dimensions (self-efficacy, interactions with teachers, content, learners, and overall satisfaction) which can potentially be related to online learning. The open-ended questions focused on Covid-19 impact, 
learning preferences, some reflections on Blackboard, and the university. The survey was posted on the university's virtual learning environment, which helped to obtain a broad range of responses from eight campuses.

\section{Results and discussion}

Nonparametric comparison tests were used to analyse the data. Thematic analysis was also used to code the themes which emerged from the open-ended questions. The general attitude towards online learning was generally positive (Table 1). Using the Mann-Whitney test, we observed that the two groups were significantly different in the self-efficacy $(p$-value=.006) and learner-content interaction $(p$-value $=.043)$.

Table 1. Differences in the five learning dimensions between first online learning experience

\begin{tabular}{|l|l|l|l|l|l|l|}
\hline \multirow{2}{*}{} & \multicolumn{5}{|l|}{ Is this your first online learning experience? } \\
\cline { 2 - 8 } & yes & \multicolumn{2}{l|}{ no } & Mann-Whitney \\
\cline { 2 - 7 } & Mean & Median & Mean & Median & z & p-value \\
\hline Self-efficacy & 3.86 & 4.00 & 4.03 & 4.00 & 2.725 & .006 \\
\hline Learner-content interaction & 3.88 & 4.00 & 3.98 & 4.00 & 2.023 & .043 \\
\hline Learner-instructor interaction & 3.93 & 4.00 & 3.95 & 4.00 & .579 & .562 \\
\hline Learner-learner interaction & 3.89 & 4.00 & 3.88 & 4.00 & .167 & .867 \\
\hline Student overall satisfaction & 3.93 & 4.00 & 3.94 & 4.00 & 1.084 & .278 \\
\hline
\end{tabular}

To explore the impact of the Covid-19 pandemic on the five categories (Table 2), the Kruskal-Wallis test was used, and a significant difference was observed in learner-instructor interaction ( $p$-value $=.041)$.

Table 2. Differences in the five learning dimensions between being affected by Covid-19

\begin{tabular}{|c|c|c|c|c|c|c|c|}
\hline & \multicolumn{7}{|c|}{ Did Covid-19 affect your study at SEU? } \\
\hline & \multirow{2}{*}{$\begin{array}{l}\stackrel{\varrho}{\text { Mean }} \\
\text { Men }\end{array}$} & \multirow{2}{*}{ 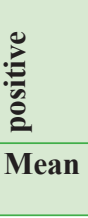 } & \multirow{2}{*}{ 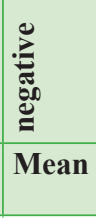 } & \multirow{2}{*}{ 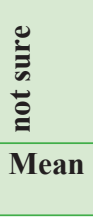 } & \multirow{2}{*}{ 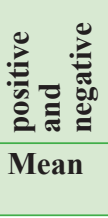 } & \multicolumn{2}{|l|}{ 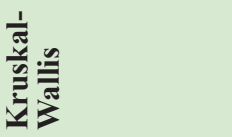 } \\
\hline & & & & & & $\begin{array}{l}\text { Chi- } \\
\text { square }\end{array}$ & p-value \\
\hline Self-efficacy & 3.93 & 3.85 & 3.81 & 3.92 & 4.14 & 4.301 & .367 \\
\hline Learner-content & 3.93 & 3.87 & 3.80 & 3.95 & 4.17 & 6.190 & .185 \\
\hline Learner-instructor & 3.95 & 3.87 & 3.93 & 3.86 & 4.31 & 9.972 & .041 \\
\hline
\end{tabular}


Is it a blessing? The impact of Covid-19 on non-traditional language...

\begin{tabular}{|l|l|l|l|l|l|l|l|}
\hline Learner-learner & 3.91 & 3.77 & 3.89 & 3.82 & 4.22 & 7.566 & .109 \\
\hline Overall satisfaction & 3.96 & 3.88 & 3.85 & 3.91 & 4.19 & 5.724 & .221 \\
\hline
\end{tabular}

For RQ1, 49.6\% of non-traditional learners expressed no effect of Covid-19 on their learning while the qualitative data revealed both positive (17.1\%) and negative (19.0\%) effects on their learning experiences. The common positive effect of the pandemic was the effectiveness of the university and its online approach in saving time and cost, enabling students to develop their learning and English skills, enhance their participation (particularly shy students), and safety (from catching the virus to accidents with long distance driving to campus). The negative impact is categorised as reduced social interactions (mostly learner-teacher interactions and reduced opportunities to practise English in a natural learning setting), disappointment connected to a lack of self-efficacy for learning English in an online environment, difficulty in managing commitments (home/work with study), and negative personal feelings (isolation, loneliness, computer eye strain).

For RQ2, despite the fact that the study participants were aware of the blended approach implemented by the university, virtual learning $(36.3 \%)$ and face to face $(30.2 \%)$ reported to be the most preferable learning approaches and only $(15.8 \%)$ favoured the blended approach. Students' self-efficacy in English and learners' commitments played roles in their preferences. That is to say, some students indicated that the online language classes improved their language skills while others - particularly beginners - found they had made no progress. In addition, learners' multiple roles in life and some workplace restrictions were behind the high percentage in favour of virtual classes.

Students also reported the reasons behind the high percentage (84.4\%) of satisfaction with their online learning experiences during the pandemic (RQ3). Most of them acknowledged the efficiency of online learning (see Table 3 below).

Results indicate that self-efficacy, learner-content interactions, and learnerinstructor interactions were the most common factors that affected students' satisfaction regarding their online learning experiences. Thematic analysis of the qualitative data gives us some explanations about the consequences of the pandemic on the participants' learning outcomes and their preferred mode of delivery.

The results show differences in self-efficacy and learner-content interactions. Selfefficacy in online learning implies students' beliefs about their ability to complete the requirements of the course and it is a vital factor in online learning satisfaction (Jaradat \& Ajlouni, 2020). Students who had low self-efficacy found it difficult to 
achieve success in their online courses. More specifically, beginner English as a Foreign Language (EFL) students reported difficulties in improving their English skills in fully online classes that lack the authentic physical learner-instructor interactions.

Table 3. Distribution of relative factors of online learning

\begin{tabular}{|c|c|c|}
\hline \multirow{6}{*}{$\begin{array}{l}\text { Did the pandemic affect } \\
\text { your study at SEU? }\end{array}$} & & Column N \% \\
\hline & no & $49.6 \%$ \\
\hline & positive impact & $17.1 \%$ \\
\hline & negative impact & $19.0 \%$ \\
\hline & do not know & $10.7 \%$ \\
\hline & positive and negative & $3.7 \%$ \\
\hline \multirow{4}{*}{$\begin{array}{l}\text { Which class do you like } \\
\text { face to face or virtual? }\end{array}$} & F2F & $30.2 \%$ \\
\hline & virtual & $36.3 \%$ \\
\hline & both & $15.8 \%$ \\
\hline & do not know & $17.6 \%$ \\
\hline \multirow{4}{*}{$\begin{array}{l}\text { Would you recommend } \\
\text { SEU to a friend? }\end{array}$} & yes & $84.4 \%$ \\
\hline & no & $7.5 \%$ \\
\hline & May be & $2.9 \%$ \\
\hline & do not know & $5.2 \%$ \\
\hline
\end{tabular}

Students' engagement with the content of learning can be related to their competence in using technology for learning, and the fact that they have to provide a sufficient score in an outer standardised English proficiency test. The inability to provide such a score is likely to affect student satisfaction as well as their willingness to further their education at SEU.

\section{Conclusion}

This study examined the impact of Covid-19 on first year non-traditional learners at SEU. Students' self-efficacy in learning language online, learner-content interaction, and learner-instructor interaction were factors that affected their satisfaction. Their response to the move to online learning as a result of Covid-19 was positive overall, even though entirely online learning is not the university's usual mode of delivery. It was considered as a blessing (quoted by some students) to fulfil their dreams by learning while managing other responsibilities. However, EFL beginners reflected a negative response to the impact of the pandemic because they felt that they could not enhance their language skills in a completely online environment. The online classes provided seem to be a suitable approach for some non-traditional learners that enables them to learn and manage their life responsibilities more effectively. 


\section{References}

Bueno-Alastuey, M. C., \& López Pérez, M. V. (2014). Evaluation of a blended learning language course: students' perceptions of appropriateness for the development of skills and language areas. Computer Assisted Language Learning, 27(6), 509-527. https://doi.org/10.1080/0958 8221.2013 .770037

Harrington, A. (2010). Adapting to fit the technology: problems and solutions for technologybased college classes. The Delta Kappa Gamma Bulletin, 76(3), 12-19.

Jaradat, S. A., \& Ajlouni, A. O. (2020). Social presence and self-efficacy in relation to student satisfaction in online learning setting: a predictive study. International Journal of Education, 8(4), 759-773.

Markova, T., Glazkova, I., \& Zaborova, E. (2017). Quality issues of online distance learning. Procedia - Social and Behavioral Sciences, 237, 685-691. https://doi.org/10.1016/j. sbspro.2017.02.043

Tosun, S. (2015). The effects of blended learning on EFL students' vocabulary enhancement. Procedia - Social and Behavioral Sciences, 199, 641-647. https://doi.org/10.1016/j. sbspro.2015.07.592 


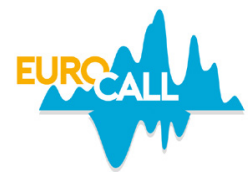

\title{
Intercultural exchanges among pre-service teachers in Israel and Sweden as a path of introduction into the epistemology and practice of teaching
}

\author{
Christopher Allen ${ }^{1}$, Stella Hadjistassou ${ }^{2}$, \\ David Richardson $^{3}$, and Tina Waldman ${ }^{4}$
}

\begin{abstract}
This paper presents the outcomes of a short intercultural exchange project involving pre-service English as a Foreign Language (EFL) teacher training establishments in Sweden and Israel. The project comprised three online meetings recorded in Zoom in which student teachers gave feedback on each other's project assignments involving lesson planning and the use of spoken English in the classroom. The sessions were moderated by a highly experienced teacher trainer with contributions from other teacher trainers in the institutions involved. With restrictions imposed on physical meetings and student mobility by the Covid-19 pandemic, the exchange helped to shed light on a number of perennial issues in English language teaching methodology and offers a feasible model for future sustainable virtual exchanges in EFL teacher training.
\end{abstract}

Keywords: intercultural exchange, intercultural digital literacy, teacher training.

\section{Introduction}

This paper reports on the outcome of an intercultural exchange involving two preservice EFL teacher training institutions, one in Sweden, the other in Israel during the autumn 2020 term. The project aimed to highlight key issues in language teaching through online discussion. With the current economic and socio-political constraints generated by the Covid-19 pandemic, the value of online exchanges in

\footnotetext{
1. Linnaeus University, Kalmar, Sweden; christopher.allen@lnu.se

2. KIOS Research and Innovation Centre, Aglantzia, Cyprus; hadjistassou.stella@ucy.ac.cy

3. Linnaeus University, Kalmar, Sweden; david.richardson@lnu.se

4. Kibbutzim College of Education, Tel Aviv, Israel; tina.waldman@smkb.ac.il
}

How to cite this article: Allen, C., Hadjistassou, S., Richardson, D., \& Waldman, T. (2021). Intercultural exchanges among preservice teachers in Israel and Sweden as a path of introduction into the epistemology and practice of teaching. In N. Zoghlami, C. Brudermann, C. Sarré, M. Grosbois, L. Bradley, \& S. Thouësny (Eds), CALL and professionalisation: short papers from EUROCALL 2021 (pp. 18-22). Research-publishing.net. https://doi.org/10.14705/rpnet.2021.54.1302 
the enrichment of pre-service teacher training programmes has assumed greater importance, serving to shed light on contrasting perspectives on global language teaching epistemologies and practices. The study reports on the affordances and culturally-enacted tensions emerging as students in Israel offered feedback to their Swedish peers on various assignments: two lesson plans, a 90-minute lesson plan, and a longer three-month series of lesson plans. In return, during the virtual workshops, students in Israel were introduced to speaking and practical techniques that could be implemented to promote speaking in the foreign language classroom.

Virtual exchanges have received extensive attention in the Computer Assisted Language Learning (CALL) literature (e.g. Dooly, 2011; O’Dowd, 2018). Within the context of international educational initiatives, virtual exchange has been one of the European Union's most successful mobility programmes, leading to the launch of the Erasmus + Virtual Exchange (EVE) project in 2018.

\section{Method}

The exchange consisted of three separate online meetings, during November 2020. The group of Swedish trainee teachers consisted of nine women and eight men aged between 20 and 25 years at high C1/C2 CEFR ${ }^{5}$ levels, all in initial teacher training with a view to teaching English at secondary or upper secondary level. The Israeli group on the other hand was made up of 21 female and two male students in the third year of a four year Bachelor of Education programme with an English language proficiency judged to be B2 to $\mathrm{C} 2$ levels.

The interactions between the groups of students took place using the Zoom video conferencing tool. A summary of each meeting's initial agenda/focus is included in Table 2 below. Central to the planning of each meeting was the giving of feedback on a number of assignments within the Swedish and Israeli course modules. These assignments are summarised in Table 1 below.

Having two groups of trainee teachers working specifically with course assignments gave this telecollaboration project a particular focus, which is often difficult to achieve. Rather than the cross-cultural differences being the focus of the interaction, the students discussed the specific assignments in small groups in breakout rooms. In each meeting the groups spent approximately 20 minutes in breakout rooms discussing the Swedish students' assignments and learning about

5. Common European Framework of Reference for languages 
each other's schools, levels of English, and cultural contexts, as well as discussing issues of general interest to students (such as study loans and social lives). After this, the groups met in recorded plenary sessions with Israeli and Swedish participants giving their impressions about the discussions in the breakout rooms. These were often opportunities to discuss specific issues relating to the teaching of English, such as ways of encouraging students to speak English in class, rather than their L1.

Meetings typically involved around 25 trainee teachers plus the four co-authors of this article and an additional teacher trainer from Israel. The sessions were led/moderated by David Richardson with additional contributions from the other teacher trainers during the course of the sessions. Sessions would begin with an introductory overview, followed by group sessions involving Swedish and Israeli students and taking place in dedicated breakout rooms (circa 20 minutes) for discussion of the assignments outlined in Table 1. Teacher trainers were not present in the breakout rooms and these individual group discussions were not recorded as part of the main session. Finally, student teachers returned to the main session for a plenary discussion of the issues raised.

Table 1. Summary of assignments within the Swedish and Israeli course modules respectively

\begin{tabular}{|l|l|l|}
\hline Country & Assignment & Description \\
\hline Sweden & 1 & $\begin{array}{l}\text { Describe your planning for a 90-minute English lesson } \\
\text { at upper secondary level, giving reasons for the choices } \\
\text { you make. You need to choose a main focus for the } \\
\text { lesson and describe how you would develop the students } \\
\text { language skills (reading, writing, listening, and speaking) } \\
\text { in relation to this focus. Mention any teaching aids } \\
\text { you are going to use and any use of technology. }\end{array}$ \\
\hline Sweden & 2 & $\begin{array}{l}\text { Describe how you would develop a series of lessons linked } \\
\text { to a theme over a three-month period. Your lessons need } \\
\text { not be the only English lessons the class has during that } \\
\text { period, but there needs to be a theme running through them. }\end{array}$ \\
\hline Israel & 1 & $\begin{array}{l}\text { Learn as much from your Swedish partners } \\
\text { about how teaching speaking is incorporated } \\
\text { into the syllabus in all grades. }\end{array}$ \\
\hline
\end{tabular}

Table 2. Summary of meetings and respective focuses

\begin{tabular}{|l|l|}
\hline Meeting 1 (3rd November) & $\begin{array}{l}\text { Getting to know you activities for the students; } \\
\text { Swedish students present their module } \\
\text { and expectations; Israeli students present a brief } \\
\text { outline of their course - teaching speaking }\end{array}$
\end{tabular}


Intercultural exchanges among pre-service teachers in Israel and Sweden...

\begin{tabular}{|l|l|}
\hline Meeting 2 (10th November) & $\begin{array}{l}\text { Israeli student teachers present feedback to their Swedish } \\
\text { counterparts on Assignment 1; Israeli students have } \\
\text { focused questions to ask about teaching speaking }\end{array}$ \\
\hline Meeting 3 (17th November) & $\begin{array}{l}\text { Israeli feedback to Swedes on Assignment 2, } \\
\text { Israelis brainstorm with Swedes about how to adapt } \\
\text { Swedish speaking pedagogy for an Israeli context }\end{array}$ \\
\hline
\end{tabular}

\section{Results and discussion}

Discussion of the results in the form of a thematic analysis of the Zoom plenary recordings will mainly focus on Meetings 2 and 3, which were the most productive in terms of responding to the three assignments which had been given to the two groups of student teachers by their host institutions. Session 1 was mainly devoted to 'getting to know you' interactions which were characterised by polite but often quite superficial interactions involving national and cultural comparisons. This was to be expected given the fact that the groups had never interacted before and that none of the trainee teachers involved had travelled to the corresponding country.

Session 2 was by far the most productive as it focused on language teaching methodologies and classroom practice. Discussion of the teaching of spoken English was brought up in the light of Israeli perceptions of high oral proficiency in English among the Swedish population. This discussion led naturally to a consideration of whether this high Swedish proficiency was the result of the success of a communicative pedagogy in the Swedish school system or alternatively high exposure to extramural English outside of the classroom. Students took with them a better understanding of the beneficial role of extramural exposure in a country like Sweden in raising proficiency levels. Israeli students outlined the preference for translation in Israeli schools and the dominance of grammatical study rather than communicative interaction. In the course of the discussion, David Richardson's experience in teaching beginner Turkish communicatively led to an appreciation among the Israelis that a foreign language can be successfully taught without translation.

As part of their assignment, Swedish student teachers had to produce lesson plans which were reviewed by their Israeli counterparts. A number of Israeli trainees felt that the plans submitted lacked sufficient procedural detail of classroom activities which led to revisions of the originally submitted outlines. These reflections prompted a discussion relating to the level of detail involved in the planning of lesson components; one of the teacher trainers present (Christopher Allen) raised the relatively detailed lesson plan template outlines designed as part 
of the international EFL teacher training courses such as the TKT and CELTA programmes. Swedish student teachers came away with a greater awareness of the need to make the language focus, classroom procedures, and technical requirements more transparent.

\section{Conclusions}

Overall, the series of Zoom meetings demonstrated the benefits of online interaction involving two teacher training organisations from widely disparate geographical and cultural contexts. By carefully targeting methodological themes and aspects of classroom practice in advance under the direction of experienced teacher trainers, valuable intercultural perspectives on international teacher education can be gained. Such perspectives can help student teachers to critically appraise pedagogical practice and methodological orthodoxy in their own contexts. The outcome of the project points the way ahead to a feasible and sustainable model of virtual collaboration.

\section{References}

Dooly, M. (2011). Crossing the intercultural borders into 3rd space culture(s): implications for teacher education in the twenty-first century. Language and Intercultural Communication, 11(4), 319-337. https://doi.org/10.1080/14708477.2011.599390

O'Dowd, R. (2018). From telecollaboration to virtual exchange: state-of-the-art and the role of UNiCollaboration in moving forward. Journal of Virtual Exchange, 1, 1-23. https://oi. org/10.14705/rpnet.2018.jve.1 


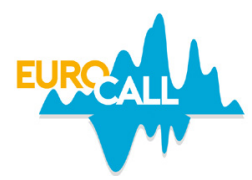

\title{
Online translators for $L 2$ writing: a comparison of student and teacher perspectives
}

\author{
Antonie $\mathrm{Alm}^{1}$ and Yuki Watanabe ${ }^{2}$
}

\begin{abstract}
This short paper reports on the preliminary findings of a study into the use of Online Translators (OTs) by university language students. Students of Chinese, French, German, Japanese, and Spanish and their teachers responded to comparative surveys on their respective use and evaluation of OTs for L2 writing in formal language learning contexts. Findings indicate that teachers have little awareness of the range of strategies students apply when using OTs as writing tools. Concerns of OT misuse for cheating or as a replacement for language learning seem largely unfounded. Students, however, perceive a lack of guidance for the appropriate use of OTs. Preliminary findings suggest that teachers need to review their assumptions about students' OT practices and that both students and teachers would benefit from technical and pedagogical OT training.
\end{abstract}

Keywords: online translators, learner experiences, teacher experiences, OT training.

\section{Introduction}

OTs such as Google Translate and DeepL are freely available and are widely used for various translation purposes. Yet when it comes to formal language learning, scepticism about their reliability and suitability remains. Prohibiting or discouraging the use of OTs, many language teachers consider their use as a form of academic dishonesty (Clifford, Merschel, \& Munné, 2013; Correa, 2014; Niño, 2009). However, the frequent and extensive use of OTs among language learners (Briggs, 2018) suggests that incorporating or at least accepting the use of OT in the language curriculum is inevitable (Groves \& Mundt, 2021). Recent studies have, in fact, shown benefits of OT use in second language (L2) writing, such

1. University of Otago, Dunedin, New Zealand; antonie.alm@otago.ac.nz; https://orcid.org/0000-0002-1232-9204

2. University of Otago, Dunedin, New Zealand; yuki.watanabe@otago.ac.nz; https://orcid.org/0000-0003-2708-9191

How to cite this article: Alm, A., \& Watanabe, Y. (2021). Online translators for L2 writing: a comparison of student and teacher perspectives. In N. Zoghlami, C. Brudermann, C. Sarré, M. Grosbois, L. Bradley, \& S. Thouësny (Eds), CALL and professionalisation: short papers from EUROCALL 2021 (pp. 23-28). Research-publishing.net. https://doi.org/10.14705/ rpnet.2021.54.1303 
as improvement in lexical and grammatical accuracy, vocabulary development, and reduction of writing anxiety (Tsai, 2020). Increased confidence through OTsupported L2 writing can also help language learners develop positive writing strategies (Lee, 2020). Further, OT training can prevent indiscriminate OT use and dependency (O’Neill, 2019) and help language learners to become more selfreliant in their writing (Tsai, 2020).

This study investigates OT practices as reported by university language students and their teachers, focusing on the following research question:

- to what extent do learner and teacher perspectives on OTs differ in terms of their use and appropriateness in formal L2 writing?

\section{Method}

This study collected quantitative and qualitative data via online surveys. Student data were gathered over two weeks using a combination of 25 closed and openended questions. Survey questions were generated in reference to studies by Niño (2009), Clifford et al. (2013), Briggs (2018), and Tsai (2020). One hundred and fifty-nine university students taking Chinese, French, German, Japanese, and Spanish at beginner, intermediate, and advanced levels participated in this study. Twelve instructors (representing all languages and levels) responded to a 16-question survey. STATA was used for the statistical analysis of the quantitative data and NVivo for the thematic analysis of the qualitative data. This article provides a preliminary analysis of the data, which will be explored in more detail in a following paper.

\section{Results and discussion}

\subsection{OT use: teachers vs students}

Three of 12 participating language teachers confirmed familiarity with OTs, using mainly Google Translate for professional and personal purposes. Another three described themselves as occasional users, whereas the other half claimed no experience with OTs. One occasional user admitted that her knowledge about Google Translate was outdated. Taking the survey might have triggered her interest as she suggested, "these translators must have improved a lot recently. I should 
check them out". Those who considered themselves experienced explained that they used OTs regularly to communicate with colleagues, family and friends, collaborate with international colleagues, or translate their own literary work.

Students, however, seemed well familiar with Google Translate and a range of other OTs, such as DeepL or Papago. About $90 \%$ of students were using OTs in their L2, both on their computer $(86.5 \%)$ or on their smartphones $(80 \%)$. Frequencies ranged from daily (23.81\%), a few times a week (56.35\%), to less than once a week (23.81\%).

As depicted in Figure 1, students reported they used OTs principally for reading (translating words or text passages) and to assist L2 writing, a practice anticipated by teachers. Responses also revealed unexpected OT use for listening and pronunciation, indicating that students were taking advantage of OT multimodal affordances.

Figure 1. Purpose of OT use: teachers versus students

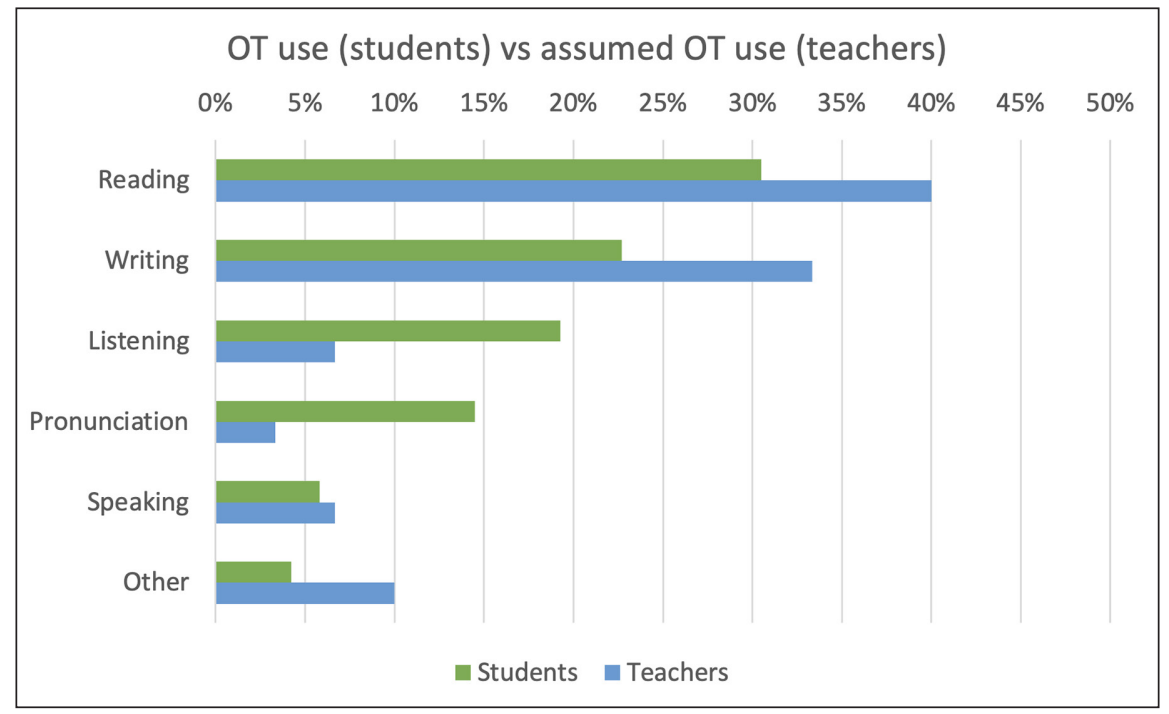

\subsection{OTs for L2 writing}

Only a few teachers provided suggestions on how their students might use OTs for L2 writing. They assumed that students were using OTs to do the work for them, "to get the assignment done quickly and with few errors and presenting it as their own" or by "writing first in L1 and then translate it into L2 to be used as 
assignment". Such assumptions reflect the widely held belief that OTs are used for cheating and are detrimental to language learning (Correa, 2014). One teacher speculated that students use OTs "to check and correct entire clauses they have first written themselves".

The analysis of the qualitative data indicates that students are using OTs to support their writing in a variety of ways, at different stages in the writing process, mainly:

- as dictionaries: aware of the limitations of OTs for longer text passages, most students (87\%) stated that they used OTs primarily for looking up words, spell checking, and improving a text stylistically by looking up synonyms and idioms;

- as grammar checkers: students identified a range of OT capabilities to deal with grammatical uncertainties while writing, such as syntax, verb conjugation, gender, and adjective agreement; and

- for proofreading: as one of the teachers suggested, students enter their L2 text into OTs to either confirm accuracy or get alternative suggestions.

These reports suggest that these students do not use OTs to bypass but to support their writing. As one student put it, OTs help "with specific words or grammar points but should not be used for whole sentences or paragraphs otherwise, you are hindering your learning". Their handling of OT output similarly suggests that they abstain from simply copying and pasting translated text in their writing assignments. To verify the accuracy of the output, they use strategies such as text manipulation (e.g. "putting smaller phrases from a bigger phrase and seeing if they are translated the same"), consult others (peers, teachers, or native speakers), or draw on additional resources (Google search, textbook, or dictionary).

\subsection{Implications for formal language learning}

Findings indicate that the majority of language students (about 89\%) are using OTs, that they are aware of their limitations, and that they have a range of strategies to use OT to support their writing. Teachers, on the other hand, show little awareness or support of these practices. Half of them had never approached the topic of OT in class, and none included guidelines for OT use in their course outlines, leaving students guessing about the appropriateness of using OT for their written work (Figure 2). 
Figure 2. Approval of OT use for L2 writing: teachers versus students

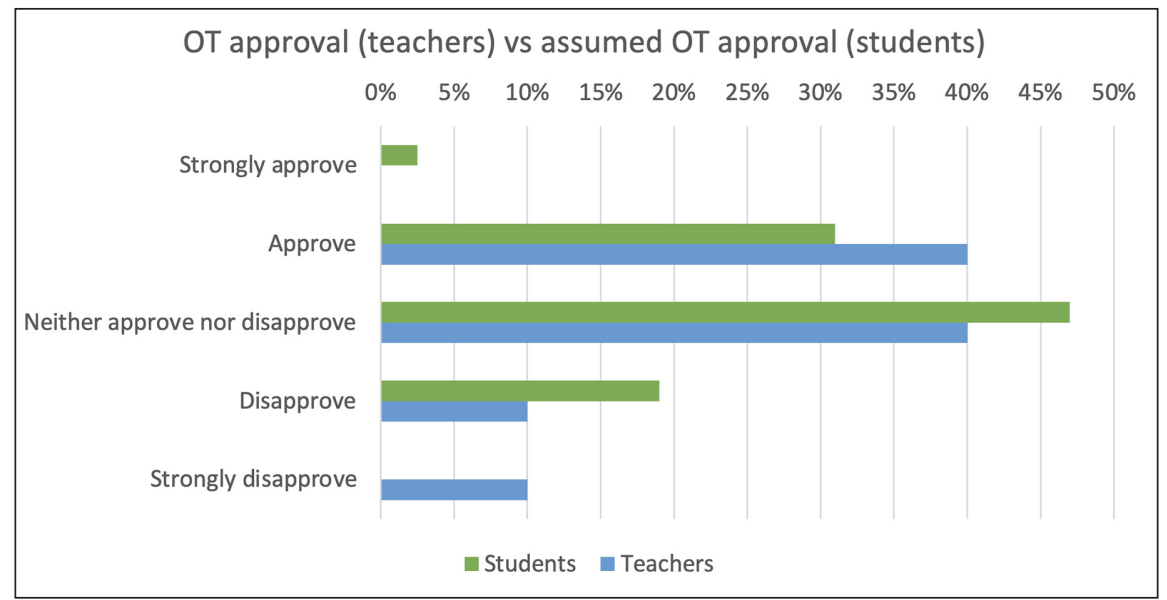

While divided or undecided on allowing students to use OTs, 92\% of teachers agreed on the benefit of OT training to ensure 'ethical' use of OT. The findings of this study thus reinforce Ducar and Schocket's (2018) recommendation that teachers need to review their assumptions about their students' OT practices and their own knowledge of OTs. It further suggests that both students and teachers would benefit from technical and pedagogical OT training.

\section{Conclusions}

As students start to seize the affordances of OT for language learning, it is crucial that language teachers adjust their teaching practices and guide students to use translation tools appropriately. The data presented in this article indicates that current student practices can help inform a pedagogical framework towards ethical and effective OT use for formal L2 writing. Further investigations into OT practices of learners at different levels of proficiency and of different languages will be explored in the full study.

\section{References}

Briggs, N. (2018). Neural machine translation tools in the language learning classroom: students' use, perceptions, and analyses. JALTCALL Journal, 14(1), 2-24. https://doi.org/10.29140/ jaltcall.v14n1.221 
Clifford, J., Merschel, L., \& Munné, J. (2013). Surveying the landscape: what is the role of machine translation in language learning? @ tic. revista d'innovació educativa, 10, 108-121. https://doi.org/10.7203/attic.10.2228

Correa, M. (2014). Leaving the "peer" out of peer-editing: online translators as a pedagogical tool in the Spanish as a second language classroom. Latin American Journal of Content \& Language Integrated Learning, 7(1), 1-20. https://doi.org/10.5294/lacli1.2014.7.1.1

Ducar, C., \& Schocket, D. H. (2018). Machine translation and the L2 classroom: pedagogical solutions for making peace with Google translate. Foreign Language Annals, 51, 779-795. https://doi.org/10.1111/flan.12366

Groves, M., \& Mundt, K. (2021). A ghostwriter in the machine? Attitudes of academic staff towards machine translation use in internationalised higher education. Journal of English for Academic Purposes 50, 100957. https://doi.org/10.1016/j.jeap.2021.100957

Lee, S. M. (2020). The impact of using machine translation on EFL students' writing. Computer Assisted Language Learning, 33(3), 157-175. https://doi.org/10.1080/09588221.2018.1553 186

Niño, A. (2009). Machine translation in foreign language learning: language learners' and tutors' perceptions of its advantages and disadvantages. ReCALL, 21(2), 241-258. https://doi. org/10.1017/S0958344009000172

O'Neill, E. M. (2019). Training students to use online translators and dictionaries: the impact on second language writing scores. International Journal of Research Studies in Language Learning, 8(2), 47-65. https://doi.org/10.5861/ijrsll.2019.4002

Tsai, S. C. (2020). Chinese students' perceptions of using Google Translate as a translingual CALL tool in EFL writing. Computer Assisted Language Learning,30, 1-23. https://doi.org/ $10.1080 / 09588221.2020 .1799412$ 


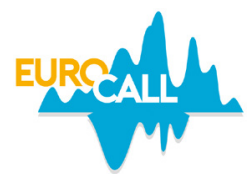

\title{
Assessing attitudes of university students toward online classes of Icelandic as a foreign and second language during COVID-19
}

\author{
Branislav Bédi ${ }^{1}$ and Lara Roje ${ }^{2}$
}

\begin{abstract}
Due to the COVID-19 pandemic, the on-campus teaching mode at local universities in Iceland changed to distance teaching and synchronous classes online. This rapid and unexpected change also affected the learners. Although videoconferencing was used as the main point of reference, this method turned out to be less suitable for synchronous online classes with instant feedback. Therefore, a new format of synchronous classes online was adopted. This enabled the teacher and the learners to interact with each other during the online classes. The present article describes a case study of international and foreign students attending regular online classes of Icelandic as a foreign and second language (L2) at a local university in Reykjavik during fall 2020. Attitudes of 26 students toward a changed teaching mode were examined. Data were collected using an online questionnaire at the end of the course and answers analysed based on responses to 72 questions in ten different themes that guided the construction of ten research questions. The results suggest that the teacher's approach to online class organisation could be improved to achieve a better wellbeing among students and create a more effective online teaching environment.
\end{abstract}

Keywords: L2 Icelandic, immigrant students, international students, online teaching, COVID-19.

\footnotetext{
1. The Árni Magnússon Institute for Icelandic Studies, Reykjavik, Iceland; branislav.bedi@arnastofnun.is; https://orcid. org/0000-0001-7637-8737

2. University of Iceland, Reykjavik, Iceland; roje@hi.is; https://orcid.org/0000-0001-9732-6151

How to cite this article: Bédi, B., \& Roje, L. (2021). Assessing attitudes of university students toward online classes of Icelandic as a foreign and second language during COVID-19. In N. Zoghlami, C. Brudermann, C. Sarré, M. Grosbois, L. Bradley, \& S. Thouësny (Eds), CALL and professionalisation: short papers from EUROCALL 2021 (pp. 29-34). Researchpublishing.net. https://doi.org/10.14705/rpnet.2021.54.1304
} 


\section{Introduction}

Due to the COVID-19 pandemic, the Face-to-Face (F2F) mode of teaching at local universities in Iceland changed and synchronous classes taught live and online (Kohnke \& Moorhouse, 2020, p. 1) were adopted. Universities in Iceland had to follow policies on gathering limits, which resulted in the cancellation of on-campus classes and adopting synchronous classes online. Due to such a rapid change, teachers could only use those tools that were readily available for them at their home institutes. Some tools, e.g. the Synchronous Meeting Tool (SMT) Microsoft Teams in our case, were originally developed for videoconferencing and online business meetings but not for teaching during live sessions. However, the traditional videoconferencing approach once used in virtual learning and teaching environments (Hampel \& Hauck, 2004) no longer supported collaborative work with immediate feedback during synchronous online classes as it lacks many features including immediate feedback and group work, which are otherwise usually present in on-campus classes. Although videoconferencing was very popular in distance learning at the beginning of the 21 st century, this method only enabled learning at a distance with an instructor and a learner in different localisations (Zähner, Fauverge, \& Wong, 2000, p. 190), often in an asynchronous way and without immediate feedback. Due to the increased demand for suitable tools with better functionalities during the pandemic, many software companies upgraded their tools allowing teachers to use them in synchronous classes online. This situation, nonetheless, represented a challenge for both teachers and students because they had to apply different approaches to teaching and learning. Another challenge was the lack of F2F contact in online classes with the teacher and other peers (Cheung, 2021, p. 1), or the different conditions each student lived in, which could have resulted in communication hindrances or isolation. The aim of the article is to present a case study investigating students' attitudes towards change in the fully online teaching mode of delivery they were exposed to during the pandemic and the challenges they faced in the online classes during fall 2020.

\section{Learners' perceptions of the online mode of the language classes}

Thirty-six participants from 14 different countries attended a university course of L2 Icelandic for beginners. The course was designed to teach a mixed class of both exchange students and local foreign students permanently living in the country. Twenty-six (72\%) students responded to the survey: 17 female, eight male, and one other gender, aged 20-44. However, 23 students perceived their level of Icelandic 
as beginner, two as advanced, and one as proficient, thus forming a mixed class of students with different previous knowledge of Icelandic. All participants were situated in Iceland but attended weekly classes during live sessions using what earlier would have been termed as a videoconferencing tool but is now referred to as an SMT tool.

An online survey was used for collecting data from volunteering students of the L2 Icelandic course. It consisted of 72 questions to collect quantitative data, six of these questions were about the participants' background, and 65 were Likert-scale questions on ten different topics concerning the online classes, and one open-ended question for collecting qualitative data on students' suggestions or further remarks. The questions were tailor-made for the actual course and mode of teaching in order to capture a realistic picture of the situation. The questions in the survey came with a Likert-scale of six options ranging from 'strongly disagree' to 'strongly agree'. These survey questions were constructed around ten different themes that guided the research questions of this study. Results summarising these ten themes are presented in the next section.

\section{Results and discussion}

Due to space, only selected answers from the survey are presented in Figure 1. Regarding language practice opportunities with the teacher and other peers (1), $46 \%$ reported lack of practice with other peers. However, $73 \%$ could practise with the teacher and $92 \%$ used the opportunity to ask the teacher questions. Regarding practising of different language skills within and outside of the synchronous online classes (2), students could practise speaking (38\%), writing (31\%), listening $(43 \%)$, and reading $(46 \%)$, but they felt that it was not sufficient due to a perceived slower mode of the online course when compared to their previous experience with on-campus teaching, i.e. the students thought that less exercises and teaching materials were provided during the synchronous classes online. Regarding feelings involved in active participation (3), however, $39 \%$ of students did not feel confident to actively participate in exercises during their classes and 34\% felt worried that other students would speak Icelandic better than themselves. Regarding the ease or difficulty in focusing on learning (4), $46 \%$ reported that they were somehow distracted by other elements in their local environment during the sessions, and $35 \%$ reported it was difficult for them to stay focused on learning during the online classes. Regarding teacher perception (5), $88 \%$ of the study participants indicated that the teacher was well prepared. Regarding the course material (6), $77 \%$ of students agreed that the pedagogical resources relied upon were presented well 
by the teacher. Regarding homework assignments (7), 35\% of students reported that homework assignments were not time consuming and that they helped them with practising speaking (27\%), writing (54\%), listening (69\%), and reading (59\%). Regarding using other online tools during homework assignments (8), 46\% used online dictionaries for Icelandic (Glosbe, Snara), 58\% used the DIM - The Database of Icelandic Morphology website - 53\% used Google Translate, and $27 \%$ reported using other online tools. Regarding their satisfaction with the course curriculum (9), 73\% agreed that it was challenging and $46 \%$ were satisfied with it. Regarding their overall satisfaction with the online format of the course (10), $46 \%$ were satisfied with it.

Figure 1. Selected data from the online survey ${ }^{3}$

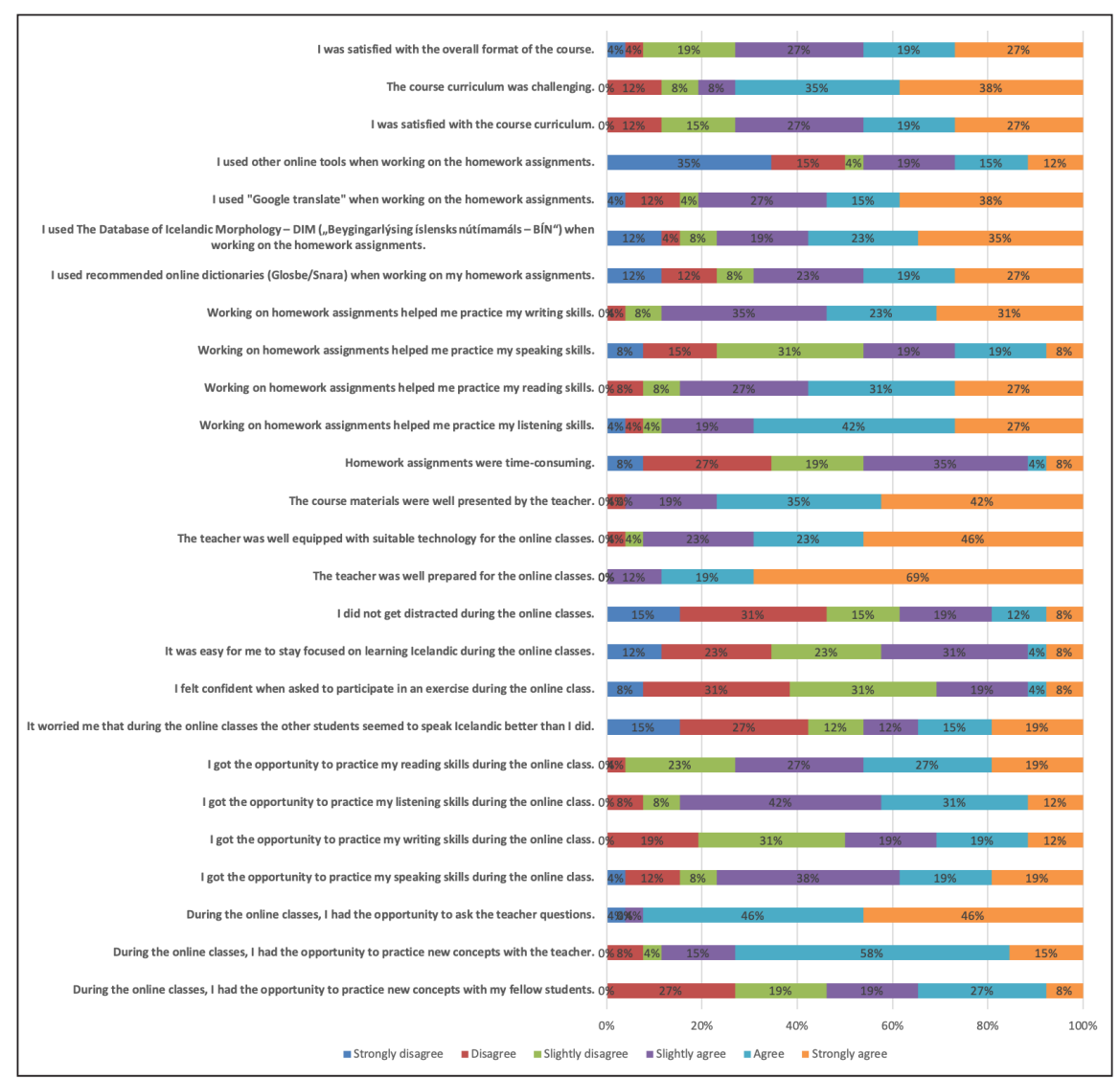

3. For a bigger version of the figure, see supplementary materials 
In the open-ended question, students reported that the course felt fast and that practising the language outside of the class with local speakers was restricted due to the COVID-19 regulations on gatherings. Although the class was divided into two groups with different levels, beginner and intermediate, some students still felt that their group could have been divided into two further smaller groups with different language levels. A reoccurring comment was that they wished for " $[\mathrm{m}]$ ore practice of Icelandic conversations between the students". There were no specific comments about the online tool used for teaching.

\section{Conclusions}

Due to lack of space, the results were not presented in full but the collected data suggest that it was important for the study participants that the teacher was (1) well prepared for each online lesson, (2) could operate with the online tool without any problems, and (3) that the course was well organised. The students perceived Microsoft Teams as a suitable remote learning solution.

Regarding language practice opportunities during the synchronous online classes, the students perceived that they could only partly practise all four language skills. Students also felt that they had sufficient opportunities to practise speaking only with the teacher but wished for more peer-to-peer speaking opportunities. At the same time, students felt worried about speaking Icelandic in the presence of other peers during the online classes. Therefore, as Moser, Wei, and Brenner (2021) also suggest, teachers should develop appropriate interaction activities for synchronous online classes. Because it was a group of students with mixed levels of Icelandic in each of the two groups, they felt it could have been divided into further smaller groups to satisfy their different language needs.

\section{Supplementary materials}

https://research-publishing.box.com/s/3w7bmjmvz3zht03nm2k93q72cmdx2ixa

\section{References}

Cheung A. (2021). Language teaching during a pandemic: a case study of Zoom use by a secondary ESL teacher in Hong Kong. RELC Journal, First view, 1-16. https://doi. org/10.1177/0033688220981784 
Hampel, R., \& Hauck, M. (2004). Towards an effective use of audio conferencing in distance language courses. Language Learning and Technology, 8(1), 66-82. https://www.lltjournal. org/item/2460

Kohnke, L., \& Moorhouse, B. L. (2020). Facilitating synchronous online language learning through Zoom. RELC Journal, First view, 1-6. https://doi.org/10.1177/0033688220937235

Moser, K. M., Wei, T., \& Brenner, D. (2021). Remote teaching during COVID-19: implications from a national survey of language educators. System, 97, 102431. https://doi.org/10.1016/j. system.2020.102431

Zähner, C., Fauverge, A., \& Wong, J. (2000). Task-based language learning via audiovisual networks. The LEVERAGE project. In M. Warschauer \& R. Kern (Eds), Network-based language teaching: concepts and practice. Cambridge University Press. 


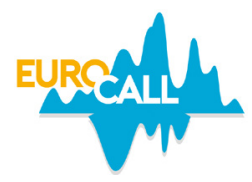

\title{
Constructing meaning in a different language: the case of doctoral students in a French University
}

\author{
Albana Canollari-Baze ${ }^{1}$ and Gaby David ${ }^{2}$
}

\begin{abstract}
Drawing from a constructivist approach, this qualitative research presents results of teaching the Doctoral English Course (DEC) at the Center for Languages (CDL), University Paris 8 Vincennes-Saint-Denis. The DEC aims to train doctoral candidates in the practice of scientific communication in English. By allowing students to (re)think and approach their thesis in English, concrete research methods and tools to produce results related to their research were provided. The analysis explored students' experiences on classroom activities and their reflections at the end of the course. Students reflected on meaningful experiences, collaborative learning, and impact of the process in developing their research. Overall, the study offers insightful contributions on the way rethinking in a different language influenced the way scientific meaning is reconstructed.
\end{abstract}

Keywords: collaborative learning, constructing meaning, doctoral students, DEC.

\section{Introduction}

Rooted in the cognitive developmental theory of Piaget (1971) and in the sociocultural development of Vygotsky (1978), constructivism views knowledge as a representation of reality and the learner in the process of constructing that reality individually and socially. Notions within constructivism have emerged as a leading paradigm in developing pedagogy in higher education. Kaufman (2004) viewed language pedagogy as an integrated instructional approach that underscores the centrality and diversity of learners emphasizing their individual and collective active engagement in a learning context.

\footnotetext{
1. University Paris 8 and Schiller International University, Paris, France; albana.baze@univ-paris8.fr

2. TransCrit, Paris 8 and IRCAV, Sorbonne Nouvelle, Paris, France; championnet4@yahoo.fr; https://orcid.org/0000-0001$7562-5767$

How to cite this article: Canollari-Baze, A., \& David, G. (2021). Constructing meaning in a different language: the case of doctoral students in a French University. In N. Zoghlami, C. Brudermann, C. Sarré, M. Grosbois, L. Bradley, \& S. Thouësny (Eds), CALL and professionalisation: short papers from EUROCALL 2021 (pp. 35-40). Research-publishing.net. https://doi.org/10.14705/rpnet.2021.54.1305
} 
In 2018, the CDL and the Doctoral Schools at the University Paris 8 implemented for the first time the first DEC (supplementary materials, Appendix 1). Three consecutive years of the implementation inspired the authors to study the incipient development of this course, which aims to familiarize students to reflect on their theses in English. Doctoral candidates came from various disciplines and were at different stages of their academic path. Students were native French speakers as well as international students for whom English was their second (L2) or third language. This study offers insight of PhD students' experiences in thinking about their thesis in English and it explores the way they construct meaning in another language. In particular, two research questions were addressed.

- What are the doctoral students' experiences in the DEC?

- How do doctoral students construct meaning in content creation (speaking and writing)?

The course textbook (Terrell, 2015) offered concrete methods and tools to support scientific research through academic written and oral communications.

\section{Methodology}

This qualitative study utilized thematic analysis (Braun \& Clarke, 2006) to explore students' reflections on an end of course survey. In addition, content analysis was applied to submitted academic work before and after intervention. Reflections on class activities offered thought-provoking insights on the impact of L2 in developing their research topics.

In this study, 34 students (13 Native French, 21 Non-Native English speakers ${ }^{3}$ ) who took an online DEC via Zoom, agreed to participate. Instructed via a studentcentered approach, participants who possessed a B2 English level engaged in creating and presenting their own content (via PowerPoint posters, abstracts, texts, etc.). At the end, they reflected on their experiences focusing on the process of rethinking their research in English. They responded to a survey in English administered via email (supplementary materials, Appendix 2).

3. Non-native students' nationalities: Argentina, Armenia, Algeria, Ecuador, Italy, Israel, Haiti, Ghana, Germany, Lebanon, Switzerland, Tunisia, etc. 


\section{Results}

Three interconnected main themes emerged from the analysis ${ }^{4}$ of students' responses: experiences, collaborative learning, and impact on the research process. Content analysis on students' delivered work focused on how they constructed academic meaning in English, accounting for a fourth theme: constructing meaning. The quotes used for illustration speak for the majority of them and are representative of the group under study.

\subsection{Experiences}

The majority of the students (31) viewed the DEC as an opportunity to upgrade their general and scientific English language skills, with some (19) expressing a sense of raised awareness in the importance of participating in international conferences.

"This online course is a really great opportunity for me [...]. I am looking to further improve my English in vocabulary and to practice speaking, so I can speak English fluently, and to grasp the maximum knowledge in scientific communication".

Most participants (28) elaborated the course as shifting their perspective while rethinking their research components.

"The exchanges we were able to have throughout the workshop allowed me to rethink my research questions and see my topic with new perspectives".

Interestingly, some students (12) expressed how the course 'broke' feelings of loneliness, claiming: "It [the course] breaks the researcher's loneliness, and it helps to find a common denominator in our daily work". Others (12) expressed that it helped build confidence and self-esteem.

\subsection{Collaborative learning}

Generated from the analysis, collaborative learning was a theme enriched through: (1) the facilitators, (2) the tools taught/used, and (3) the peers. Half of the students valued the role of their facilitators as mediators, while emphasizing the importance of receiving feedback on the spot.

4. For an illustration of the thematic analysis, please see supplementary materials, Appendix 3. 
"Expert feedback is crucial for a young researcher. Having a professor who can comment 'live' on mistakes or an approach is essential to progress".

Students (28) identified taught tools as mediators of their thinking process: "DEC helped me to focus on the problem statement and to rethink my thesis in a different way". Others (11) also reflected on their peers' mediation: "this workshop is a great tool to better formulate one's research subject in a simple way as well as to learn and exchange about other researchers' subjects and methodologies".

\subsection{Impact on research process}

The majority (n.30) elaborated the course as impactful and that it supported them "to think about the aspects that I can and cannot control in my research process". Overall, it was evident that students believed that the course reinforced "a solid foundation to write a scientific article in English".

\subsection{Constructing meaning}

Throughout the course, students were invited to rewrite their thesis content in English, including research components (i.e. purpose statement, research questions). Table 1 presents examples illustrating improvements before and after intervention, showing the differences in meaning construction through language mastery.

Table 1. Examples on students' meaning construction before and after intervention $^{5}$

\begin{tabular}{|l|l|}
\hline Before intervention & After intervention \\
\hline $\begin{array}{l}\text { Thesis statement: } \\
\text { dimension of oil conflict in Iraq } \\
\text { and its impact on Kurdish-Arab } \\
\text { relations between } 2003 \text { and } 2017 .\end{array}$ & $\begin{array}{l}\text { This article explores the Kurdish } \\
\text { national identity dimension during } \\
\text { the oil conflict in Iraq and the impact } \\
\text { of this conflict on Kurdish-Arab } \\
\text { relations between } 2003 \text { and } 2017 .\end{array}$ \\
\hline Problem statement: & $\begin{array}{l}\text { The subject of morality is present in } \\
\text { many philosophical writings of Jean-Paul } \\
\text { The problem of morality is present } \\
\text { in many philosophical writings of } \\
\text { did not attempt to give a definition } \\
\text { of this concept despite the efforts. } \\
\text { definition of that despite the efforts. }\end{array}$
\end{tabular}

5. For an illustration of the thematic analysis before and after intervention, please see the second table in supplementary materials, Appendix 3. 
These examples reflect ways in which students were able to rethink concepts, clarify wording to fit research, and master naturalized language in formulating statements, showing evidence of reconstructing meaning (i.e. from identity dimension of oil conflict to national identity dimension during oil conflict).

\section{Discussion and conclusions}

This study explored doctoral students' experiences in the DEC and how thinking about their thesis in English (L2) impacted the ways they constructed scientific meaning. As presented in the results, three main components were significant for the students. First, their overall course experience presents a meaningful opportunity to master general English skills as well as to approach their own thesis through different lenses, while improving their scientific skills. Unintendedly, the course has gone a step further in motivating some students to break that sense of loneliness by fostering self-esteem and confidence. Furthermore, collaborative learning stressed out the mediating role of instructors, research tools, and peers operating as a support system influencing their efforts to recreate scientific content in L2. The course also allowed students to become more aware of areas in the research process that they can and cannot control, building a foundation toward writing scientific articles in English. Lastly, being hands-on in re-creating scientific content from French to English offers an insight of how the process allowed students to reconstruct meaning, suggesting the impactful role of L2 in a French university.

Going back to the theory, constructivism recognizes that learning is a social construct and that conceptual schemes are transmitted by means of language. As Vygotsky viewed it, knowledge is a co-constructed process. All seems to imply that the DEC not only impacts and has implications on doctoral candidates' English proficiency, but also in reconstruction of meaning of their own research in French.

To conclude, meaning construction in scientific English (L2) is a process developed through positive course experiences and collaborative learning, and driven by the mediating role of facilitators, peers, and tools. The experience supports students' doctoral process, how they take ownership of their thesis, while positioning themselves as future researchers in an international community. In doing so, reflecting doctoral topics in collaborative interdisciplinary groups in English enriches students' meaning creation.

This research fills in the gap that concerns the literature in English for academic purposes related to a French context and offers a novel ground for meaning 
construction in an online course through insights of doctoral students in a French university. Further research could include other universities; we hope future contributions will take lead.

\section{Acknowledgments}

We would like to thank all those who participated in the DEC at University Paris 8.

\section{Supplementary materials}

https://research-publishing.box.com/s/ur0aj7z4471tfc65ur2cecherfnyehh8

\section{References}

Braun, V., \& Clarke, V. (2006). Using thematic analysis in psychology. Qualitative Research in Psychology, 3(2), 77-101. https://doi.org/10.1191/1478088706qp063oa

Kaufman, D. (2004). Constructivist issues in language learning and teaching. Annual Review of Applied Linguistics, 24, 303-319. https://doi.org/10.1017/S0267190504000121

Piaget, J. (1971). Psychology and epistemology: towards a theory of knowledge. Grossman.

Terrell, S. R. (2015). Writing a proposal for your dissertation: guidelines and examples. The Guilford Press.

Vygotsky, L. (1978). Mind in society. Harvard University Press. 


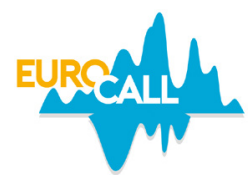

\title{
Interaction games to boost students' engagement in foreign language virtual exchanges: the case of virtual worlds and video-communication
}

\author{
Silvia Canto ${ }^{1}$ and Kristi Jauregi-Ondarra ${ }^{2}$
}

\begin{abstract}
Game-based learning is gaining popularity in language education. For the present study, three games were developed with a central focus on intercultural interaction to be played internationally in dyads or small groups using VideoCommunication (VC) tools or a Virtual World (VW). The interactions were carried out in Spanish as a Lingua Franca (LF) between 32 university students over a period of three weeks. Different sources of data were gathered in order to study how games, played in an intercultural setting in VWs and VC, influence or not key affective variables in language learning. Initial results of the final questionnaires show that the interaction games did boost students' engagement in virtual exchanges, but results were more promising for the $\mathrm{VC}$ than the VW condition.
\end{abstract}

Keywords: game-based learning, virtual exchange, virtual worlds, videocommunication, intercultural interaction.

\section{Introduction}

Game-based learning (Gee, 2017; Prensky, 2003) has gained popularity in language education practices for the potential that games offer to make learning processes more enjoyable and to increase students' engagement (Reinhardt, 2019). The aim of the present study was to study how games played in an intercultural setting in VWs and VC influence or not key variables in language learning such as motivation (Dörnyei, 2019), self-efficacy beliefs (Wang \& Sun, 2020), and anxiety (Kruk, 2018).

1. Utrecht University, Utrecht, the Netherlands; s.canto@uu.nl; https://orcid.org/0000-0003-4044-2439

2. Utrecht University, Utrecht, the Netherlands; k.jauregi@uu.nl; https://orcid.org/0000-0002-9096-9450

How to cite this article: Canto, S., \& Jauregi-Ondarra, K. (2021). Interaction games to boost students' engagement in foreign language virtual exchanges: the case of virtual worlds and video-communication. In N. Zoghlami, C. Brudermann, C. Sarré, M. Grosbois, L. Bradley, \& S. Thouësny (Eds), CALL and professionalisation: short papers from EUROCALL 2021 (pp. 41-45). Research-publishing.net. https://doi.org/10.14705/rpnet.2021.54.1306 


\section{Method}

Three games were developed following task-based language teaching approaches with a central focus on intercultural interaction. They were played internationally in dyads or groups of three students as part of a virtual exchange between the universities of Utrecht (The Netherlands) and Queen Mary (UK). The two environments chosen to play were VC and the VW of OpenSim. The interactions were carried out in Spanish as a LF.

The participants were 19 students from Utrecht University and 13 from Queen Mary University. At Utrecht University all students were enrolled in the language course Español 3 (B1, CEFR ${ }^{3}$ ). They were split into two groups and each group was assigned to one condition (VW or VC) at random. Students from Queen Mary University were all volunteers with the B1 required level. Here, also, groups were randomly assigned to each condition.

Participants played three games in three consecutive weeks: Snakes and Ladders, a cultural quiz, and a treasure hunt or escape room. Before task performance, students received a set of guidelines with instructions to prepare themselves and record the interaction, and the links to the tasks and the corresponding reflection diary. In addition, several online tutorial meetings were organised for the students participating in the VW condition, as the VW was new to them. They also received video instructions illustrating the dynamics of each game.

Snakes and Ladders gave them the opportunity to get to know each other with questions related to personal experiences, and the cultural quiz tested their knowledge of their partner's culture. The escape room (VC) was designed as a mission to find the secret to learn Spanish and the treasure hunt (VW) took place in virtual Valencia.

Different sources of data have been gathered (pre- and post-questionnaires, reflection diaries, recordings of the interactions, and focus groups) to analyse the following aspects:

- how games, played in an intercultural setting in VWs and VC, influence or not key affective variables in language learning processes (self-efficacy beliefs, anxiety, and motivation);

3. Common European Framework of Reference for languages 
- engagement in interaction processes facilitated (or not) by presence and immersion; and

- differences between the VC and VW conditions.

\section{Results and discussion}

The initial results presented here are based on the final questionnaire filled in by 20 students participating in the VC condition and 12 students in the VW condition. A five-point Likert scale was used for closed items.

For students participating in VW, the environment was completely new. Some of them faced quite a few technological issues (e.g. not being able to download the viewer, sound problems, computers loading the world at a slow pace). Although they were given several tutorials, some students found it quite difficult to start and use the tool. This seems to have highly influenced their overall game experience. In the VW condition, there was a great diversity of perceptions, as can be seen in the high standard deviation values. While some liked the VW and found it easy to use, others were critical. In addition, while being an avatar felt very positive for some students in the VW group, others found it annoying not to be able to see the person they were playing with. By contrast, those students in the VC environment, who were using a known tool, experienced less technological hindrances when playing the games and were able to fully enjoy the international game experience (see supplementary materials, Table 1).

Participants in both conditions enjoyed the task games they played (see supplementary materials, Table 2). They remarked that the games were an added value because not only did they let them get acquainted with another person and culture, they also stimulated and guided the conversations. Users felt the games were fun assignments, "different from a normal language exchange", engaging and entertaining. The following student's words summarise the general feeling about the positive aspects of the experience: "I had fun, met a new person, practiced Spanish, and learned about a new culture". When asked whether the environment had contributed to making the interaction games more interesting and fun, participants in the VW condition ( $\overline{\mathrm{x}}: 3.2)$ were more critical than the students in the VC condition ( $\overline{\mathrm{x}}: 4.3)$. The perceptions in the VW group were quite split, as we can see in the high standard deviation value. While five of the participants were extremely positive about the VW, four were quite negative, and three were neutral. 
Although valued positively and an effective ice breaker, some students found Snakes and Ladders slightly long and at times repetitive. Personal preferences were split between the other two games. Students saw in the cultural quiz an opportunity to learn about their partner's culture and reflect upon their own. The escape room/ treasure hunt gave them the chance to learn more about Hispanic culture. The VW group pointed out to have enjoyed the interactivity required to play it.

Interestingly, key characteristic concepts of the VW (immersiveness and copresence) were perceived more strongly in the VC than in the VW condition (see supplementary materials, Table 3), except for the third item ("I was so immersed playing the interaction games in the VC/VW environment that I lost track of time") where the difference between conditions was marginal.

The international dimension of the games, that is, meeting new people from another country, was the first thing they mentioned when asked what they liked about the experience (see supplementary materials, Table 4). They valued that all participants were approximately the same age and therefore had many things in common, being able to create a connection easily. Students stated to have felt relaxed during the game sessions since their partner was at the same language proficiency level, valuing LF communication in Spanish. Some of the participants in the VW group mentioned that they would have preferred to interact with native speakers.

Anxiety level was higher in the VW than in the VC condition across items (see supplementary materials, Table 5), while self-efficacy values were alike in both groups, except for being confident about their speaking skills, which was considerably lower in the VW condition.

\section{Conclusions}

Students in both conditions enjoyed the interaction games for the opportunities they create to communicate and learn in a fun, spontaneous, and relaxed setting (Pujolà $\&$ Appel, 2020). They were particularly fond of the international dimension of the experience, as games were played in virtual exchange sessions with peers abroad. The VC group, who used a tool they were familiar with and who experienced minor technical issues, valued very positively the tool, the games, and the LF setting and felt co-present and fully engaged in the communication game with a peer they could 'see'. In the VW group perceptions were split. While some were very positive about the affordances of the VW, others experienced many technological issues, 
which seemed to hinder the possibility for them to fully immerse themselves and enjoy engaging in communication game processes (Hubbard, 2013). Additional analysis of the different data sources gathered will help us understand in more depth these initial findings.

\section{Supplementary materials}

https://research-publishing.box.com/s/90b7iaaz8jpleaijmm5b8yeow05htudc

\section{Acknowledgements}

We would like to thank Elina Vilar (Queen Mary) and Sabela Melchor-Couto for their collaboration.

\section{References}

Dörnyei, Z. (2019). Towards a better understanding of the L2 learning experience, the Cinderella of the L2 motivational self system. Studies in Second Language Learning and Teaching, 9(1), 19-30. https://doi.org/10.14746/ssllt.2019.9.1.2

Gee, J. P. (2017). Games, passion, and "higher" education. In W. G. Tierney, Z. B. Corwin, T. Fullerton \& G. Ragusa (Eds), Postsecondary play: the role of games and social media in higher education (pp. 171-187). Johns Hopkins University Press.

Hubbard, P. (2013). Making a case for learner training in technology enhanced language learning environments. CALICO Journal, 30(2), 163-178. https://doi.org/10.11139/cj.30.2.163-178

Kruk, M. (2018). Changes in foreign language anxiety: a classroom perspective. International Journal of Applied Linguistics, 28(1), 31-57.

Prensky, M. (2003). Digital game-based learning. Computers in Entertainment, 1(1), 1-4.

Pujolà, J., \& Appel, C. (2020). Gamification for technology-enhanced language teaching and learning. In M. Kruk \& M. Peterson (Eds), New technological applications for foreign and second language learning and teaching (pp. 93-111). IGI Global.

Reinhardt, J. (2019). Gameful second and foreign language teaching and learning: theory, research, and practice. Palgrave Macmillan.

Wang, C., \& Sun, T. (2020). Relationship between self-efficacy and language proficiency: a meta-analysis. System, 95(10), 23-66. 


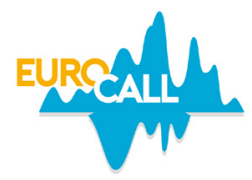

\title{
The mediating effects of teacher-student power relations in a blended English course for academic purposes
}

\author{
Li Cheng $^{1}$
}

\begin{abstract}
Guided by the theory of Language Socialization (LS), this study investigates the mediating effects of teacher-student power relations in an academic English course. To do so, several sets of data were collected: responses to a questionnaire survey, a series of semi-structured interviews, and the online interactions which took place on two teaching platforms (WeChat and QQ). Our results show that together with other factors, the power relations highlighted in this study influenced the participants' academic performances. Besides, three types of teacher-student power relations were brought to the fore. Eventually, the power relations identified affected the construction of role identity in our study. The findings provide supporting evidence for the complicated power relations which exist between language learners and their community of practice.
\end{abstract}

Keywords: teacher-student power relations, language socialization, blended learning.

\section{Introduction}

In the past ten years, many researchers have studied how language learners communicate with each other through a variety of communication platforms and how power relations mediate their language learning (Klimanova \& Dembovskaya, 2013; Schreiber, 2015). The literature of the field particularly shows that good relationships between/among teachers and students result in optimal guidance

1. Beijing University of Posts and Telecommunications, Beijing, China; licheng@bupt.edu.cn

How to cite this article: Cheng, L. (2021). The mediating effects of teacher-student power relations in a blended English course for academic purposes. In N. Zoghlami, C. Brudermann, C. Sarré, M. Grosbois, L. Bradley, \& S. Thouësny (Eds), CALL and professionalisation: short papers from EUROCALL 2021 (pp. 46-51). Research-publishing.net. https://doi.org/10.14705/ rpnet.2021.54.1307 
and support and increased academic performance among students (Badie, 2017; Pennings \& Hollenstein, 2020).

The purpose of this study is to explore the mediating effects of the power relations (i.e. teacher-student power relations and student-student power relations) which took place in a blended English course for academic purposes implemented in a Chinese university. The research questions under study are the following.

- What are the major factors related to the teacher-student power relations?

- What power relations can be identified in the learning situations under study?

- How are power relations related to the students' social identities/roles?

\section{Method}

The theoretical framework underpinning this study is LS (Duff, 2010; Schieffelin \& Ochs, 1986). Researchers of LS maintain that learners are socialized in a community of practice. In this respect, the concept of identity/role serves to better understand the power relations underlying any learning situation (Block, 2007).

This ten-month study (September of 2019 to June of 2020) took place in an English course at a university in Beijing. It was a two-term course with the teaching focus of Term 1 being 'academic speaking' and that of Term 2 'academic writing and conference communication'. The final team project of the course was the participation in a student conference: the Model International Conference 2020 (MIC). There were requirements related to MIC, e.g. topic selection, paper writing, and team presentations. Due to the outbreak of COVID-19 in December of 2019, a blended teaching approach was used in the course; the online component of the course included the delivery of online academic lectures followed by guided discussions on two social media platforms (WeChat and QQ) and an offline mode of face-to-face tutoring.

After the launch of the project, 185 students volunteered to participate in this study and signed the dedicated consent forms. A set of data collection techniques were employed: a 40-item questionnaire survey, 15,732 WeChat and QQ messages posted on the platforms of the course, and 20 one-hour semi-structured focused group interviews conducted in Chinese. 
The questionnaire was adapted from Tierney and Farmer (2002) and consisted of five sections: teacher-student power relations (Cronbach's $\alpha=0827$ ), students' role identity (Cronbach's $\alpha=0723$ ), social support (Cronbach's $\alpha=0841$ ), learner autonomy (Cronbach's $\alpha=0926$ ), and individual innovation (Cronbach's $\alpha=0793$ ).

The questionnaire was distributed to the participants in mid-June 2020 and 183 (98.9\%) replies were collected. The interviews were digitally recorded, transcribed, and analyzed following Hycner's (1985) guidelines. All the WeChat and QQ messages were coded following Gee's (2011) tools and Jamshidnejad's (2011) guidelines for interactional discourse.

\section{Results and discussion}

Discussion in this section attempts to answer the three research questions detailed above.

\subsection{Factors related to teacher-student power relations}

Table 1 presents the descriptive analysis of the questionnaire data and the factors related to the teacher-student power relations which were highlighted.

Table 1. Descriptive analysis of the questionnaire data

\begin{tabular}{|l|l|l|}
\hline & Mean & Standard Deviation \\
\hline Teacher-student power relations & 4.235 & 0.743 \\
\hline Students' identities/roles & 4.001 & 0.832 \\
\hline Social support & 3.904 & 0.768 \\
\hline Learner autonomy & 3.536 & 0.732 \\
\hline Individual innovation in research projects & 3.342 & 0.802 \\
\hline
\end{tabular}

Statistical analysis indicates that the students' social identities/roles were closely related to 'teacher-student power relations'. Moreover, different types of teacherstudent power relations enhanced - in varying degrees - the students' learning autonomy and motivation in this study (see discussion below). This was supported by the fact that 36 participants received institutional funding to take part in the MIC event. Eventually, 65 out of 100 focal students in the group interviews mentioned that their teachers and the most competent members in the teams were of great help for the completion of the MIC projects. 


\subsection{Types of teacher-student power relations}

The analysis of the 15,732-word messages posted on WeChat and QQ revealed three major types of teacher-student relations (Table 2): (1) 'instructor and tutor', with direct instructions and commands, indicated a controlled type of relationship (frequency in $\mathrm{CI}=1,432$, frequency in $\mathrm{OE}=1,092$ ), (2) 'facilitator and trainer' highlighted the guidance and training support which the students benefited from during their projects to help them master content knowledge and develop the skills they needed to see them through to completion (frequency in $\mathrm{CI}=812$, frequency in $\mathrm{OE}=892$ ), and (3) 'friends and buddy', who provided each other with mutual support to complete their assignments (frequency in $\mathrm{CI}=322$, frequency in $\mathrm{OE}=292$ ).

Table 2. The major types of teacher-student power relations identified

\begin{tabular}{|l|l|l|}
\hline & Frequency in CI & Frequency in OE \\
\hline Instructor and Tutor & 1,432 & 1,092 \\
\hline Facilitator and Trainer & 812 & 892 \\
\hline Friend and Buddy & 322 & 292 \\
\hline
\end{tabular}

Note: frequency refers to the number of sentences indicating power relations in the interactions.

\subsection{Power relations and students' social identities}

As mentioned earlier, MIC was the final project of the course. It implied organizing the conference itself and delivering various outputs (i.e. the students' academic papers and presentations). Table 3 presents the communication activities the participants carried out while completing their MIC projects and the number of recorded interactions per communication activity.

Table 3. Form-focused and meaning-focused activities on WeChat and QQ

\begin{tabular}{|l|l|l|}
\hline & $\begin{array}{l}\text { Form-focused communication activities } \\
\text { and number of online interactions }\end{array}$ & $\begin{array}{l}\text { Meaning-focused communication } \\
\text { activities and number of interactions }\end{array}$ \\
\hline 1 & Studying language points $(1,172)$ & $\begin{array}{l}\text { Exchanging information, } \\
\text { e.g. academic search }(2,307)\end{array}$ \\
\hline 2 & Correcting errors and mistakes $(1,559)$ & Maintaining the relationship $(3,462)$ \\
\hline 3 & Consulting language form $(355)$ & Checking the task requirements $(628)$ \\
\hline 4 & $/$ & $\begin{array}{l}\text { Asking about the tests and } \\
\text { final examination }(119)\end{array}$ \\
\hline
\end{tabular}

Note: the numbers provided in Table 3 refer to the number of sentences related to MIC in the data collected.

According to Gee (2011) and Jamshidnejad (2011), in educational contexts, the interpersonal communication processes and the relationships established between participants are usually meaning-focused and/or form-focused. Therefore, the 
analysis of the students' online interactions and the identities/roles identified in the interactions can reflect the power relations which exist between the members of a given communication community. Through the analysis of the online messages posted by the study participants, seven types of communication activities were thus identified, among which three were form-focused and four meaning-focused.

It should be noted that although 412 out of the 732 theme-based group exchanges collected were initiated by the team leaders, all the team members had clear work instructions to follow in their MIC projects. The completion of different communication activities led the students to develop their teambuilding skills and perform different roles, such as team leader, team player, coordinator, negotiator, helper, or observer. In one focused group interview, Hanna said

“My English is poor. I didn't talk much but I'm a good listener. And I'm a good PowerPoint designer. I designed all the PowerPoint for our team presentation ((smile, confident))" (Interview, 2020-05-30).

As such, the analysis of the communication activities and the students' roles provides supporting evidence for the important role played by power relations in language learning contexts (Badie, 2017; Pennings \& Hollenstein, 2020).

\section{Conclusion}

This study explored the dynamics of the teacher-student relations taking place in an English course. Data analysis shows that teacher-student power relations are closely related to students' social identities/roles. Moreover, three types of power relations were identified. Finally, these power relations were reflected in the students' meaning-based or form-based communication activities. The findings provide supporting evidence for the complicated relations which exist between language learners and their communication community. With the increasing popularity of the use of digital technology in the language classroom in China, it is suggested that more attention be paid to longitudinal investigations exploring the cognitive, social, and affective aspects of the power relations which take place in natural settings.

\section{Acknowledgments}

This research was supported by the research fund (2021Y041). 


\section{References}

Badie, F. (2017). A conceptual mirror: towards a reflectional symmetrical relation between mentor and learner. International Journal of Information and Education Technology, 7(3), 199-203. https://doi.org/10.18178/ijiet.2017.7.3.866

Block, D. (2007). Second language identities. Continuum International.

Duff, P. A. (2010). Language socialization into academic discourse communities. Annual Review of Applied Linguistics, 30, 169-192. https://doi.org/10.1017/S0267190510000048

Gee, J. P. (2011). How to do discourse analysis: a toolkit. Routledge. https://doi. org/10.4324/9780203850992

Hycner, R. H. (1985). Some guidelines for the phenomenological analysis of interview data. Human Studies, 8(3), 279-303. https://doi.org/10.1007/BF00142995

Jamshidnejad, A. (2011). Functional approach to communication strategies: an analysis of language learners' performance in interactional discourse. Journal of Pragmatics, 43(15), 3757-3769. https://doi.org/10.1016/j.pragma.2011.09.017

Klimanova, L., \& Dembovskaya, S. (2013). L2 identity, discourse, and social networking in

Russian. Language Learning \& Technology, 17(1), 69-88.

Pennings, H, J., \& Hollenstein, T. (2020). Teacher-student interactions and teacher interpersonal

styles: a state space grid analysis. The Journal of Experimental Education, 88(3), 382-406. https://doi.org/10.1080/00220973.2019.1578724

Schieffelin, B. B., \& Ochs, E. (1986). Language socialization. Annual Review of Anthropology,

15, 163-191. https://doi.org/10.1146/annurev.an.15.100186.001115

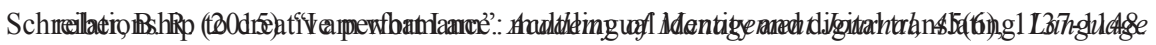

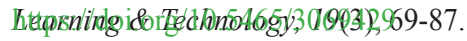

Tierney P., \& Farmer S M. (2002). Creative self - efficacy: its potential antecedents and 


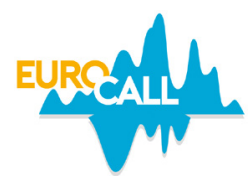

\title{
Context, method, and theory in CALL research articles
}

\author{
Yazdan Choubsaz ${ }^{1}$, Alireza Jalilifar ${ }^{2}$, and Alex Boulton ${ }^{3}$
}

\begin{abstract}
This paper is an initial report of the data analysis phase of a larger study that traces the evolution of Computer Assisted Language Learning (CALL). All published Research Articles (RAs) from four major CALL journals - ReCALL, CALL, Language Learning \& Technology (LL\&T) and CALICO Journal - from the very first issues to the end of 2019 were downloaded, sorted, and checked to form the final corpus of 426 highly cited RAs. The trends and themes (research contexts, research participants, and theoretical and methodological considerations of the RAs) were all recorded to see how CALL has evolved over time. Primary findings indicate that empirical studies where learners are physically or virtually involved in the process of technology-mediated language instruction dominate the field of CALL research. Authors resort to both quantitative and qualitative methodologies for data collection and analysis, though mixed-methods has gained more weight in the past two decades. Sociocultural theory stands over and above other theories in Second Language Acquisition (SLA) to frame CALL studies. The paper discusses these issues, and problems detected.
\end{abstract}

Keywords: CALL synthesis, CALL research articles, CALL history, research trends.

\section{Introduction}

In the past five decades, CALL has been extensively used to support learning, evaluate learners' language, and collect data for both in- and out-of-class inquiry. With the expansion of CALL, dedicated journals have emerged as technologyspecialized platforms to invite their readers to keep up with the pace of technological advances through academic RAs. These CALL papers have been combined with

\footnotetext{
1. Shahid Chamran University of Ahvaz, Ahvaz, Iran / Sultan Qaboos University, Muscat, Oman; y.choubsaz@squ.edu.om; https://orcid.org/0000-0002-4916-5573

2. Shahid Chamran University of Ahvaz, Ahvaz, Iran; ar.jalilifar@gmail.com; https://orcid.org/0000-0002-8123-6757

3. ATILF, CNRS \& University of Lorraine, Nancy, France; alex.boulton@atilf.fr; https://orcid.org/0000-0001-6306-8158
}

How to cite this article: Choubsaz, Y., Jalilifar, A., \& Boulton, A. (2021). Context, method, and theory in CALL research articles. In N. Zoghlami, C. Brudermann, C. Sarré, M. Grosbois, L. Bradley, \& S. Thouësny (Eds), CALL and professionalisation: short papers from EUROCALL 2021 (pp. 52-56). Research-publishing.net. https://oi.org/10.14705/rpnet.2021.54.1308 
other academic genres such as book chapters, theses, and conference proceedings to form CALL history over time. This study, as a part of an ongoing $\mathrm{PhD}$ dissertation, traces that history by limiting its scope to highly cited CALL-oriented RAs. The question that stands out is how the contextual, theoretical and methodological dimensions of high-impact CALL RAs have changed over time. An ultimate aim of this narrative synthesis is the provision of a roadmap that can complement similar surveys (Gillespie, 2020; Lim \& Aryadoust, 2021), tell us where we are now with CALL and how we got here - and, building on that, propose avenues for further research.

\section{Method}

The pool of data consists of a corpus of 2,397 RAs published in English, from the very first issues up to the end of 2019, in four major CALL journals: ReCALL, CALL, LL\&T and CALICO Journal. Google Scholar citation metrics were used as a criterion to reduce the pool of papers and produce a manageable final corpus of 426 high-impact RAs (see Choubsaz, Boulton, \& Jalilifar, 2020 for the choice of journals and data collection procedure). A coding book was developed to investigate CALL research trends and extract the main themes: research contexts, participants, and theoretical and methodological considerations. The first category covered countries, settings, programs, learning environments, and technology use, while the second recorded the status, age group, proficiency, L1, and L2 of the research participants. For the third category, theoretical and methodological considerations, our synthesis covered the applied methodologies of the studies and the theories/approaches the authors adopt to frame their work. About $10 \%$ of the data was coded in two separate rounds by two independent coders and an inter-rater $r$ of 89.8 was attained. Part of the coding procedure was done manually, but our synthesis also made use of NVivo 12 Plus and AntConc in extracting, categorizing, and merging the principal themes and sub-themes.

\section{Results and discussion}

The United States is the leading contributor to the field (31\% of all publications), English as a Second Language and English as a Foreign Language - ESL and EFL - $(32 \%)$ are the most used settings, and a huge portion of studies are conducted in university contexts (58\%) either in classrooms $(28 \%)$ or laboratories $(15 \%)$, with an increasing number of virtual learning environments $(26 \%)$ in the past two decades. Research participants have the status of learners $(68 \%)$ 
who are predominantly at the intermediate (21\%) and advanced (14\%) levels of language proficiency and are aged 18-30 (20\%). Nearly half of participants speak English $(31 \%)$ or Chinese (14\%) as their first languages; the target language is overwhelmingly English (42\%). These findings no doubt partly reflect the reality of learners and teachers as well as research cultures (and the huge input from researchers in the US working in second language environments), though it should be remembered that the journals studied all publish in English, which may encourage studies on this language by researchers sufficiently familiar with it themselves. Another point, more difficult to quantify as rarely explicitly stated, is that many authors/researchers are also teachers in university settings, while few teachers are researchers worldwide; this raises questions about how research reflects typical teaching concerns and practices.

Authors frequently adhere to quantitative methodologies $(25 \%)$ for data collection and analysis, followed by qualitative (20\%) and eclectic methodologies (18\%) defined as a combination of qualitative and quantitative data and analysis with no mention of the term mixed-methods. In this, CALL research and SLA in general may be in thrall to Science, Technology, Engineering, and Mathematic (STEM) practices, with extensive use of statistical analysis (notably null hypothesis significance testing, despite the problems noted in journals such as Language Learning, and increasingly in psychology and medicine as a whole), partly reflected in the use of terms such as subject, treatment, and intervention (as if the learners were sick), while control groups are usually comparison groups, and so on. Power is limited by small sample size, generalizability by the use of intact groups in a single context, and impact by the lack of delayed data collection which is still vastly underused. More encouragingly, truly mixed-method studies (where the same data set is subjected to multiple analysis, rather than simply aligning e.g. post-tests and questionnaires) are on the increase (6\%).

The theoretical underpinnings the authors bring to the fore to justify their research are not specific to CALL but are SLA-oriented. Sociocultural theory is the most frequently cited (15\%), followed by interactionism (9\%), social-constructivism $(8 \%)$ and collaborative learning $(7 \%)$, with many others being cited just a few times. In line with the results of Yim and Warschauer (2017), our analysis indicates that 120 RAs (28\%), especially the ones published in the 1980's, 1990's, and 2000's, failed to adopt a theory or an approach to frame their work. This lack of theoretical underpinning is perhaps to be expected in the empirical studies favored in RAs, where it often seems to frame a study almost as an afterthought rather than being a major factor inspiring the research itself. Pure theory/position papers are more likely found in books or chapters, or in conference presentations and proceedings, 
so there would seem to be a place for theory to drive empirical research or to be tested directly.

An increased interest in theory alongside pedagogical considerations might also help reduce a tendency to seek technological novelty as the main thrust behind a publication. In our survey, text chatting and WeChat (7\%), multimedia (5\%), digital gaming (4\%) and mobile phones (4\%) seem to be used quite frequently, these low numbers highlighting the diversity of technology, perhaps for technology's sake. In other words, research should not be driven by noticing (or creating) a new tool and seeing what it can be used for, but by learners' needs, in addition to research gaps. Contrasting this is a possible lack of ambition, with many studies covering well-trod ground and reproducing (rather than replicating) earlier findings, perhaps due to the difficulty of gaining a solid overview of CALL research which is published in so many diverse sources. The 'publish or perish' syndrome is no doubt a contributing factor, with output motivated by career rather than new questions to be supported by original research.

A final issue, not specific to CALL, is the lack of clarity while collecting demographic information of the RAs. In fact, not many papers report all the useful information, or if they do, they report it in ways that are not easy to compare. Even very basic information like the number of participants, age, L1 and L2, context, discipline, the technology used, and what the learners actually did is often missing, incomplete, or of limited use. Two particular problems here are duration and L2 proficiency. The former is variably measured in minutes/hours, sessions, weeks, months, semesters, and years; but a ten-week course may be intensive and include out-of-class work, or involve a one-hour class every second week not including holidays, with only a fraction of the time given over to the main research question. The latter, if stated, may simply be listed as e.g. 'intermediate' with no further indication, which clearly means different things to different people.

\section{Conclusions}

As the study is still ongoing, definitive results are yet to be reached. However, the increasing number of high-impact publications (204 in the 1980's to 893 in the 2010's) and the preponderance of empirical studies (63\%) with learners being physically or virtually present in classrooms, all attest to the healthy state of CALL research after four decades of presence. On the flip side, the increase in output has not resolved some long-standing controversies. This paper has outlined some of these, including methodological problems of design, logistical or contextual 
constraints, a lack of theoretical consideration, and poor reporting practices. While many of these issues are long-standing, there is some indication of positive evolution, such as the increase of mixed-methods studies.

\section{Acknowledgments}

We would like to thank Jozef Colpaert for granting access to the earliest issues of CALL.

\section{References}

Choubsaz, Y., Boulton, A., \& Jalilifar, A. (2020). Laying the groundwork for a historical overview of high-impact CALL papers. In K.-M. Frederiksen, S. Larsen, L. Bradley \& S. Thouësny (Eds), CALL for widening participation (pp. 47-51). Research-publishing.net. https://doi. org/10.14705/rpnet.2020.48.1163

Gillespie, J. (2020). CALL research: where are we now? ReCALL, 32(2), 127-144. https://doi. org/10.1017/S0958344020000051

Lim, M. H., \& Aryadoust, V. (2021). A scientometric review of research trends in computerassisted language learning (1977-2020). Computer Assisted Language Learning (advance access). https://doi.org/10.1080/09588221.2021.1892768

Yim, S., \& Warschauer, M. (2017). Web-based collaborative writing in L2 contexts: methodological insights from text mining. Language Learning \& Technology, 21(1), 146165. https://doi.org/10125/44599 


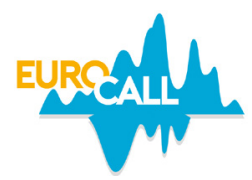

\title{
The affective benefits of speech recognition systems on pronunciation monitoring
}

\author{
Junko Chujo ${ }^{1}$
}

\begin{abstract}
This research aimed to investigate the effects of pronunciation monitoring on learners' affective factors through self-monitoring activities using speech recognition systems. The effect of a specifically designed pronunciation activity for Japanese university students was analyzed. The worksheet form of the activity was based on the use of speech recognition systems such as Siri and Google apps. A special focus was placed on the development of students' affective phase toward English and pronunciation learning. The research concluded that the activity had a positive impact for increasing awareness of, interest in, and motivation toward pronunciation improvement and it highlighted the important role of teaching pronunciation in English oral communication skills in the limited English exposure of the English as a Foreign Language (EFL) context.
\end{abstract}

Keywords: monitoring, pronunciation, material design and development, EFL.

\section{Introduction}

To investigate effective pedagogical means of monitoring in instruction, this research examined the effects of pronunciation monitoring on Japanese university English learners' affective domain through self-evaluation activities using speech recognition systems such as Siri and Google apps. The importance of monitoring and self-repair in English pronunciation acquisition has been discussed (Bailey, 1999; Kormos, 2000); however, neither the development nor the examination of implementable, systematic materials has been assessed. To fill this gap, systematic affect-oriented pronunciation activities were designed and experimented (Chujo, 2010, 2018). In these studies, Chujo (2010, 2018) revealed that developing learners' self-monitoring and self-repair skills is essential for fostering autonomous learners

1. Tokyo City University, Yokohama, Japan; jchujo@tcu.ac.jp

How to cite this article: Chujo, J. (2021). The affective benefits of speech recognition systems on pronunciation monitoring. In N. Zoghlami, C. Brudermann, C. Sarré, M. Grosbois, L. Bradley, \& S. Thouësny (Eds), CALL and professionalisation: short papers from EUROCALL 2021 (pp. 57-62). Research-publishing.net. https://oi.org/10.14705/rpnet.2021.54.1309 
and that the monitoring activity had a strong positive impact on the learners' affective phase. In the previous studies, students used a mirror, audio recordings, and video recordings to self-monitor. The developed materials were summarized in the form of a textbook, and over 4,000 copies have been circulating in the Japanese university teaching ground. Meanwhile, instructors who used the textbooks made pedagogical requests for the inclusion of an evaluation method that was more prompt and accessible for both instructors and students. The continuing motivating force behind this redesign was a positive effect on the affective domain of the learners.

\section{Theoretical background}

The affective domain is believed to be very important in education and training (Heinich, Molenda, \& Russell, 1993) and concerns "attitudes, appreciations, values and emotions such as enjoying, conserving and respecting" (Heinich et al., 1993, p. 104). Activities such as chants, music, and poetry are said to be effective for accessing the affective domain because they "can produce lowered anxiety and greater ego permeability among second language learners" (Richard-Amarto, 2010, p. 271). Monitoring is related to the affective domain both for language learning and for pronunciation in particular. Celce-Murcia, Brinton, and Goodwin (1996) state that

"monitoring is assuming a larger role than it has previously played in language teaching. As part of learners taking responsibility for their own learning, self-monitoring is vital to learners' sense of control over their progress" (p. 349).

Monitoring pronunciation through the use of smartphones using video and apps such as Google Translation are used not only in English education but also in multilingual language education in Japan (Iwai, 2020).

\section{Material design}

The materials were designed with the aim of having students realize (1) their current level of English pronunciation intelligibility, (2) the importance of pronunciation and how the lack of pronunciation skill has a negative effect on oral communication, and (3) that there are handy, efficient, and free pronunciation monitoring tools which they can easily access. The materials were developed with special emphasis on the learners' affective growth; the goals were to (1) raise students' interest in and 
awareness of the elements of pronunciation in English language learning, and (2) increase their motivation for and understanding of the importance of pronunciation practice.

A worksheet was designed for the activity (Figure 1). Segmental features were targeted, with a focus on ten consonants which often cause communication breakdowns due to the negative influence of learners' first language, Japanese. These were $/ \mathrm{l} /, / \mathrm{r} /, / \mathrm{w} /, / \mathrm{f} /, / \mathrm{v} /, / \theta /, / \mathrm{d} /, / \mathrm{s} /, / \mathrm{z} /$, and $/ \mathrm{J} /$. In the worksheet, these targeted phonemes were placed at the beginning of each word and presented for students to pronounce in the monitoring activity. The target words were: real, volunteer, weather, locker, button, vanilla, surfing, theater, girl, and battery. The monitoring activity was designed to be simple and self-explanatory to help the learners focus on their tasks. There were five steps: (1) switch an application on the device into English language mode, (2) pronounce the presented word five times, (3) record each recognition result, whether recognition was successful or not (if the trial is not recognized, write the misrecognized word), (4) record the number of times the word is recognized among the five attempts, and (5) write a comment.

Figure 1. Worksheet sample

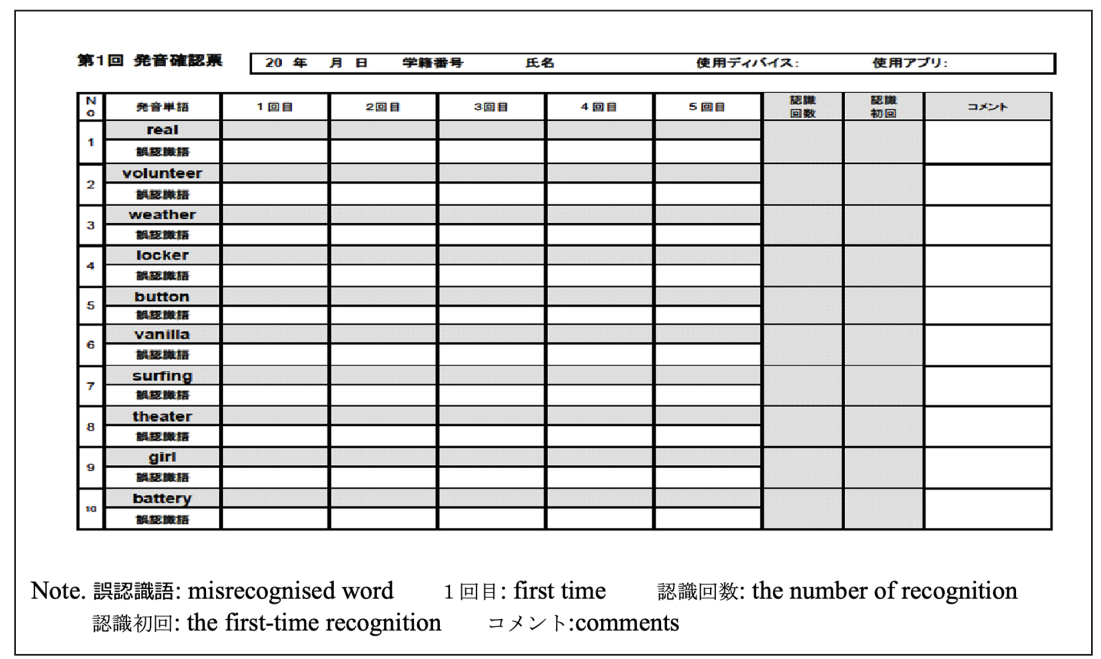

\section{Methodology}

The 50 participants in this study were intermediate level first year students majoring in engineering in a Japanese university. Due to Covid-19, the entire class 
was conducted online; students watched and listened to the teaching materials, then practiced individually. The developed activity was implemented twice during the semester: pre and post-instruction. Between the developed activities, explicit pronunciation instruction was held. To examine the effectiveness and suitability of the activity, students responded to a written questionnaire after each monitoring activity. Students responded to the question items in the form of five-point Likert scale (one, strongly disagree, five, strongly agree) and the responses were statistically calculated for obtaining the mean (M) and standard deviation (SD).

\section{Results and discussion}

Thirty students used Siri, 18 used Google Translate, and two used other applications for this activity. Forty-nine students responded to the pre-instruction questionnaire and 43 to the post-instruction questionnaire. Table 1 shows the question items and their results.

Table 1. Results of pre and post instructional monitoring activity

\begin{tabular}{|c|c|c|c|c|c|}
\hline \multirow[t]{3}{*}{ No. } & \multirow[t]{3}{*}{ Statement } & \multirow{2}{*}{\multicolumn{2}{|c|}{\begin{tabular}{|l|} 
Pre-instruction \\
$(\mathrm{n}=49)$ \\
\end{tabular}}} & \multirow{2}{*}{\multicolumn{2}{|c|}{$\begin{array}{l}\text { Post-instruction } \\
(n=43)\end{array}$}} \\
\hline & & & & & \\
\hline & & M & SD & M & SD \\
\hline 1 & I enjoyed this activity. & 3.59 & 1.12 & 3.77 & 0.97 \\
\hline 2 & $\begin{array}{l}\text { I was happy when my } \\
\text { pronunciation was recognized. }\end{array}$ & 4.08 & 1.04 & 4.30 & 0.89 \\
\hline 3 & $\begin{array}{l}\text { I lost confidence when my } \\
\text { pronunciation was not recognized. }\end{array}$ & 3.59 & 1.22 & 3.70 & 1.10 \\
\hline 4 & $\begin{array}{l}\text { It is a convenient way to } \\
\text { check pronunciation. }\end{array}$ & 3.59 & 1.14 & 3.84 & 0.87 \\
\hline 5 & $\begin{array}{l}\text { It is an effective way to } \\
\text { check pronunciation. }\end{array}$ & 3.49 & 1.06 & 3.86 & 0.97 \\
\hline 6 & $\begin{array}{l}\text { I raised my awareness } \\
\text { toward pronunciation. }\end{array}$ & 3.84 & 0.90 & 4.16 & 0.97 \\
\hline 7 & $\begin{array}{l}\text { I raised my interest toward } \\
\text { pronunciation. }\end{array}$ & 3.65 & 1.01 & 4.00 & 0.87 \\
\hline 8 & $\begin{array}{l}\text { I would like to attain the English } \\
\text { pronunciation skill to be recognized. }\end{array}$ & 4.20 & 1.02 & 4.40 & 0.69 \\
\hline
\end{tabular}

All the results (except three which had a negative statement) showed a positive effect on the students, even in the pre-instruction phase, which was their first trial of the developed activity. However, the post-instruction results showed an even greater positive effect, revealing that the same activity presented at a different time in the class had a different degree of effectiveness. 
Statements 6 and 7 showed that students raised their awareness and interest toward pronunciation through this activity [Pre $(M=3.84, S D=0.90)$, Post $(M=4.16$, $\mathrm{SD}=0.97)]$ and $[\operatorname{Pre}(\mathrm{M}=3.65, \mathrm{SD}=1.01)$, Post $(\mathrm{M}=4.00, \mathrm{SD}=0.87)]$ respectively.

Results from Statements 2 and 8 showed that even with the devices, the students' feelings were strongly engaged [Pre $(\mathrm{M}=4.08, \mathrm{SD}=1.04), \operatorname{Post}(\mathrm{M}=4.30, \mathrm{SD}=0.89)]$ and they exhibited a strong desire to be understood [Pre $(\mathrm{M}=4.20, \mathrm{SD}=1.02)$, Post $(\mathrm{M}=4.40, \mathrm{SD}=0.69)]$. These results show that they endeavored to communicate in English using the device as an interlocutor.

The results of Statements 4 and 5 showed that the speech recognition system was a convenient and efficient monitoring tool [Pre $(\mathrm{M}=3.59, \mathrm{SD}=1.14)$, Post $(\mathrm{M}=3.84$, $\mathrm{SD}=0.87)]$ and $[\operatorname{Pre}(\mathrm{M}=3.49, \mathrm{SD}=1.06)$, Post $(\mathrm{M}=3.86, \mathrm{SD}=0.97)]$.

Statement 1 revealed that the enjoyment rate was not high, as expected [Pre $(\mathrm{M}=3.59, \mathrm{SD}=1.12)$, Post $(\mathrm{M}=3.77, \mathrm{SD}=0.97)]$. The on-demand instruction style might have affected these results.

The result from Statement 3 showed that loss of confidence following unsuccessful trials was stronger after instruction [Pre $(\mathrm{M}=3.59, \mathrm{SD}=1.22)$, Post $(\mathrm{M}=3.70$, $\mathrm{SD}=1.10)$ ]. One possible reason could be that even with one semester of practice their performance outcome had not improved as much as they had hoped.

\section{Conclusions}

This research examined the effects of pronunciation monitoring on learners' affective factors through self-monitoring activities using speech recognition systems. Further research requires the examination of when (and how often) to use this method of monitoring depending on its pedagogical purposes and how to revise it to bring about an even stronger effect in the actual classroom. However, the presented self-monitoring activity provided effective monitoring tools that had a positive impact on Japanese university students' affective domain by raising their awareness, and motivation to attain intelligible pronunciation.

\section{References}

Bailey, K. M. (1999). Washback in language testing (TOEFL Monograph Series MS-15). Educational Testing Service. 
Celce-Murcia, M., Brinton, D. M., \& Goodwin, J. M. (1996). Teaching pronunciation: a reference for teachers of English to speakers of other languages. Cambridge University Press.

Chujo, J. (2010). Incorporation and evaluation of jazz chants instruction in Japanese university English classes. In M. Pinto \& D. Shaffer (Eds), KOTESOL Proceedings 2010 (pp. 83-96). Korea TESOL.

Chujo, J. (2018). Examination of beneficial and enjoyable pronunciation activities [practitioner report]. JACET International Convention, Selected Papers, 5, 157-176. http://www.jacet. org/SelectedPapers/JACET56_2017_SP_5.pdf

Heinich, R., Molenda, M., \& Russell, J. D. (1993). Instructional media and the new technologies of instruction (4th ed.). Wiley.

Iwai, H. (2020). An attempt to "encourage multilingual language learning" at a medical college: practical report on face-to-face and online classes. Journal of Plurilingual and Multilingual Education, 8, 106-116.

Kormos, J. (2000). The timing of self-repairs in second language speech production. Studies in Second Language Acquisition, 22(2), 145-167. https://doi.org/10.1017/S0272263100002011 Richard-Amarto, P. (2010). Making it happen (4th ed.). Pearson Education. 


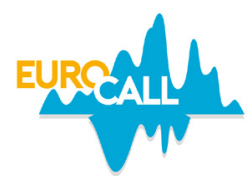

\title{
A needs survey of overseas Irish language learners
}

\author{
Ronan Connolly ${ }^{1}$
}

\begin{abstract}
The vast majority of endangered languages are expected to have vanished from community use within one to two generations (Lackaff \& Moner, 2016). One such language, Irish, may die out as a vernacular within a decade in the Irishspeaking regions of Ireland (Ó Giollagáin \& Charlton, 2015). However, there is growing interest in the Irish language overseas, particularly in the USA (Schwartz, 2020). In this study, a survey was conducted with 92 respondents to identify the needs of learners living outside of Ireland. The findings of this needs assessment suggest that overseas Irish learners would benefit from the provision of an online Irish language community that connects members through communicative and collaborative language activities. Positioned in the context of similar developments and innovations internationally (e.g. Henry, Carroll, Cunliffe, \& Kop, 2018), this research builds on existing literature in online sociocultural language learning.
\end{abstract}

Keywords: social learning, Irish language, design-based research, online language communities.

\section{Introduction}

The Irish language has been described as 'definitely endangered' (Moseley, 2010) and as being in a state of severe decline (Ó Giollagáin \& Charlton, 2015). This trend contrasts with a significant interest in learning Irish beyond Ireland, particularly in the USA (Hickey \& Stenson, 2016). These overseas learners, however, tend to have limited opportunities for sociocultural language learning and practice. Design-Based Research (DBR) is a methodological approach that aims to provide practical solutions to real world problems (McKenney \& Reeves, 2014). In advance of implementing a DBR intervention, Reeves (2006) proposes close consultation with relevant researchers and practitioners. The use of a needs

1. National University of Ireland, Galway, Ireland; ronan.connolly@nuigalway.ie; http://orcid.org/0000-0001-7527-4952

How to cite this article: Connolly. R. (2021). A needs survey of overseas Irish language learners. In N. Zoghlami, C. Brudermann, C. Sarré, M. Grosbois, L. Bradley, \& S. Thouësny (Eds), CALL and professionalisation: short papers from EUROCALL 2021 (pp. 63-68). Research-publishing.net. https://doi.org/10.14705/rpnet.2021.54.1310 
survey allows for educators to discern learners' requirements, attitudes, and preferences (Basturkmen, 1998; Elisha-Primo et al., 2010). In this needs survey, the data collected will be used to inform a DBR intervention to support overseas Irish learners.

\section{Method}

The principal objective of this survey was to identify the needs of overseas Irish language learners, and to gather their feedback on a potential online language community. This objective led to the following research questions for the needs survey.

- What is the profile and background of these learners?

- What is the current status of their Irish language studies?

- What are their thoughts on a future online Irish language platform?

Participants in this survey identified as Irish language learners who were located outside of Ireland. A total of 92 learners responded to the online needs survey questionnaire via an online questionnaire using Google Forms. The survey was distributed widely using a number of social media platforms, namely Facebook and Twitter. All students voluntarily participated with informed consent. Both quantitative and qualitative data were collected regarding learners' current status of study, personal preferences when studying Irish, and their views on a potential online community. The first section of the questionnaire consisted of questions regarding learners' profiles. The second section gathered quantitative data on learners' language level, length of time studying Irish so far, how often they attend classes, use of Irish outside of classes, preferred devices for learning, and how they learn best. The third section asked learners about their interest in the development of a collaborative online resource, including three open-ended, qualitative questions regarding the problems they faced when learning Irish, and what suggestions they might have for an online platform that supports their language learning.

Quantitative data were de-identified and exported from Google Forms into SPSS 26 software for descriptive analysis. Participant characteristics including age, gender, location, duration of study, and language level were summarised in frequency tables. Qualitative data were imported into NVivo software and 
systematically coded using a thematic approach, as demonstrated by Braun and Clarke (2012).

\section{Results and discussion}

\subsection{What is the profile and background of these learners?}

The responses to this question helped inform the design of the intervention by providing information on the potential participants of an online community. A vast $87 \%$ of respondents to the needs survey reported being at beginner/A1 level Irish. Two-thirds (65\%) were located in the USA. The remaining 35\% consisted mainly of those located in Australia, Canada, and parts of Europe. Over half $(60 \%)$ identified as female and $40 \%$ as male. The median age range was $31-36$.

\subsection{What is the current status of their Irish language studies?}

Language usage among respondents was varied, with 33\% stating that they use their Irish occasionally, followed by $26 \%$ who speak Irish every day, and $30 \%$ who claimed to use their Irish most days. Respondents reported being strongest at Irish reading, but requiring more help with speaking, followed by writing and listening. Respondents were asked to describe what they perceived to be their barriers to Irish language learning. Responses were coded line-by-line in NVivo, and six themes emerged. The foremost challenge for $54 \%$ of learners was a lack of opportunity to speak, practise, and connect with other learners, as detailed in Table 1. Additional challenges included a need for pronunciation guides $(13 \%)$, shortage of time $(11 \%)$, a lack of access to language experts $(9 \%)$, the absence of a central online resource or portal for Irish language learners (9\%), and a lack of motivation (4\%). Learners also indicated that they enjoyed using apps for learning and practice, that they were not committed to book learning alone, and that they would like to collaborate with fellow learners.

Table 1. Challenges reported by overseas Irish language learners

\begin{tabular}{|l|l|l|}
\hline Theme & Codes & $\begin{array}{l}\text { \% of } \\
\text { respondents }\end{array}$ \\
\hline $\begin{array}{l}\text { Lack of opportunity } \\
\text { to practise with } \\
\text { other learners }\end{array}$ & $\begin{array}{l}\text { speakers, chance to chat, other people, other } \\
\text { learners, no speakers, no opportunities, } \\
\text { lack of practice, isolated, lack of contact, } \\
\text { no one, other speakers, conversation, } \\
\text { places, face-to-face, connecting }\end{array}$ & 54 \\
\hline
\end{tabular}




\begin{tabular}{|l|l|l|}
\hline Pronunciation guide & hear, sounds, pronunciation, speak, listen & 13 \\
\hline Time & $\begin{array}{l}\text { time, opportunity, routine, regularly, } \\
\text { lack of structure in own learning }\end{array}$ & 11 \\
\hline $\begin{array}{l}\text { Resources/ } \\
\text { central portal }\end{array}$ & $\begin{array}{l}\text { no resources, need for a portal, } \\
\text { something centralised }\end{array}$ & 9 \\
\hline $\begin{array}{l}\text { Lack of experts/ } \\
\text { expertise }\end{array}$ & $\begin{array}{l}\text { teachers, native, experts, helpers, lack } \\
\text { of structure, questions, grammar }\end{array}$ & 4 \\
\hline $\begin{array}{l}\text { Motivation, usefulness, } \\
\text { loss of confidence }\end{array}$ & $\begin{array}{l}\text { lack of motivation, getting motivated, } \\
\text { usefulness, feeling out of practice }\end{array}$ & 4 \\
\hline
\end{tabular}

\subsection{What are their thoughts on a future online Irish language community?}

Almost all (92\%) of respondents indicated a willingness to collaborate with fellow learners and to contribute to an online Irish language community. Of all learners surveyed, 73\% stated that they very rarely, or never, meet up with an Irish speaker outside of class for language practice, and $66 \%$ of respondents reported not knowing a person with whom they could practice conversing. Respondents stated that they felt somewhat isolated in their studies. They also cited a lack of routine and time in which to study Irish. Survey participants were asked an openended question on how their Irish development could be better supported beyond a classroom environment. Primary codes were assigned to these responses, and 15 themes emerged from the data. The most common suggestions from learners was an increased opportunity for interaction with fellow learners $(23 \%)$, access to educational resources, such as notes, videos and easy-to-follow podcasts $(16 \%)$, feedback from teachers and helpers $(11 \%)$, and the provision of online language activities (10\%).

\section{Conclusions}

The findings of the needs survey suggest potential benefits in designing an online Irish language community. The absence of a central resource for overseas learners can be addressed by providing a social platform where learners are able to connect and interact with each other. Responses from overseas learners indicate that a lack of opportunity to communicate in Irish, and especially through speaking, can be mitigated through the provision of asynchronous language activities and live conversation sessions. Respondents' willingness to contribute to an online community suggests that the platform may also foster a collaborative learning environment conducive to sociocultural learning for overseas learners. 
The proposed design compliments the research of Lackaff and Moner (2016), who state that "audiences exist for minority language social platforms, and those who tackle the challenge of designing for these audiences will benefit from a framework that leads to a better understanding of the minority language user in the design research process" (p. 8). The findings of this needs survey, alongside a comprehensive literature review, will be used to inform a DBR intervention allowing overseas Irish learners to 'connect, communicate, and collaborate' in an online community, located at the domain Gaeltacht.net. This process will result in a prototype design model, the 3Cs Model for Online Language Communities, and a series of theoretical contributions, which can be utilised by educators to support similar endangered language groups.

\section{Acknowledgements}

The author would like to acknowledge the funding of the Digital Arts and Humanities Scholarship, National University of Ireland, Galway.

\section{References}

Basturkmen, H. (1998). Refining procedures: a needs analysis project at Kuwait University. English Teaching Forum, 36(4), 2-9.

Braun, V., \& Clarke, V. (2012). Thematic analysis: APA handbook of research method in psychology. APA Books.

Elisha-Primo, I., Sandler, S., Goldfrad, K., Ferenz, O., \& Perpignan, H. (2010). Listening to students' voices: a curriculum renewal project for an EFL graduate academic program. System, 38(3), 457-466. https://doi.org/10.1016/j.system.2010.02.002

Henry, M., Carroll, F., Cunliffe, D., \& Kop, R. (2018). Learning a minority language through authentic conversation using an online social learning method. Computer Assisted Language Learning, 31(4), 321-345. https://doi.org/10.1080/09588221.2017.1395348

Hickey, T. M., \& Stenson, N. (2016). One step forward and two steps back in teaching an endangered language? Revisiting L2 reading in Irish. Language, Culture and Curriculum, 29(3), 302-318. https://doi.org/10.1080/07908318.2016.1231200

Lackaff, D., \& Moner, W. J. (2016). Local languages, global networks: mobile design for minority language users. In Proceedings of the 34th ACM International Conference on the Design of Communication (pp. 1-9). https://doi.org/10.1145/2987592.2987612

McKenney, S., \& Reeves, T. (2014). Educational design research. In J. Spector, M. Merrill, J. Elen \& M. Bishop (Eds), Handbook of research on educational communications and technology (pp. 131-140). Springer. https://doi.org/10.1007/978-1-4614-3185-5_11 
Moseley, C. (2010). Atlas of the world's languages in danger. UNESCO Publishing. http://www. dspace.cam.ac.uk/handle/1810/243434

Ó Giollagáin, C., \& Charlton, M. (2015). Nuashonrú ar an Staidéar Cuimsitheach Teangeolaioch ar Úsáid na Gaeilge sa Ghaeltacht 2006-2011: Priomhfhaisnéis na Limistéar Pleanála Teanga. Údarás na Gaeltachta/Gaeltacht Development Authority, Ireland. https://www.rte.ie/ documents/news/udaras-na-gaeltachta.pdf

Reeves, T. C. (2006). Design research from a technology perspective. In J. van den Akker, K. Gravemeijer, S. McKenney \& N. Nieveen (Eds), Educational design research (pp. 52-66). Routledge.

Schwartz, O. (2020, February 14). Hawaiian, Gaelic, Yiddish: so you want to learn an endangered language on Duolingo? The Guardian. https://www.theguardian.com/lifeandstyle/2020/ feb/14/hawaiian-gaelic-yiddish-learn-endangered-language-duolingo 


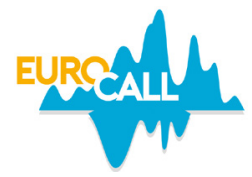

\title{
The challenges of dynamic teacher training for a short English for academic purposes course when using multimodal digital platforms: a case study
}

\author{
Karla K. de Lima Guedes ${ }^{1}$ and Vanessa Mar-Molinero ${ }^{2}$
}

\begin{abstract}
Despite the benefits of multimodal technology in the language classroom and common practice to introduce digital tools in language teaching, research has shown that many language teachers do not feel confident to engage with and create online multimodal learning resources and environments. This exploratory study examines data from five experienced English for Academic Purposes (EAP) teachers and discusses the dynamic challenges faced when training them to engage with multimodal teaching, learning, and assessment methods, such as digital learning, confidence and community building, and supporting them in creating multimodal learning resources. It also discusses the Dynamic Teacher Training model developed as a result of this experience to support teachers in developing the skills they needed to fully engage with the different digital teaching tools and teacher feedback on this.
\end{abstract}

Keywords: multimodal learning, online learning, EAP, digital skills, teacher training.

\section{Introduction}

Many EAP programmes, previously delivered only in-person in British Higher Education (UKHE) using more traditional pedagogical approaches, had to be reconceived and delivered virtually in a limited timeframe in 2020-2021 due to the COVID-19 pandemic, such as the EAP pre-sessional case study in this paper. Consequently, several of these programmes were designed to include

\footnotetext{
1. University of Southampton, Southampton, United Kingdom; k.de-lima-guedes@soton.ac.uk; https://orcid.org/0000-0001$5470-0756$

2. University of Southampton, Southampton, United Kingdom; v.mar-molinero@soton.ac.uk

How to cite this article: De Lima Guedes, K. K., \& Mar-Molinero, V. (2021). The challenges of dynamic teacher training for a short English for academic purposes course when using multimodal digital platforms: a case study. In N. Zoghlami, C. Brudermann, C. Sarré, M. Grosbois, L. Bradley, \& S. Thouësny (Eds), CALL and professionalisation: short papers from EUROCALL 2021 (pp. 69-74). Research-publishing.net. https://doi.org/10.14705/rpnet.2021.54.1311
} 
multimodal learning objects. In second language (L2) education research, the term multimodality commonly refers to "the coordination of multiple different systems of signification to communicate a single, or at least a unified, message or meaning" (Dressman, 2019, p. 39), and this combination of modes produces a mutually reinforcing complex of cues to meaning making that can facilitate communication and aid comprehension (e.g. Hardison \& Pennington, 2021). L2 research has shown the benefits of multimodality and students' preference for it (e.g. Peng, 2019), and thus teacher awareness and understanding of these learning modalities are of great significance, in particular when teaching online.

Although using a range of semiotic resources and introducing digital tools into the L2 classroom are common practice, teachers often feel insufficiently prepared to engage with multimodal pedagogy and lack the skills to design and deliver multimodal practices (e.g. Farías \& Véliz, 2019). Therefore, alongside the introduction of multimodal digital developments, curriculum designers also need to tackle the training and needs of the teachers who will deliver and engage students using these pedagogies. Therefore, this paper aims to examine the dynamic challenges faced when training EAP staff to engage with and create online multimodal learning materials, present the training approach used, and discuss teacher feedback.

\section{Method}

Participants in this study consisted of five EAP practitioners teaching an online five-week pre-sessional course, Prepare for Pre-sessional (P4P). Teachers were experienced EAP practitioners, but only one had online teaching experience. P4P aimed to introduce students to EAP and the university systems and used a combination of asynchronous and synchronous activities. Most asynchronous activities took place via Blackboard and used a multimodal learning approach by using a combination of text, video, audio, discussion forums, and H5P activities ${ }^{3}$. The synchronous activities consisted of one-hour daily lessons and weekly oneto-one tutorials. P4P used a flipped learning approach where students were asked to engage with the asynchronous activities before joining the interactive live lessons, which were used for further practice, content consolidation, and students' questions.

Staff training took place over one intensive week's induction where teachers were introduced to the course, the digital tools to be used, and online language

3. https://h5p.org/ 
teaching. In addition to engaging with the virtual learning environment learning materials and with students via different channels (e.g. Blackboard, discussion forums, and Collaborate), teachers were asked to take ownership of the course and contribute to the multimodal learning materials by creating engaging learning videos to accompany the weekly text-based and H5P activities. This, however, came with several challenges, such as training teachers on how to use the relevant tools, supporting them throughout this steep learning process, and building their confidence as online language teachers and content creators. An example of this was learning how to use the video recording tool Panopto ${ }^{4}$. Teachers were expected to use Panopto to create the aforementioned videos but were not familiar with it or with video recording themselves. We quickly realised the induction sessions would not be enough and had to design a training plan to support teachers. Data for this study were collected from team discussion notes and reflections from weekly meetings and post-course qualitative written teacher feedback.

\section{Results and discussion}

This section first discusses the training model developed for P4P - the Dynamic Teacher Training model (Figure 1), and then teacher feedback. The Dynamic Teacher Training model is made of four dynamic main steps. In Step 1, teachers were introduced to the tool(s) in a live session and given a step-by-step guide to using them independently. In Step 2, teachers were given the opportunity to have a go at using the tools and asking questions. Step 3 consisted of teachers being asked to use the tools independently and were given feedback by their coordinators and peers. Finally, in the last step, teachers started using the tools to create multimodal learning materials and were given support when needed.

Figure 1. Dynamic Teacher Training model

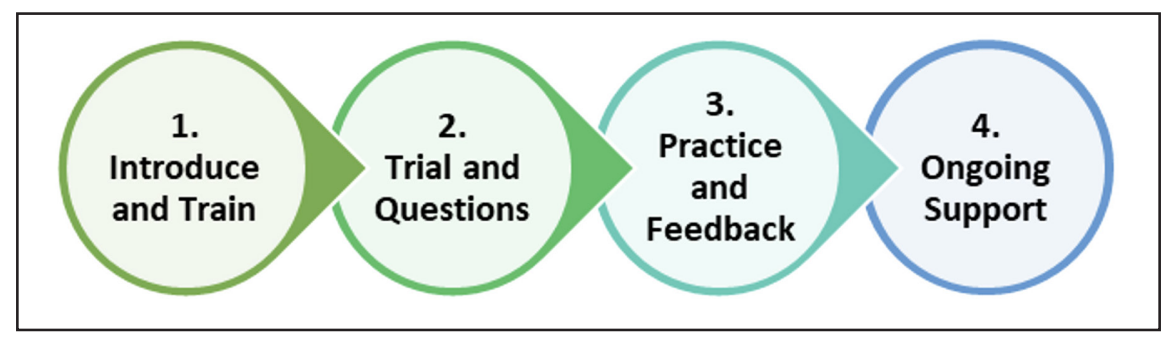

4. https://www.panopto.com/ 
Throughout the entire process, teachers were encouraged to share their experiences and contact coordinators via a group chat. From Step 2 onwards, peer support was encouraged, and teachers became gradually more independent, which was crucial to their digital learning, confidence-building, and community building process, as shown below.

"I enjoyed how we all helped and supported each other - it felt like a real team effort, with each of us contributing something different and everyone being able to play to their strengths" (T02).

"It was a steep learning curve during the induction week! [...] We were all learning together which again was a bonus" (T03).

This dynamic teacher training approach was used throughout the course, allowing teachers to feel supported in using the technologies they needed to teach online, develop their digital competencies, feel confident in creating asynchronous multimodal learning experiences, and become aware of using these modalities. Below are examples of teacher feedback regarding the training model used:

"Excellent training, support and communication which helped reassure and inspire confidence" (T01).

"Brilliant! [...] I always felt I could ask for help, which I think was one of the best things about having such a small and lovely team" (T02).

Feedback was also positive regarding the multimodal asynchronous activities team leaders and teachers created for the Blackboard. Teachers felt that "collectively [they had done] a good job of making some uninspiring materials more interesting and accessible to [students]" (T02) and that their "asynchronous videos and live classes enlivened the materials for the students" (T03), creating "[what] seemed [to be] a perfect combination of learning suited to all types of learners" (T04).

Despite the positive feedback from teachers on their training and the activities they created for the course, the initial steps were challenging for teachers and coordinators, in particular, due to time constraints:

"For me, the first couple of weeks were really hard work and even though I know I'm fairly slow (!), I don't think I could have done everything necessary just working 9-5" (T02). 
Both teachers and coordinators had to dedicate extra hours to develop the digital skills themselves and support teachers with developing theirs. In addition, team size was critical for this type of dynamic training and continuous peer support to take place. Teachers felt they "could ask for help, which [...] was one of the best things about having such a small and lovely team" and reported having positive teaching experiences as a result.

The fact that teachers had to take ownership of the course and create multimodal experiences themselves created an interest in digital development, a sense of curiosity, and a stronger community of practice. Teacher feedback suggests that applying the Dynamic Teacher Training model in bigger teams online would require not only a bigger support team but greater efforts in building a sense of community, peer-sharing, and camaraderie.

\section{Conclusion}

As many L2 teachers experienced teaching online for the first time in 2020, some noticed how unprepared they were and that their role had changed, and so had the digital skills they needed to teach effectively and confidently. Digital competence is one of the main challenges facing teachers today (Fernández-Batanero, Montenegro-Rueda, Fernández-Cerero, \& García-Martínez, 2020); therefore, supporting teachers was crucial to developing an engaging language learning environment and building teacher digital teaching confidence. Our early findings suggest that it is imperative to not only make teachers aware of these modalities but also, and most importantly, support them in developing the skills they need to engage with different tools and environments fully. To ensure the quality of the delivery and of student (and teacher) experience, we believe training teachers to become confident in using multimodal approaches is crucial for them to thrive in the many new L2 digital learning environments they will be using with their students in a post-COVID-19 era.

\section{References}

Dressman, M. (2019). Multimodality and language learning. In M. Dressman \& R. W. Sadler (Eds), The handbook of informal language learning (pp. 39-55). Wiley.

Farías, M., \& Véliz, L. (2019). Multimodal texts in Chilean English teaching education: experiences from educators and pre-service teachers. Profile: Issues in Teachers' Professional Development, 21(2), 13-27. https://doi.org/10.15446/profile.v21n2.75172 
Fernández-Batanero, J. M., Montenegro-Rueda, M., Fernández-Cerero, J., \& García-Martínez, I. (2020). Digital competences for teacher professional development. Systematic review. European Journal of Teacher Education, 1-19. https://doi.org/10.1080/02619768.2020.182 7389

Hardison, D. M., \& Pennington, M. C. (2021). Multimodal second-language communication: research findings and pedagogical implications. RELC Journal, 52(1), 62-76. https://doi. org/10.1177/0033688220966635

Peng, J.-E. (2019). The roles of multimodal pedagogic effects and classroom environment in willingness to communicate in English. System, 82, 161-173. https://doi.org/10.1016/j. system.2019.04.006 


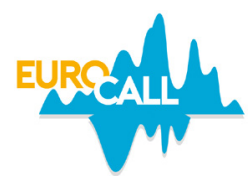

\title{
Collaborative skills in language courses: how to support pupils?
}

\section{Carole Delforge ${ }^{1}$}

\begin{abstract}
The aim of this study is to examine how collaborative skills can be developed among secondary school pupils using digital tools (Word online, Adobe Spark Video) in the language classroom. Several types of data were collected: semistructured interviews with teachers and learners, and observation of collaborative activities in the language classroom (video recordings, research log, observation notes, etc.). The case studies show different collaborative activities, which fall into three categories: coordination, articulation, and production. The analysis suggests that many factors can have an impact on collaboration between students, and this paper focuses on one in particular: digital tools. The findings revealed that digital tools can support collaboration if they meet the specific needs of the task (synchronous collaboration, asynchronous collaboration, or no collaboration) and its accessibility for the pupils (one tool for the group, one tool per student). Moreover, the analysis highlights the need to provide techno-pedagogical training (Stockwell \& Hubbard, 2013) to the pupils so that they are able to use the tool efficiently in collaborative activities.
\end{abstract}

Keywords: online collaboration, digital literacies, productive skills, secondary education.

\section{Introduction}

In a society where information and communication technologies increase the possibilities for collaboration, the question of the media and digital skills required for citizens in the 21 st century becomes central (Voogt \& Roblin, 2012). In foreign language teaching, collaboration enables pupils to be involved in communicative tasks and makes the latter meaningful to the learners (Council of Europe, 2001).

1. University of Namur, Namur, Belgium; carole.delforge@unamur.be; https://orcid.org/0000-0002-7212-9167

How to cite this article: Delforge, C. (2021). Collaborative skills in language courses: how to support pupils? In N. Zoghlami, C. Brudermann, C. Sarré, M. Grosbois, L. Bradley, \& S. Thouësny (Eds), CALL and professionalisation: short papers from EUROCALL 2021 (pp. 75-79). Research-publishing.net. https://doi.org/10.14705/rpnet.2021.54.1312 
However, collaboration is not innate and requires specific skills (Hämäläinen \& Häkkinen, 2010; Voogt \& Roblin, 2012). As stated by Dillenbourg and Tchounikine (2007), collaboration relies on many external factors, including the ability of the students in the group to collaborate.

The aim of this study is to answer the following research question: how can collaborative skills be developed among secondary school pupils using digital tools in the language classroom? The final aim of this research is to provide language teachers or teacher trainers with guidelines for implementing activities that require collaborative skills from their learners.

\section{Method and data collection}

In order to build an in-depth understanding of the processes involved in setting up a collaborative activity, four iterative data collection and analysis phases were planned. This paper will focus on the research methodology and the results of the first two iterative phases, which took place in 2018-2019 and 2019-2020. As shown in Figure 1, several types of data were collected in each phase: semi-structured interviews with teachers and learners, and observation of collaborative activities in the language classroom (video recordings, research log, observation notes, etc.).

Figure 1. Timeline and data collected

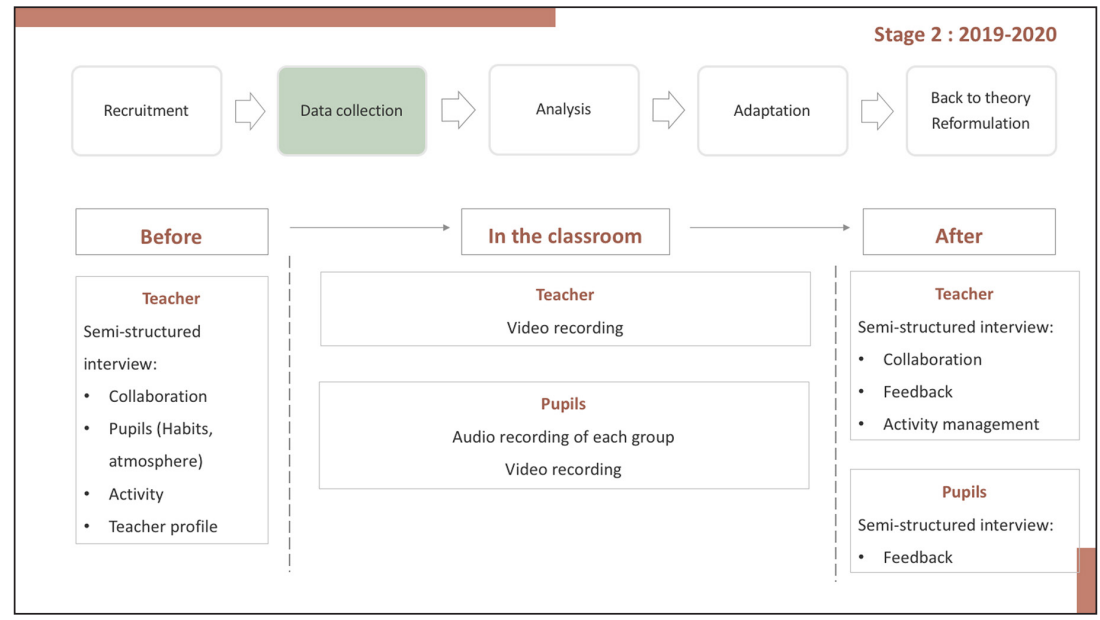

Based on all the data collected, categories were created using a qualitative methodology to identify factors that potentially influence collaboration skills. 
Classroom observations during the first phase (2018-2019) highlighted three dimensions: the teacher (profile, framing of the activity), the pupils (profile and collaborative activity), and the context (classroom habits and atmosphere). This analysis served as the basis for the second phase (2019-2020) in which two classroom projects were analyzed. The first project was carried out with eight pupils in the first year of secondary school. The aim of the project was the inpair collaborative writing of a letter in English with Microsoft Word online for synchronous collaboration. For the second project, 15 pupils in the fifth year of secondary school had to create in groups various short films in Spanish with Adobe Spark Video. This tool allowed everyone to have access to the edited videos but did not enable the pupils to collaborate synchronously on the interface.

\section{Results and discussion}

The analyses of the classroom observations revealed different collaborative activities, which we have grouped into three main dimensions presented in Table 1. These dimensions and activities are inspired by the work of Ligurgo et al. (2019) and might evolve with the following phases of the research.

Table 1. Collaborative activities identified

\begin{tabular}{|l|l|}
\hline Dimensions & Activities \\
\hline Coordination & Establishing the rules of collaboration \\
\cline { 2 - 2 } & Distributing the sub-tasks \\
\hline \multirow{2}{*}{ Articulation } & Negotiating the general content \\
\hline Production (collective, individual) & Adjusting the rules to achieve the tasks \\
\cline { 2 - 2 } & Giving feedback \\
\cline { 2 - 2 } & Implementing tasks \\
\hline
\end{tabular}

We found that pupils' collaborative activities differed between projects, showing that, as stated by Dillenbourg and Tchounikine (2007), external factors influence collaboration. This allows us to formulate some hypotheses about factors that may or may not prompt collaborative work. In order to encourage collaborative work, digital tools have to be physically and cognitively accessible to all learners. The analysis shows that in the Spanish project, where the pupils had one computer per group, only one pupil - the one who considered himself the most competent - used the computer. Consequently, the other members of the group were not able to fully participate in the activity and showed a more passive behavior. 
However, access to the digital tool is not enough to encourage collaborative work, everyone must also be able to use it. In the observed activities, the pupils did not have the same level of digital literacy, which played a role in the distribution of tasks and in the work performed by each member of the group. In seven out of the eight groups, the pupil who felt the most comfortable with the digital tool was the one who performed the digital tasks. In six out of these seven groups, this person became the leader of the group. In five out of the eight groups, the leader took over the work and strongly limited the collaborative tasks. In order to foster collaboration during the task, it is therefore recommended that everyone has been trained to use the digital tool (Stockwell \& Hubbard, 2013).

This training cannot be only technical (Hulin, 2013). The analysis of the two projects stresses the importance of specialized training in the expected use of the tool, which is confirmed in similar studies (Van de Vyver \& Delforge, 2020). In the English project, the technical aspects of the digital tool were shown quickly before the activity (changing the font, etc.), whereas the collaborative use was explained orally. The analysis of the pupils' collaborative activities shows that the oral explanations did not allow the pupils to imagine what they had to do with the tool (e.g. copy and paste parts of the text, modify them on their own computer). Two groups out of four therefore copied the letter for most of the activity, as they would have done on a sheet of paper, without taking advantage of the technology. Mastery of the tool before the activity is all the more important because, if not, the language activity may take a back seat to the technical difficulties associated with the use of the digital tool (Van de Vyver \& Delforge, 2020).

Finally, it appears necessary from the observations that the digital tool meets the specific needs of the task in order to support collaboration. In both projects, the collaborative activities took place in the classroom during class time; it was therefore necessary that the tool allows synchronous collaborative work. In the first project, the collaborative tool allowed for synchronous work and was used to carry out collaborative activities, thus prompting collaboration. In the second project, the tool was collaborative since the projects could be shared. Nevertheless, it did not enable synchronous collaboration. In this context, the pupil in front of the computer took over the work and no collaborative activities could be carried out.

\section{Conclusions}

Our research question was: How can collaborative skills be developed among secondary school pupils using digital tools in the language classroom? At this stage, 
it appears that learning to collaborate can be influenced by many elements. The access for each learner to the digital tool and the choice of a tool that corresponds to the context of learning (asynchronously or synchronously collaborative) are two conditions under which the digital activity fosters collaboration. Furthermore, it appears from the results that pupils need to be trained in digital collaboration, which includes showing the technical use of the tool and working on its collaborative features.

\section{References}

Council of Europe. (2001). Cadre européen commun de référence pour les langues : apprendre, enseigner, évaluer. https://rm.coe.int/16802fc3a8

Dillenbourg, P., \& Tchounikine, P. (2007). Flexibility in macro-scripts for computer-supported collaborative learning. Journal of Computer Assisted Learning, 23(1), 1-13. https://doi. org/10.1111/j.1365-2729.2007.00191.x

Hämäläinen, R., \& Häkkinen, P. (2010). Teachers' instructional planning for computer-supported collaborative learning: macro-scripts as a pedagogical method to facilitate collaborative learning. Teaching and Teacher Education, 26(4), 871-877. https://doi.org/10.1016/j. tate.2009.10.025

Hulin, T. (2013). Enseigner l'activité « écriture collaborative». Tic \& société, 7,1. https://doi. org/10.4000/ticetsociete.1314

Ligurgo, L., Fastrez, P., Jacques, J., Collard, A.-S., \& Philippette, T. (2019). Chapter 2 : A definition of digital media literacy competences required by workers to collaborate in distance work environments. In A.-S. Collard \& J. Jacques (Eds), Digital media literacy in teamwork and distance work: competences, discourse and organizational design (pp. 131186). Presses Universitaires de Namur

Stockwell, G., \& Hubbard, P. (2013). Some emerging principles for mobile-assisted language learning. TIRF: The International Research Foundation for English language education, 1-15. https://www.tirfonline.org/wp-content/uploads/2013/11/TIRF_MALL_Papers_ StockwellHubbard.pdf

Van de Vyver, J., \& Delforge, C. (2020). Vers une intégration efficace du numérique en classe : croisement d'expériences et pistes de réflexion. NEXUS: Connecting teaching practice and research, 1(1). https://doi.org/10.14428/nexus.v1i1.54193

Voogt, J., \& Roblin, N. (2012). A comparative analysis of international frameworks for $21 \mathrm{st}$ century competences: implications for national curriculum policies. Journal of Curriculum Studies, 44(3), 299-321. https://doi.org/10.1080/00220272.2012.668938 


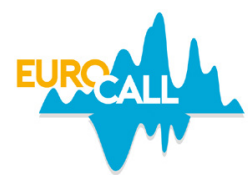

\title{
Machine translation literacy: a panorama of practices at Swiss universities and implications for language teaching
}

\author{
Alice Delorme Benites ${ }^{1}$, Sara Cotelli Kureth ${ }^{2}$, \\ Caroline Lehr ${ }^{3}$, and Elizabeth Steele ${ }^{4}$
}

\begin{abstract}
This short paper presents the quantitative results of an online survey of Swiss university students and staff on their use of Machine Translation (MT). The analysis of the 3,713 responses throws light on the context, purposes, degree of successive revisions, and ethical considerations surrounding the use of MT. With regards to language teachers and students, the quantitative data allows us to draw three preliminary conclusions: MT is a well-established but unspoken practice in Swiss universities, MT is not seen as an alternative to language learning, and MT is seen and already being used as a tool to improve language skills.
\end{abstract}

Keywords: machine translation, machine translation literacy, digital literacy.

\section{Introduction}

Fostering language diversity is particularly important in Switzerland, with its four national languages and widespread use of English as a lingua franca. This may be facilitated by recent advances in neural MT (Forcada, 2017), which have led to frequent and generalised use (Nurminen \& Papula, 2018). However, users are rarely aware of the pitfalls of such technologies and therefore tend to blindly trust them (Martindale \& Carpuat, 2018). Students in language classes are no

\footnotetext{
1. ZHAW Zurich University of Applied Sciences, Winterthur, Switzerland; alice.delormebenites@zhaw.ch; https://orcid. org/0000-0002-5254-4988

2. University of Neuchâtel, Neuchâtel, Switzerland; sara.cotelli@unine.ch; https://orcid.org/0000-0002-5213-2801

3. ZHAW Zurich University of Applied Sciences, Winterthur, Switzerland; caroline.lehr@zhaw.ch; https://orcid.org/00000002-1690-5117

4. Bern University of Applied Sciences BFH, Bern, Switzerland; elizabeth.steele@bfh.ch; https://orcid.org/0000-0001-8534-2576

How to cite this article: Delorme Benites, A., Cotelli Kureth, S., Lehr, C., \& Steele, E. (2021). Machine translation literacy: a panorama of practices at Swiss universities and implications for language teaching. In N. Zoghlami, C. Brudermann, C. Sarré, M. Grosbois, L. Bradley, \& S. Thouësny (Eds), CALL and professionalisation: short papers from EUROCALL 2021 (pp. 80-87). Research-publishing.net. https://doi.org/10.14705/rpnet.2021.54.1313
} 
exception: while they already know and employ free MT solutions (O'Neill, 2019), they are not aware of how these technologies work and how reliable their output is, which leads to uncritical use (Zhu, 2020). Conversely, although teachers are familiar with these tools, they rarely use them in language teaching, being reluctant to adopt new technologies which they fear may be disruptive or even threatening (García \& Pena, 2011; Hiew \& Chew, 2016; Niño, 2008; Yamada, 2019).

In this context, a four-year project started in 2021 to develop MT literacy (Bowker, 2020) among Swiss university language teachers and students. The first stage involves gaining a better understanding of current practices in language teaching and learning in higher education in the MT era by asking students and staff about their use of MT. This short paper presents the main quantitative results of the survey and the initial conclusions that can be drawn from it.

\section{Method}

The survey was conducted in four Swiss universities amongst students and staff. It consisted of 248 close-ended and open-ended questions, addressing the following topics: awareness of MT, user experience, beliefs and attitudes, training needs. The data were collected and managed using REDCap electronic data capture tools (Harris et al., 2009) in three different languages (German, English, and French). We gathered a total of 3,713 responses. In the following, we focus on the university teaching staff (666 respondents) and students (1,926 respondents $)^{5}$.

\section{Results and discussion}

The analysis confirms that a huge majority of respondents (94.8\% for staff, $97.2 \%$ for students) have already used MT systems. Both teachers and students use MT regularly (on average a little less than weekly) in their academic work, more often than for leisure activities, non-academic work, or private life (Figure 1). They use MT for all kinds of documents related to their main activities within the university (see Figure 2).

5. Students: $67 \%$ female, 28 male, $5 \%$ other or n/a; ages ranged from 26 to $65+$, with $60 \%$ in their early twenties. Teachers: 51 female, 44,6 male, $2.4 \%$ other or n/a; ages ranged from 18 to $65+$, with $62 \%$ between 46 and 55 y.o. 
Figure 1. Frequency of use of MT in various contexts

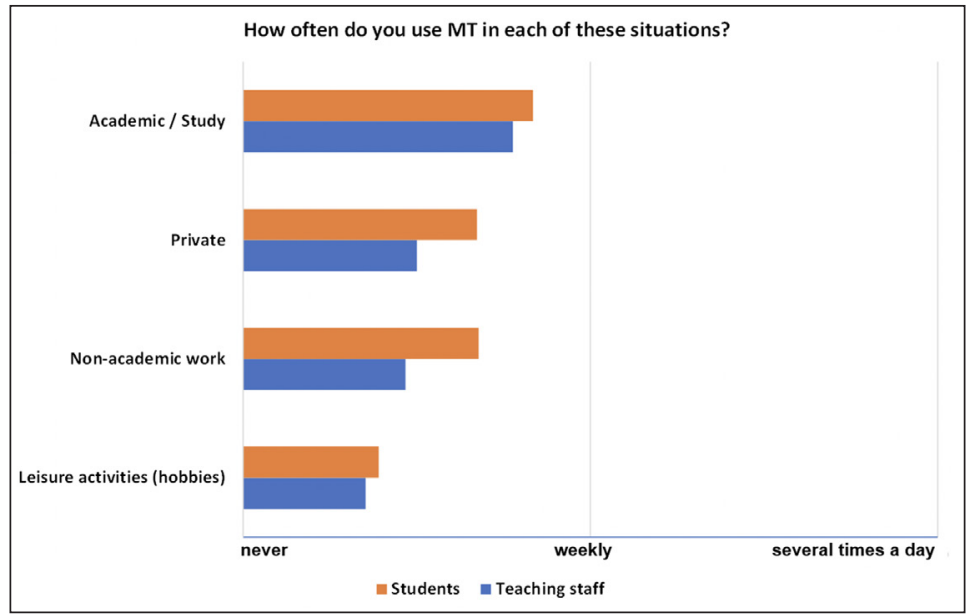

Figure 2. Documents for which MT is used

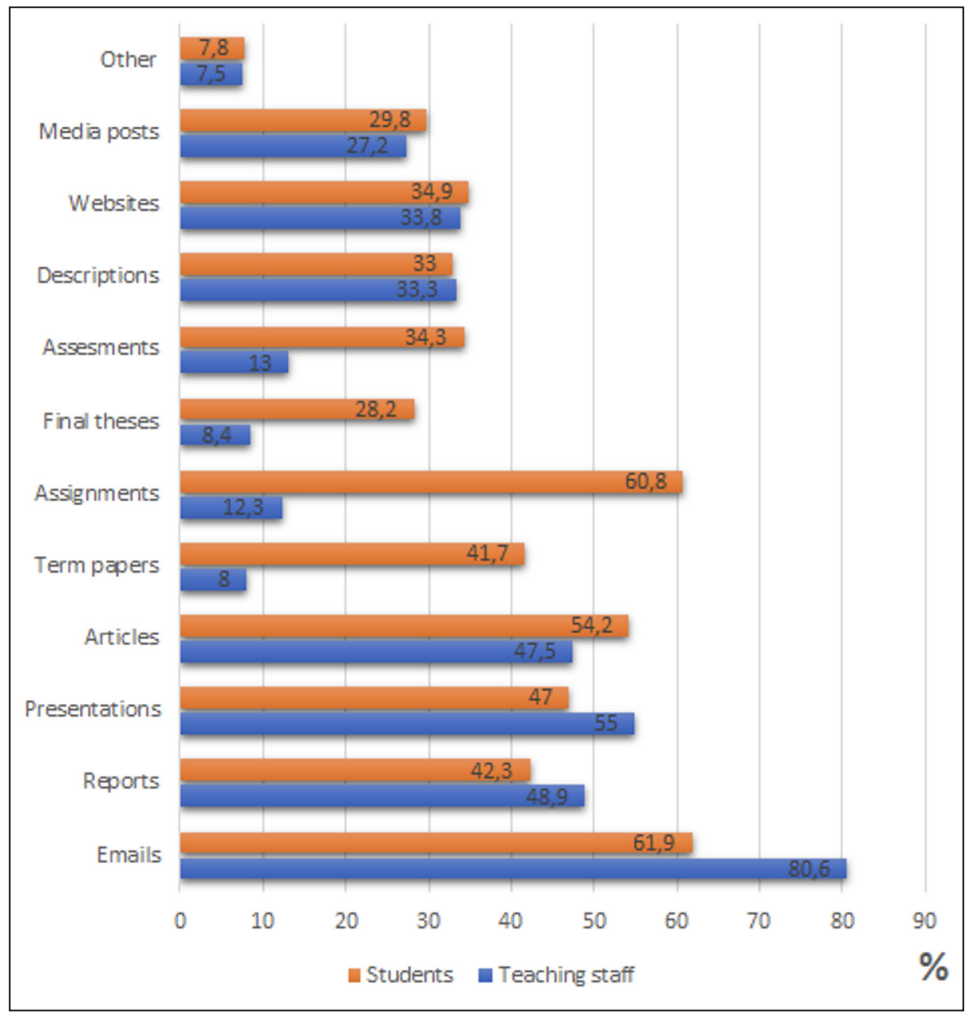


The second main finding is that, although the use seems widespread, there is very little talk or training about MT at universities. For example, only $4 \%$ of teachers say they explain to their students how MT works and its potential and risks, compared to $18.8 \%$ who mention some basics, and $77.1 \%$ who do not mention MT at all. This closely matches the mirror question we asked students: $83.9 \%$ have never had any explicit instruction on using MT. Yet, when asked if they understand how MT systems work, students seem to be quite confident, more so than teachers (Figure 3 and Figure 4, the red dots to the right of the centre line indicate the centre of the distribution).

Figure 3. How confident are you that you understand how MT systems work? (students, $n=1,435$, on a scale from 0 to 100 )

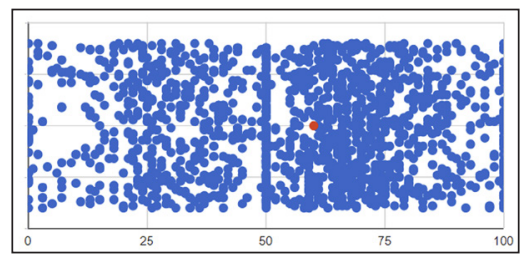

Figure 4. How confident are you that you understand how MT systems work? (teaching staff, $\mathrm{n}=511$, on a scale from 0 to 100 )

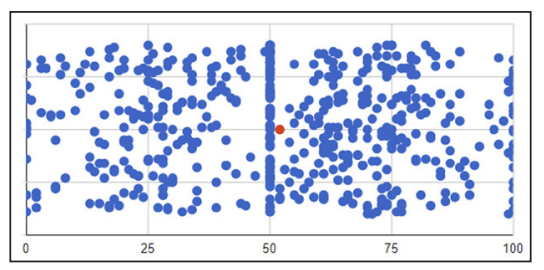

Students also seem to have more trust in their peers' and their teachers' awareness of the risks of using MT (Figure 5), while teachers take a more sceptical stance. Such different perceptions of one's own and others' knowledge show that there has been very little discussion about the topic. This silence around a tool that is already established in our lives bears many risks, especially since MT is still prone to errors (Koehn \& Knowles, 2017), but these are not always easy to spot (Loock, 2020). Finally, less than $10 \%$ of teachers and students claimed the existence of official guidelines, training or explicit instructions on MT at their universities.

The third finding is that, although the question has been raised in the media, most students and teachers do not see MT as a replacement for language proficiency (Figure 6; see also Hellmich \& Vinall, 2021). This is not due to poor performance 
by MT systems: both students and teachers are, on average, satisfied with MT output $65 \%$ of the time. Both groups rather see MT as a tool (Figure 7 ), and $40 \%$ of the students even indicated that they already use MT to improve their language skills. This shows the importance of integrating MT into language teaching approaches, not as a constraint but as a rightful CALL tool (see also Briggs, 2018).

Figure 5. Estimated others' awareness of risks

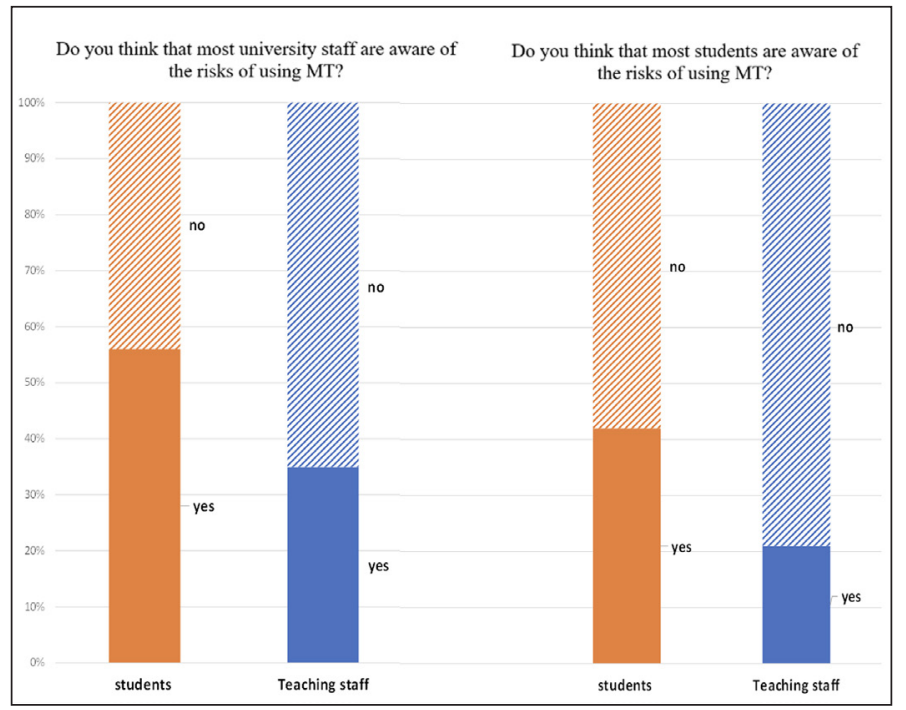

Figure 6. How do you think MT will change the need to learn languages?

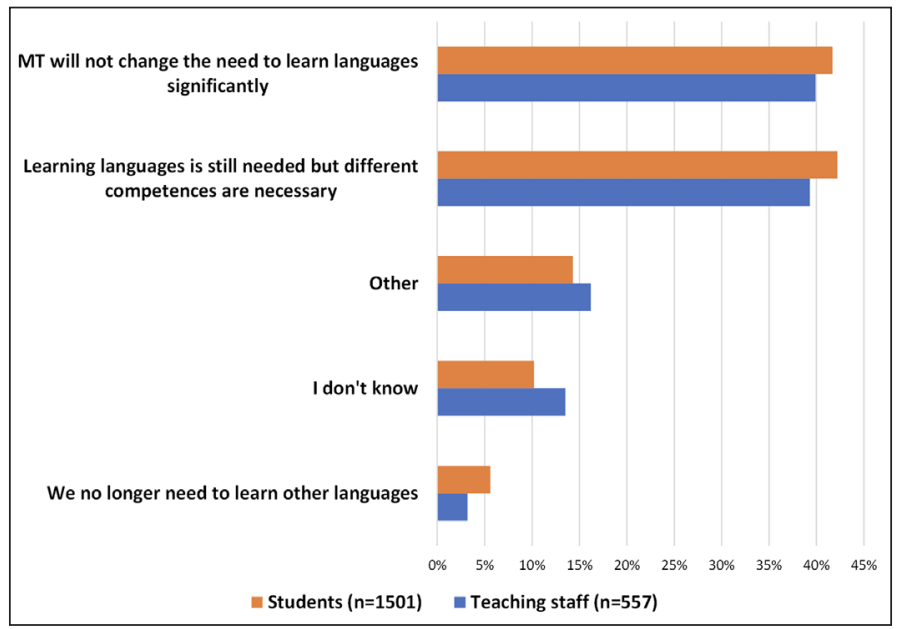


Figure 7. How do you think MT will change teaching and learning practices?

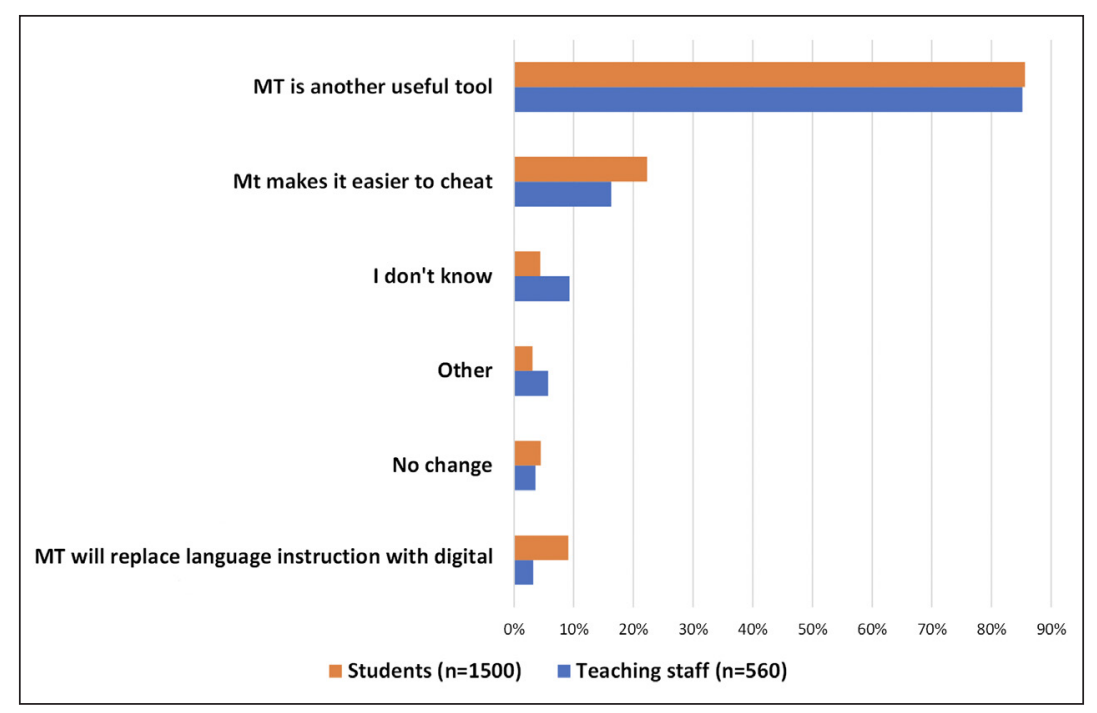

\section{Conclusions}

The quantitative results of the survey allow us to draw three preliminary conclusions: (1) using MT is common practice in Swiss academic contexts but is not part of the institutional and/or pedagogical discussion; (2) in the view of most respondents, the need to learn languages will not be affected by MT; and (3) most respondents see MT as another useful tool to improve language skills and learn languages.

On the one hand, these findings confirm much anecdotal evidence informally gathered from language teachers; on the other hand, they also show that teachers' fears might not be justified. More generally, the panorama of practices revealed through this survey shows the urgent need for including MT literacy in efforts to improve digital literacy among both teachers and students.

\section{Acknowledgements}

We would like to thank Maureen Ehrensberger-Dow for her valuable contribution to this short paper, as well as swissuniversities and ZHAW Digital, the University of Neuchâtel, and Bern University of Applied Sciences for co-funding the project. 


\section{References}

Bowker, L. (2020). Machine translation literacy instruction for international business students and business English instructors. Journal of Business \& Finance Librarianship, 25(1-2), $25-$ 43. https://doi.org/10.1080/08963568.2020.1794739

Briggs, N. (2018). Neural machine translation tools in the language learning classroom: students' use, perceptions, and analyses. JALT CALL Journal, 14(1), 2-24.

Forcada, M. (2017). Making sense of neural machine translation. Translation Spaces, 6(2), 291309. https://doi.org/10.1075/ts.6.2.06for

García, I., \& Pena, M. (2011). Machine translation-assisted language learning: writing for beginners. Computer Assisted Language Learning, 24(5), 471-487.

Harris, P. A., Taylor, R., Thielke, R., Payne, J., Gonzalez, N., \& Conde, J. G. (2009). Research electronic data capture (REDCap) - a metadata-driven methodology and workflow process for providing translational research informatics support. Journal of Biomedical Informatics, 42(2), 377-381. https://doi.org/10.1016/j.jbi.2008.08.010

Hellmich, E., \& Vinall, K. (2021). FL instructor beliefs about machine translation: ecological insights to guide research and practice. IJCALLT, 11(4), 1-18. https://doi.org/10.4018/ IJCALLT.2021100101

Hiew, C., \& Chew, E. (2016). Seams remain in seamless learning. On the Horizon, 24(2), 145152. https://doi.org/10.1108/oth-09-2015-0063

Koehn, P., \& Knowles, R. (2017). Six challenges for neural machine translation. Proceedings of the First Workshop on Neural Machine Translation (pp. 28-39). Association for Computational Linguistics. https://doi.org/10.18653/v1/w17-3204

Loock, R. (2020). No more rage against the machine: how the corpus-based identificaton of machine-translationese can lead to student empowerment. The Journal of Specialised Translation, 34, 150-170.

Martindale, M., \& Carpuat, M. (2018). Fluency over adequacy: a pilot study in measuring user trust in imperfect MT. In Proceedings of the 13th Conference of the Association for Machine Translation in the \{A\}mericas (Vol. 1: Research Track, pp. 13-25). Association for Machine Translation in the Americas.

Niño, A. (2008). Evaluating the use of machine translation post- editing in the foreign language class. Computer Assisted Language Learning, 21(1), 29-49. https://doi. org/10.1080/09588220701865482

Nurminen, M., \& Papula, N. (2018). Gist MT users: a snapshot of the use and users of one online MT tool. In S.-M. E.-G. Pérez-Ortiz (Ed.), Proceedings of the 21st Annual Conference of the European Association for Machine Translation (pp. 199-208). European Association for Machine Translation.

O’Neill, E. (2019). Online translator, dictionary, and search engine use among L2 students. CALL-EJ: Computer-Assisted Language Learning-Electronic Journal, 20(1), 154-177. 
Yamada, M. (2019). Language learners and non-professional translators as users. In M. O’Hagan (Ed.), The Routledge handbook of translation and technology (pp. 183-199). Routledge. https://doi.org/10.4324/9781315311258-11

Zhu, X. (2020). Machine translation in foreign language learning classroom-learners' indiscriminate use or instructor's discriminate stance. English Linguistics Research, 9(4), 1-5. https://doi.org/10.5430/elr.v9n4p1 


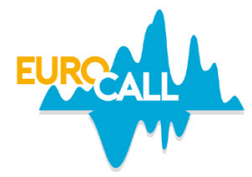

\title{
Facilitating reflection in teletandem through automatically generated conversation metrics and playback video
}

\author{
Aparajita Dey-Plissonneau ${ }^{1}$, Hyowon Lee ${ }^{2}$, Michael Scriney ${ }^{3}$, \\ Alan F. Smeaton ${ }^{4}$, Vincent Pradier ${ }^{5}$, and Hamza Riaz
}

\begin{abstract}
This pilot study focuses on a tool called L2L that allows second language (L2) learners to visualise and analyse their Zoom interactions with native speakers. L2L uses the Zoom transcript to automatically generate conversation metrics and its playback feature with timestamps allows students to replay any chosen portion of the conversation for post-session reflection and self-review. This exploratory study investigates a seven-week teletandem project, where undergraduate students from an Irish university learning French (B2) interacted with their peers from a French university learning English (B2+) via Zoom. The data collected from a survey $(\mathrm{N}=43)$ and semi-structured interviews $(\mathrm{N}=35)$ show that the quantitative conversation metrics and qualitative review of the synchronous content helped raise students' confidence levels while engaging with native speakers. Furthermore, it allowed them to set tangible goals to improve their participation, and be more aware of what, why, and how they are learning.
\end{abstract}

Keywords: conversation metrics, reflection, L2 learning, teletandem.

\section{Introduction}

In the context of the Covid-19 pandemic, the possibilities of enhancing the learning and teaching experience by developing the affordances of online

\footnotetext{
1. Dublin City University, Dublin, Ireland; aparajita.dey-plissonneau@dcu.ie; https://orcid.org/0000-0003-1429-6861

2. Dublin City University, Dublin, Ireland; hyowon.lee@dcu.ie; https://orcid.org/0000-0003-4395-7702

3. Dublin City University, Dublin, Ireland; michael.scriney@dcu.ie; https://orcid.org/0000-0001-6813-2630

4. Dublin City University, Dublin, Ireland; alan.smeaton@dcu.ie; https://orcid.org/0000-0003-1028-8389

5. Paris Sciences et Lettres Université, Paris, France; vincent.pradier@psl.eu; https://orcid.org/0000-0002-7050-6408

6. Dublin City University, Dublin, Ireland; hamza.riaz2@mail.dcu.ie; https://orcid.org/0000-0001-6339-6194
}

How to cite this article: Dey-Plissonneau, A., Lee, H., Scriney, M., Smeaton, A. F., Pradier, V., \& Riaz, H. (2021). Facilitating reflection in teletandem through automatically generated conversation metrics and playback video. In N. Zoghlami, C. Brudermann, C. Sarré, M. Grosbois, L. Bradley, \& S. Thouësny (Eds), CALL and professionalisation: short papers from EUROCALL 2021 (pp. 88-93). Research-publishing.net. https://doi.org/10.14705/rpnet.2021.54.1314 
learning platforms has been a pressing need. In foreign language education, videoconferencing platforms afford connecting with native speakers in geographically distant institutions for language and intercultural competences development via telecollaboration (Dooly \& O'Dowd, 2018). Facilitated by technological progress, innovative learning activities, such as students reviewing the recordings of their online interactions for reflection and learning, are gaining importance in language pedagogy (Rivière \& Guichon, 2014). This pilot study describes a tool that we conceived and developed in Dublin City University (DCU) called the L2L platform (Dey-Plissonneau et al., 2021) that automatically generates conversation metrics and content visualisation of L2 learners' synchronous Zoom teletandem interactions with native speakers.

As part of this tandem project that involved seven weekly sessions in the second semester of the 2020-2021 academic year, 60 students in DCU learning French (B2, 20-21 years, mixed gender) interacted via Zoom with 45 students in Paris Sciences et Lettres (PSL) learning English (B2+, 19-20 years, mixed gender). DCU students majored in business, media, law, and translation studies, while PSL students majored in humanities and sciences. The objectives of these interactions were to develop their second language (L2) knowledge, interaction skills, and intercultural competences. Various challenges encountered in previous teletandem projects led us to the creation of the L2L platform. Firstly, high attrition rates in the context of online learning, especially as monitoring synchronous interactions on a weekly basis, is a tall order for lecturers. Secondly, the fast-pace of synchronous interactions in the target language involves high cognitive load, anxiety, and code-switching. These need to be complemented by asynchronous reflection as the synchronous interactions are too ephemeral for retention. Finally, intermediate students often feel that they have reached a plateau in their learning progress (Richards, 2008), and thus need to set very specific learning objectives.

The L2L platform uses Zoom's automated transcript facility to create conversation metrics for each interaction session, at the individual and interindividual levels. Figure 1 shows the L2L dashboard right after a conversation was held between two DCU and two PSL students. Students can visualise their conversation share and the conversation flow between all the participants of their group. Additionally, a video playback timeline with colour-coded audio graphs allows one to select any point on the timeline and play the recording from that point onward. These affordances allow students to review (self- and peer-review) their otherwise ephemeral synchronous exchanges both at the quantitative and qualitative levels. 
Figure 1. Dashboard of the L2L platform

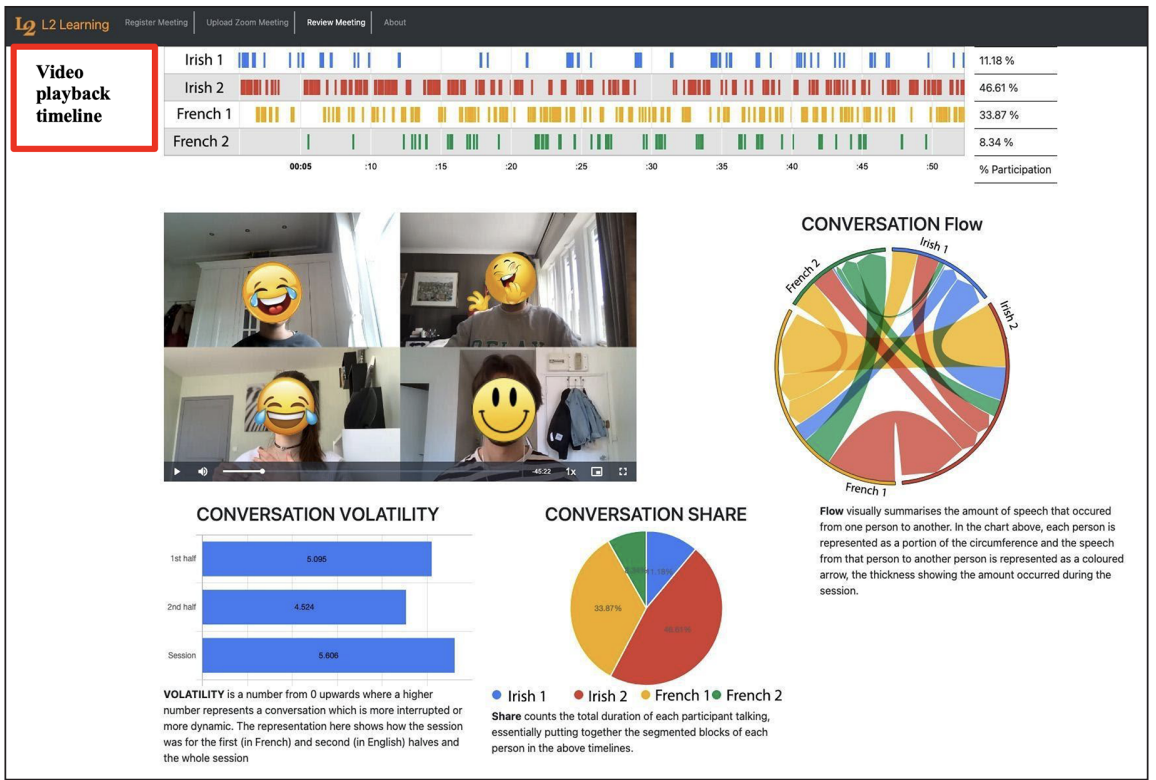

This study examines the principles for the pedagogical design that are generated, as successful learners are those who are "aware of their perceptions, attitudes, and abilities and are knowledgeable about the learning process" (Hauck, 2005, p. 73). Introducing the L2L platform tool in the pedagogical design of the teletandem project led us to focus on the following research questions.

- What is the added value of using participation visualisations on students' learning via teletandem?

- What principles for the pedagogical design are generated?

\section{Method}

The unit of analysis in this exploratory study is the participating DCU students who were engaged in self-review/reflection using the L2L platform and had participated in two other teletandem projects in the previous semesters without L2L. The data used includes the results of a survey taken by 43 DCU students and semi-structured interviews of 35 DCU students gathered after the end of the seven-week teletandem project using L2L. Our thematic analysis of the 
interviews sheds light on the correlation between the learners' perception of the L2L visualisations and their influence on the L2 learning process. The pedagogical design for the teletandem comprised weekly activities conducted in three phases (Mayer, 2005):

- asynchronous pre-session written interactions on forums;

- synchronous conversation-based videoconferencing in triads (two DCU and one PSL) and quadruplets (two DCU and two PSL); and

- post-session individual reflections on their interactions using L2L.

The asynchronous forum and synchronous Zoom interactions were based on topics related to personal interests and university life in the first two sessions, and then moved on to current affairs such as statelessness, racism, state violence, geopolitics, and the treatment of these debates in French and Irish/English newspapers, in line with their respective module curricula. Four post-session quantitative and qualitative reflections using L2L were conducted by DCU students with the aim to review their strengths and weaknesses in effectively interacting with native speakers.

\section{Results and discussion}

In response to the survey question whether graphs and video playback were helpful to analyse their post-session reflection and learning, $76.7 \%$ of respondents replied 'yes' (see Figure 2).

Figure 2. Learner feedback on L2L

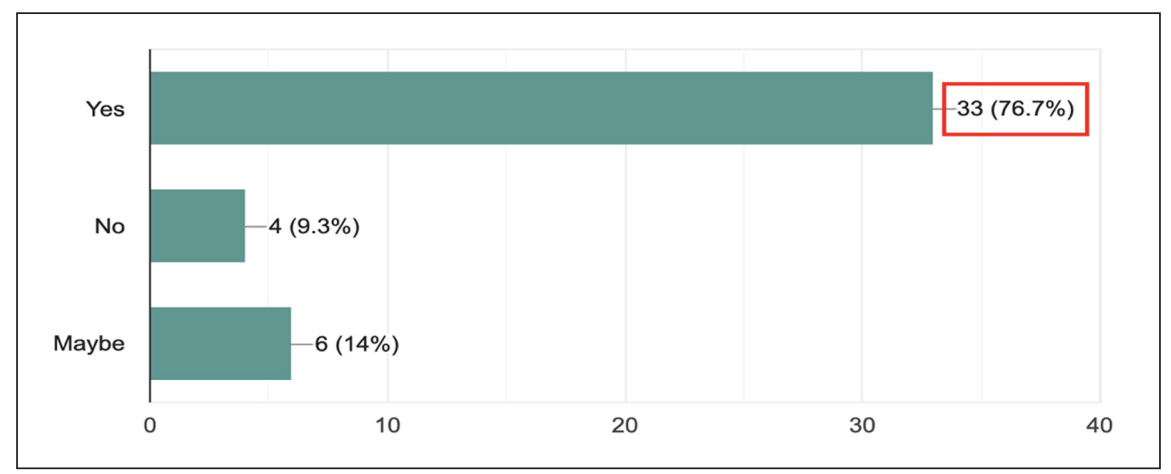


Some students reported that the graphs helped them set goals, either to participate more actively and increase their turn-taking (47.6\%), or to stop monopolising the floor time and allow others to speak (7.1\%) (see Figure 3). An important finding of our study is that students $(64.3 \%)$ found that the L2L visualisations mainly enhanced their confidence in their L2 interaction with native speakers. According to the students, in previous teletandem projects, they often came out of the interactions thinking that they had not participated much in French, but thanks to $\mathrm{L} 2 \mathrm{~L}$, they were pleasantly surprised to discover that their interaction was quite high in French too.

Figure 3. Learner feedback on how L2L proved helpful

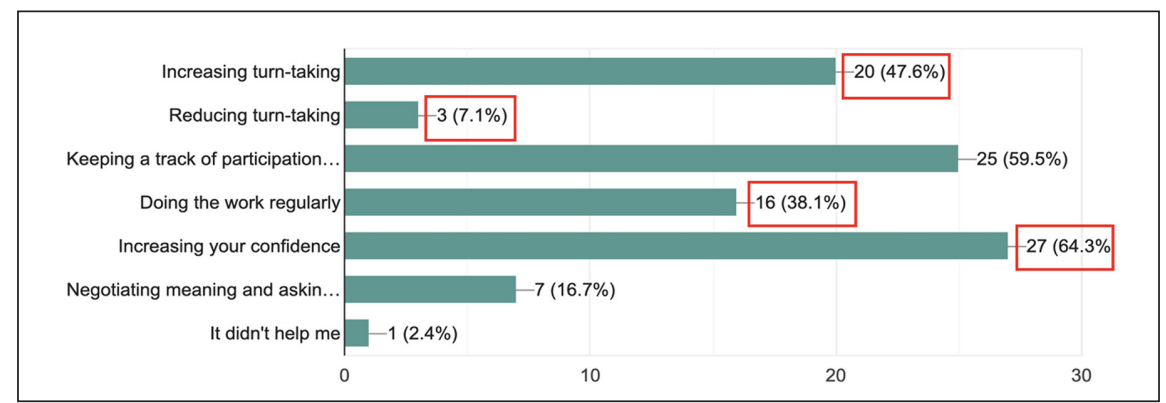

The four most recurring benefits of the visualisations reported in students' qualitative feedback were getting weekly visual feedback on how much they participated; keeping a check on their engagement and setting objectives to improve in following sessions; finding the motivation to improve each week; and gaining confidence and regulating their interaction in following instantiations. About $38 \%$ of respondents (Figure 3) felt that L2L helped them to come out of their comfort zones and engage in their synchronous interactions regularly instead of avoiding them as was the case in previous teletandem projects, as students' full interactions could now be easily monitored by the lecturer. With regard to whether the L2L system helped students improve their language learning experience or not, a student reflected:

"Definitely! At first I didn't understand the point of it but as I'm currently rewatching our sessions, I can easily identify the parts where I spoke the most/least and identify the reason why".

L2L, therefore, acted as a means of empowering language learners by inciting them "to make conscious decisions about what they can do to improve their learning" (Anderson, 2008, p. 99). This in turn helped them to work on the quality of their interactions with native speakers. In general, students felt that L2L made the 
interactions more interactive, and although students mentioned that it helped them notice grammar mistakes, most students thought that it helped with interaction skills, such as long pauses, hesitations, poor backchanneling, low or high participation, and metacognitive awareness to understand why this was happening and how it could be overcome, rather than language learning per se.

\section{Conclusions}

L2L was deemed useful by students to get weekly visual feedback, keep track of their participation, and set objectives for the next session, but mainly to gain confidence and regulate the quantity of their interactions in following instantiations. The automated quantitative and qualitative data allowed students to engage in reflection as part of the pedagogical design and set objectives for themselves. The video playback function allowed students to focus on the quality of the synchronous content although this was not exploited fully. A possible future step could be the organisation of co-reflections between students using the playback function to facilitate peer-review.

\section{References}

Anderson, N. J. (2008). Metacognition and good language learners. In C. Griffiths (Ed.), Lessons from good language learners (pp. 99-109). Cambridge University Press.

Dey-Plissonneau, A., Lee, H., Pradier, V., Scriney M., Smeaton A. F. (2021). The L2L system for second language learning using visualised Zoom calls among students. In T. De Laet, R. Klemke, C. Alario-Hoyos, I. Hilliger \& A. Ortega-Arranz (Eds), Technology-enhanced learning for a free, safe, and sustainable world. EC-TEL 2021. Lecture Notes in Computer Science (vol 12884). Springer. https://doi.org/10.1007/978-3-030-86436-1_45

Dooly, M., \& O'Dowd, R. (2018). (Eds). In this together. Teacher's experiences with transnational telecollaborative projects. Peter Lang. https://doi.org/10.3726/b14311

Hauck, M. (2005). Metacognitive knowledge, metacognitive strategies, and CALL. In J. L. Egbert \& G. M. Petrie (Eds), CALL research perspectives (pp. 65-86). Lawrence Erlbaum.

Mayer, R .E. (2005). Cognitive theory of multimedia learning. In R. E. Mayer (Ed.), The Cambridge handbook of multimedia learning (pp. 31-48). Cambridge University Press.

Richards, J. C. (2008). Moving beyond the plateau. Cambridge University Press.

Rivière, V., \& Guichon, N. (2014). Construction de bilans rétroactifs par des apprentis tuteurs de langue en ligne : régimes d'action et dynamiques sociocognitives. Le Français dans le monde - Recherches et applications, 56, 118-135. 


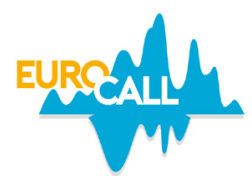

\title{
Helping aerospace engineering students develop their intercultural communicative competence
}

\author{
Sofia Di Sarno-García ${ }^{1}$
}

\begin{abstract}
This paper presents a six-week telecollaborative project carried out between B2 (Common European Framework of Reference for languages - CEFR) level learners of English from the Universitat Politècnica de València (UPV), Spain, and B1 (CEFR) level students of Spanish as a foreign language from the University of Bath (UK). The aim of the project was to help Spanish-speaking students develop their Intercultural Communicative Competence (ICC). Students carried out asynchronous discussions focusing on two cultural topics in groups of four through the social network MeWe and participated in synchronous Zoom sessions in pairs. To conclude the project, students completed a collaborative task with their overseas partners. Qualitative data was gathered through the analysis of the transcripts of the Zoom sessions, the students' posts on MeWe, as well as a final project questionnaire. Results revealed that the students who engaged the most in the synchronous sessions and felt curiosity about their partners' culture were also the same ones who contributed the most to the cultural discussions on MeWe. At the end of the course all participants felt they had learnt something about their partners' culture.
\end{abstract}

Keywords: intercultural communicative competence, asynchronous computermediated communication, telecollaboration, social network.

\section{Introduction}

Nowadays it is crucial that university students acquire the necessary skills to be able to appropriately interact with foreign people. As Seiz Ortiz et al. (2015) claimed, engineering students will probably need effective intercultural skills in their future

1. Universitat Politècnica de València, Valencia, Spain; sodisar@doctor.upv.es; https://orcid.org/0000-0001-9952-4178

How to cite this article: Di Sarno-García, S. (2021). Helping aerospace engineering students develop their intercultural communicative competence. In N. Zoghlami, C. Brudermann, C. Sarré, M. Grosbois, L. Bradley, \& S. Thouësny (Eds), CALL and professionalisation: short papers from EUROCALL 2021 (pp. 94-99). Research-publishing.net. https://doi.org/10.14705/ rpnet.2021.54.1315 
professional life, as well as the ability to successfully communicate in English, which today is of paramount importance (Gimeno-Sanz, 2013). The purpose of this study was therefore to develop the ICC of a group of aerospace engineering students $(\mathrm{n}=8)$ through a telecollaborative exchange project with students from the University of Bath (UK) $(n=8)$. This paper discusses the six-week telecollaborative project in which students from both groups engaged in asynchronous cultural discussions and synchronous videoconference sessions.

Byram (1997) defined ICC in terms of five savoirs, or objectives:

- attitudes of curiosity and openness;

- knowledge of social groups and their products;

- skills of interpreting and relating;

- skills of discovery and interaction; and

- critical cultural awareness/political education.

We used this model to assess students' ICC in this telecollaborative project. In fact, telecollaboration is a beneficial approach to develop language learners' ICC (O'Dowd, 2012). Studies such as Vinagre (2014) and Oskoz and Gimeno-Sanz (2020) demonstrated the effectiveness of telecollaborative exchanges to foster students' ICC. The novelty of the study presented here lies in the tool used for the cultural discussions, which is the social network MeWe. As far as we know, this is the first time that this instrument has been used to sustain intercultural discussion among students in a telecollaboration project.

\section{Method}

The study belongs to a larger project leading to a doctoral dissertation. Therefore, it will be replicated to complete the whole study. Here we try to answer the following research question: will students perceive that they have acquired cultural knowledge regarding their international partners' culture?

The study involved eight third year aerospace engineering students enrolled in an optional B2 level English course from UPV and eight highly proficient speakers of English taking a B1 level Spanish course enrolled in different degree programmes at the University of Bath.

Students from both universities completed a pairing questionnaire consisting of nine open questions to match them with somebody who had similar interests. 
Afterwards, the participants started meeting in synchronous Zoom sessions where they accomplished collaborative tasks and where they were given free time to interact in pairs. Students also carried out asynchronous cultural discussions on a weekly basis in groups of four on the MeWe social network. The topics discussed were (1) the independence of Catalonia and (2) digital education. Topic 1 was conducted entirely in Spanish, and Topic 2 in English.

MeWe was the channel chosen for the cultural discussions because it allows users to upload and share different types of file formats such as PDF, images, and videos. The researcher created a private group, which the students were each invited to join. After registering and joining the group, the participants were required to upload a video presentation or a picture of themselves with a recording so that they could 'meet' their keypals before the first Zoom session. At the beginning of the two cultural discussions, the researcher provided a text and a video to trigger the dialogue. Students were required to ask the questions below.

- ¿Por qué se ha llegado a pedir la independencia de Cataluña en España? [Why has the independence of Catalonia been demanded in Spain?]

- What do you think about digital education in your country?

In both cases we intended to make participants focus on the different perspectives that each student could have depending on their cultural background.

At the end, students from both universities created a sound-enhanced PowerPoint presentation with their MeWe partners where the main ideas from the cultural discussions were summarised and they explained how they felt while dealing with those topics with partners from different cultures.

Finally, students completed a final project questionnaire whose aim was to explore their opinion regarding the project in general, the tools used, and whether they felt they had learnt something about their partners' culture. It was made up of 13 questions using a five-point Likert scale, one multiple-choice question, and an open question.

The Zoom conversations were transcribed through MediaUpv, which is a digital tool developed by UPV that allows users to generate automatic subtitles in the selected language and to modify them in short chunks while one listens to the audio.

Data was collected through the analysis of the transcripts, the PowerPoint presentation, and the final questionnaire. The comments posted on MeWe were 
analysed following Byram's (1997) objectives for the assessment of ICC, led by the fact that previous studies such as Vinagre (2014) found evidence or traces of the objectives proposed by Byram thanks to cultural discussions and active dialogue.

\section{Results and discussion}

A qualitative analysis demonstrated that the students who met more times with their keypals on Zoom also participated more actively on MeWe. A quantitative analysis (Pearson coefficient) further revealed that there is a high correlation between the number of Zoom sessions and the number of times those sessions dealt with cultural topics spontaneously. Figure 1 represents this relation.

Figure 1. Correlation between No. of Zoom sessions and No. of sessions dealing with culture

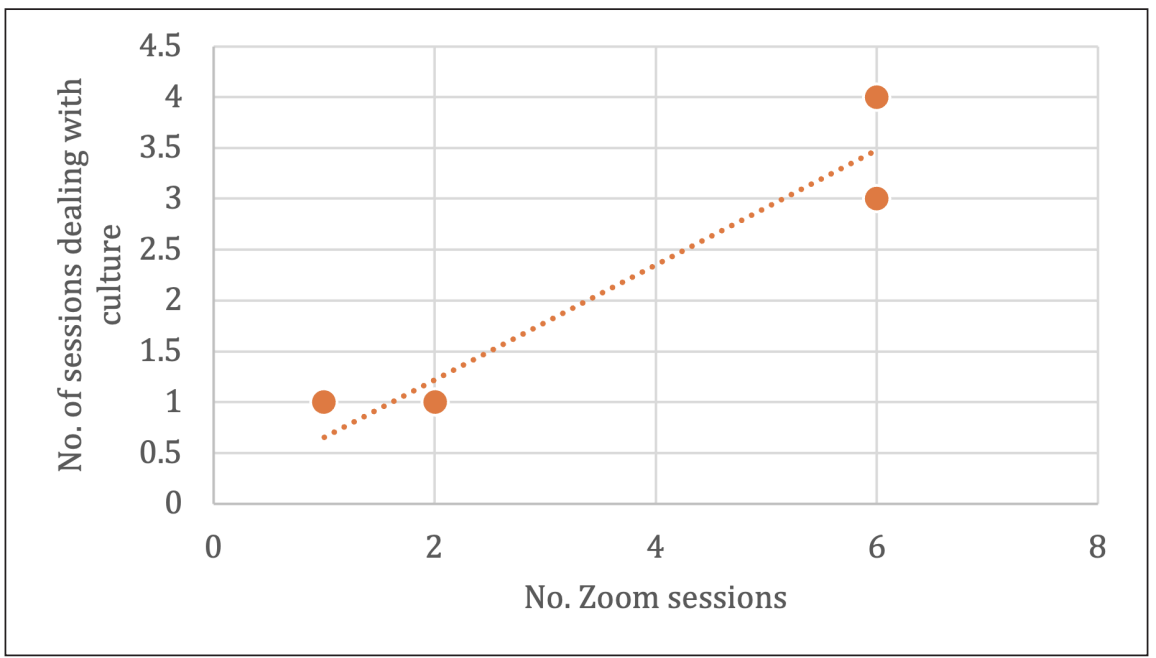

Students discussed topics such as differences among educational systems; linguistic diversity in Spain; differences among Spanish varieties across the world; preferred sports in each country; phonetics; differences in food and eating time; notions of family; and Christmas and New Year's Eve traditions.

Turning to the analysis of the participants' comments on MeWe, Spanish students posted a total amount of 45 comments (including the short description of their video introduction). These included several instances of entries that illustrate the 
development of ICC according to Byram's (1997) five objectives. Table 1 below quantifies them. However, due to space limitation, examples cannot be provided.

Table 1. Number of instances of Byram's (1997) objectives of ICC

\begin{tabular}{|l|l|}
\hline Objective & Number of instances or traces \\
\hline Attitudes of curiosity and openness & 42 \\
\hline Knowledge of social groups and their products & 13 \\
\hline Skills of interpreting and relating & 2 \\
\hline Skills of discovery and interaction & 17 \\
\hline Critical cultural awareness/political education & 9 \\
\hline
\end{tabular}

The final artefact and the comments sent to the researcher provided insightful feedback regarding the students' degree of satisfaction, which was high although some students had preferred to discuss the cultural topics orally. For instance, one student wrote "it has been a great experience and I take with me a new friend". Another one said in his presentation, "it has been a pleasure to be part of this telecollaborative project in which we have been able to meet, interact and discuss with people from another culture. It has been very rewarding". In line with that, results from the final project questionnaire revealed an overall satisfaction regarding the project since $71.4 \%$ of the participants chose the fifth option to the item In general, I found the project useful, while $28.6 \%$ selected the fourth. Additionally, to the item I have learnt something about my partner's culture, $85.7 \%$ chose the fifth option, and 14,3\% selected the fourth. All the participants found the Zoom ( $100 \%$ for the fifth) and MeWe $(28.6 \%$ for the fifth and $71.4 \%$ for the fourth) sessions useful.

\section{Conclusions}

The results of this study corroborate those suggested by similar studies that used online tools such as wikis (Vinagre, 2014) and online forums (Oskoz \& GimenoSanz, 2020), where learners successfully engaged in intercultural discussions gaining insight into and understanding of their partners' culture. We can therefore conclude that MeWe is a suitable tool since it gives language learners the opportunity to engage in meaningful dialogue with target language speakers and to enable them to show an ability to maintain an established relationship. This is a key feature an intercultural speaker should cultivate, and thus the ideal that language learners should pursue instead of trying to become a native speaker (Byram, 1997), which could lead to unnecessary frustrations. Also, the asynchronous written activities 
gave the participants time to reflect on the topics discussed, which helped them to foster their ICC.

\section{Acknowledgements}

This study belongs to a research project financed by UPV (PAID-01-19), resulting in a doctoral dissertation.

\section{References}

Byram, M. (1997). Teaching and assessing intercultural communicative competence (1st ed.). Multilingual Matters.

Gimeno-Sanz, A. (2013). Enhancing the foreign language learner's experience through Clilstore. In L.-H. Wong et al. (Eds), 21st International Conference on Computers in Education (pp. 734-739). Asia-Pacific Society for Computers in Education.

O'Dowd, R. (2012). Intercultural communicative competence through telecollaboration. In J. Jackson (Ed.), The Routledge handbook of language and intercultural communication (1st ed., pp. 342-358). Routledge.

Oskoz, A., \& Gimeno-Sanz, A. (2020). Exploring L2 Learners' engagement and attitude in an intercultural encounter. Language Learning \& Technology, 24(1), 187-208.

Seiz Ortiz, R., Magal-Royo, T., Perry, D., Gimeno Sanz, A., \& Romero Forteza, F. (2015). Integrating effective communication competence in higher education. In 8th International Conference of Education, Research and Innovation (ICERI 2015).

Vinagre, M. (2014). El desarrollo de la competencia intercultural en los intercambios telecolaborativos. Revista De Educación A Distancia, 41, 1-22. http://www.um.es/ead/red/41 


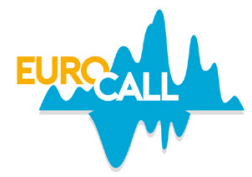

\title{
Using virtual reality and peer feedback to reduce L2 speaking anxiety: an exploratory study
}

\author{
Isabelle Godefridi ${ }^{1}$, Ferran Suñer ${ }^{2}$, \\ Cécile Leblanc ${ }^{3}$, and Fanny Meunier ${ }^{4}$
}

\begin{abstract}
The present study explored whether the use of Virtual Reality (VR) technology can help lower public speaking anxiety in the L2. To this end, we conducted an exploratory effect-of-instruction study using a one-group pre-test/posttest design with nine learners of English as an L2. The results from the post-test show that using VR in combination with peer feedback offers an interesting gateway to reducing public speaking anxiety.
\end{abstract}

Keywords: virtual reality, peer feedback, oral presentation skills.

\section{Introduction}

Although oral presentation skills in the foreign language (L2) are considered to be crucial for academic achievement and career success, most students are faced with many linguistic and psychological challenges when presenting in public in an L2 (Kim, 2020). In this context, recent advances in VR technology offer an interesting gateway to the enhancement of oral presentation skills since they allow students to train in an immersive learning environment and, at the same time, to benefit from tools such as video recordings and automated feedback on behavioural aspects of presentation delivery.

So far, educational research into the effectiveness of such VR-based applications has reported positive effects (Van Ginkel et al., 2019). However, these studies

\footnotetext{
1. Université catholique de Louvain, Louvain-la-Neuve, Belgium; isabelle.godefridi@uclouvain.be

2. Université catholique de Louvain, Louvain-la-Neuve, Belgium; ferran.suner@uclouvain.be

3. Université catholique de Louvain, Louvain-la-Neuve, Belgium; cecile.leblanc@student.uclouvain.be

4. Université catholique de Louvain, Louvain-la-Neuve, Belgium; fanny.meunier@uclouvain.be
}

How to cite this article: Godefridi, I., Suñer, F., Leblanc, C., \& Meunier, F. (2021). Using virtual reality and peer feedback to reduce L2 speaking anxiety: an exploratory study. In N. Zoghlami, C. Brudermann, C. Sarré, M. Grosbois, L. Bradley, \& S. Thouësny (Eds), CALL and professionalisation: short papers from EUROCALL 2021 (pp. 100-105). Research-publishing.net. https://doi.org/10.14705/rpnet.2021.54.1316 
have neglected to look into how these applications can help students present in the foreign language, especially for aspects that are more challenging for L2 learners such as the lack of linguistic autonomy or difficulties linked to fluency or speaking anxiety (Teimouri, Goetze, \& Plonsky, 2019). Furthermore, the role of feedback as one of the most crucial components in every learning process should also be examined in such contexts. Whilst feedback research has extensively investigated the effect of different feedback techniques on different aspects of L2 learning, feedback on oral presentations in the L2 still remains a relatively underexplored domain (Tsang, 2020). In this context, it is important to note that peer feedback has been found to be beneficial to reduce foreign language classroom anxiety and increase self-confidence (Motallebzadeh, Kondori, \& Kazemi, 2020).

In order to fill this research gap, the present study seeks to investigate the impact of such VR-based training environments on L2 learners' public speaking anxiety. Accordingly, we addressed the following research questions.

- To what extent does training combining VR and peer feedback help reduce students' speaking anxiety?

- How does training combining VR and peer feedback affect L2 learners' self-efficacy beliefs and perceived usefulness?

\section{Method}

\subsection{Design of the study and sample}

In order to see whether training combining VR and the use of peer feedback improves L2 oral presentation skills and reduces speaking anxiety before and/or during the presentation, we used a pre-test/post-test study design. Accordingly, the participants were tested on their oral presentation skills and their speaking anxiety both before and after the training sessions.

The sample of the study consisted of eight French-speaking and one Germanspeaking students from UCLouvain (Belgium), five women and four men, aged between 21 and 27. They all learn or have learned English as an L2 but felt the need to improve their oral presentation skills in English, be it for study, work, or everyday life. Their self-assessed level of English ranged from B2 to C1. 


\subsection{Materials and treatment}

The tool OVATION VR allows students to train their presentation in front of simulated audiences. It offers the possibility to record and share the presentation with peers, teachers, or other OVATION VR users for further analysis. In order to ensure that all participants were able to give relevant and well-argued feedback with suggestions for reflection and improvement, we organised two feedback training sessions, including the understanding and appropriation of the evaluation grid and some trial practice.

\subsection{Data collection instruments}

With regard to anxiety about public speaking in an L2, we used McCroskey's (1970) Personal Report of Public Speaking Anxiety (PRPSA) questionnaire, which allows for a general analysis of public speaking in the context of an oral presentation. The PRPSA questionnaire consists of 34 questions such as I get anxious when I think about a speech coming up, which participants answer on a scale of one (strongly disagree) to five (strongly agree). The scores can range between 34 and 170, with scores above 131 indicating high anxiety, scores between 98 and 131 moderate anxiety, and scores below 98 low anxiety.

In addition to the PRPSA, we also used Wolpe's (1969) Subjective Units of Distress Scale (SUDS), which allowed us to measure the degree of anxiety at a specific moment (e.g. two minutes before the presentation) on a scale of 0 to 100 , where zero represents a state of total relaxation and 100 a state of fear that makes it impossible to deliver the presentation. Whilst the SUDS is frequently used in clinical and mental health settings (e.g. Kiyimba \& O'Reilly, 2020), its use in SLA research has - to our knowledge - not yet been documented.

Finally, we asked some questions using a five-point Likert-scale based Davis's (1989) Technology Acceptance Model (TAM), about the self-efficacy beliefs and perceived usefulness regarding VR-based training tools and the use of peer feedback (e.g. OVATION VR is a valuable tool to counteract the anxiety of presenting to an audience).

\subsection{Procedure}

Figure 1 shows the timeline of the treatment, the data collection instruments, and the different measurement time points. 
Figure 1. Timeline of the study

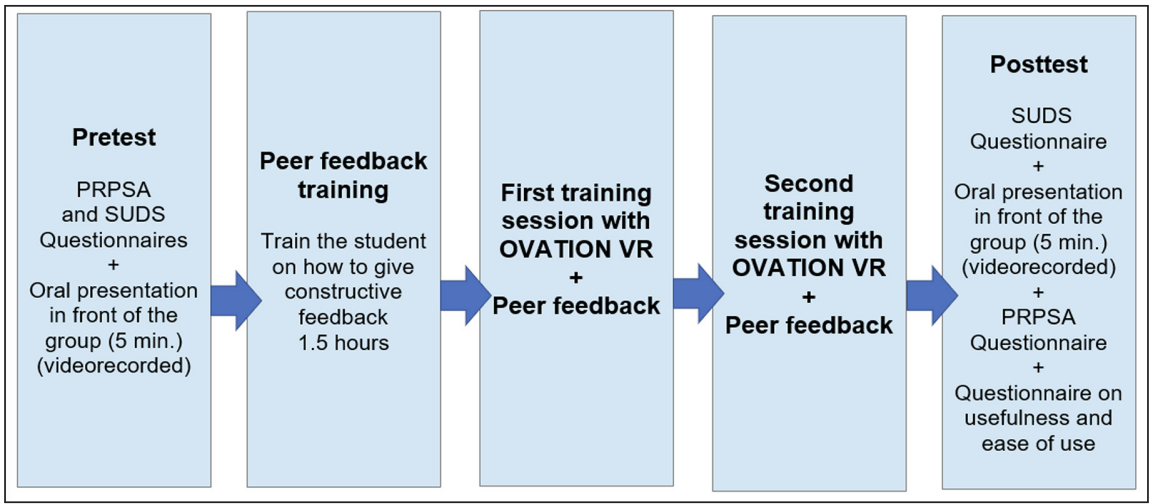

\section{Results and discussion}

With regard to public speaking anxiety, the pre-test showed two participants with high anxiety, four with moderate anxiety, and three with low anxiety. The post-test analysis indicated an improvement with only one participant narrowly meeting the threshold for high anxiety, five participants meeting the threshold for moderate anxiety, and three for low anxiety. Overall, five participants had a lower anxiety score on the post-test, two other participants an equal score, and two a score only slightly higher (Table 1, left).

Regarding participants' anxiety just before their presentation, we can see a decrease for most participants (see Table 1, right ${ }^{5}$ ). In the pre-test, three participants had a state of moderate anxiety (above 50) and two participants a state of high anxiety (80). One participant scored at exactly 50 and three below 50. The post-test showed that two participants scored above 50, three at exactly 50 and four below 50. Overall, five participants were less anxious. Three experienced the same level of anxiety and one a slight increase (from 0 to 10). As Table 1 shows, no remarkable differences were observed between the results from both speaking anxiety measures (PRPSA and SUDS). The decrease in student's anxiety is well-aligned with previous research on VR (see literature review by Van Ginkel et al., 2019).

5. See the ratings for the simplified version of the scale with guide points under the following link: https://www.verywellmind. com/what-is-a-suds-rating-3024471 
Table 1. Left: results from PRPSA questionnaire; right: results from SUDS before presenting

\begin{tabular}{|l|l|l|l|l|}
\hline Participants & $\begin{array}{l}\text { PRPSA } \\
\text { Pre-test }\end{array}$ & $\begin{array}{l}\text { PRPSA } \\
\text { Post-test }\end{array}$ & $\begin{array}{l}\text { SUDS } \\
\text { Pre-test }\end{array}$ & $\begin{array}{l}\text { SUDS } \\
\text { Post-test }\end{array}$ \\
\hline 1 & $\mathbf{1 4 2}$ & 132 & $\mathbf{7 0}$ & $\mathbf{6 0}$ \\
\hline 2 & 119 & 119 & $\mathbf{7 0}$ & $\mathbf{6 0}$ \\
\hline 3 & 79 & 79 & 10 & 10 \\
\hline 4 & $\mathbf{1 4 6}$ & $\mathbf{1 2 5}$ & $\mathbf{8 0}$ & $\mathbf{5 0}$ \\
\hline 5 & 67 & 71 & 0 & 10 \\
\hline 6 & $\mathbf{1 1 4}$ & $\mathbf{1 0 4}$ & $\mathbf{6 0}$ & $\mathbf{5 0}$ \\
\hline 7 & $\mathbf{1 0 3}$ & $\mathbf{1 0 2}$ & 50 & 50 \\
\hline 8 & 63 & 64 & 30 & 30 \\
\hline 9 & $\mathbf{1 1 8}$ & $\mathbf{1 0 8}$ & $\mathbf{8 0}$ & $\mathbf{3 0}$ \\
\hline $\begin{array}{l}\text { Average of all } \\
\text { participants }\end{array}$ & $\mathbf{1 0 5 . 6 7}$ & $\mathbf{1 0 0 . 4 4}$ & $\mathbf{5 0}$ & $\mathbf{3 8 . 8 9}$ \\
\hline Low & Moderate & High & & \\
\hline
\end{tabular}

We also asked the participants about the perceived usefulness of the training. Most students indicated that it was an interesting and pleasant experience. Sixty-six percent of the students stated that OVATION VR helped them improve their L2 oral presentation skills and $78 \%$ felt that they could better manage the related stress during the post-test. Eighty-nine percent of the students found that OVATION VR is a useful tool, but they also pointed to some technical problems faced during the training.

With respect to peer feedback, it was perceived as less stressful than teacher feedback. Most of the participants found the peer feedback useful, which is consistent with previous research (Motallebzadeh et al., 2020). However, some would also have liked to receive feedback from a teacher who was considered as more experienced and more qualified.

\section{Conclusions}

The analysis of the results shows that the intervention helped students reduce their speaking anxiety and feel more confident. Future research should consider testing whether combining peer and teacher feedback techniques during such a VR-based training might prove more efficient and have a more positive impact on self-efficacy. Finally, it is important to note that such VR-based training could also be implemented in other contexts such as teacher training programmes, since pre-service L2 teachers sometimes also suffer from a lack of linguistic autonomy and anxiety. 


\section{References}

Davis, F. D. (1989). Perceived usefulness, perceived ease of use, and user acceptance of information technology. MIS Quarterly, 13(3), 319-340. https://doi.org/10.2307/249008

Kim, K.-R. (2020). Oral presentations as an alternative approach to enhance L2 learning and communication skills. Journal of Digital Convergence, 18(7), 111-122. https:/doi. org/10.14400/JDC.2020.18.7.111

Kiyimba, N., \& O'Reilly, M. (2020). The clinical use of Subjective Units of Distress scales (SUDs) in child mental health assessments: a thematic evaluation. Journal of Mental Health, 29(4), 418-423. https://doi.org/10.1080/09638237.2017.1340616

McCroskey, J. C. (1970). Measures of communication-bound anxiety. Speech Monographs, 37, 269-277. https://doi.org/10.1080/03637757009375677

Motallebzadeh, K., Kondori, A., Kazemi, S. (2020). The effect of peer feedback on EFL learners' classroom anxiety. Language Teaching Research Quarterly, 18, 40-52.

Teimouri, Y., Goetze, J., \& Plonsky, L. (2019). Second language anxiety and achievement: a metaanalysis. Studies in Second Language Acquisition, 41(2), 363-387. https://doi.org/10.1017/ S0272263118000311

Tsang, A. (2020). Enhancing learners' awareness of oral presentation (delivery) skills in the context of self-regulated learning. Active Learning in Higher Education, 21(1), 39-50. https://doi.org/10.1177/1469787417731214

Van Ginkel, S., Gulikers, J., Biemans, H., Noroozi, O., Roozen, M., Bos, T., van Tilborg, R., van Halteren, M., \& Mulder, M. (2019). Fostering oral presentation competence through a virtual reality-based task for delivering feedback. Computers \& Education, 134, 78-97. https://doi. org/10.1016/j.compedu.2019.02.006

Wolpe, J. (1969). The practice of behavior therapy. Pergamon Press. 


\title{
Design-based research as a framework for developing and deploying augmented reality applications and scenarios for intercultural exchange
}

\author{
Stella Hadjistassou ${ }^{1}$, Petros Louca ${ }^{2}$, Shaunna Joannidou ${ }^{3}$, \\ and Pedro Jesus Molina Muñoz ${ }^{4}$
}

\begin{abstract}
This paper delves into the underlying phases involved in designing, developing, and deploying Augmented Reality (AR) applications and game-based scenarios that will be implemented during intercultural exchanges among students in two different academic institutions in Sweden and Cyprus. Building on principles of design-based research (Barab \& Squire, 2004; Klopfer \& Squire, 2008), the aim is to expand the learning ecology by leveraging instructional tools and developing novel scenarios to broaden the trajectories of collaboration, intercultural understanding and communication, and cultural knowledge. The AR applications and scenarios are in the process of being developed as part of the Digital Methods Platform for Arts and Humanities (DiMPAH) project, where game-based activities will foster intercultural collaboration, exploration of cultural heritage sites, intercultural understanding, knowledge, and interaction. Adopting a bottom-up approach, instructors collaborate with a software developer and an extended research team to design pedagogically and culturally potent scenarios embedded in novel technologies that bring the virtual into the physical world.
\end{abstract}

Keywords: augmented reality, intercultural exchange, design-based research.

\footnotetext{
1. KIOS Research and Innovation Center of Excellence, Nicosia, Cyprus; stella1@asu.edu; https://orcid.org/0000-0003-2963-8393

2. University of Cyprus, Nicosia, Cyprus; louca.petros@ucy.ac.cy; https://orcid.org/0000-0002-3616-1557

3. University of Cyprus, Nicosia, Cyprus; shaunna@ucy.ac.cy; https://orcid.org/0000-0001-7067-7867

4. University of Cyprus, Nicosia, Cyprus; munoz@ucy.ac.cy; https://orcid.org/0000-0002-5251-1406

How to cite this article: Hadjistassou, S., Louca, P., Joannidou, S., \& Molina Muñoz, P. J. (2021). Design-based research as a framework for developing and deploying augmented reality applications and scenarios for intercultural exchange. In N. Zoghlami, C. Brudermann, C. Sarré, M. Grosbois, L. Bradley, \& S. Thouësny (Eds), CALL and professionalisation: short papers from EUROCALL 2021 (pp. 106-111). Research-publishing.net. https://doi.org/10.14705/rpnet.2021.54.1317
} 


\section{Introduction}

The integration of design-based research principles to investigate the affordances and complexities involved in the design and development of software and applications for learning has incited discussion on the pedagogical, design, and technological implications of these technologies (Klopfer \& Squire, 2008; Scott, Wenderoth, \& Doherty, 2020). Design-based research captures the iterative nature of the design and development processes within the naturalistic contexts that they unfold, as well as the new theoretical trajectories and practices that emerge (Barab, 2014). As Anderson and Shattuck (2012) postulate, design-based research "evolved near the beginning of the 21 st century and was heralded as a practical research methodology that could effectively bridge the chasm between research and practice in formal education" (p. 16). Multiple studies have been conducted in various formal educational contexts, with particular emphasis being placed on science, technology, engineering, and Math-related subjects (40.6\%), while only $21.9 \%$ of these studies delved into the arts and humanities, including language learning (Bacca et al., 2014). As part of the three-year long European funded project DiMPAH, this study investigates the multiple iterations involved in the design and development of AR applications and scenarios for intercultural exchange.

In this paper, the key phases involved in the inception, design, development, and elaboration of a working architecture, as well as in the testing, modification, realization, and implementation of the AR apps, are explored. Within this ecology, clashing forces emerge as this collective design activity is intended to enact gamedriven AR-mediated applications and scenarios that enclose further pedagogical, learning, and technological implications. On one hand, tailored pedagogically-driven scenarios designed to meet learning needs and promote intercultural exchanges call for a collective interdisciplinary endeavor. On the other hand, this collective endeavor adds to the complexity and demands of the design of these AR applications and scenarios. Customizable AR applications and scenarios call for a collective effort to design game-based activities for higher education students that offer imaginary experiences with real-world pedagogical, social, and historical implications. They form a tool for exploring and understanding cultural heritage, negotiating meaning, and engaging in mystery game-driven experiences during intercultural exchanges.

\section{Method}

An interdisciplinary pool of instructors, researchers, and a software developer from Sweden and Cyprus identified four culturally and historically salient sites in their 
countries. In this paper, the focus is placed on the Neolithic settlement of Choirokoitia and the Iron age ringfort of Sandby borg. Drawing on the mystery involved in the disappearance of Choirokoitia residents and the Sandby borg massacre, this research team is designing and developing AR-mediated scenarios. The virtual settings of Choirokoitia and Sandby borg will be enriched with interactive 2D and 3D artifacts, avatars, and settings. Through multiple collaborative activities, students will explore customs, cultural traditions, language, beliefs, communities, and shared values within each society. Students will engage in multiple game-driven activities while participating in intercultural exchanges to solve mysteries. To develop a better understanding of the processes involved in the design, development, and implementation of these AR scenarios, a case study approach is used as a guiding principle. Expanding on Klopfer and Squire's (2008) work, seven phases are proposed to examine the underlying processes involved in the scenario design.

\section{Results and discussion}

The design process invites the contemplation of multiple and often contradictory principles, including design principles for developing AR game-based learning scenarios, user experience, and user interaction during intercultural exchanges in historically and culturally laden sites.

\subsection{Phase one: virtual site selection and game-driven AR-mediated scenario contemplation}

Site selection and game-driven scenarios require consideration of multiple interrelated variables and dynamics to meet the learning needs of an intercultural and interdisciplinary pool of students and at the same time to accurately depict the cultural, historical, and linguistic significance of that era. Already developed virtual sites were deployed and modified for designing activities, 2D and 3D objects, non-player characters, simulated tools, and multiple other artifacts of each era. Choirokoitia and Sandby borg presented sites that could be enriched with gamelike activities using Unity game engine features and C\# programming language, and involved mysteries related to the residents' disappearance or massacre.

\subsection{Phrase two: AR-mediated game-driven scenarios consideration}

To develop immersive, engaging, and collaborative game-driven scenarios that will enact affordances for collaborative explorations to solve a mystery, the rich historical, 
cultural, and linguistic values, as well as the importance of each civilization, the economic activity, and multiple other variables were taken into consideration. The aim is to capture and convey to users the given era, through a game-driven scenario, where they will need to investigate and derive cogent arguments on the underlying reasons that have led to the disappearance or massacre of the local residents. Both instructors and historians were consulted during this process.

\subsection{Phase three: AR-mediated game-driven scenario prototype development}

At the current stage, the research team is focusing on the development of the prototype of both scenarios where the Unity game engine and $\mathrm{C} \#$ programming language, along with other programming software, are deployed to design markerbased and dynamic trigger-based AR scenarios. Simultaneous localization and mapping is also deployed to stabilize tracking for AR by adjusting the predictions performed by the Inertial Measurement Unit (IMU) and the actual IMU tracking. Further, 2D and 3D objects, simulated tools, non-player characters, interactions, and multiple other features are being added to the two sites to enrich these scenarios.

\subsection{Phase four: AR scenario pilot testing}

Upon completion of the prototype, the game-driven activities and AR-mediated scenarios will be pilot tested among both students and instructors in Cyprus and Sweden to ensure their functionality and usability, and to examine how students and instructors interact with the scenarios and AR technology, the different elements of the AR game-driven activities, object recognition, and multiple other elements that will help mediate students' intercultural exchanges. Participants' feedback will guide the research team in enhancing the AR scenarios and game-driven activities. The pedagogical and learning implications of these AR-mediated scenarios will be further explored and adapted to meet students' learning needs.

\subsection{Phase five: AR scenario implementation during intercultural exchanges}

The AR scenarios will be implemented during intercultural exchanges among students enrolled in the participating academic institutions in Cyprus and Sweden. The goal is to enact pedagogically and culturally laden learning experiences mediated by AR applications and game-driven activities that will immerse students in problem-solving, deductive reasoning, and intercultural exchanges. Cultural knowledge and understanding, as well as interaction with 
historically salient sites and artifacts will enrich students' knowledge and cultural understanding.

\subsection{Phase six: scenario enrichment and implementation in additional contexts}

The two scenarios will be implemented in additional contexts during intercultural exchanges among students in the two participating academic institutions to further explore their pedagogical implications and added value. Additional features, artifacts, and other 2D and 3D objects, as well further modifications/adaptations to the scenarios will be made to ensure that they can enrich students' learning and collaborative activities.

\subsection{Phase seven: scenario expansion and implementation in new contexts}

The research team has identified two additional historical sites that are available in virtual contexts and the Unity game engine and $\mathrm{C} \#$ programming language will be integrated to design game-driven activities in these settings. Discussions also focus on making these activities more demanding and engaging, with new collaborative tasks, to further expand students' interaction, learning, and collaboration. Additional features and functionalities will also be added to enrich the sites.

\section{Conclusions}

Within the trajectories of design-based research, this paper introduced an initial framework for examining seven phases involved in the design, deployment, and integration of AR game-oriented activities in culturally and historically rich sites. Their design and development framework is a collaborative interdisciplinary process with multiple iterations and contemplation of pedagogical and technological implications and contradictions. Their value is yet to be fully explored but their pedagogical potential should form the guiding principle for their further development and implementation in different formal institutional contexts.

\section{References}

Anderson T, \& Shattuck J. (2012). Design-based research: a decade of progress in education research? Educational Researcher, 41(1), 16-25. https://doi.org/10.3102/0013189x11428813 
Bacca, J., Baldiris, S., Fabregat, R., Graf, S., \& Kinshuk, K. (2014). Augmented reality trends in education: a systematic review of research and applications. Journal of Educational Technology \& Society, 17(4), 133-149. https://doi.org/10.14742/ajet.4182

Barab, S. A. (2014). Design-based research: a methodological toolkit for engineering change. In R. K. Sawyer (Ed.), Handbook of the learning sciences (vol. 2, pp. 233-270). Cambridge University Press.

Barab, S., \& Squire, K. (2004). Design-based research: putting a stake in the ground. Journal of the Learning Sciences, 13(1), 1-14.

Klopfer, E., \& Squire, K. (2008). Environmental detectives - the development of an augmented reality platform for environmental simulations. Educational Technology Research and Development, 56, 203-228. https://doi.org/10.1007/s11423-007-9037-6

Scott, E., Wenderoth, M., \& Doherty, J. (2020). Design-based research: a methodology to extend and enrich biology education research. CBE Life Sciences and Education, 19(3), 1-12. https://doi.org/10.1187/cbe.19-11-0245 


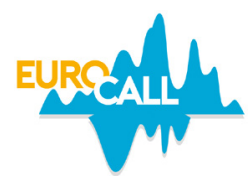

\title{
Internationalisation at home through virtual exchange: an encounter between distance language learners and trainee language teachers
}

\author{
Xavière Hassan ${ }^{1}$, Annie Eardley ${ }^{2}$, and Christelle Combe ${ }^{3}$
}

\begin{abstract}
Undergraduate language students from the Open University (OU) and master's degree students from Aix-Marseille Université (AMU) participated in an innovative Virtual Exchange (VE) as part of our institutions' internationalisation at home strategy. Due to the pandemic, the one-week Residential School (RS) abroad, which is part of the Bachelor of Arts (BA) in modern languages at the OU, was replaced with an Alternative Learning Experience (ALE) - a one-week online intensive programme which included a VE. Its objectives were to support the development of OU students' French oral skills, and the professionalisation of AMU students, by developing their pedagogical and digital skills. Qualitative and quantitative data collected showed a high level of participants' interaction and collaboration, and positive feedback highlighting an increase in motivation and confidence to speak French (OU students) and a valued experience in developing professional ethos, and digital teaching skills (AMU students).
\end{abstract}

Keywords: virtual exchange, internationalisation at home, professionalisation.

\section{Introduction}

This VE linked 67 language undergraduates from the OU with 25 postgraduate students from AMU training to become specialists of French as a foreign language as part of their master's degree in language learning and teaching pedagogies.

\footnotetext{
1. The Open University, Milton Keynes, United Kingdom; xaviere.hassan@open.ac.uk; https://orcid.org/0000-0002-0026-8758 2. The Open University, Milton Keynes, United Kingdom; annie.eardley@open.ac.uk

3. Aix-Marseille Université, Aix-en-Provence, France; christelle.combe@univ-amu.fr; https://orcid.org/0000-0002-4841-9463

How to cite this article: Hassan, X., Eardley, A., \& Combe, C. (2021). Internationalisation at home through virtual exchange: an encounter between distance language learners and trainee language teachers. In N. Zoghlami, C. Brudermann, C. Sarré, M. Grosbois, L. Bradley, \& S. Thouësny (Eds), CALL and professionalisation: short papers from EUROCALL 2021 (pp. 112-118). Research-publishing.net. https://doi.org/10.14705/rpnet.2021.54.1318
} 
At the OU, the BA in modern languages integrates international and intercultural dimensions into its formal and informal curriculum, with an academic content covering a wide range of resources and viewpoints from the French, Spanish, or German speaking worlds, as well as a compulsory one-week RS taking place in the relevant countries. A six-week online alternative is available for students who cannot travel. This forms part of an internationalisation at home strategy, as defined by Beelen and Jones (2015).

During the pandemic, the traditional week abroad was replaced with an online, intensive ALE. This six-day programme included a VE that recreated the learning experiences and intercultural encounters of the face-to-face RS version.

Besides fostering VE key competences such as "digital competence (the ability to communicate and collaborate effectively online), foreign language competence, communication skills, media literacy and the ability to work in a diverse cultural context (Jager et al., 2019, p. 7), our objectives were to help OU students develop their French oral skills while working in pairs or small groups, and AMU students their language teaching and digital skills through tutoring actual undergraduates.

The overall ALE included tutorials led by OU tutors, student-led synchronous and asynchronous collaborative sessions, periods of independent learning, and the VE during which OU students were in groups of three to four to maximise speaking opportunities. Most afternoons were dedicated to preparing a collaborative project. This consisted of producing, by the end of the ALE, a PowerPoint and group oral presentation focusing on a specific aspect of Aix-en-Provence (e.g. its cultural life, environmental issues, local politics, or social issues). For OU students, this project, based on personal research, collaborative work, and VE participation, is a necessary output to 'pass' the ALE, which is a compulsory element of their qualification.

For AMU students, the VE tasks included the preparation of a self-presentation video, a 45-minute tutorial - delivered to two different groups - and a participation in a 30-minute online conversation led by OU students that would feed into their group oral presentation. These VE tasks conclude a module on Online Language Tutoring and contribute to developing the AMU students' techno-semiopedagogical competence as defined by Guichon (2012). Taking part in this VE then feeds into their compulsory end-of-module assignment, which is a reflective evaluation based on their experiences as online tutors. 


\section{Method}

Relevant briefing documents were distributed to all participants, ahead of the VE. A training phase followed, during which AMU students learnt to use the OU platform. Pedagogical questions related to the specific needs of mature distance language learners, including accessibility, were also addressed.

A Moodle-based infrastructure was built for the ALE and the VE to store texts, audio, and videos, and support asynchronous and synchronous communication, independent as well as collaborative work, and tutor-led as well as student-led sessions, with two types of online rooms - standard and advanced - to allow different levels of rights and affordances to different categories of participants (Figure 1).

Figure 1. VLE infrastructure

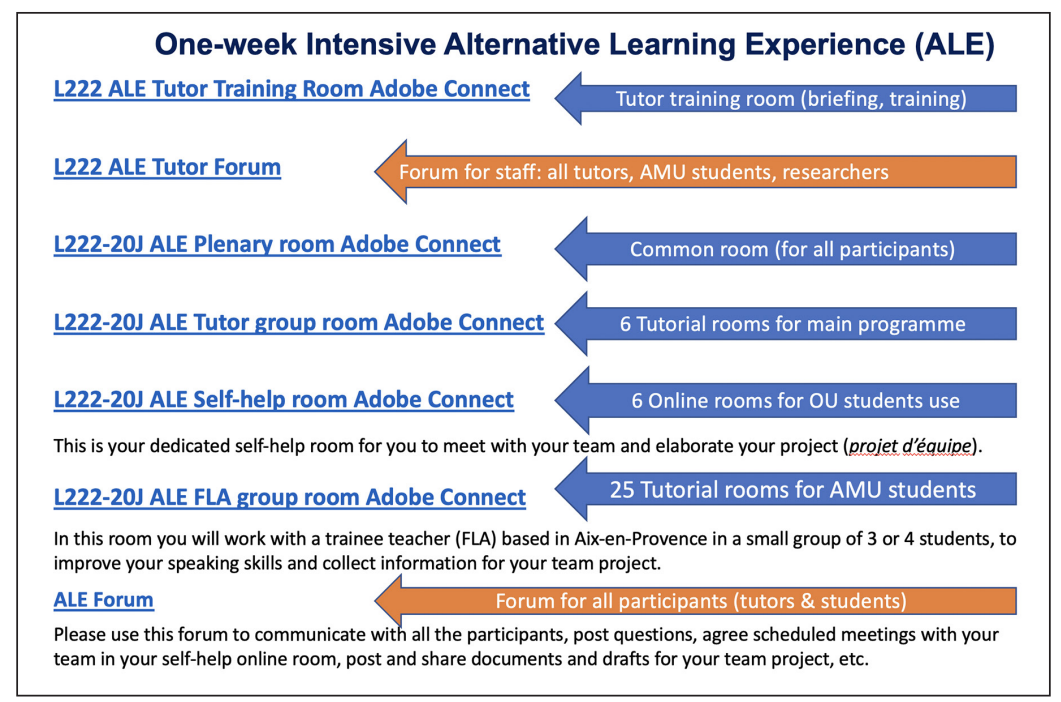

The VE was then carried out over two afternoons for its synchronous part and until the end of the week for the asynchronous part (forum). AMU students were advised not to prepare an action-oriented educational scenario, but to focus instead on activities that encourage oral production, aiming at B1-B2 level, using authentic, newsworthy documents related to one of the topics studied by OU students during the year.

Feedback was collected at the end of the programme using an evaluation questionnaire for OU students, and a reflexive evaluation for AMU students; 59 out of 67 OU 
students returned the questionnaire and 25 out of 27 AMU students submitted their reflective evaluations. Interaction on the student forum, OU students' output, and video recordings of the VE sessions provided further informal feedback.

\section{Results and discussion}

Overall, the evaluations received were positive (Figure 2). Most OU students enjoyed the opportunity to speak with students based in France, as in a reallife situation, even if they found exchanging with native speakers sometimes challenging, while $86 \%$ of OU respondents $(n=59)$ said they very much enjoyed the programme, one of the students describing it as an "almost perfect replacement" (to the RS).

Figure 2. OU students' responses from the evaluation questionnaire $(n=59)$

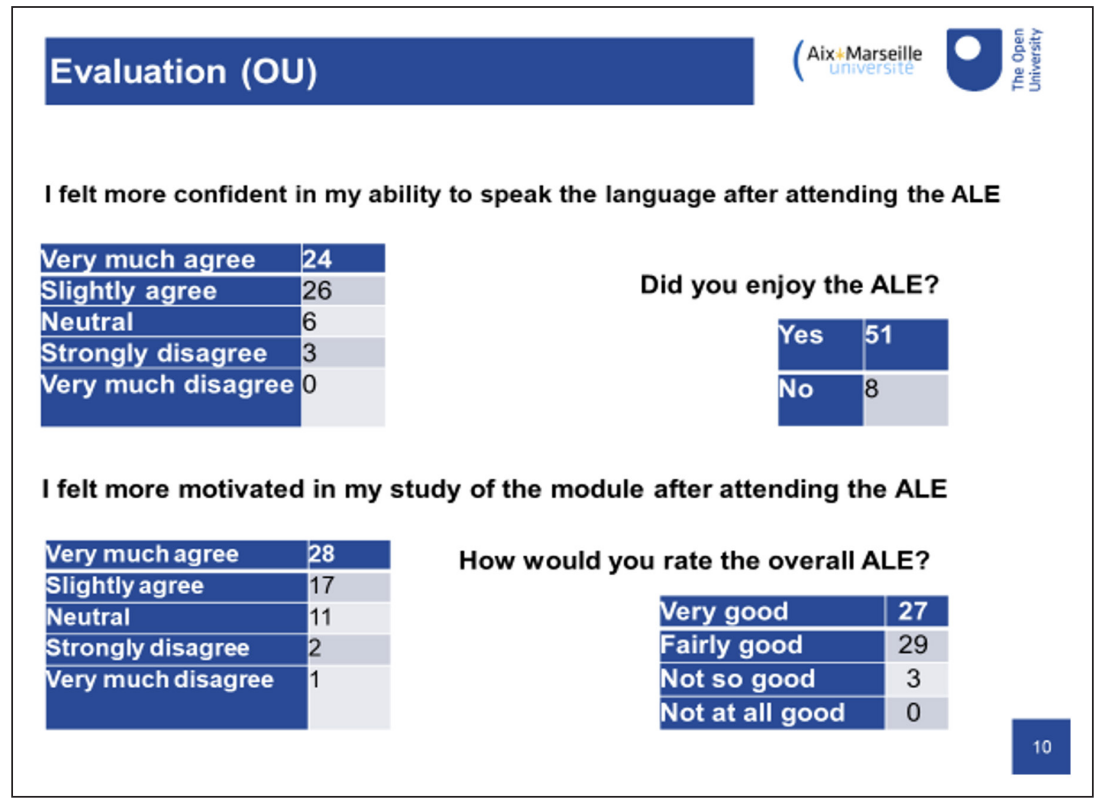

Qualitative feedback complemented statistical data, with OU students commenting favourably about the VE and its positive impact on their learning. The VE boosted their confidence and motivation, as illustrated in these quotes:

"The opportunity to speak to the language assistants [AMU] really boosted my confidence: I used what I had and successfully conveyed my ideas/ 
input to a native speaker and to then have that understood and reciprocated was very validating and satisfying".

"The key activities in my opinion that helped me improve my speaking of French were the two meetings with the French assistants [AMU] and the group session preparing presentations".

"The conversations with the Aixois language assistants were very useful".

The feedback revealed that participating in the collaborative project and the VE were deemed the most successful activities in terms of gaining confidence in speaking French (Figure 3).

Figure 3. Activities that helped students gain confidence in speaking French $(n=59)$

\begin{tabular}{|l|l|}
\hline Gaining confidence in Speaking French & (Aix-Marseille \\
\hline Which activity/activities helped you most to gain confidence in speaking French? & 28 \\
\hline Collaborative project & 21 \\
\hline Les Aixois (Virtual Exchange) & 16 \\
\hline OU Tutorials (debates) & 8 \\
\hline Break out rooms (smaller groups) & 6 \\
\hline ALE materials (printed texts) & 6 \\
\hline All activities & 4 \\
\hline Grammar & 1 \\
\hline Building lasting support network with peers & 1 \\
\hline None & \\
\hline
\end{tabular}

For AMU students, the VE experience was valuable in terms of gaining professional training, developing their professional ethos, and understanding the importance of planning a tutorial to respond to students' specific needs.

"I see the experience with the OU as a series of attempts that have served me to target my tutoring ethos". 
"The second session was very different, not only thanks to a new structure (which made me much more comfortable) but also because the two new learners were much more curious and much more talkative. From there, we can already conclude that the choice of documents and the course will only be better, by really knowing my audience".

Also mentioned was the impact of using a webcam on self-consciousness when teaching online.

"Having to do this session via videoconference was stressful, as I saw myself on the screen. It made me more aware of how I can feel. After a while, I managed to forget my screen because both learners were listening and responding to me, and I was able to conduct my session properly. We even finished early and were able to take advantage of having more time to discuss other things: tourism, architecture, gastronomy, among others".

Other feedback revealed a mismatch in the brief given to the participants: OU students were told the conversation with AMU students would focus on life in Aixen-Provence while AMU students were expecting to share personal interests and passions in life. This created some misunderstanding during the VE. The pandemic led to a further complication as some AMU students, confined at home - often in a different city or region - did not know Aix-en-Provence!

\section{Conclusions}

The analysis briefly presented here revealed that OU students very much valued the VE and intercultural encounters with AMU students; most reported an increased level of motivation and confidence when communicating in French. The OU students' group oral presentations produced solely online were of a higher quality than those produced during face-to-face RS. Judging from the feedback, the VE played a significant role in this success.

AMU students reported that this experience helped them develop their professional ethos, increase their confidence in using a variety of online conferencing platforms, tools, and affordances, and become more aware of their target audience, including accessibility needs.

The VE, mirroring the contacts that usually take place in the face-to-face RS, proved to be a welcome addition to the online ALE. It allowed authentic, valuable 
interaction and intercultural encounters. It will now serve as a blueprint for other OU language modules and will be repeated in future years. It will remain a valid option once face-to-face RS programmes resume.

\section{References}

Beelen J., \& Jones E. (2015) Redefining internationalization at home. In A. Curaj, L. Matei, R. Pricopie, J. Salmi, \& P. Scott (Eds), The European higher education area. Springer. https:// doi.org/10.1007/978-3-319-20877-0_5

Guichon N. (2012). Vers l'intégration des TIC dans l'enseignement des langues. Didier.

Jager, S., Nissen, E., Helm, F., Baroni, A., \& Rousset, I. (2019). Virtual exchange as innovative practice across Europe: awareness and use in higher education. EVOLVE Project Baseline Study. 


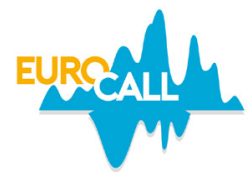

\title{
Student evaluation of teachers' pedagogical skills during the first COVID-19 period
}

\author{
Çiler Hatipoğlu ${ }^{1}$, Elżbieta Gajek ${ }^{2}$, Lina Milosewska³ \\ and Nihada Delibegović Džanić ${ }^{4}$
}

\begin{abstract}
With the COVID-19 outbreak at the beginning of 2020, many language teachers worldwide who were successfully implementing face-to-face teaching had to abruptly switch to online education, which was not something they were trained for or had experience with. Were they successful? The present study asked students from Turkey (TUR), Poland (POL), the Republic of North Macedonia (RNM), and Bosnia and Herzegovina $(\mathrm{B} \& \mathrm{H})$ to evaluate their teachers' professional adaptation and success during the first emergency online teaching semester. The results of the study showed that there were important similarities in the ways students in the examined four countries approached and evaluated the level of professionalism of their teachers in the first COVID-19 period regarding their teachers' computer literacy, online teaching skills, creation of materials appropriate for online teaching.
\end{abstract}

Keywords: online teaching, teacher computer skills, COVID-19, student evaluations.

\section{Introduction}

With the COVID-19 outbreak at the beginning of 2020, many Language Teachers (LT) around the world who were successfully implementing face-to-face teaching had to abruptly switch to online education, which was not something that many were trained for or had experience with. Some of the technology standards for LT (Healey et al., 2011) and the Technological Pedagogical Content Knowledge

\footnotetext{
1. Middle East Technical University, Ankara, Turkey; ciler@metu.edu.tr; https://orcid.org/0000-0002-7171-1673

2. University of Warsaw, Warsaw, Poland; e.gajek@uw.edu.pl; https://orcid.org/0000-0003-2971-8334

3. University of Information Science and Technology "St. Paul the Apostle", Ohrid, Republic of North Macedonia; lina. miloshevska@uist.edu.mk; https://orcid.org/0000-0003-3856-5448

4. University of Tuzla, Tuzla, Bosnia and Herzegovina; nihada.delibegovic@untz.ba; https://orcid.org/0000-0002-8241-6338

How to cite this article: Hatipoğlu, Ç., Gajek, E., Milosewska, L., \& Delibegović Džanić, N. (2021). Student evaluation of teachers' pedagogical skills during the first COVID-19 period. In N. Zoghlami, C. Brudermann, C. Sarré, M. Grosbois, L. Bradley, \& S. Thouësny (Eds), CALL and professionalisation: short papers from EUROCALL 2021 (pp. 119-125). Researchpublishing.net. https://doi.org/10.14705/rpnet.2021.54.1319
} 
(Mishra \& Koehler, 2006) had been established, but LT varied in their stages of technology adoption. Their awareness, confidence, learning, creative application, and adaptation to new contexts differed (Knezek \& Christensen, 2008). However, because of COVID-19, LT had to change their teaching methods, materials, and classroom interactions within weeks.

Were LT successful in adapting to the online teaching environment? Answering this question is crucial since the new developments in the organisation of education triggered the need to rethink the teaching profession in terms of competencies, means of instruction, and strategies for coping with processes that affect teaching.

Aiming to contribute to this strand of research and following studies (Rafiee \& Abbasian-Naghneh, 2019) showing that LT, students, and infrastructure are all essential for the successful use of online tools, the present study aims to uncover how students evaluate their teachers' professional adaptation during the emergency COVID-19 period. The specific research question we aim to answer is: how do university/high school students evaluate the pedagogical skills of their teachers during the first COVID-19 period?

\section{Method}

\subsection{Data collection}

The data were collected in TUR, POL, RNM, and B\&H using questionnaires in English specifically developed for this study and comprising two parts. 'Part A: Background' included questions eliciting information about the students (e.g. age, gender), while 'Section B: Evaluation' had four Likert scale questions (19 items) aiming to uncover students' assessments of their instructors' computer literacy, teaching, roles, and interaction skills during the emergency COVID-19 period. Students' questionnaire submissions were anonymous, and they were given specific definitions of teacher roles and criteria to evaluate their teachers' online teaching skills (see the lists in Q3 and Q4).

\subsection{Data analysis}

Responses to the questionnaires were analysed both quantitatively and qualitatively, keeping in mind country and context-specific peculiarities. 


\subsection{Participants}

A total of 216 (87 M, $128 \mathrm{~F}$, one not given) high school/university students aged 16-22 participated in this study. There were 75 (34.7\%) TUR, 23 (10.6\%) POL, 49 (22.7\%) RNM and 69 (31.9\%) B\&H participants.

\section{Results and discussion}

\subsection{Q1. How do you evaluate your teachers' computer literacy?}

Question 1 related results show that, despite some numerical differences, students in the examined countries evaluated their teachers' computer literacy similarly. Only a few participants stated that their teachers' literacy was 'beginner', while most of them ticked either 'intermediate' (55.1\%) or 'advanced' (36.1\%) (Figure 1). This is an interesting finding because regardless of LT's background and/or previous knowledge, they were evaluated as proficient users of the new technology required for the successful delivery of online classes by their students.

Figure 1. How do you evaluate your teachers' computer literacy?

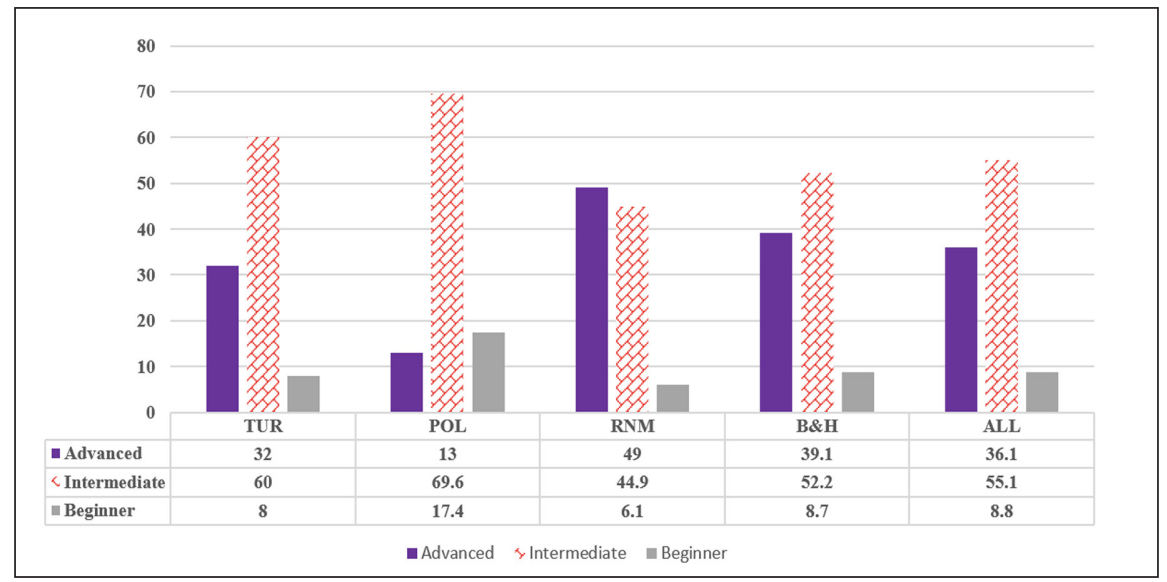

\subsection{Q2. How do you rate your teachers' online teaching skills?}

When students were asked to evaluate the online teaching skills of their teachers, $66.6 \%$ of them chose 'good' or 'very good', and $14.4 \%$ selected 'excellent' 
(Figure 2 ). The high percentage (81\%) of the positive students' evaluations can be related to the results of Question 1. It could be argued that LT were successful in online teaching because they had good computer literacy skills and applied them while teaching online.

Figure 2. How do you rate your teachers' online teaching skills?

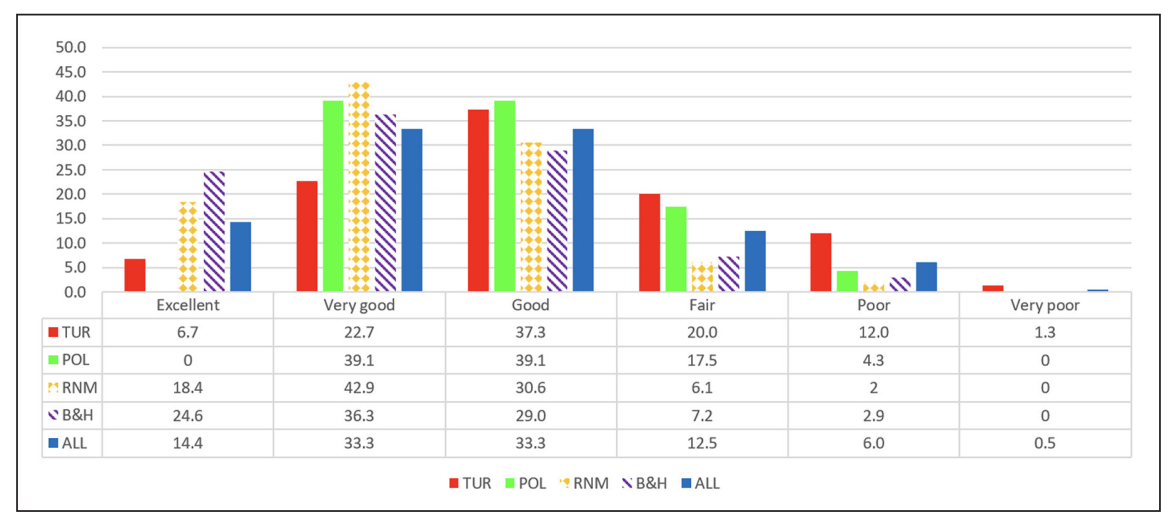

\subsection{Q3: How would you rate your teachers' roles when you compare face-to-face teaching with online teaching?}

Question 3 asked participants to rate the roles LT played during the first online period and indicate the extent to which these roles differed from in-class teaching. Students were given ten categories and asked to rate the roles on a scale of one (completely different) to four (exactly the same).

The list below shows that students, who have been provided with the specific definitions of ten teacher roles, predominantly believed that the teachers' roles in online teaching were either somewhat the same or exactly the same as the ones in face-to-face teaching.

- A role model in the use of digital tools for learning $=62 \%$.

- Adviser $=79.2 \%$.

- $\quad$ Assessor $=77.7 \%$.

- Facilitator $=73.1 \%$.

- Feedback provider $=75.5 \%$.

- Manager of class $=64.4 \%$.

- Material provider $=83.4 \%$.

- Motivator $=58.3 \%$. 
- Organiser of learning $=69.9 \%$.

- Supporter $=72.3 \%$.

These results might lead to the conclusion that teachers successfully played the roles they typically perform in class in the new teaching environment despite the abrupt shift and lack of preparation. The findings support a study conducted by UNICEF (2021) in RNM, which showed that $68 \%$ of the students rated positively the support they received from their teachers during the online period.

\subsection{Q4: How would you evaluate your teachers' work during this online teaching period?}

Question 4 was a Likert scale item with seven statements asking students to assess their teachers' performance from one (strongly disagree) to five (strongly agree). The list below shows that all criteria were evaluated with 'agree' or 'strongly agree' by at least $53.7 \%$ of the students. The instructors (are):

- competent in online teaching (agree and strongly agree $=58.8 \%$ );

- easy to reach $(\mathrm{A} \& \mathrm{SA}=63.9 \%)$;

- effective in dealing with potential content difficulties (A\&SA=57.8\%);

- encourage student participation during online classes (A\&SA=55.6\%);

- regularly hold synchronous classes (A\&SA=53.7\%);

- regularly send the necessary materials (A\&SA=82.9\%); and

- effectively use digital tools to support learning ( $A \& S A=63 \%)$.

The high positive evaluation of the 'regularly send the necessary materials' criterion demonstrates that LT tried to compensate for the lack of face-to-face contact by regularly sending students study materials. Also, $63.9 \%$ and $63 \%$ of the students stated that their teachers were easy to reach and used the available digital tools to support students' learning. These results parallel the findings of two reports published by the Council of Higher Education (YÖK, 2020, 2021) in TUR and by Rahić et al. (2021) in B\&H. The reported students' reactions to the ad hoc online teaching and testing during the first COVID-19 period in these documents were also mainly positive. Students pointed that their teachers rapidly accommodated/ integrated into the new distance education system, and it was easier to reach them and the course materials.

Student evaluations related to the remaining four criteria were still positive but varied between $53.7 \%$ and $58.8 \%$. The lower positive evaluations for the 'competence in online teaching', 'effectively dealing with potential content difficulties', 
'encouraging student participation during online classes', and 'regularly holding synchronous classes' criteria show that holding regular synchronous classes and handling content difficulties or encouraging students to participate during online teaching were more challenging topics for the LT in the examined countries.

\section{Conclusions}

The study results show important similarities in how LT in TUR, POL, RNM, and $\mathrm{B} \& \mathrm{H}$ are perceived and evaluated by their students.

Differently from some other studies (cf. Miloshevska et al., 2020) arguing that online teaching was overwhelmed with different problems, our findings show that:

- students' evaluations of LT's computer literacy and online teaching skills mainly were positive in the examined countries;

- teacher roles mostly remained the same as in the face-to-face teaching environment; and

- despite the hardships of the COVID-19 crisis, LT tried to support their students' learning by being easy to reach and regularly prepared good quality materials that they shared with their students.

In contrast, according to their students, holding regular synchronous classes, managing content difficulties, or encouraging student participation during online teaching were topics that LT were less successful with in the examined countries.

Despite the rigour with which the data collection and analysis procedures were carried out, the results of the current study cannot be generalised as data were collected from only a limited number of students in our four countries. Studies with other groups of students might lead to different results. Also, for a more complete picture of the difficulties faced by LT during the first COVID-19 period, data from the LT should be added and analysed.

\section{References}

Healey, D., Hanson-Smith, E., Hubbard, P., Ioannou-Georgiou, S., Kessler, G., \& Ware, P. (2011). TESOL technology standards: description, implementation, integration. TESOL. 
Knezek, G., \& Christensen, R. (2008). The importance of information technology attitudes and competencies in primary and secondary education. In J. Voogt \& G. Knezek (Eds), International handbook of information technology in primary and secondary education (pp. 321-331). Springer. https://doi.org/10.1007/978-0-387-73315-9_19

Miloshevska L., Gajek E., Delibegović Džanić N., \& Hatipoğlu Ç. (2020). Emergency online learning during the first Covid-19 period: students' perspectives from Bosnia and Herzegovina, North Macedonia, Poland and Turkey. Explorations in English Language and Linguistics, 8(2), 110-143. https://doi.org/10.2478/exell-2021-0002

Mishra, P., \& Koehler, M. J. (2006). Technological pedagogical content knowledge: a framework for teacher knowledge. Teachers College Record, 108(6), 1017-1054.

Rafiee, M., \& Abbasian-Naghneh, S. (2019). E-learning: development of a model to assess the acceptance and readiness of technology among language learners. Computer Assisted Language Learning, 34(5-6), 730-750. https://doi.org/10.1080/09588221.2019.1640255

Rahić, O., Sirbubalo, M., Tucak, A., Hadžiabdić, J., Elezović, A., \& Vranić, E. (2021). COVID-19 challenges in organising teaching at a faculty of pharmacy. BMJ Simulation and Technology Enhanced Learning, 7(6). https://doi.org/10.1136/bmjstel-2021-000896

UNICEF. (2021). Experiences and attitudes about distance learning. https://www.unicef.org/ northmacedonia/mk/media/6886/file

YÖK. (2020 May 3). YÖK üniversitelerimizdeki uzaktan öğretimin bir aylık fotoğrafinı çekti. https://www.yok.gov.tr/Sayfalar/Haberler/2020/uzaktan-egitime-yonelik-degerlendirme.aspx

YÖK. (2021). Pandemi sürecinde online ĕgitimin verimliliğine ilişkin öğrenci anket raporu. https://www.yok.gov.tr/HaberBelgeleri/Haber\%20\%C4\%B0\%C3\%A7erisindeki\%20 Belgeler/Dosyalar/2021/ogrenci-anket-sonuclari.pdf 


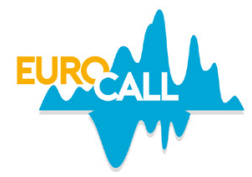

\title{
Can online translators and their speech capabilities help English learners improve their pronunciation?
}

\author{
Yue $\mathrm{He}^{1}$ and Walcir Cardoso ${ }^{2}$
}

\begin{abstract}
This study investigated whether a translation tool (Microsoft Translator - MT) and its built-in speech features (Text-To-Speech synthesis - TTS - and speech recognition) can promote learners' acquisition in pronunciation of English regular past tense -ed in a self-directed manner. Following a pretest/posttest design, we compared 29 participants' performances of past -ed allomorphy (/t/, /d/, and /id/) by assessing their pronunciation in terms of phonological awareness, phonemic discrimination, and oral production. The findings highlight the affordances of MT regarding its pedagogical use for helping English as a Foreign Language (EFL) learners improve their pronunciation.
\end{abstract}

Keywords: translation tools, EFL, pronunciation learning, SDL.

\section{Introduction}

The literature reports a number of limitations that affect the teaching and learning of foreign languages, including insufficient time for students to practice (Life, 2011), which may negatively affect language teaching (Wahid \& Sulong, 2013). To mitigate these limitations, one 'solution' is to encourage students to practice at their own time and pace (e.g. via Self-Directed Learning - SDL), outside the classroom. Studies have shown that technology-enriched environments are beneficial for the development of SDL behaviors (Mishra, Fahnoe, \& Henriksen, 2013). Two speech technologies, TTS and Automatic Speech Recognition (ASR), have proved to positively impact L2 learning. Via TTS, learners have access to unlimited and varied input, which can raise their phonological awareness and aural perception (Liakin, Cardoso, \& Liakina, 2017). Similarly, ASR can increase

1. Concordia University, CSLP, Montreal, Canada; yuehe.ca@gmail.com

2. Concordia University, CSLP, Montreal, Canada; walcir.cardoso@concordia.ca; https://orcid.org/0000-0001-6376-185X

How to cite this article: He, Y., \& Cardoso, W. (2021). Can online translators and their speech capabilities help English learners improve their pronunciation? In N. Zoghlami, C. Brudermann, C. Sarré, M. Grosbois, L. Bradley, \& S. Thouësny (Eds), CALL and professionalisation: short papers from EUROCALL 2021 (pp. 126-131). Research-publishing.net. https://doi.org/10.14705/ rpnet.2021.54.1320 
students' self-efficacy and provide them with instant feedback, thus facilitating their pronunciation development (Celce-Murcia, Brinton, Goodwin, \& Griner, 2010). So far, only a handful of studies have combined ASR and TTS into a single tool to explore their effectiveness in fostering L2 learning (e.g. Van Lieshout \& Cardoso, in press). Online translators, which have high levels of accessibility and availability, are tools that combine both technologies (see Figure 1). In our study, MT was adopted.

This study explores the affordances of these MT's speech capabilities for the development of English past -ed morphophonemics (/d/,/Id/,/t/as in play/d/, visit/Id/ and walk/t/ respectively). It adopts Celce-Murcia et al.'s (2010) recommendations for pronunciation instruction (which also reflects its acquisition), starting with the development of phonological/sound awareness (Stage 1), proceeding to phonemic discrimination (Stage 2), and culminating with production (controlled, guided, and communicative - Stages 3, 4, and 5 respectively). Due to the short duration of our study (two hours of SDL), we examined the development of past -ed pronunciation for the initial three stages only.

The study was guided by the following research questions: (1) can EFL learners acquire aspects of past -ed morphophonemics using MT's TTS and ASR capabilities in an SDL manner (without direct guidance from an instructor), and (2) if yes, which of the three stages of pronunciation development is affected by the proposed instruction: phonological awareness, phonemic discrimination, and/ or oral production?

Figure 1. MT: interface and features

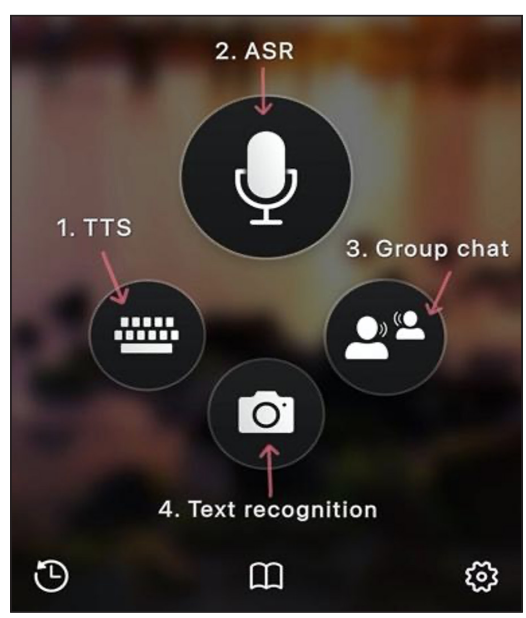




\section{Method}

Twenty-nine Chinese-speaking participants were recruited via convenient sampling (15 females and 14 males aged 16-18, intermediate English proficiency) at a secondary school in China. The study followed a pretest-posttest design. Participants first completed a background questionnaire, followed by the pretest, which included an assessment of their knowledge of English past -ed in terms of phonological awareness, phonemic discrimination, and oral production (as discussed earlier). After the 1-hour SDL treatment (conceptualized as a homework assignment), the posttest was conducted (a slightly modified version of the pretest). Finally, 15 participants were randomly invited to participate in an exit interview session. Figure 2 below illustrates a visual summary of the study design and procedures.

Figure 2. Research design and procedures

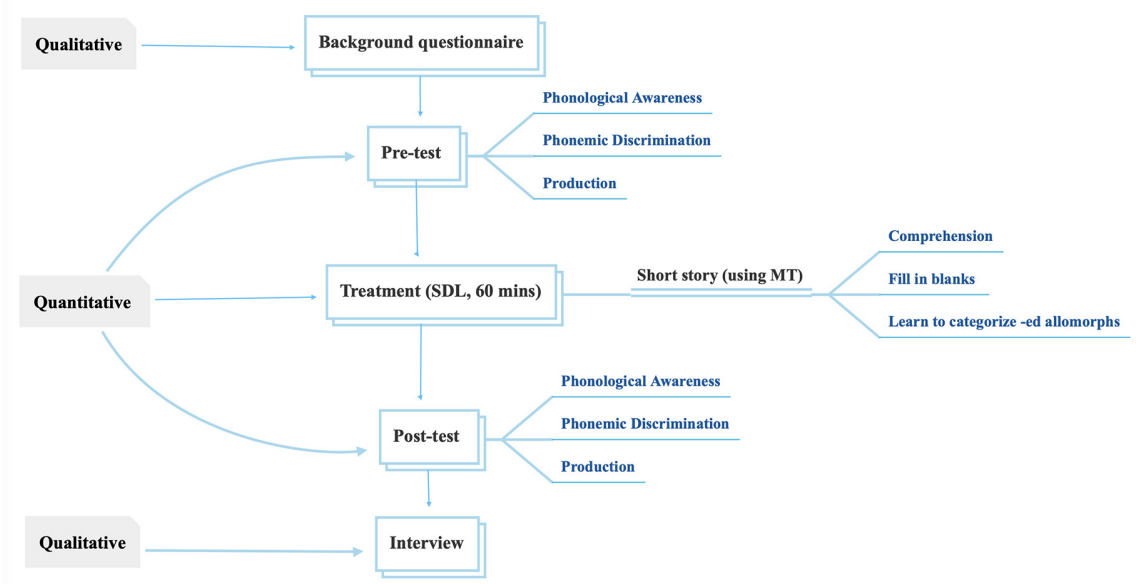

Pre and posttest were collected assuming the first three stages of Celce-Murcia et al.'s (2010) recommendation for pronunciation development (two tests for each stage): (1) phonological awareness (survey questions about the participants' phonological knowledge and an ABX test); (2) phonemic discrimination (the first task evaluated participants' ability to identify past versus non-past forms, while the second assessed their ability to discriminate among the three allomorphs); and (3) oral production (read-aloud task for controlled production and role-playing for spontaneous speech).

For the one-hour treatment, which was designed to emulate a homework assignment, participants were asked to install MT on their mobile devices (Android 
or iOS). The learning materials were two English short stories, each including target past tense -ed words, with the number of each allomorph evenly distributed. All participants completed four activities for each story: (1) story comprehension; (2) listening to stories in TTS and filling in the blanks with the verbs they heard; (3) categorizing sets of -ed forms on how they sounded; and (4) speaking to the ASR for feedback (via the orthographic output).

\section{Results and discussion}

Due to space limitations, only the final stage of the statistical analysis is reported, without the effects of individual allomorphs. Table 1 summarizes the main findings observed (Standard Deviations - SDs - are only provided in the report when relevant).

For the first phonological awareness test (survey), observe that the number of participants who were rated as Partially Aware (PA) decreased (from 72\% to $20.69 \%$ ) while the number of Fully Aware (FA) increased (from $17.24 \%$ to $79.31 \%$ ), indicating that the participants' phonological knowledge of past -ed pronunciation improved during the treatment. For the second phonological awareness test $(\mathrm{ABX})$, t-test results show that the participants' overall phonological awareness significantly improved from pretest $(M=0.733, S D=0.152)$ to posttest $(M=0.782, S D=0.151), t(28)=-2.131, p=0.042<0.05$.

Regarding the first phonemic discrimination test (past or non-past), we did not observe any significant improvements on the participants' ability to discriminate past from non-past constructions at the end of the experiment: $M=0.705$, $S D=0.118$ on the pretest, and $M=0.703, S D=0.128$ on the posttest, $t(28)=0.117$, $p=0.908>0.05$. Interestingly, for the second phonemic discrimination test $(/ \mathrm{t} /, / \mathrm{d} /$, /id/ discrimination), the participants' ability to aurally discriminate among / $/$, $/ \mathrm{d} /$, and $/ \mathrm{id} /$ significantly improved from pretest $(M=0.427, S D=0.153)$ to posttest $(M=0.474, S D=0.162), t(28)=-2.238, p=0.033<0.05$.

Finally, for oral production, significant improvements were observed in the participants' performance in -ed pronunciation in the two tests, $t(28)=-5.143$, $p=1.87493 \mathrm{E}-05<0.05$ for read aloud, and $t(28)=-5.925, p=0.000002<0.05$ for role play.

Our results indicate that the participants significantly benefited from the proposed self-directed MT-based pedagogical treatment, thus corroborating the only previous 
research available on the use of another translation tool with embedded speech capabilities (Google Translate; see Van Lieshout \& Cardoso, in press). Although no significant improvements were observed in one of the listening discrimination tests (past versus non-past), their ability to identify individual -ed allomorphs significantly improved during the treatment, especially for allomorph / $/$ / (not illustrated in the statistical results). We can thus conclude that the pedagogical use of MT and its embedded TTS and ASR features can help learners acquire (at least aspects of) the target pronunciation feature, in at least three stages of L2 pronunciation development.

Table 1. Mean and t-test results

\begin{tabular}{|l|l|l|l|l|l|l|}
\hline & & & Pretest & Posttest & \\
\hline & & & $\%$ & & $\%$ & P value \\
\hline \multirow{2}{*}{$\begin{array}{l}\text { Phonological } \\
\text { awareness }\end{array}$} & 1. Survey & PA & 72.41 & 20.69 & $* *$ N/A \\
\cline { 2 - 6 } & FA & 17.24 & 79.31 & N/A \\
\cline { 2 - 6 } & 2. ABX & & 73.33 & 78.16 & $* 0.042$ \\
\hline \multirow{2}{*}{$\begin{array}{l}\text { Phonemic } \\
\text { discrimination }\end{array}$} & 1. Past or Non-Past & & 70.47 & 70.26 & 0.908 \\
\hline & 2./t/, /d/, /id/ discrimination & 42.67 & 47.41 & $* 0.033$ \\
\hline Oral production & 1. Read aloud & & 67.93 & 77.47 & $* 1.87493 \mathrm{E}-05$ \\
\cline { 2 - 6 } & 2. Role play & & 68.39 & 74.71 & $* 0.000$ \\
\hline
\end{tabular}

Note: all values are provided in percentages for ease of exposition (the number of target forms for each test is not uniform; for instance, while the read-aloud task had 30 items, the role-playing test consisted of 12 target words).

* The difference is statistically significant $(\mathrm{p} \leq 0.05)$

$* * \mathrm{~N} / \mathrm{A}=$ not applicable due to the nature of the computation

\section{Conclusions}

We conclude that participants were able to acquire aspects of past -ed morphophonemics (/t/, /d/, /id/) using MT's TTS and ASR on their own, as if completing a homework assignment. Additionally, three stages of pronunciation development (i.e. phonological awareness, phonemic discrimination, and oral production) were positively affected by the treatment, reflected in the participants' significant improvements. Despite the obvious limitations of this study, which should be addressed in future research (e.g. short treatment, focus on a single pronunciation feature, number of participants, lack of a control group), the main pedagogical implication is that instructors should encourage the self-directed use of online translators (e.g. DeepL Translator, Google Translate, MT) to extend the reach of the classroom (e.g. via technology-enhanced homework assignments) and thus alleviate some of the limitations that affect the EFL context, as discussed earlier. 


\section{References}

Celce-Murcia, M., Brinton, D., Goodwin, J., \& Griner, B. (2010). Teaching pronunciation: reference for teachers of English to speakers of other languages. Cambridge University Press.

Liakin, D., Cardoso, W., \& Liakina, N. (2017). The pedagogical use of mobile speech synthesis (TTS): focus on French liaison. Computer Assisted Language Learning, 30(3-4), 348-365. https://doi.org/10.1080/09588221.2017.1312463

Life, J. (2011). Motivation and EFL university students in North-East Asia. The Asian EFL Journal, 13(3), 11-41.

Mishra, P., Fahnoe, C., \& Henriksen, D. (2013). Creativity, self-directed learning and the architecture of technology rich environments. Techtrends, 57(1), 10-13. https://doi. org/10.1007/s11528-012-0623-Z

Van Lieshout, C., \& Cardoso, W. (in press). Google Translate as a tool for self-directed language learning. Language Learning \& Technology.

Wahid, R., \& Sulong, S. (2013). The gap between research and practice in the teaching of English pronunciation: insights from teachers' beliefs and practices. World Applied Sciences Journal, $21,133-142$. 


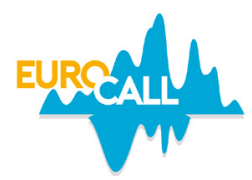

\title{
Participation, inclusion, and success in emergency remote online teaching and learning
}

\author{
Sandra Healy ${ }^{1}$
}

\begin{abstract}
Covid-19 affected educational institutions worldwide, and many moved online engaging in Emergency Remote Teaching and Learning (ERTL). It had a particular impact in Japan due to the low levels of computer usage in Japanese educational institutions and a reliance on traditional methods. This study uses semi-structured interviews with five participants to explore their perceptions of the move to online learning in a Japanese university context. Four factors emerged as significant: participants' experiences prior to entering university; the importance of Social Networking Systems (SNS) in the process of becoming part of the university academic community; changes in spoken interactional patterns; and changes in learning patterns. It was found that the disruption due to ERTL led to fresh ways to learn and promoted an inclusive environment.
\end{abstract}

Keywords: ERTL, disruptive technology, multimodal learning, inclusive learning.

\section{Introduction}

The emergence of the Covid-19 pandemic had an enormous impact on educational institutions worldwide. Many schools and universities moved their learning online suddenly and engaged in what is termed ERTL. It had a particular impact in Japan due to the low levels of computer usage in Japanese educational institutions and a reliance on traditional methods (Takashiro, 2018). The aim of this study is to understand the students' perceptions of the effects of this disruption on their learning.

1. Kyoto Institute of Technology, Kyoto, Japan; healy@kit.ac.jp; https://orcid.org/0000-0003-4387-259X

How to cite this article: Healy, S. (2021). Participation, inclusion, and success in emergency remote online teaching and learning. In N. Zoghlami, C. Brudermann, C. Sarré, M. Grosbois, L. Bradley, \& S. Thouësny (Eds), CALL and professionalisation: short papers from EUROCALL 2021 (pp. 132-136). Research-publishing.net. https://doi.org/10.14705/rpnet.2021.54.1321 


\section{Method}

The present study formed part of a larger research project exploring how the sudden move to online learning affected the students. Five participants took part in semistructured interviews in English on Zoom for between 45 minutes and two hours and 45 minutes. Both open and closed questions were used to explore participants' perceptions. There were three male and two female Japanese participants aged between 18 and 21. The audio recordings were uploaded to a transcription application, Otter.ai, and the resulting transcripts were then manually corrected. They were then read multiple times and coded using the SCAT method developed by Otani (2008) which consists of four steps: identifying noteworthy words or phrases from the text; paraphrasing them; establishing concepts that emerge from the text; and developing themes from the data.

\section{Results and discussion}

Four overarching themes emerged: the importance of the participants' experiences prior to entering university; the importance of SNS in the process of becoming part of the university academic community; changes in spoken interactional patterns due to moving online; and changes in learning patterns.

During the pandemic, Japanese high schools did not go online and students who matriculated directly from school reported adaptation issues due to a lack of community connections and change in learning style. In contrast, students who had had a year off before entering university to prepare for the university entrance examinations, common at prestigious universities in Japan, found it easier to adapt, and reported little change in their lifestyles, as Participant 4 noted, "Actually last year I was in [sic] home so nothing changed". Also, firstyear students who matriculated in September 2019, rather than the usual April 2020 in Japan, had already developed a community before embarking on ERTL and found the transition less problematic. Participant 1, for example, said, "I am lucky I met my friends and teachers and so feel comfortable even though it is hard".

Prior experience using Information and Communications Technology (ICT), both academically and socially, was also a key factor in students' ability to participate in their new online environment. Healy (2021) found that nearly all students had access to mobile technology; 98\% owned a smartphone, usually received in junior high school, and 94\% a laptop computer largely purchased on entering 
university, with only $19 \%$ owning desktop computers and $32 \%$ tablets. Three had extensive experience using computers at home as their families had owned and used computers since they were small children, while the other two participants had little prior experience. Four of the participants who attended Japanese schools also had almost no experience using ICT in academic contexts, saying the main way they used technology was to take photographs of the blackboard or handouts. In contrast, one student who had attended an international school in Japan had significant experience using ICT both socially and academically. All participants were active users of SNS, the most popular applications being LINE, followed by Twitter and Instagram (Healy, 2021). Prior to entering university, SNS was a way of connecting with friends and a method of entertainment. After entering university the students found that their use of applications changed. Before university the participants reported using Twitter to connect with their friends and follow the news, but after, it became a way of finding information about what was happening at the university, "Twitter is to collect information about classes. Before it was fun. I previous use Twitter to communicate with friends or I use them without thinking. But now I watch carefully to collect information and I don't tweet anymore [sic]" (Participant 2). Similarly, while in the past they had used LINE to communicate with friends and family, it was now also used by teachers to create online classrooms and study groups, and became a place where students interacted concerning their studies. This usage provided support for students while they were physically isolated from their peers, and all of the participants commented on how important it was for them. Participant 3 said, "I use SNS everyday to talk to my classmates and ask about homework. I can also ask my teacher questions on LINE. It is better than email". Japanese university students are often not familiar with email, but are very familiar with LINE. Using SNS can provide vital inclusion and support encouraging success in academic contexts. As a result, it is important that all students can access and use SNS and ICT equally.

The participants noted changes in the spoken interaction online compared to the traditional classroom. Due to the computer conversation lag, they found that turn-taking was impacted. Students experienced difficulty and were frustrated by frequently and unintentionally interrupting each other. However, they noted an interesting finding: increased participation from students in online classes compared to the face-to-face classroom. Japanese students have been characterized as silent in the classroom (Sasaki \& Ortlieb, 2017), but the participants reported a change in this tendency online: "Before the online, they are not eager to speak, you know speak first. But thanks to online they are encouraged to speak by themselves [sic]" (Participant 5). Another way that led 
to increased student participation was the use of the chat function in conjunction with spoken interaction. Students enjoyed the multimodality: "In some classes they have a chat while the professor is speaking. It is good for people to have another way to communicate" (Participant 4).

Along with changes in spoken interaction the participants noted changes in their learning patterns. They described a number of different kinds of online classes including Zoom discussions and presentations, videos with online assignments, and PDF files to be completed. The participants stated that they enjoyed the Zoom classes because they could interact with the other students and teachers. They also enjoyed the classes in which they watched videos and completed some assignments as these allowed the students to organize their time themselves, increasing their autonomy (Baru, Tenggara, \& Mataram, 2020). This also enabled them to work at their own pace, watching and re-watching the videos as needed. The participants' least preferred method of study was completing asynchronous PDF based assignments and uploading them to the university LMS due to a lack of interaction and feedback.

The changes in both educational and interactional patterns had a significant impact on all participants, but in particular, two of the participants found the move to online learning beneficial. Participant 1, who has dyslexia, stated that his grades improved as a result of having access to class materials in a variety of forms, especially videos that he could watch repeatedly while taking notes. This sentiment was echoed by all of the students. Participant 5, who has autism, also preferred working online as he likes to focus only on words, does not like to engage in eye contact or physical gestures, and prefers to work alone. Being online reduced the stress he feels during face-to-face social interactions although he questioned whether it was better in terms of second language acquisition. Multimodal forms of online interaction can provide affordances and opportunities enhancing educational opportunities for all (Guichon \& Cohen, 2016).

\section{Conclusions}

While ERTL is often viewed negatively, the disruption it caused may have provided a necessary push for institutions and teachers in Japan to move away from traditional instructional approaches leading to positive gains for many students, particularly neurodiverse students. This new environment provided fresh ways for our students to participate and succeed and should be harnessed positively for the future. 


\section{References}

Baru, M., Tenggara, W. N., \& Mataram, M. U. (2020). Promoting students' autonomy through online learning media in EFL class. International Journal of Higher Education, 9(4), 320-331.

Guichon, N., \& Cohen, C. (2016). Multimodality and CALL. In F. Farr \& L. Murray (Eds), The Routledge handbook of language learning and technology (pp. 509-521). Routledge.

Healy, S. (2021). COVID-19 pandemic-influenced changes to Japanese university student digital identity. In P. Clements, R. Derrah \& P. Ferguson (Eds), Communities of teachers and learners. JALT. https://doi.org/10.37546/JALTPCP2020-44

Otani T. (2008). "SCAT" a qualitative analysis method by four-step coding: easy startable and small scale data applicable process of theorization. Bulletin of the Graduate School of Education and Human Development (Educational Sciences), Nagoya University, 54(2), 27-44.

Sasaki, Y., \& Ortlieb, E. (2017). Investigating why Japanese students remain silent in Australian university classrooms: the influences of culture and identity. Journal of Asian Pacific Communication, 27(1), 85-98. https://doi.org/10.1075/japc.27.1.05sas

Takashiro, N. (2018). Technology use and middle school students' participation in shadow education in Japan. International Psychology Bulletin, 22(4), 14-21. 


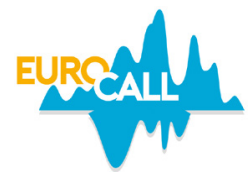

\title{
Immersive virtual reality versus webcam in an online language course
}

\author{
Borja Herrera ${ }^{1}$
}

\begin{abstract}
This paper investigates the differences between Immersive Virtual Reality (IVR) and the webcam (WBC) in the context of a Spanish distancelearning course. Two specific objectives were set: (1) to determine the existence of a relationship of dependence between the device used and the oral interaction, and (2) to analyse the existence of a dependency relationship between the device utilised and the perception of copresence. To that end, online courses and semi-structured interviews were conducted. Regarding the first objective, there is a higher chance of speaking exchanges between student-tutor and tutor-student when using WBC. As for the second objective, we did not have sufficient feedback to determine whether the perception of copresence varies depending on the two profiles. However, the analysis indicates that non-verbal communication was essential for IVR volunteers to experience copresence. The conclusions suggest that the IVR could be more appropriate than WBC for socio-constructivist and communicative teaching pedagogies $^{2}$.
\end{abstract}

Keywords: immersive virtual reality, CALL, CMC.

\section{Introduction}

\subsection{The interest of the research}

Three reasons led us to investigate IVR: first, the scarcity of studies in the field of language teaching at the time of this research. It has not been until recently that investigations have flourished (Jauregi Ondarra, Gruber, \& Canto, 2020; Melchor-

1. Complutense University of Madrid, Madrid, Spain; borja.herrera@gmail.com; https://orcid.org/0000-0003-4458-5357

2. Article based on a PhD research, for more detail visit: https://eprints.ucm.es/id/eprint/64682/

How to cite this article: Herrera, B. (2021). Immersive virtual reality versus webcam in an online language course. In N. Zoghlami, C. Brudermann, C. Sarré, M. Grosbois, L. Bradley, \& S. Thouësny (Eds), CALL and professionalisation: short papers from EUROCALL 2021 (pp. 137-142). Research-publishing.net. https://doi.org/10.14705/rpnet.2021.54.1322 
Couto \& Herrera, in press; Yang, Lo, Hsieh, \& Wu, 2020). The second reason was to explore its potential use as a Computer-Mediated Communication (CMC) device for distance courses. Finally, the drop in prices is favouring the use of this product, with models such as the Oculus Quest 2 that stands out from other devices (see supplementary materials).

\subsection{Aim and objectives}

The generic aim of our research was to analyse the performance of the IVR and WBC in the context of a distance Spanish course. In more detail, our specific objectives were the following: to determine if there was a dependency relationship between the technological device used and the oral interaction maintained during the communicative exchange; and to analyse the possible existence of a dependency relationship between the technological device used and the perception of copresence by the students.

\section{Method}

\subsection{Research design}

We designed an empirical study in which the two main aspects mentioned above were examined: oral interactions and perception of copresence, defined as "the sense of being together with others in a mediated - either remote or virtual environment" (Zhao, 2003, p. 445). To achieve the first objective, it was intended to verify in quantitative terms the sustained oral interaction between the educational actors of two groups of L2 learners of Spanish, differentiated according to the role of the communicator, tutor or student, as well as the devices used to maintain communication: Head Mounted Display (HMD) or WBC. As for the corpus of analysis, we took a sample of all sessions, consisting of five hours and 39 minutes for the WBC group and six hours and 25 minutes for the IVR group. Regarding the analysis, firstly, we transcribed the corpus from the recordings. Secondly, we added it to an Excel file, where it was divided into turns and labelled. Finally, we loaded all data to SPSS for statistical analysis.

Regarding the second specific objective, we intended to go in-depth, from a qualitative perspective, about how the perception of copresence could be related to the device employed. We considered that the use of WBC or the HMD could promote different ways of interacting with the environment and with the rest of 
the communicators, which could be reflected in the perception of copresence. To accomplish this objective, a content analysis of the semi-structured interviews ${ }^{3}$ was carried out, eight with volunteers belonging to the IVR profile and two to the WBC profile. As for the data process, we transcribed the interviews and loaded them to Atlas.ti 8, where a content analysis was realised.

\subsection{Participants}

We planned two profiles (IVR and WBC) depending on the device used. Each profile would have three groups with three members each, for a total of 18 volunteers plus an extra pilot group for the IVR profile. However, we had difficulties finding students for the WBC profile, and finally, we could only create one group formed by two members.

\subsection{Course design}

We designed an A1.1 Spanish online course with approximately 32 hours that followed the flipped methodology. The course was divided into two parts (Figure 1): the first one, an individual practice on a Moodle platform; and the second one, composed of interactive activities that took place in a virtual environment of synchronous communication - Facebook Spaces (IVR model) or Zoom, used in conjunction with PowerPoint (WBC model). It is important to note that each student participated from home with their device. In Figure 2 we can see an example of the lessons in both environments.

Figure 1. Course diagram

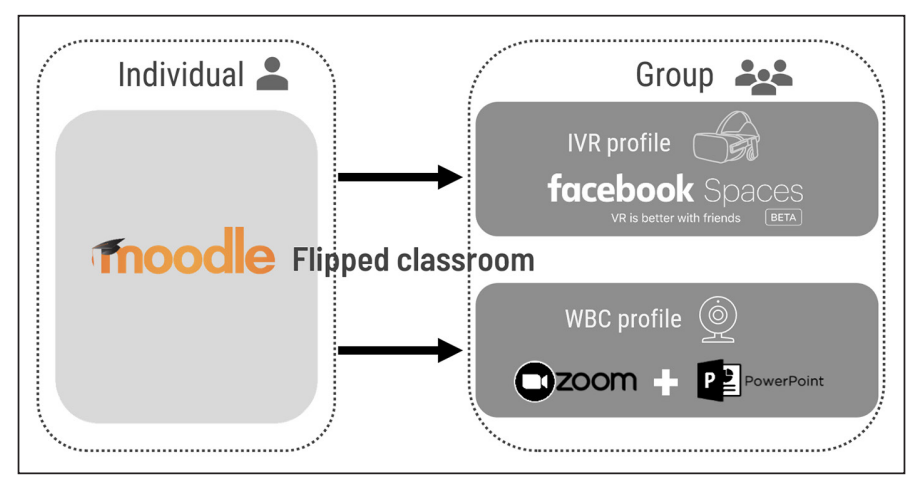

3. Script available at: https://www.iris-database.org/iris/app/home/detail?id=york:939552 
Figure 2. Grammar exercise with WBC and IVR groups

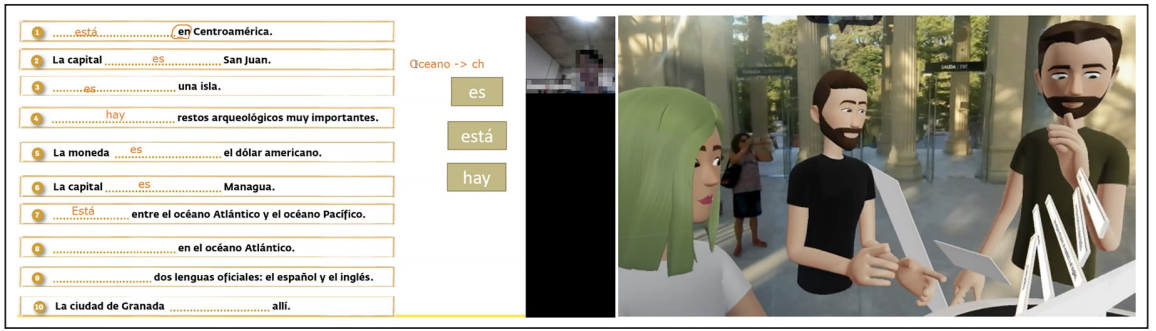

\section{Results and discussion}

\subsection{First specific objective}

An analysis of a contingency table was used (Table 1) for the verification of this objective.

Table 1. Contingency table speaker-listener*device

\begin{tabular}{|c|c|c|c|c|}
\hline & \multicolumn{2}{|l|}{ Device } & \multirow[t]{2}{*}{ Total } \\
\hline & & IVR & WBC & \\
\hline \multirow[t]{2}{*}{ Student-student } & Count & 413 & 194 & 607 \\
\hline & $\%$ within Device & $10.4 \%$ & $6.3 \%$ & $8.6 \%$ \\
\hline \multirow{2}{*}{$\begin{array}{l}\text { Student-class } \\
\text { (tutor+student) }\end{array}$} & Count & 466 & 198 & 664 \\
\hline & \% within Device & $11.7 \%$ & $6.4 \%$ & $9.4 \%$ \\
\hline \multirow[t]{2}{*}{ Student-tutor } & Count & 1,388 & 1,271 & 2,659 \\
\hline & $\%$ within Device & $34.8 \%$ & $41.0 \%$ & $37.5 \%$ \\
\hline \multirow[t]{2}{*}{ Tutor-student } & Count & 908 & 1,002 & 1,910 \\
\hline & $\%$ within Device & $22.8 \%$ & $32.3 \%$ & $27 . \%$ \\
\hline \multirow{2}{*}{$\begin{array}{l}\text { Tutor-class } \\
\text { (student+student) }\end{array}$} & Count & 808 & 436 & 1,244 \\
\hline & $\%$ within Device & $20.3 \%$ & $14.1 \%$ & $17.6 \%$ \\
\hline \multirow[t]{2}{*}{ Total } & Count & 3,983 & 3,101 & 7,084 \\
\hline & \% within Device & $100 \%$ & $100 \%$ & $100 \%$ \\
\hline
\end{tabular}

This table shows that the participants who used IVR as a medium have higher percentages in the categories 'student-student', 'student-class', and 'tutor-class'. On the other hand, the users who used the WBC show higher percentages in the categories 'student-tutor' and 'tutor-student'. This seems to indicate a greater tendency for bidirectional interactions to occur between the tutor and the student if the device used is WBC. On the other hand, in the case of using the IVR, the 
messages seem to be more group-oriented or more one-to-one, but between students. This interpretation of the percentages was corroborated by an analysis of the residual errors (Table 2).

Table 2. Corrected typified residuals speaker-listener*device

\begin{tabular}{|l|l|l|}
\hline \multirow{2}{*}{} & \multicolumn{2}{|l|}{ Device } \\
\cline { 2 - 3 } & IVR & WBC \\
\hline Student-student & 6.1 & -6.1 \\
\hline Student-class (tutor+student) & 7.6 & -7.6 \\
\hline Student-tutor & -5.3 & 5.3 \\
\hline Tutor-student & -9 & 9 \\
\hline Tutor-class (student+student) & 6.8 & -6.8 \\
\hline
\end{tabular}

Finally, we decided to check the strength of the relationship between the device and the communicative actors with Cramèr's V, which yielded a result of 0.169 . This value indicates an existing, although low, relationship. In conclusion, we can affirm that the device used is related to oral interactions. These results invite us to think that the interaction between communicators of the IVR environment is more natural, more similar to that which can be given in person, an interpretation that is based on our experience as tutors of the lessons.

\subsection{Second specific objective}

The lack of informants from the WBC profile has impeded our ability to verify whether the sense of copresence of this type of user was lower than those who used the IVR. However, we believe that some observations point in this direction, especially from the assessments of the 'experienced realism' dimension, which measures the subjective experience of realism in the virtual environment (Schuber, Friedmann, \& Regenbrecht, 2001). The information collected in the interviews with the IVR volunteers shows that the avatar in Facebook Spaces was able to transfer elements of non-verbal communication in a very satisfactory way, which allowed a more fluid and natural communication and, consequently, a high perception of copresence. This assessment could explain the results observed concerning the first specific objective.

\section{Conclusions}

With our first specific objective we have proved that using an HMD in an IVR environment encourages oral interactions between students in a more effective 
manner than WBC. As for our second specific objective, it was not possible to contrast it; nevertheless, we found two relevant observations:

- the students who used the HMD state that the main factor to have a copresence feeling is the capability to receive/transmit non-verbal elements; and

- the HMD seems to be more suitable, compared to a WBC, to receive/ transmit non-verbal elements. Therefore, the HMD could facilitate the oral exchange in a better way. This evaluation could explain the results obtained in the first objective.

If we go back to our main objective, these conclusions invite us to consider that the HMD is more suitable than WBC in the context of an online course where we want to promote oral interactions among participants.

\section{Supplementary materials}

\section{https://www.iris-database.org/iris/app/home/detail?id=york:939666}

\section{References}

Jauregi Ondarra, K., Gruber,A., \& Canto, S. (2020). When international avatars meet-intercultural language learning in virtual reality exchange. In K.-M. Frederiksen, S. Larsen, L. Bradley \& S. Thouësny (Eds), CALL for widening participation: short papers from EUROCALL 2020 (pp. 138-142). Research-publishing.net. https://doi.org/10.14705/rpnet.2020.48.1178

Melchor-Couto, S., \& Herrera, B. (in press). Immersive virtual reality: exploring possibilities for virtual exchange. In A. Potolia \& M. Derivry-Plard (Eds), Virtual exchange for intercultural language learning and teaching: fostering communication for the digital age. Routledge.

Schubert, T., Friedmann, F., \& Regenbrecht, H. (2001). The experience of presence: factor analytic insights. Presence: Teleoperators and Virtual Environments, 10(3), 266-281. https:// doi.org/10.1162/105474601300343603

Yang, F.-C. O., Lo, F.-Y. R., Hsieh, C., \& Wu, W.-C. V. (2020). Facilitating communicative ability of EFL learners via high-immersion virtual reality. Journal of Educational Technology \& Society, 23(1), 30-49. https://www.jstor.org/stable/26915405

Zhao, S. (2003). Toward a taxonomy of copresence. Presence: Teleoperators and Virtual Environments, 12(5), 445-455. https://doi.org/10.1162/105474603322761261 


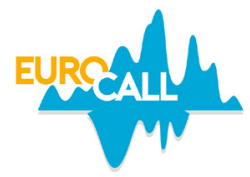

\title{
Immigrant families' home use of electronic and online Icelandic L2 materials for children
}

\author{
Kelsey P. Hopkins ${ }^{1}$ and Branislav Bédi ${ }^{2}$
}

\begin{abstract}
This article presents two studies performed on 14 immigrant families with children aged one to $16 ; 12$ families in Iceland and two Icelandic families living abroad. Lack of exposure and availability of online materials for learning Icelandic as an L2 may affect what skills children can practise at home. This study represents 32 children aged one to 16, all of whom practise Icelandic (L2) at home. Data regarding use and availability of online and offline learning materials were collected by means of a survey containing both open-ended and closed questions. A comprehensive, central directory of available materials was created in parallel as a desktop research. These studies reveal that Icelandic is spoken in most homes but children require further development of specific language skills, predominantly reading. Families consider reading, writing, and vocabulary to be the most important skills to practise, while grammar, speaking, and listening take lower priority. Children's books are the most frequently used learning material, while textbooks, audiobooks, and other language programmes or apps are used less frequently. TV, films, and online channels (e.g. YouTube) are used to provide language exposure.
\end{abstract}

Keywords: electronic materials, children's education, Icelandic L2, online learning.

\section{Introduction}

Computer-assisted language learning is interdisciplinary in its nature and reflects innovative approaches in designing materials, curriculum specifications, and the use of technology in language education (Levy, 1997, pp. 1-2). Different kinds of language learning materials are available on the Internet; however, not all are

\footnotetext{
1. University of Iceland, Reykjavík, Iceland; kph1@hi.is

2. The Árni Magnússon Institute for Icelandic Studies, Reykjavík, Iceland; branislav.bedi@arnastofnun.is; https://orcid. org/0000-0001-7637-8737

How to cite this article: Hopkins, K. P., \& Bédi, B. (2021). Immigrant families' home use of electronic and online Icelandic L2 materials for children. In N. Zoghlami, C. Brudermann, C. Sarré, M. Grosbois, L. Bradley, \& S. Thouësny (Eds), CALL and professionalisation: short papers from EUROCALL 2021 (pp. 143-148). Research-publishing.net. https://doi.org/10.14705/ rpnet.2021.54.1323
} 
freely accessible or suitable for children. This article aims to explore the needs that parents have for children learning different skills in Icelandic L2 and the kinds of materials available on the Internet.

Children of immigrant families in Iceland and Icelandic families abroad often lack exposure to the Icelandic language for various reasons. For instance, children in immigrant families who move to Iceland may be of various ages and need to practise Icelandic L2 both at school and at home at different levels and in different contexts. Similarly, while some Icelandic families relocate abroad permanently, others intend to return to Iceland, and their children need to continue practising Icelandic L2 at different levels. In both cases, lack of language exposure remains an issue. The amount of input can therefore vary, which affects the length of time needed for learning and acquiring Icelandic L2 (Thordardottir \& Juliusdottir, 2013, p. 412). Children's requirements and needs may vary depending on age, interests, parental support, family arrangements, and not least of all the availability and accessibility of language materials and tools. A wide variety of learning materials in Icelandic L2 for children is already available online, though parents and guardians are often unaware of how to access them. This article presents two parallel studies: a qualitative investigation of families' experiences using such material and their learning goals for their children, and the creation of a comprehensive central database of currently available online/electronic Icelandic L2 material for children. By comparing the results of both studies, we hope to identify areas in which to further develop the selection of these materials and to improve their accessibility. Respondents included 14 immigrant families in Iceland and abroad: six monolingual, seven bilingual, and one trilingual.

\section{Method}

The study is twofold and consists of an online survey with open-ended and closed questions regarding use and availability of online materials, and the creation of a comprehensive central directory of available materials. The survey was distributed to the parents and guardians of every child who has attended Tungumálatöfrar, a summer course for Icelandic L2, since 2017, using purposeful sampling method (Palinkas et al., 2016). The survey was designed to collect specific qualitative data from this sample (Chapelle, 2001). Information collected includes demographic data from 14 families with 32 children aged one to 16 (family makeup, children's ages, language(s) spoken at home, parents' native languages, country of residence, and intention to return to Iceland if applicable); information regarding Icelandic usage and study practices at home (e.g. frequency of purposeful study, type and 
frequency of materials used, and language skill areas emphasised); and further information pertaining to families' experience of online L2 material (e.g. ease of locating and using material, children's interest in material, materials that parents would like to see available in the future).

The parallel desktop research involved locating and analysing all relevant online materials for children learning Icelandic L2. Keywords 'Icelandic as a second language', 'children at primary school level', and 'learning materials for children at primary school level' were used respectively in Google Search until no new resources were presented. Each resource was inspected using content analysis (Cohen, Manion, \& Morrison, 2011). A central database was created with a general overview of each resource provider, providing a brief description of materials available. Moreover, 11 more exhaustive lists containing a total of 336 resources were created and analysed in terms of material type (e.g. book, app, PDF, audiobook, game, website, etc.) and target audience (e.g. parents, educators, and learners).

\section{Results and discussion}

Results revealed that families consider reading, writing, and vocabulary to be the most important skills to practise, while grammar, speaking, and listening take lower priority. Children's books are the most frequently used teaching materials, while textbooks, audiobooks, other language programmes, and apps are used less frequently. TV, films, and other online materials (e.g. YouTube) are used for language exposure (Figure 1).

In contrast with Figure 1, however, parents believe that children express the most interest in books, interactive online materials (e.g. websites with games and exercises), online courses (e.g. Icelandic Online), and YouTube for language exposure and practice. Nearly half of the children represented (43\%) practise Icelandic only once a week, another near half (43\%) practise five to seven times a week, and only $14 \%$ practise at home once to twice a week. Some parents/ guardians report difficulty in locating suitable materials online, while others express interest in a greater variety of downloadable and printable materials to reduce their children's screen time.

The accompanying directory of available materials, platforms, websites, programmes, and other resources for Icelandic L2 supplements this survey by helping to make existing resources readily available (supplementary materials). The directory is presented in an overview table and includes essential information 
about 19 collections of resources intended to streamline users' search for specific materials.

Figure 1. How often do children use different types of materials to learn Icelandic L2 at home?

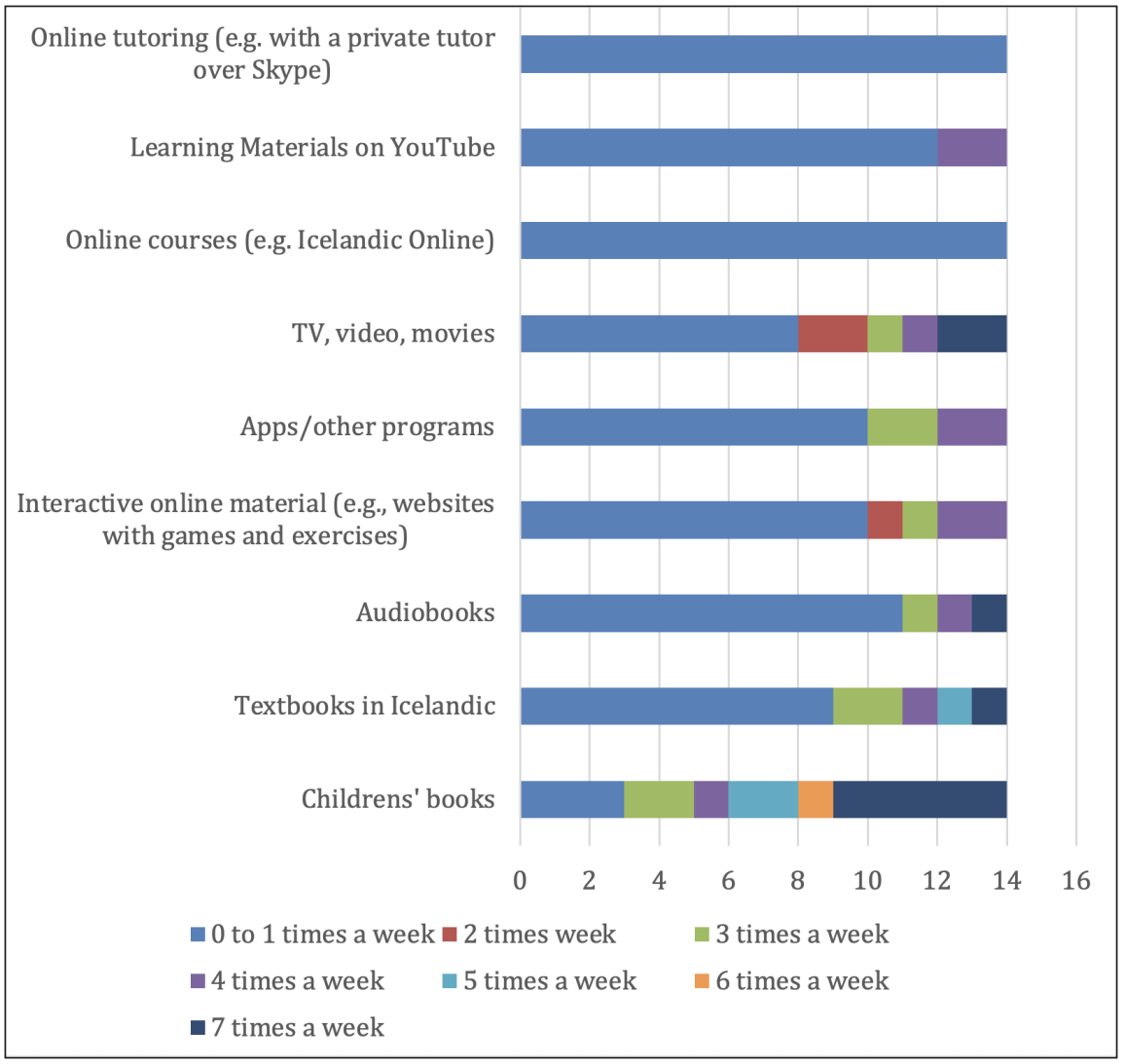

\section{Conclusions}

Families reported that reading, writing, and vocabulary are the most important skills for their children to practise, while giving grammar, speaking, and listening less priority. The most widely used learning materials are children's books, TV, videos and movies, textbooks, interactive online materials, apps and other programmes, learning materials on YouTube, other online courses, and audio books. Regarding actual use of materials, however, children prefer books, interactive online materials, online courses, and YouTube for language exposure and practice. Practice time is 
divided according to frequency: $43 \%$ of participants practise once a week, $43 \%$ five to seven times a week, and $14 \%$ up to twice a week. Due to the quantity of resources collected, the supplementary material is not exhaustive and aims only to show the layout of the overview of a total of 19 resource providers, nine of which offer teaching materials free of cost. The other ten resource providers offer information for parents and educators, or are subscription-based or locked to the general public. One informational resource (Frceðsluskot) provided two material lists; these lists are made into a total of 11 exhaustive directories that are not part of the overview. The number and variety of individual learning materials available per resource provider varies greatly, from four (Íslenskuhorn Hófiar) to eighty (Kötluvefurinn). Some materials and resources are offered by more than one provider. Some providers specialise in one type of material (e.g. Mímisbrunnur and Snjallskóli offer apps and interactive programmes), while others offer greater variety. Because of the comprehensive nature of the data collection, all resource providers are included in the overview and directories. Some offer mass produced/ professionally developed materials, while others are homemade by parents/ educators; the resources' and materials' quality therefore varies greatly.

\section{Acknowledgements}

Gratitude is expressed to the Icelandic Centre for Research RANNÍS for funding this study, and to Tungumálatöfrar, The Árni Magnússon Institute for Icelandic Studies and Móðurmál for their collaboration.

\section{Supplementary materials}

Resource directories of teaching materials for children learning L2 Icelandic readily available online: https://research-publishing.box.com/s/ pv2pdwwld7vftsi6recujw4pcofhkp3h

\section{References}

Chapelle, A. C. (2001). Computer applications in second language acquisition: foundations for teaching, testing and research. Cambridge University Press. https://doi.org/10.1017/ CBO9781139524681

Cohen, L., Manion, L., \& Morrison, K. (2011). Research methods in education (7th ed.). Routledge. 
Levy, M. (1997). Computer-assisted language learning. Context and conceptualization. Oxford University Press.

Palinkas, L. A., Horowitz, S. M., Green, C. A., Wisdom, J. P., Duan, N., \& Hoagwood, A. (2016). Purposeful sampling for qualitative data collection and analysis in mixed method implementation research. Administration and Policy in Mental Health and Mental Health Services Research, 42(5), 533-544. http://doi.org/10.1007/s10488-013-0528-y

Thordardottir, E., \& Juliusdottir, A. G. (2013). Icelandic as a second language: a longitudinal study of language knowledge and processing by school-age children. International Journal of Bilingual Education and Bilingualism, 16(4), 411-435. https://oi.org/10.1080/13670050 .2012 .693062 


\title{
Effects of repeating after stimuli sounds during computer assisted HVPT on Japanese learners' perception and production of English fricatives
}

\author{
Atsushi Iino ${ }^{1}$ and Brian Wistner ${ }^{2}$
}

\begin{abstract}
This study investigated the effects of using an online High Variability Phonetic Training (HVPT) program for university students whose first language is Japanese and who studied English as a foreign language. The target sounds were English fricatives, which many of the participants felt were challenging to distinguish and articulate. The training was conducted for five weeks; each week consisted of three HVPT sessions. The training process consisted of an initial explanation of how to articulate the sounds followed by a video that showed the physical articulative movements. The participants listened to stimuli sounds, produced the sounds after each stimulus, and completed an identification task. Based on pre and posttests, the perception performance of the participants improved significantly through the HVPT training. Regarding production, a positive effect was found for one phoneme, while no difference was found for the other. Questionnaire results were generally positive but indicated the need for explicit instruction for some of the fricatives that exhibited relatively lower successful production and perception rates.
\end{abstract}

Keywords: pronunciation, fricatives, HVPT, perception, production.

\section{Introduction}

Among the current practices applying HVPT in English as a Foreign Language (EFL) instructional environments, a mixture of computer assisted pronunciation training and HVPT has shown positive effects in learners' second language (L2) perception and production, particularly under the condition when learners are

1. Hosei University, Tokyo, Japan; iino@hosei.ac.jp; https://orcid.org/0000-0002-6439-5529

2. Hosei University, Tokyo, Japan; wistner@hosei.ac.jp; https://orcid.org/0000-0003-2774-773X

How to cite this article: Iino, A., \& Wistner, B. (2021). Effects of repeating after stimuli sounds during computer assisted HVPT on Japanese learners' perception and production of English fricatives. In N. Zoghlami, C. Brudermann, C. Sarré, M. Grosbois, L. Bradley, \& S. Thouësny (Eds), CALL and professionalisation: short papers from EUROCALL 2021 (pp. 149-154). Researchpublishing.net. https://oi.org/10.14705/rpnet.2021.54.1324 
required to repeat after stimuli sounds (Iino, Yabuta, \& Wistner, 2020). Following this finding, the present study investigated the effects of using the same online HVPT program, English Accent Coach (EAC; Thomson, 2017), on L2 learners' recognition and production of English fricatives, which are challenging consonants for many Japanese learners of English to recognize and/or articulate (Lambacher, Martens, Nelson, \& Berman, 2001). The following research questions were examined in this study: (1) what are the effects of HVPT with explicit instruction and production practice after stimuli sounds on L2 learners' perception of $/ \mathrm{f} /, / \theta /$, /s/, /h/, and /s/?; (2) under the same conditions, what are the effects of HVPT on learners' production of /f/ and / $\theta /$ ?; and (3) what is the relationship between the training outcomes and the learners' reaction to the training?

\section{Method}

The participants were 19 first-year students (six females and 13 males) enrolled in a university in Japan. Their English proficiency level was roughly at CEFR ${ }^{3} \mathrm{~B} 1$ based on the average score of their TOEIC ${ }^{4}$ reading and listening test: $M=581.1$, $S D=82.2$. They took a required English course focusing on reading in the fall semester of 2019. All of the participants accepted the research conditions and signed an agreement to participate in the research.

The training was conducted for five weeks in between the pretests and posttests; each week consisted of one in-class EAC session and two more individual sessions done outside of class (Table 1). The participants were engaged in perception training with EAC in word and word-like syllable environments - i.e. target consonant plus any vowel (CV) and other 'levels' provided in EAC. Before the training began, a video that demonstrated how to articulate the target sounds was shown by the instructor. It emphasized the acoustic features of fricatives. The participants were then strongly encouraged to repeat after the stimuli sounds during EAC before responding to its forced-choice identification task. As a pretest, the participants' perception performance was measured with Level 3 (CV) training; for production, the participants read aloud seven sentences presented on slides shown on a computer display - the production performances were recorded. Two fricatives, $/ \mathrm{f} / \mathrm{and} / \theta /$, were included in the sentences, which were evaluated by two native speakers of English and one nonnative (Japanese) speaker of English.

3. Common European Framework of Reference for languages

4. Test of English for International Communication 
Table 1. Research procedure

\begin{tabular}{|c|c|c|c|c|c|c|c|c|c|}
\hline$\frac{\theta}{Z}$ & 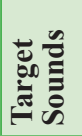 & 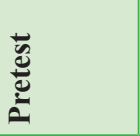 & 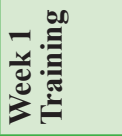 & 禺 & m & 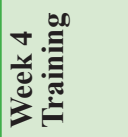 & 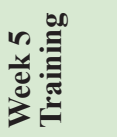 & 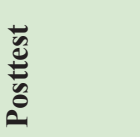 & \\
\hline .0ّ & $\begin{array}{l}/ \mathrm{f} /, \\
/ \theta /, \\
/ \mathrm{s} /, \\
/ \mathrm{h} /, \\
/ \mathrm{s} /\end{array}$ & $\begin{array}{l}\text { EAC } \\
\text { Level } 3 \\
(\mathrm{C}+\mathrm{V}) \\
\text { Correct } \\
\% \text { of } \\
\text { FCID } \\
\text { with } 200 \\
\text { stimuli }\end{array}$ & $\begin{array}{l}\text { EAC } \\
\text { Level 4: } \\
\text { initial C } \\
+ \text { all V, } \\
\text { single } \\
\text { syllable } \\
\text { words }\end{array}$ & $\begin{array}{l}\text { EAC } \\
\text { Level } \\
\text { 5: final } \\
\text { C + all } \\
\text { vowels, } \\
\text { single } \\
\text { syllable } \\
\text { words }\end{array}$ & $\begin{array}{l}\text { EAC } \\
\text { Level 6: } \\
\text { initial C } \\
\text { first } \\
\text { syllable } \\
+ \text { all V }\end{array}$ & $\begin{array}{l}\text { EAC } \\
\text { Level 7: } \\
\text { initial C, } \\
\text { second } \\
\text { syllable } \\
+ \text { all V }\end{array}$ & $\begin{array}{l}\text { EAC } \\
\text { Level 8: } \\
\text { final C } \\
+ \text { all V, } \\
\text { second } \\
\text { syllable }\end{array}$ & $\begin{array}{l}\text { Level } 3 \\
\text { with the } \\
\text { same } \\
\text { conditions } \\
\text { as the } \\
\text { pretest }\end{array}$ & 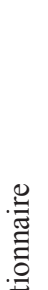 \\
\hline 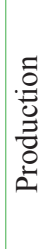 & $\begin{array}{l}/ \mathrm{f} / \\
/ \theta /\end{array}$ & $\begin{array}{l}\text { Read } \\
\text { aloud } \\
\text { seven } \\
\text { sentences } \\
\text { with } \\
18 \text { target } \\
\text { sounds }\end{array}$ & \multicolumn{5}{|c|}{$\begin{array}{l}\text { Repeat aloud HVPT stimuli } \\
\text { three sessions in each week }\end{array}$} & $\begin{array}{l}\text { The same } \\
\text { as the } \\
\text { pretest }\end{array}$ & $\stackrel{0}{2}$ \\
\hline
\end{tabular}

\section{Results and discussion}

\subsection{Perception}

The overall results confirmed that the perception performance of the participants improved after the HVPT training with EAC (see Table 2; Figure 1). Statistical significance was observed for all the sounds except for $/ \mathrm{h} /$, which was already $96 \%$ correct in the pretest. The progress made was about $10 \%$, which exhibited large effect sizes. After the HVPT training, the sounds $/ \mathrm{s} /, / \mathrm{h} /$, and $/ \mathrm{J} /$ seemed easier to perceive than $/ f /$ and $/ \theta /$. The percentage correct for those two sounds was relatively lower even on the posttest, which indicates that those sounds were difficult for Japanese EFL learners to perceive. Even with these differences in difficulty, the participants' reactions indicated that over $60 \%$ thought that the use of EAC was effective for perception, and that their listening skills improved (Figure 3, Q1 and Q2). However, the amount of progress in total was smaller than that reported in Iino et al. (2020), in which /1/,/r/, and /w/ were examined. This result could be due to the shorter length of training (five weeks versus ten weeks) and the inclusion of five sounds instead of three. 
Table 2. Descriptive statistics and analyses for $/ \mathrm{f} /, / \theta /, / \mathrm{s} /, / \mathrm{h} /, / \mathrm{J} /$ perception $(N=19)$

\begin{tabular}{|l|l|l|l|l|l|l|l|l|l|}
\hline & \multicolumn{3}{|l|}{ Pretest } & \multicolumn{3}{l|}{ Posttest } & \multicolumn{3}{l|}{ Post-Pre } \\
\cline { 2 - 12 } & M (\%) & SD & M (\%) & SD & M (\%) & SD & Cohen's d & t-value & \\
\hline f & 68.53 & 12.6 & 78.63 & 9.5 & 10.11 & 12.7 & .93 & 3.48 & $* *$ \\
\hline$\theta$ & 53.00 & 3.8 & 63.58 & 3.0 & 10.58 & 15.7 & .73 & 2.94 & $* *$ \\
\hline s & 85.84 & 14.5 & 95.74 & 3.6 & 9.89 & 12.1 & .96 & 3.55 & $* *$ \\
\hline h & 96.21 & 4.6 & 95.89 & 6.3 & 0.32 & 6.8 & .06 & .20 & n.s. \\
\hline J & 81.74 & 12.9 & 94.79 & 5.7 & 13.05 & 2.3 & 1.34 & 4.63 & $* *$ \\
\hline Total & 78.32 & 8.6 & 87.00 & 4.7 & 8.68 & 6.4 & 1.29 & 5.94 & $* *$ \\
\hline
\end{tabular}

$* \mathrm{p}<.05 ; * * \mathrm{p}<.01$

Figure 1. Left: boxplots of perception rates in $/ \mathrm{f} /, / \theta /, / \mathrm{s} /, / \mathrm{h} /, / \mathrm{f} /$ between pre and posttests $(\%, \mathrm{~N}=19)$; right: overall change of perception $(\%)$

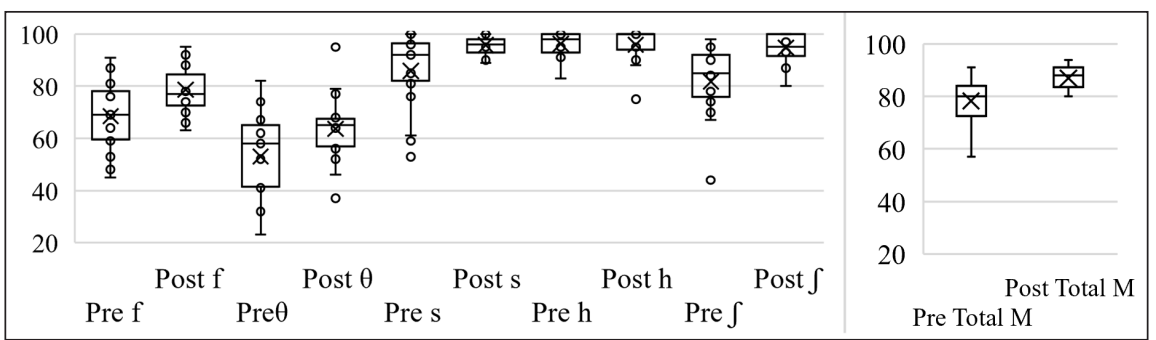

\subsection{Production}

The results for production of the two fricatives with lower perception rates are shown in Table 3 and Figure 2. For /f/, statistically significant progress was observed with a small effect size $(t=2.44, d f=18, p<.01, d=.34)$, while no significant progress was made for $/ \theta /$. This finding supports the relationship between perception and production - progress in production might be based on increases in perception.

Based on the questionnaire results, $38 \%$ of the participants perceived the employed explicit instruction as helpful, but 48\% were not sure (Figure 3, Q5: 24\%+14\% agreed). Although $48 \%$ of the participants perceived the benefits of EAC on producing the segmental sounds, 29\% did not (Q3). Additionally, regarding the effect on overall pronunciation (Q4), 43\% expressed their uncertainty by choosing not sure, while a similar number found it effective (Q4, 24+19\% agreed). For /f/ and $/ \theta /$, more intensive instruction and articulatory practice may be necessary. During the assessment process, it was noted among the raters that some participants replaced the Japanese voiceless bilabial $/ \phi /$ for $/ \mathrm{f} /$ and $/ \mathrm{s} /$ for $/ \theta /$. 
Table 3. Descriptive statistics and statistical analyses for $/ \mathrm{f} / \mathrm{and} / \theta /$ production $(N=19)$

\begin{tabular}{|c|c|c|c|c|c|c|c|c|c|c|c|c|c|}
\hline \multirow{2}{*}{\multicolumn{2}{|c|}{$\begin{array}{l}\text { No. of } \\
\text { items }\end{array}$}} & \multicolumn{3}{|c|}{ Pretest } & \multicolumn{3}{|c|}{ Posttest } & \multicolumn{6}{|c|}{ Post-Pre } \\
\hline & & \multirow{2}{*}{$\begin{array}{l}\mathbf{M} \\
4.45\end{array}$} & \multirow{2}{*}{$\begin{array}{l}(\%) \\
(49.4)\end{array}$} & \multirow{2}{*}{$\begin{array}{l}\text { SD } \\
3.3\end{array}$} & \multirow{2}{*}{$\begin{array}{l}\mathbf{M} \\
5.50\end{array}$} & \multirow{2}{*}{$\begin{array}{l}(\%) \\
(61.1)\end{array}$} & \multirow{2}{*}{$\begin{array}{l}\text { SD } \\
3.0\end{array}$} & \multirow{2}{*}{\begin{tabular}{|l|}
$\mathbf{M}$ \\
1.05 \\
\end{tabular}} & \multirow{2}{*}{$\begin{array}{l}(\%) \\
(11.7) \\
\end{array}$} & \multirow{2}{*}{$\begin{array}{l}\text { SD } \\
1.9 \\
\end{array}$} & \multirow{2}{*}{$\begin{array}{l}\text { Cohen's } \\
\text { d }\end{array}$} & \multicolumn{2}{|c|}{ t-value } \\
\hline /f/ & 9 & & & & & & & & & & & 2.44 & $*$ \\
\hline$/ \theta /$ & 9 & 3.13 & (34.8) & 3.6 & 3.82 & (42.4) & 3.5 & 0.68 & $(7.6)$ & 1.7 & .20 & 1.79 & n.s \\
\hline Total & 18 & 7.58 & $(42.1)$ & 6.7 & 9.32 & (51.8) & 6.2 & 1.74 & (9.6) & 2.9 & .28 & 2.63 & $*$ \\
\hline
\end{tabular}

${ }^{*} \mathrm{p}<.05 ; * * \mathrm{p}<.01$

Figure 2. Left: pre-post production for $/ \mathrm{f} /$ and $/ \theta /$ (raw score $/ 9$ words); right: overall pre-post production $(/ 18)$

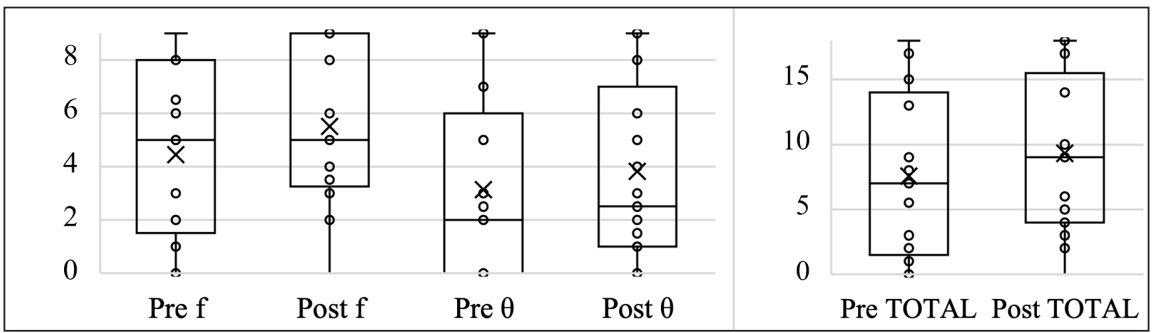

Figure 3. Results of the questionnaire on the use of EAC for perception and production $(\mathrm{N}=19)$

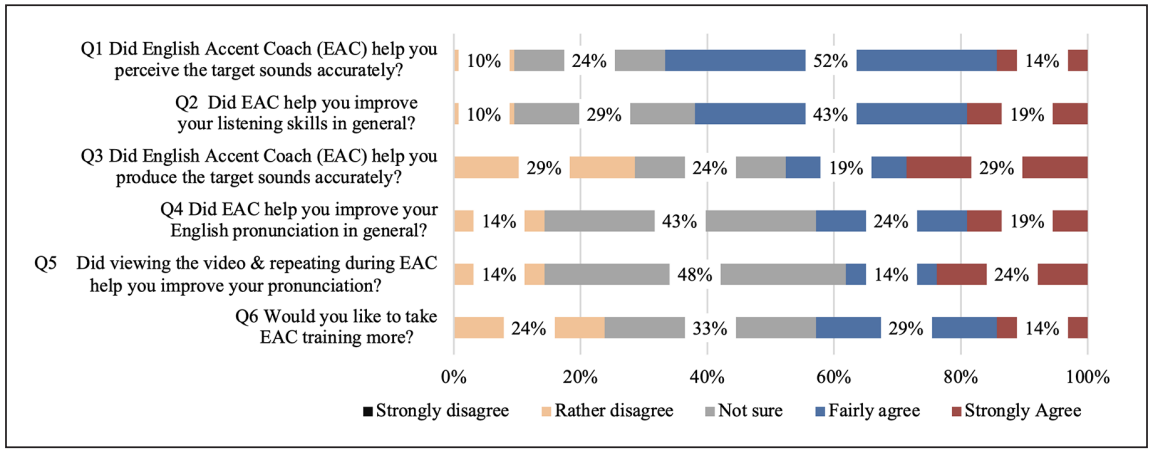

\section{Conclusion}

The overall results of the training indicated positive effects of HVPT on L2 learners' perception of the target fricatives. This finding supports the idea that incorporating such training inside and outside of the L2 classroom could be beneficial for 
improving L2 phonemic perception skills. To further investigate the effectiveness on production, focus-on-form pronunciation instruction could be utilized in class, through which learners pay attention to target sounds after engaging in meaningfocused communicative activities.

\section{Acknowledgments}

This work was supported by JSPS KAKEN Grant No. 20K00785 (Principal Investigator: Atsushi Iino; Co-Investigator: Brian Wistner).

\section{References}

Iino, A., Yabuta, Y., \& Wistner, B. (2020). Effects and users' reactions to the use of CAPT and HVPT on Japanese EFL learners' segmental perception and production. In K.-M. Frederiksen, S. Larsen, L. Bradley \& S. Thouësny (Eds), CALL for widening participation: short papers from EUROCALL 2020 (pp. 107-113). Research-publishing.net. https://doi.org/10.14705/ rpnet.2020.48.1173

Lambacher, S., Martens, W., Nelson, B., \& Berman, J. (2001). Identification of English voiceless fricatives by Japanese listeners: the influence of vowel context on sensitivity and response bias. Acoustical Science and Technology, 22(5), 334-343. https://doi.org/10.1250/ast.22.334 Thomson, R. (2017). English accent coach [Computer software]. Version 2.3. www. englishaccentcoach.com 


\title{
Pedagogical experiences in a virtual exchange project using high-immersion virtual reality for intercultural language learning
}

\author{
Kristi Jauregi-Ondarra ${ }^{1}$, Alice Gruber ${ }^{2}$, and Silvia Canto ${ }^{3}$
}

\begin{abstract}
Social Virtual Reality (VR) applications enable real-time interpersonal conversation and allow users to perform activities together. They have the potential of changing the ways learners practise speaking a foreign language. Following a previous study (Jauregi Ondarra, Gruber, \& Canto, 2020), we designed the present study to explore how presence, immersion, and interactivity affect overall social experience. Students from Germany and the Netherlands engaged in Highimmersion VR (HiVR) virtual exchange sessions, using Spanish as a lingua franca at A2 level. International dyads carried out four interaction tasks in AltspaceVR, using head-mounted devices. To examine students' HiVR virtual exchange experiences, different sources of data were gathered: questionnaires, reflection diaries, recordings, and focus group interviews. The preliminary results, based on the surveys and reflection journals, show that students liked to use a social VR app to communicate in the target language with peers from other countries, as they felt completely immersed and co-present in the social interactive VR space. This might enhance engagement and lower anxiety levels.
\end{abstract}

Keywords: high-immersion VR, social VR applications, Spanish as a lingua franca, interactivity, language learning.

1. Utrecht University, Utrecht, the Netherlands; k.jauregi@uu.nl; https://orcid.org/0000-0002-9096-9450

2. Heilbronn University of Applied Sciences, Heilbronn, Germany; alice.gruber@hs-heilbronn.de; https://orcid.org/0000-00031558-673X

3. Utrecht University, Utrecht, the Netherlands; s.canto@uu.nl; https://orcid.org/0000-0003-4044-2439

How to cite this article: Jauregi-Ondarra, K., Gruber, A., \& Canto, S. (2021). Pedagogical experiences in a virtual exchange project using high-immersion virtual reality for intercultural language learning. In N. Zoghlami, C. Brudermann, C. Sarré, M. Grosbois, L. Bradley, \& S. Thouësny (Eds), CALL and professionalisation: short papers from EUROCALL 2021 (pp. 155-160). Research-publishing.net. https://doi.org/10.14705/rpnet.2021.54.1325 


\section{Introduction}

Social HiVR might have the potential to enhance meaningful communication processes in the target language in an authentic, virtual environment. Following our first successful pedagogical VR experiences for being an adequate and motivating technology for conducting virtual exchange experiences using English as lingua franca (Jauregi Ondarra et al., 2020), we organised a follow-up study to investigate what opportunities social VR applications offer to enrich foreign language learning experiences and analyse how learners utilise them. We especially focused on the way learners experience presence, immersion, and interactivity and how these aspects influence students' engagement and motivation.

\section{Method}

Twenty-four students from Utrecht University (the Netherlands) and Heilbronn University (Germany) volunteered to participate in the study. Twenty-two students were aged between 18 and 24. Two German students reported being a little bit older, between 25 and 30. The Dutch students were taking the course Español 2 and the German students were enrolled in different Spanish courses leading towards A2 $\left(\mathrm{CEFR}^{4}\right)$ level. The students were grouped in international dyads and asked to arrange the meetings at their convenience within a set timeframe. Before the interactions started, information meetings were held to explain the dynamics of the HiVR experience and head-mounted display pick-ups were arranged. Students were all given access to manuals and video tutorials on how to use their displays and the social app.

The VR interactions were carried out outside classroom hours in Spanish as lingua franca. The interaction tasks were performed in AltspaceVR, a social VR platform where public and private events can be organised. Users can meet and communicate with real people represented by a customisable avatar. AltspaceVR, which is free to use, is available on many HiVR headsets and also in 2D mode on PCs (Figure 1).

Task guidelines were created to prepare participants for their interactions. Task 1 was an icebreaker for students to get to know each other and customs of their partners' country. In Task 2, students had to decide where they would spend an exchange period together. In Task 3 , they had to make decisions about the house they would share during their exchange. Task 4 was organised as a live event

4. Common European Framework of Reference for languages 
(a quiz - guess the famous person) for all participants in the project. During task performance, while interacting with their partner, students were requested to interact with the environment (e.g. customise their houses, visit other locations).

Data were gathered to investigate the impact immersive virtual exchange experiences might have on students' learning: questionnaires, reflection journals, recordings, and focus group interviews at the end of the project. The initial results presented here focus on the questionnaires and journals.

Figure 1. Interactions in AltspaceVR

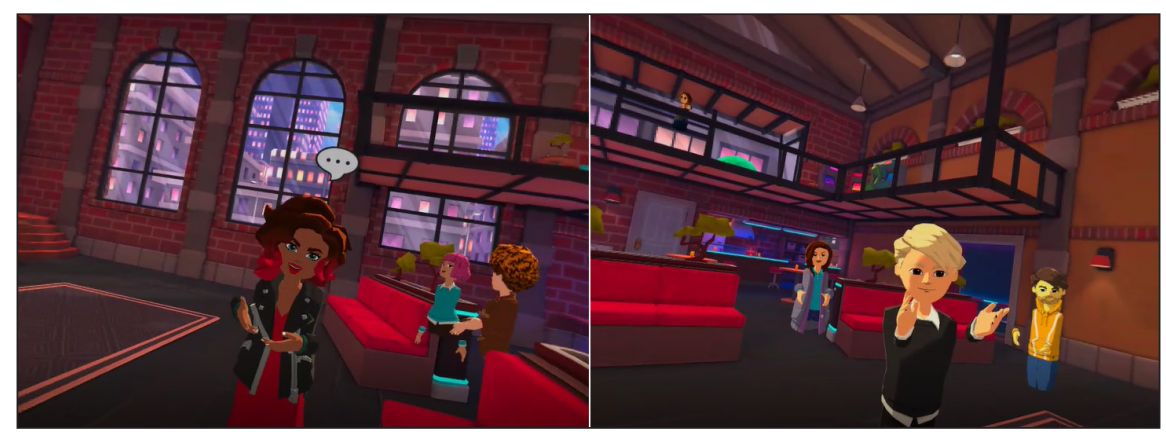

\section{Results and discussion}

The results of the final questionnaires containing five point Likert scale items and open-ended questions (see supplementary material) show that students (n:17) found it easy to start ( $\mathrm{x}: 3.8)$ and use ( $\mathrm{x}: 3.7)$ the tool. It was not difficult to use the VR environment ( $\overline{\mathrm{x}}: 2.7)$ and most of them liked AltspaceVR ( $\overline{\mathrm{x}}: 3.3)$. The sound, a key issue in communication, was good ( $\bar{x}: 3.7)$.

Fourteen out of 17 students very much liked to communicate in VR (n:14; $\bar{x}: 4)$, meet students from other countries ( $\overline{\mathrm{x}}: 4.2)$, and would recommend others to participate in these HiVR exchanges ( $\overline{\mathrm{x}}: 4.2)$.

Most students felt completely immersed and co-present ( $\overline{\mathrm{x}}: 3.8)$ in the HiVR space, which contributed to enhanced engagement. Students reported doing their best when interacting in the VR environment ( $\overline{\mathrm{x}}$ : 4.7) to concentrate well when interacting ( $\overline{\mathrm{x}}$ : 3.8) and to feel so involved in the interaction task in VR that they ignored everything around them ( $\mathrm{x}: 3.7)$. In addition, the VR environment was felt to be safe and comfortable ( $\overline{\mathrm{x}}: 3.7)$, which contributed to lower anxiety levels 
for most students, clearly stimulating student engagement, as we can see in the qualitative data gathered in the survey (open questions) and the reflection journals.

"The environment is cheerful with fun colours which makes it feel less like a 'very important university assignment' and more like a fun educational conversation with someone else".

Moving around in a private virtual house in VR was also seen to contribute to a relaxed atmosphere during the conversation.

"It is nice to have the opportunity to walk around and show stuff to the other person. That makes the situation more relaxed".

"It was relaxing because we just walked around our home and showed what we put there and what is important to us".

According to another student, seeing the same environment "gives you a lot to talk about. That makes it more calming", and another student stated: "it felt like talking to a friend in a comfortable surrounding".

Six out of the 17 students felt that the use of an avatar was positive, clearly contributing to lower anxiety levels to communicate in a foreign language: "I liked that we didn't actually see each other, it put me at ease, and I was less nervous than I usually am when trying to speak Spanish". However, seven students felt very negative about being an avatar and not having access to visual cues which helps personalise a communication event.

Regarding the interaction with objects in AltspaceVR in terms of aiding language learning, participants' perceptions varied. For example, one student remarked that "some objects help explain something when we're having trouble with finding the right word", while another stated that "you could see many things and do some cool stuff. But it isn't really needed to learn the language, it is more of a distraction for me".

The possibility to interact with the environment was considered an added value by 13 students in their reflection journals. Students could customise their houses, play basketball, throw snowballs, etc. Although customising the environment was more challenging for some students than for others, it was generally felt to be a positive feature. The personal touches they could add were claimed to make the interaction more relaxed and enjoyable. 
"The surrounding and self-made construction sparked some fun conversations. Building something did take some time to learn".

"The way we had to interact with our surroundings was a major plus".

Attending a live group event (Task 4 - quiz) in AltspaceVR was also perceived as a positive experience. Participants seemed to feel part of the group and collaboratively engaged in action.

"The added value of the group session is to see how everyone has grown and the fun of the game element. It was fun to do and there was no pressure. It also has added value because it is a playful way to finish the research and it is nice to get something from the other participants and the possibilities of VR to do something with a group".

For students who were uncomfortable with public speaking, the avatars provided them with support to lower their anxiety.

"This helped me a lot with my fear of speaking in front of large groups: I didn't have to look at anyone directly and yet I was speaking in front of a whole group of people. Because they were avatars, I was a lot less intimidated".

Finally, we noticed that some students (n:7) were very sensitive to the high VR information density and experienced cybersickness.

\section{Conclusions}

The preliminary results indicate that students liked to use a social VR app to communicate in the target language with peers as they felt completely immersed and co-present in the social interactive VR space. Presence, immersion, and the possibility to interact in and with the environment seem to have contributed to enhanced engagement and lower anxiety levels. Going to different places in AltspaceVR, both public (e.g. the campfire) and the students' own personalised virtual houses, has several advantages. It offers the possibility of changing the location, which could help avoid awkward silence or trigger a change of topic. Moving around virtual spaces can give learners at beginner level a break and ease the pressure when they struggle with the cognitive demands of speaking Spanish. Being able to walk around each other's room makes the experience more casual, 
engaging, and more real for some students. However, handling the environment and a conversation simultaneously in the target language could lead to cognitive overload (Kaplan-Rakowski \& Gruber, 2021).

\section{Supplementary material}

https://research-publishing.box.com/s/lgsjcg6x2fz1zf80pk7mswewleqxsi06

\section{References}

Jauregi Ondarra, K., Gruber, A., \& Canto, S. (2020). When international avatars meet-intercultural language learning in virtual reality exchange. In K.-M. Frederiksen, S. Larsen, L. Bradley \& S. Thouësny (Eds), CALL for widening participation: short papers from EUROCALL 2020 (pp. 138-142). Research-publishing.net. https://doi.org/10.14705/rpnet.2020.48.1178

Kaplan-Rakowski, R., \& Gruber, A. (2021). One-on-one foreign language speaking practice in high-immersion virtual reality. In Y. J. Lan \& S. Grant (Eds), Contextual language learning - real language learning on the continuum from virtuality to reality (pp. 187-202). Springer. https://doi.org/10.1007/978-981-16-3416-1_9 


\title{
Comics for inclusive English language learning: the CIELL app, supporting dyslexic English language learners
}

\author{
Shaunna Joannidou ${ }^{1}$ and Julie-Ann Sime ${ }^{2}$
}

\begin{abstract}
As teaching moves increasingly online, language teachers are faced with the challenge of how to support dyslexic students in an inclusive manner in and out of the classroom. This paper will focus on an innovative educational multi-modal, mobile application - Comics for Inclusive English Language Learning (CIELL) supporting upper-intermediate and advanced English as a Foreign Language (EFL) students with dyslexia when faced with language proficiency tests and academic writing tasks. A cyclical educational design research methodology (McKenney \& Reeves, 2019) was used to include three cycles of feedback from stakeholders so that their views and suggestions would inform the development of an alpha, beta, and gamma version of the app, thereby maximising practical relevance. The discussion of the quantitative and qualitative feedback is supported by educational design research.
\end{abstract}

Keywords: mobile learning, dyslexia, educational design research.

\section{Introduction}

Dyslexia, as mentioned on the CIELL website ${ }^{3}$, is a specific learning difference characterised by difficulties with word decoding, spelling, handwriting, reading, memory, and attention span which affects around $10 \%$ of the UK population. Dyslexic-type difficulties also cause challenges in writing in another language, which is often assessed in high-stakes testing contexts and is an essential skill

\footnotetext{
1. University of Cyprus, Nicosia, Cyprus; shaunna@ucy.ac.cy; https://orcid.org/0000-0001-7067-7867

2. Lancaster University, Lancaster, United Kingdom; j.sime@lancaster.ac.uk; https://orcid.org/0000-0002-3964-0684

3. https://ciell.eu/
}

How to cite this article: Joannidou, S., \& Sime, J.-A. (2021). Comics for inclusive English language learning: the CIELL app, supporting dyslexic English language learners. In N. Zoghlami, C. Brudermann, C. Sarré, M. Grosbois, L. Bradley, \& S. Thouësny (Eds), CALL and professionalisation: short papers from EUROCALL 2021 (pp. 161-166). Research-publishing.net. https://doi.org/10.14705/rpnet.2021.54.1326 
in higher education across Europe (Kormos \& Smith, 2012). The introduction of comics, being used by teachers for many years, to encourage reluctant readers, to make learning fun, and to strengthen confidence and enjoyment in reading, was deemed as an interesting approach for the research team for the development of the planned learning intervention through the app. Educational research suggests that art improves memory and academic outcomes (Hardiman, Johnbull, Carran, \& Shelton, 2019). Sousanis (2015) argues for the value of visual thinking in teaching and learning as it can help us to understand multiple perspectives. He proposes that words and images are equal partners in meaning-making and that understanding is always an active process of evaluating different perspectives. This is our reason, our theoretical basis, for promoting visual representations in teaching writing. Specifically, the CIELL app supports dyslexic students preparing for the written component of high-stakes language proficiency exams such as IELTS and Cambridge Advanced and Proficiency. It focuses on supporting the process of planning opinion essays, reviews, and article writing. Writing guidelines and sample essays have been created in comic form and visual representations in the form of an infographic presenting a basic essay structure. The topics of the 17 sample essays have been based on the 17 United Nations sustainable development goals for 2030 (see supplementary materials, Appendix A).

Educational research design, which focuses on solving real world problems through effective interventions, will be presented. Elements of this methodology engage both the researchers and target group in analysis and exploration, design and construction, evaluation and reflection, and implementation and spread (McKenney \& Reeves, 2014). It is an iterative cycle in which interventions are created, tested, adopted, implemented, re-tested, and refined. The quantitative and qualitative feedback received from the researchers and target groups gave insight in how to effectively address successful strategies to be implemented through an app to support dyslexic learners in advanced level writing. The paper will discuss the three iterative evaluation cycles that influenced the development of the CIELL app.

\section{Method}

An interdisciplinary pool of EFL instructors, technology-enhanced researchers, a software developer, and an artist from the UK, Cyprus, Germany, and Greece participated in the design of the CIELL app, which was shaped by the opinions of key education stakeholders so that the design is informed by their views and maximises practical relevance. The reason that this approach was adopted was to 
ensure that user perceptions influenced the design and development of the app, thereby maximising practical relevance as well as incorporating Universal Design for Learning (UDL, 2021) principles. UDL aims to minimise obstacles to learning and increase flexibility, thereby making designs more accessible to students, for example, by providing audio and video; the stories in the app can be read aloud by learners who struggle with reading in English as well as by learners using their mobile phones.

\section{Results and discussion}

The three iterative cycles of evaluation present data that contributed to the further development and enhancement of the CIELL app. The survey questions used were developed using a five-point Likert scale and open-ended questions. Each survey generated quantitative and qualitative data. Each cycle will be reviewed and the data presented will illustrate the importance of the participative approach in developing a learning intervention to support EFL learners with dyslexia.

\subsection{Cycle 1}

The process began with a stakeholder survey $(\mathrm{N}=79)$ to establish the potential acceptance of the app and the area of the curriculum in English language learning. The survey data show an overall positive response towards the use of software apps in teaching and learning. Moreover, the participants' responses to the challenges faced in English language learning as a second or foreign language indicate the following areas of high importance: speaking, understanding speaking, understanding written text, and writing essays. Spelling and vocabulary learning were of least concern.

The first cycle of design, development, and evaluation concluded with an evaluation by 376 language teachers interested in how to teach students with dyslexia and other specific learning difficulties. Their written comments about the app and its potential use were thematically analysed according to Braun and Clarke (2006), and used to refine the design for Cycle 2. The thematic analysis of the responses for the alpha version of the app reveal the following four themes:

- it helps students understand the structure/format of essay writing;

- the visual image/info-graphics and audio explore different learning styles;

- it is relevant to meeting the needs of dyslexic learners - multisensory and interesting; and 
- it provides the chunking of knowledge to reduce cognitive overloading.

Possible suggestions for the improvement of the app are cited by the stakeholders as (1) use lighter colours for the illustrations, (2) make the tasks more interactive, and (3) provide instructions concerning how to use the app. All suggestions were implemented, especially the inclusion of the Teachers' Compendium, giving insight into the development and use of the app in teaching and learning.

\subsection{Cycle 2}

The second cycle concluded with an evaluation of the app by piloting teachers $(\mathrm{N}=10)$ and their learners $(\mathrm{N}=183,12.5 \%$ self-declared dyslexia as a learning difficulty) who provided feedback via two questionnaires (see supplementary materials, Appendix B).

Although the teacher and the student responses in the pilot phase are overwhelmingly positive, areas of difficulty were cited by the teachers concerning their typical adaptation of materials for students with dyslexia. Moreover, students also suggested the following improvements for the app in open-ended questions and the most prevalent statements are provided here.

Tell us what you liked about the app?

- Development of stories and topics of social issues facing society today;

- the artwork of the comics; and

- multi-modal learning with art, text, and audio.

How do you think we can improve CIELL for other students?

- Add more tasks: level of difficulty, critical thinking, and add the full text to the infogram tasks;

- more stories: longer, more modern student-centred topics; and

- audio for all of the stories.

\subsection{Cycle 3}

The final evaluation was undertaken by a wider stakeholders' audience $(\mathrm{N}=122)$ which provided further insight into their perceptions, attitudes, and needs. The analysis of the data from the questionnaire provided further suggestions for changes to the app's third cycle of design, development, and evaluation: (1) all 
stories received an audio version of the stories/essays, (2) two different levels of difficulty of the essays were provided, and (3) different task types were discussed and applied. These results led to a final and fourth version of the app.

\section{Conclusions}

Overall, 770 end-users contributed to the development of the CIELL app. The cyclical educational design research methodology enabled the research team to include feedback from stakeholders so that their perspectives and suggestions informed the development process, and their perceptions influenced the design and development of the mobile application, thereby maximising practical relevance. This meant that the final educational resource was more complex than initially planned and more fit for purpose. While the app was intended for the purpose of supporting the writing of essays for EFL students with dyslexia, teachers could also see its potential value in supporting listening, speaking, reading, and writing activities for all their EFL students.

\section{Supplementary materials}

\section{https://research-publishing.box.com/s/qg556ha1u4t8ouq4keu52yc4astax6p2}

\section{Acknowledgements}

This research has been co-funded by the European Union under the ERASMUS+ programme, with Centre for Technology-Enhanced Learning, Lancaster University (UK); Language Centre, University of Cyprus (Cyprus); Institute for Learning Innovation, Friedrich-Alexander University (Germany); and AKTO Art and Design College (Greece).

\section{References}

Braun, V., \& Clarke, V. (2006). Using thematic analysis in psychology. Qualitative Research in Psychology, 3(2), 77-101. https://doi.org/10.1191/1478088706qp063oa

Hardiman, M., Johnbull, R., Carran, D., \& Shelton, A. (2019). The effects of arts-integrated instruction on memory for science content. Trends in Neuroscience and Education, 14, 2532. https://doi.org/10.1016/j.tine.2019.02.002 
Kormos, J., \& Smith, A. M. (2012). Teaching languages to students with specific learning differences. Multilingual Matters. https://doi.org/10.21832/9781847696212

McKenney, S., \& Reeves, T. C. (2014). Methods of evaluation and reflection in design research. Zeitschrift für Berufs- und Wirtschaftspädagogiek, 27, 141-153.

McKenney, S., \& Reeves, T. C. (2019). Conducting educational design research (2nd ed.). Routledge. https://doi.org/10.4324/9781315105642

Sousanis, N. (2015). Unflattening. Harvard University Press. https://www.hup.harvard.edu/ catalog.php?isbn=9780674744431

UDL (2021). The UDL guidelines. https://udlguidelines.cast.org/ 


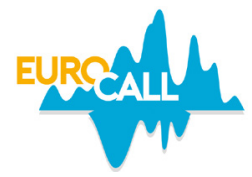

\title{
Speaking to write: examining language learners' acceptance of automatic speech recognition as a writing tool
}

\author{
Carol Johnson $^{1}$ and Walcir Cardoso ${ }^{2}$
}

\begin{abstract}
This mixed-methods one-shot study examines L2 writers' perceptions of using Automatic Speech Recognition (ASR) to write using the Technology Acceptance Model (TAM), based on three criteria: usefulness, ease of use, and intention to use. After receiving training on Google voice typing in Google Docs, 17 English as a Second Language (ESL) students carried out two ASR-based writing tasks over a two-hour period. After the treatment, participants filled in a TAM-informed survey and participated in semi-structured interviews to measure their perceptions based on the target criteria. Findings indicate positive perceptions of ASR as a writing tool in terms of usefulness (language learning potential) and ease of use (e.g. user-friendly voice commands). We believe that these positive perceptions might lead to an intention to continue to use ASR, suggesting that the technology has L2 pedagogical potential.
\end{abstract}

Keywords: automatic speech recognition, L2 writing, technology acceptance model.

\section{Introduction}

Good writing requires attention not only to linguistic form but also to content, context, genre, and the writing process (Hyland, 2011). However, in ESL writing classes, students often focus on form, to the detriment of the other aspects, as they believe this is what will have the greatest impact on their grades (Ding \& Zhao, 2019).

1. Concordia University, Montreal, Canada; carol.johnson@concordia.ca

2. Concordia University, Montreal, Canada; walcir.cardoso@concordia.ca; https://orcid.org/0000-0001-6376-185X

How to cite this article: Johnson, C., \& Cardoso, W. (2021). Speaking to write: examining language learners' acceptance of automatic speech recognition as a writing tool. In N. Zoghlami, C. Brudermann, C. Sarré, M. Grosbois, L. Bradley, \& S. Thouësny (Eds), CALL and professionalisation: short papers from EUROCALL 2021 (pp. 167-171). Research-publishing.net. https://oi.org/10.14705/rpnet.2021.54.1327 
Using ASR, a technology that converts speech to text, may remove some of the burden of producing error-free form, allowing students to pay attention to other aspects of writing such as content. Not only is this technology accessible and free (e.g. Google voice typing in Google Docs), but it fulfills Chapelle's (2001) criteria of an effective Computer Assisted Language Learning (CALL) tool: ASR has potential for language learning through the feedback, presents opportunities to engage with language at an appropriate level (it is the learner's own text), allows for an attention to meaning as the learner constructs a text, provides for an authentic use of language in a text type the learner will frequently encounter, contributes to the development of effective writing strategies, and is practical (e.g. available at no cost). Despite its multiple affordances, there is only one study examining ASR as an L2 writing tool, and it is in the context of children with emerging literacy (Arcon, Klein, \& Dombroski, 2017).

The aim of this study is to determine if adult language learners would accept to use ASR to write academic texts using the framework adapted from Venkatesh and Davis's (2000) revised TAM. TAM posits that users' intentions to use new technologies is based on perceived usefulness and perceived ease of use. Perceived usefulness is conceptualized as "the degree to which a person believes that using a particular system would enhance his or her job performance", while perceived ease of use is the degree which learning a new technology is perceived as "free from effort" (Davis, 1989, p. 320). Venkatesh and Davis (2000) revised the original TAM framework to add factors that influence perceived usefulness: job relevance (academic relevance in this study; the degree to which the technology is applicable to the task), output quality (how well the technology performs the task), and result demonstrability (the tangible results of using the technology to complete a task). The study was guided by the following research question: How do L2 students perceive ASR as a writing tool in terms of usefulness, ease of use, and intention to use?

\section{Method}

This mixed-methods study was conducted with 17 ESL students enrolled in a university-level English for Academic Purposes class in Quebec, Canada. Individual research sessions began with training on using Google voice typing in Google Docs. Two short writing tasks were then carried out following the procedure used in the participants' writing class. To measure their perceptions of using ASR to write, the participants were then asked to complete a TAM-informed survey consisting of statements measuring perceived usefulness, perceived ease of use, and intention to use, scored on a seven-point Likert scale. Later, 
semi-structured interviews were conducted to explore participants' perceptions of writing using ASR. Means of the survey responses were calculated and interviews were analyzed for positive, negative, neutral, or mixed perceptions (Saldaña, 2009).

\section{Results and discussion}

As illustrated in Table 1, an analysis of the TAM survey showed positive perceptions, as the means of the items for each category were above the level of neutrality (i.e. four), indicating that the users saw the technology as useful, easy to use, and consequently, they intend to use it again in their future language learning endeavors. Interviews revealed that participants appreciated the ease of producing texts without having to worry about orthography and grammar, the possibility to improve their pronunciation and self-efficacy when speaking, and the user-friendly voice commands. However, some participants felt their current level of English was not high enough to use ASR, since their utterances were not always intelligible to the technology. Others, however, found practice helped them overcome this issue. These results confirm our hypothesis that participants would appreciate the affordances offered by ASR as a suitable tool to use for writing.

Table 1. Descriptive statistics of survey results: main categories

\begin{tabular}{|l|l|l|}
\hline TAM Constructs & Mean/7 & SD \\
\hline Perceived Usefulness $(\alpha=.82)$ & 4.71 & 1.69 \\
\hline Cognitive Influences $(\alpha=.83)$ & 4.71 & 1.77 \\
\hline Academic Relevance $(\alpha=.92)$ & 4.16 & 1.80 \\
\hline Output Quality $(\alpha=.96)$ & 4.10 & 1.79 \\
\hline Result Demonstrability $(\alpha=.52)$ & 5.84 & 1.30 \\
\hline Perceived Ease of Use $(\alpha=.88)$ & 5.25 & 1.58 \\
\hline Intention to Use $(\alpha=.60)$ & 5.78 & 1.10 \\
\hline
\end{tabular}

The positive perceptions of ASR as a writing tool can be better understood when examining the TAM constructs through the lens of Chapelle's (2001) criteria for evaluating CALL tools. Participants found the technology useful (it promoted language learning) and authentic (it was used to write authentic texts), and it fostered a focus on meaning (not form). There was learner fit, as ASR allowed participants to work at their level of English on texts for their ESL class, creating the potential for a positive impact on their writing abilities and grades. In terms of ease of use, participants appreciated the ease with which they could get the 
meaning of their ideas into texts without focusing on form, and the practicality of using a tool that is already available for free on their devices (which they already use to compose shorter text messages in their L1s).

\section{Conclusions}

The purpose of this study was to examine ESL learners' perceptions of using ASR to write academic texts in English to assess its usability as a writing tool. Both quantitative and qualitative data indicate that users had positive perceptions, suggesting that this technology has the potential to be used by and to benefit L2 English writers.

Certain limitations must be taken into consideration. This research was completed during the COVID pandemic, and the university from which the participants were recruited was completely shut down. Participants studied at home and had very few opportunities to speak English. This may have affected their fluency and pronunciation, thus diminishing the accuracy of the ASR output and their positive perceptions of the usefulness of the tool. Additionally, this was a one-shot intervention, and we recognize that the effective use of ASR when writing may take time and practice. This lack of practice may have limited the participants' perceptions of the usefulness of the technology.

Now that the suitability of using ASR for writing has been established, the next stage is to assess its pedagogical effectiveness (Cardoso, in press). Studies are needed to determine its true pedagogical potential, as well as strategies for its use and best practices for classroom implementation. Research is also needed into using ASR to write in other L2s. French is an interesting target language because of its unpredictable orthography (e.g. the phoneme $/ \varepsilon /$ can be spelled as -ait, $-\hat{e}$, or -aient). ASR may offer affordances for students to learn about grapheme-tophoneme associations in such a language. Writing involves more than creating texts with correct form. Writers deserve a technology that allows them to focus on other elements of writing such as content and genre. ASR has the potential to be such a technology, as its use yields positive perceptions among ESL learners.

\section{Acknowledgments}

We would like to thank Dr Heike Neumann and Nina Padden at Concordia's ESL Center for their assistance and support. 


\section{References}

Arcon, N., Klein, P., \& Dombroski, J. (2017). Effects of dictation, speech to text, and handwriting on the written composition of elementary school English language learners. Reading and Writing Quarterly, 33(6), 533-548. https://doi.org/10.1080/10573569.2016.1253513

Cardoso, W. (in press). Technology for speaking development. In T. Derwing, M. Munro \& R. Thomson (Eds), Routledge handbook on second language acquisition and speaking. Routledge, Taylor \& Francis Group.

Chapelle, C. (2001). Computer applications in second language acquisition: foundations for teaching, testing, and research. Cambridge University Press.

Davis, F. (1989). Perceived usefulness, perceived ease of use, and user acceptance of information technology. MIS Quarterly, 13(3), 319-340. https://doi.org/10.2307/249008

Ding, Y., \& Zhao, T. (2019). Chinese university EFL teachers' and students' beliefs about EFL writing: differences, influences, and pedagogical implications. Chinese Journal of Applied Linguistics, 42(2), 163-181. https://doi.org/10.1515/CJAL-2019-0010

Hyland, K. (2011). Learning to write: issues in theory, research, and pedagogy. In R. Manchón (Ed.), Learning to write and writing to learn in an additional language (pp. 17-35). John Benjamins. https://doi.org/10.1075/11lt.31.05hyl

Saldaña, J. (2009). The coding manual for qualitative researchers. Sage Publications.

Venkatesh, V., \& Davis, F. (2000). A theoretical extension of the technology acceptance model: four longitudinal field studies. Management Science, 46(2), 186-204. https://doi.org/10.1287/ mnsc.46.2.186.11926 


\title{
OFLEBO, an online teacher-training programme for teachers of French in Botswana as an example of professionalisation
}

\author{
Boingotlo Winnie Kaome ${ }^{1}$ and Anne-Laure Foucher ${ }^{2}$
}

\begin{abstract}
Technology has influenced not only our everyday lives, but our education systems and the opportunities for teacher development. The introduction of information and communications technology has presented new training platforms to respond to the needs of the workforce. While traditional institutions have greatly impacted teachers, there are now other viable outlets through which many of the required 21 st century skills, such as professionalism, can be satisfied. Our project $O F L E B O$ is one such example, an online training tool targeting the teaching of oral skills for in-service teachers of the French language in Botswana. This area was chosen because of the teachers' admission on finding teaching oral skills a challenging task. This paper therefore aims to study the professionalisation of teachers through the OFLEBO project. Professionalisation as a process is continuous, and practice is its focus, therefore the aim is to inspire the evolution of classroom practices concerning the teaching of oral skills.
\end{abstract}

Keywords: teacher-training, professional development, continuing education, French as a foreign language, Botswana, OFLEBO.

\section{Introduction}

"In an era of school reform, many consider the education and professional development of teachers as the keystone to educational improvement" (Hawley \& Valli, 1999 cited in Darling-Hammond \& Sykes, 2010, p. 127). It is from this

1. Université Clermont Auvergne, Clermont-Ferrand, France; boingotlo_winnie.kaome@etu.uca.fr

2. Université Clermont Auvergne, Clermont-Ferrand, France; a-laure.foucher@uca.fr

How to cite this article: Kaome, B. W., \& Foucher, A.-L. (2021). OFLEBO, an online teacher-training programme for teachers of French in Botswana as an example of professionalisation. In N. Zoghlami, C. Brudermann, C. Sarré, M. Grosbois, L. Bradley, \& S. Thouësny (Eds), CALL and professionalisation: short papers from EUROCALL 2021 (pp. 172-176). Research-publishing.net. https://doi.org/10.14705/rpnet.2021.54.1328 
school of thought that the project $O F L E B O^{3}$ was born. This paper reports on an ongoing study in Botswana where French is taught as a foreign language in secondary schools and will discuss the first results from the data collected. The teaching of French started in 2000 in this context, hence there is a lot still to be achieved to promote the teaching and learning of the language. Taking into consideration that it is the first foreign language in the country's syllabus, there are many learning curves and opportunities for growth. One area identified is the need for further training of teachers as far as the teaching and development of oral skills is concerned, which is how OFLEBO came about. OFLEBO's main aim is to address the gaps that the teachers have identified in their teaching of oral skills, in the form of training modules that concentrate on the difficulties they experience e.g. how to choose teaching aids for oral comprehension, how to evaluate oral skills etc. This paper will share the first results of the study so far. We are demonstrating professionalisation in the sense of Ingersoll, Alsalam, Quinn, and Bobbitt (1997) who see it as "the movement to upgrade the status, training, and working conditions of teachers, including their credentials, induction, professional development, authority and compensation" (p. 7), the focus being on training and professional development. Moreover, we will also consider Snoek's (2010) addition that professionalisation is "a process in which a professional group pursues, develops, acquires and maintains more characteristics of a profession" (p. 3). The definitions are what led us to conclude that our project is indeed an example of professionalisation. The following research questions guided this study.

- How do teachers in Botswana define teaching oral skills?

- What are their current practices when teaching oral skills?

- What difficulties do they have in teaching oral skills?

- What kind of training would inspire the transformation of classroom practices that develop students' oral skills better?

\section{Method}

A form of action research was chosen to carry out the project whereby a problem was identified, and all concerned stakeholders were invited to work together to try and find a solution. This form of research calls for the same tools to be used

3. Oral Français Langue Étrangère in Botswana 
in the different phases of the research, hence a somewhat circular effect of using the same tools at different phases. From the data collected at the beginning of the research, a pilot project is designed online, influenced by the fact that there are training workshops in this context that aim to accompany teachers in their practice. However, they take place once or twice a year, and still do not reach the whole teacher population because of distance and time constraints. To respond better to the needs of teachers, an online training was prioritised in this project, responding to the shortcomings that the current set-up presents.

\subsection{Participants}

Secondary school teachers of French were asked to participate in this study. They were randomly invited to take part in the questionnaire in the first phase of the research and 42 out of a total of 90 responded. In the second phase, class observations were done with seven teachers (out of 12) from one region of the country. The reason for the choice of the region was that the teachers in this region rarely benefit from in-service training due to distance constraints.

\subsection{Data collection}

An online questionnaire was set up, then administered to 42 teachers, being $46 \%$ of the population of teachers. The main aim of this tool was to understand the teachers' understanding of oral didactics, what classroom practices are associated with the teaching of oral skills, what material is used, and how oral skills are evaluated. The questionnaire had both open-ended and closed-ended questions. Class observations were also conducted with seven teachers from the Maun region to witness exactly how the teaching of oral skills is currently done.

\section{Discussion and results}

The questionnaire showed that teachers in this context were not confident in teaching oral skills, $61 \%$ of the participants responded that it was a challenging task for them, while $95 \%$ expressed the desire for further training in the area. The survey revealed that teachers find teaching oral difficult and are not certain of ways to go about it. Their initial training, comprised of a bachelor's degree of four years and a postgraduate diploma of one year, was proving not to be enough for them to organise and put in place the kind of teaching that developed the oral skills of their students. As a result, the students in this context often have problems expressing themselves orally. Our project was piloted as a possible solution to address the gaps 
that the teachers have identified from their initial training. OFLEBO came about as a way of providing support and further development to in-service teachers.

The first results from the first phase of the project, i.e. the pre-training stage, bring to light what teaching oral currently looks like for our participants. It is evident that further training is needed to bring teachers up to speed with evolving teaching methods, hence making sure they develop their craft and are in a better position to serve their students. The following were noted from the questionnaire results:

- teaching oral language is deemed essential but difficult to implement by $61 \%$ of the teachers in this context;

- the level of experience does not seem to be a factor on those who made the above conclusion, as $79 \%$ of our respondents had more than five years of experience. This suggests that even with practice, the problem persists hence the need for intervention;

- the teachers identify external causes as being the source of the problem e.g. lack of resources (83\%) and lack of motivation of learners $(57 \%)$;

- there is no clear method used when it comes to teaching and evaluating oral skills, the teaching is not presented in an organised manner; and

- teachers admit to needing help in the area.

After administering the questionnaire, the researcher had the opportunity to carry out classroom observations to observe the reality of the students' experiences. This further provided insights into the teachers' interpretations of teaching oral skills and the following conclusions were drawn:

- the atmosphere in which teaching is done seems conducive to learning, however, there is not enough use of activities aimed at oral competence;

- learners are not very involved in oral activities;

- the type of communication that is dominant is that of question-and-answer type, with very little interaction; and

- there is a rare use of teaching aids. 
With the observations, another reality is painted, and that is the fact that besides the external sources that were cited previously, there seems to be a need for further training on how to proceed with the teaching of oral skills. With one-on-one interviews that were carried out with teachers after the classroom observations, they stated that they were not satisfied with their own lessons and that they need guidance to improve.

\section{Conclusion}

The results from this survey reinforced the need for in-service training of teachers of French in Botswana. The data collected helped the researcher in establishing the kind of training to deliver as well as the content that training could cover, therefore guiding the next step of the training tool design. The study investigated how the teaching of oral skills is currently organised, and the results showed that a transformation of classroom practices is necessary if teachers are to produce competent communicative learners. The survey made way for the next step of the research, which is the training design, and then the evaluation of the training thereafter to establish if it inspired any new classroom practices.

\section{References}

Darling-Hammond, L., \& Sykes, G. (2010). Teaching as the learning profession: handbook of policy and practice. Jossey-Bass.

Hawley, W., \& Valli, L. (1999). The essentials for effective professional development: a new consensus. In L. Darling-Hammond \& G. Sykes (Eds), Teaching as the learning profession: handbook of policy and practice. Jossey Bass.

Ingersoll, R. M., Alsalam, N., Quinn, P., \& Bobbitt, S. (1997). Teacher professionalization and teacher commitment: a multilevel analysis. National Center for Education Statistics.

Snoek, M. (2010). Theories on and concepts of professionalism of teachers and their consequences for the curriculum in teacher education. https://www.semanticscholar.org/paper/Theorieson-and-concepts-of-professionalism-of-and-Snoek/7560a953f19897334e444aad6feb37bc9 ce $41 \mathrm{cbc}$ 


\title{
Students' perceptions of digital storytelling in primarily asynchronous EFL classes at a Japanese university
}

\author{
Naoko Kasami ${ }^{1}$
}

\begin{abstract}
This study aims to analyse the initial use of Digital Storytelling (DS) in primarily asynchronous classes in order to yield results and recommendations for future courses. All participants were students in elective English courses at a Japanese university in Spring, 2020. Due to COVID-19, the courses were redesigned and conducted remotely with the use of pre-recorded materials. Data were collected through a post-questionnaire. This short paper reports what was found from the data by analysing the questionnaire with CALL evaluation criteria developed by Jamieson, Chapelle, and Preiss (2005). From the post-questionnaire, it was revealed that the DS assignment was perceived positively to some extent in remote learning settings. However, it also highlighted the need for further in-depth technical and language support and interactive learning opportunities.
\end{abstract}

Keywords: digital storytelling, on-demand course, remote learning, EFL, university students.

\section{Introduction}

The purpose of this study is to review and clarify potential improvements in DS assignments with pre-recorded materials in primarily asynchronous classes prepared during the COVID-19 pandemic. This study focused on the DS in primarily asynchronous English as a Foreign Language (EFL) courses which ran from May to August 2020. The study goal of the course was to acquire skills and knowledge to present ideas and messages effectively with the use of Information

1. J. F. Oberlin University, Tokyo, Japan; naoko.kasami@gmail.com; https://orcid.org/0000-0002-3775-6827

How to cite this article: Kasami, N. (2021). Students' perceptions of digital storytelling in primarily asynchronous EFL classes at a Japanese university. In N. Zoghlami, C. Brudermann, C. Sarré, M. Grosbois, L. Bradley, \& S. Thouësny (Eds), CALL and professionalisation: short papers from EUROCALL 2021 (pp. 177-183). Research-publishing.net. https://doi.org/10.14705/ rpnet.2021.54.1329 
and Communications Technology (ICT) and English. DS was the main assignment of the course and was conducted in the latter half of the term.

Recent studies have reported students' perceptions of DS from various perspectives with questionnaires (Liu, Wang, \& Tai, 2016; Oskoz \& Elola, 2016). In this paper, the students' perceptions of DS assignments in primarily asynchronous classes were investigated using questions based upon a questionnaire evaluating CALL materials which was produced by Jamieson et al. (2005) and based on six criteria defined by Chapelle (2001): (1) language learning potential, (2) meaning focus, (3) learner fit, (4) authenticity, (5) positive impact, and (6) practicality.

This study aimed to answer the two research questions below.

- What were the students' perceptions of the DS assignment with prerecorded materials in terms of the six criteria?

- What factors were preferable and what should be considered in the DS assignment for future remote courses?

\section{Method}

\subsection{Participants and courses}

Most students were basic or intermediate level English learners majoring in ICT related fields. In spring 2020, 90 students enrolled in the elective EFL courses for second to fourth year students, and 64 (44 male and 20 female) students agreed to participate in this research by answering the post-questionnaire survey.

The DS assignment was conducted in primarily asynchronous classes, supported with complementary short (30-minutes) online (synchronous) meetings held every few weeks in Spring, 2020. Each student was supposed to create a digital story about their 'future dream'. The pre-recorded videos for DS covered; (1) basic grammar (to infinitive) instruction relating to expressing future dreams, (2) an example of DS (which included various English expressions related to future dreams), (3) how to write a scenario in English, and (4) how to create a digital story technically including tips for recording narration clearly and checking pronunciation with the use of Google Translate. The length of most pre-recorded videos was less than 15 minutes, and was accessed from the university learning management system. 
On each weekly page, students could view instructions, pre-recorded materials, lecture notes, comprehension quizzes, tasks and challenging content on their schedules. They could also post and share their essays, create digital stories, and receive feedback from the teacher and classmates.

\subsection{Data collection}

In the course, three questionnaires were conducted during the term similarly to the past courses (Kasami, 2017). The post-questionnaires in the term consisted of four sections - general impression of the remote course, students' perceptions of DS, self-evaluation of DS, and learning motivation. The study focused on the section of students' perceptions of DS. In Jamieson et al. (2005)'s research, the CALL material, Longman English Online (LEO), was evaluated. This study customised the students' questionnaires of Jamieson et al. (2005, pp.131-133) by changing the terms LEO to DS (see supplementary materials, Appendix 1).

Even though the DS assignment with pre-recorded materials was not included in CALL materials, CALL evaluation criteria were used in this study, as most questions seemed to be appropriate and useful to get a grasp of the perceptions and problems of the DS assignment. The post-questionnaires were analysed using Google Forms after the peer-reviews at the end of the course.

\section{Results and discussion}

\subsection{Students' perceptions of the DS assignment as measured by the six criteria}

The results from the questionnaires, which explored the six criteria are shown in supplementary materials Appendix 2, are reported according to each criterion.

- Language learning potential. Most of the students reported that their English improved to some extent after working on the DS assignment, but three students (4.7\%) answered that their English did not improve. Most students thought that they understood the grammar explanation and the quizzes helped them to learn English to some extent.

- Meaning focus. Most of the students tried to understand the story in the sample DS whose topic was 'future dream' (to publish a travel photo book). 
- Learner fit. Students were asked about the difficulty of the DS assignment. Though most $(87.5 \%)$ of the students reported that the DS assignment was set at a good level of difficulty, $10.9 \%$ of students felt it was very difficult (see Figure 1).

- Authenticity. The students found that what they learned from the DS assignment was useful and nobody negatively answered the question: is what you learned in the DS assignment useful outside of class?

- Positive impact. It was reported that $45.3 \%$ of students liked the DS assignment, and $42.2 \%$ of students liked it somewhat. There were $12.5 \%$ of the students who did not like it.

- Practicality. Figure 2 shows that $78.1 \%$ of students thought they understood the directions, while $45.3 \%$ of students reported that they needed some help. There were six responses to the open-ended question, of which four answers were technically related. Two students also commented that they needed assistance with writing English sentences. More than $90 \%$ of students reported that they spent between one to four hours writing their scenarios in English. The time spent for creating DS varies from student to student: about $70 \%$ of students spent one to five hours creating their DS while about $14 \%$ of students spent more than five hours.

In this study of the DS assignment, learner fit tended to be comparatively higher than other criteria. However, it was reported that $45.3 \%$ of students needed help to some degree.

Figure 1. Learner fit

Learner fit - Measurement of student perception of the difficulty of the assignment

How difficult was the DS assignment for you? $(n=64)$

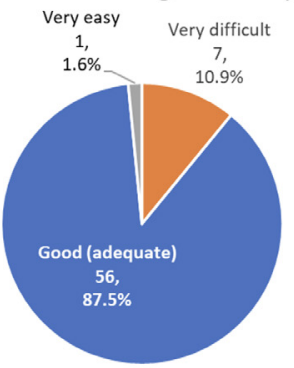


Figure 2. Practicality

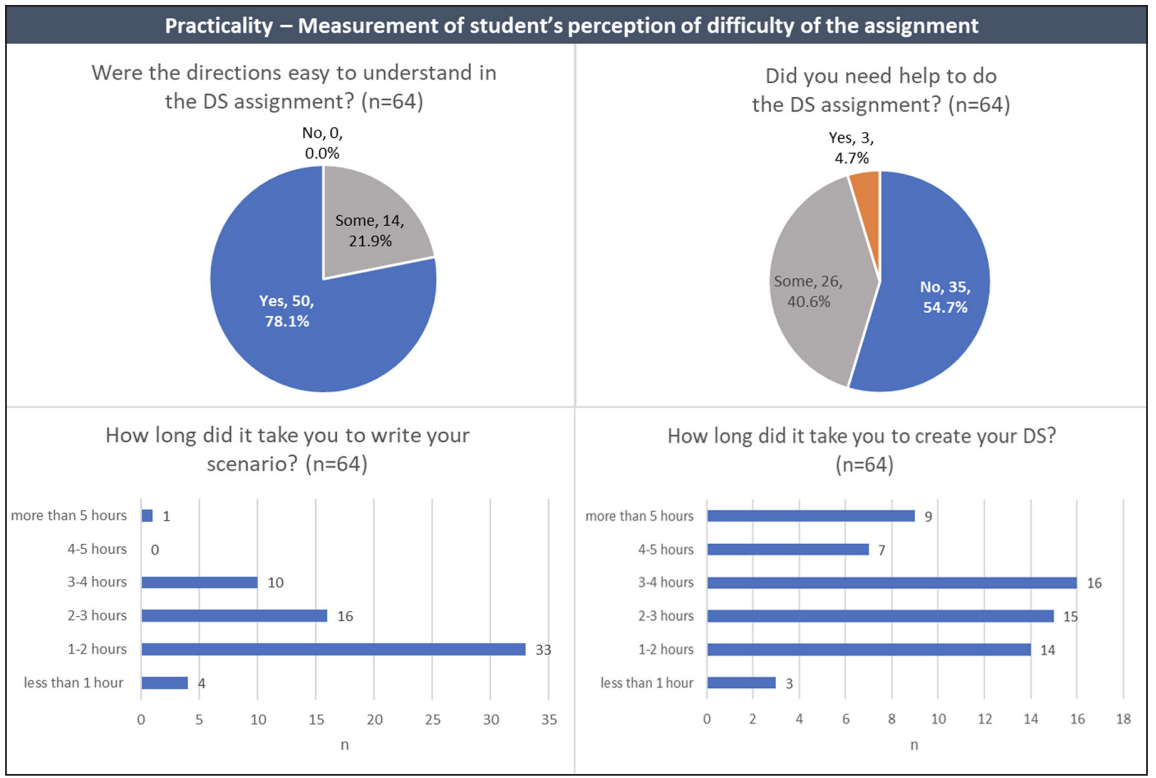

\subsection{What was preferable and what could be improved?}

Two open-ended questions were presented, and answers solicited from the students. For the question regarding which points were preferable in the DS assignment, there were 28 responses as follows.

"It was good to know what each person thought and felt from each video and message. I also enjoyed reviewing each participant's work with the peer review sheet. I was glad that I learned something new from work created by my classmates".

"Conducting this assignment was very rewarding. I enjoyed watching other people's work".

"Though I do not have many opportunities to pronounce English in my daily life, I had chances to listen to my English narration and noticed how to improve my pronunciation".

For another question concerning which points were bad (or needed to be improved) in the DS assignment, there were nine responses as follows. 
"I wanted to talk about our work with my classmates more. The time spent for peer review should have been longer".

"I felt that it would be easier to understand if there were more models or example digital stories".

"The operation sometimes did not work due to the different versions of PowerPoint. So, I would feel more confident if there had been more Q\&A functions or FAQs".

These comments suggest that for future courses it is important to hold more and longer online meetings so that students can have more support and interaction with their classmates and teacher.

\section{Conclusion}

From the analysis of the post-questionnaire, most students regarded the DS assignment in primarily asynchronous classes somewhat positively, and most students $(87.5 \%)$ rated the difficulty level of the assignment as appropriate, and the DS assignment allowed students to enjoy sharing ideas and learning together even in remote settings. Despite this, seven of the participating students $(10.9 \%)$ found the DS assignment was very difficult, and more than $45 \%$ of students needed some help. Therefore, in-depth language and technical support should be provided with revised FAQs and additional online meetings to allow students to ask questions and communicate with others.

The courses of 2021 are in progress with these improvements, and the results of the courses will be reported in future studies.

\section{Supplementary materials}

https://research-publishing.box.com/s/2gby678h21brd08fshi0n5zjplqv1832

\section{Acknowledgements}

I would like to thank Dr Julian Lewis for his advice on my paper. 


\section{References}

Chapelle, C. A. (2001). Computer applications in second language acquisition. Cambridge University Press. https://doi.org/10.1017/CBO9781139524681

Jamieson, J., Chapelle, C. A., \& Preiss, S. (2005). CALL evaluation by developers, a teacher and students. CALICO Journal, 23(1), 93-138. https://doi.org/10.1558/cj.v23i1.93-138

Kasami, N. (2017). The comparison of the impact of storytelling and digital storytelling assignments on students' motivations for learning. In K. Borthwick, L. Bradley \& S. Thouësny (Eds), CALL in a climate of change: adapting to turbulent global conditions short papers from EUROCALL 2017 (pp. 177-183). Research-publishing.net. https://doi. org/10.14705/rpnet.2017.eurocall2017.709

Liu, C. C., Wang, P. C., \& Tai, S. J. D. (2016). An analysis of student engagement patterns in language learning facilitated by Web 2.0 technologies. ReCALL, 28(2), 104-122. https://doi. org/10.1017/S095834401600001X

Oskoz, A., \& Elola, I. (2016). Digital stories: bringing multimodal texts to the Spanish writing classroom. ReCALL, 28(3), 326-342. https://doi.org/10.1017/S0958344016000094 


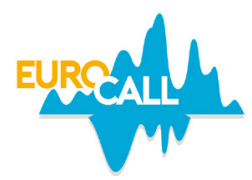

\title{
Independent learner strategies to improve second language academic writing in an online course
}

\author{
Olivia Kennedy ${ }^{1}$
}

\begin{abstract}
This article explores how 40 first-year students in a compulsory English for Academic Purposes (EAP) course undertook written tasks during a semester suddenly undertaken online. The university in Japan described here provided ondemand lessons via the Learning Management System (LMS) during the first COVID-19 pandemic lockdown. Students prepared three-minute reflective videos as part of their course work describing their strategies to improve their second language (L2) academic writing and their perceptions of how these strategies affected their learning. These videos were transcribed, coded, and analysed. The use of Machine Translation (MT) to proofread work before submission was used by $58 \%$ of the participants, of whom $45 \%$ report improved assignment grades and higher levels of confidence in their L2 writing skills. Results suggest that learners should be encouraged to use MT for this step in the L2 academic writing process.
\end{abstract}

Keywords: L2 academic writing, writing strategies, machine translation, proofreading, self-reflective videos.

\section{Introduction}

In early 2020, learners across the globe found themselves suddenly taking courses online as the first lockdowns to contain the spread of COVID-19 shuttered campuses. While some institutions provided lessons in real time, the university in Western Japan described here uploaded on-demand lessons to the LMS. This action research article explores the ways that 40 first-year students in an EAP course undertook the written tasks assigned to them. Participants were able to identify appropriate tools and were found to be using a variety of such resources in

\footnotetext{
1. Nagahama Institute of Bioscience and Technology, Shiga, Japan; o_kennedy@nagahama-i-bio.ac.jp; olivia_1_kennedy@ yahoo.com; https://orcid.org/0000-0003-0144-2516

How to cite this article: Kennedy. O. (2021). Independent learner strategies to improve second language academic writing in an online course. In N. Zoghlami, C. Brudermann, C. Sarré, M. Grosbois, L. Bradley, \& S. Thouësny (Eds), CALL and professionalisation: short papers from EUROCALL 2021 (pp. 184-188). Research-publishing.net. https://doi.org/10.14705/ rpnet.2021.54.1330
} 
their writing processes including MT to proofread L2 writing before submission. Surveying a similar university population in Korea, Briggs (2018) found 48.8\% to believe that MT had value for language learning. In a study designed by Lee (2020), a group of 34 university English as a foreign language learners were taught to compare their own L2 translations of their L1 compositions with an MT version. Both the participants of this study and those observed by Lee reported higher levels of efficacy and efficiency after adopting this practice.

\section{Participants and setting}

The 40 participants are Japanese, with an average TOEIC score of 570, equating to approximately $\mathrm{B} 1$ on the $\mathrm{CEFR}^{2}$ scale. This compares well to the national average of 520 points (Educational Testing Service TOEIC, 2018). Participant levels of both autonomy and motivation are also high, as evidenced by 12 (33\%) having spent a year of independent study before matriculation due to the difficulty of the admission examinations and their desire to enter this specific highly ranked university.

The course followed the same structure online as previous in-person course iterations. Students first learned to write a well-structured paragraph, then a problem-solution essay, and finally a five-paragraph essay. Their tasks followed the same pattern each week: to read a news article and answer multiple-choice comprehension questions, to write sentences practising vocabulary from the article, and finally to write a paragraph or essay related to the topic. Formative assessment was delivered in two-week cycles, with the instructor collecting, commenting on, and returning student work covering an expanding list of proficiencies, which included constructing topic sentences and thesis statements, the use of signposting at the start of and within paragraphs, the formation and ordering of details and examples to support points made, and appropriate citation and referencing.

\section{Method}

As part of their coursework, students were asked to submit a three-minute reflective video to the LMS about the specific processes by which they performed writing tasks. Reflective videos have been found to be not only a useful way to gather explorative qualitative data (Gubrium, Hill, \& Flicker, 2014) but also to occasion

2. Common European Framework of Reference for languages 
meaningful reflective learning with minimal instruction (Nonaka \& Konno, 1998) and were therefore chosen for this project. Participants understood that they could choose for their videos to not be included in this study, and that while their L2 complexity and fluency would be graded for assessment purposes, the strategies or opinions expressed would not.

Videos were first each watched twice to form an overall understanding of the data set. The data were then digitally transcribed using the dictation function in Word (version 16.51) then checked manually for accuracy. A total of 112 minutes of data resulted, with a total word count of 13,248 words. The transcripts were then coded with a three-cycle thematic analysis approach (Otani, 2009), which has its roots in grounded theory. This method was chosen to allow for themes to first emerge organically from the data, and then to be confirmed within the data set. Microsoft Excel was used to chart each participant's writing process, with thematic codes heading each column.

\section{Results and discussion}

Themes relating to the process by which participants undertook their assigned writing tasks are outlined here in the order of the writing process and highlighted in bold where possible. Many participants $(60 \%)$ described using the same process every week, with approximately half (47\%) approaching their extended writing tasks first on paper offline. Four students explained why they did this. One stated that this let him capture and organise his ideas. Another talked about how when using his laptop, he felt distracted by his own inadequacy and sought better ways to express his ideas and sometimes better ideas than his own on the Internet. By writing on paper, he could control these feelings. The remaining two participants talked about the difficulty of staying on task when using an online device.

After this first step on paper, for all but one (98\%) of the participants, who submitted photographs of his notebook for assessment, it became the modus operandi to use online tools. Most (70\%) typed their work into a Microsoft Word file, or the Notes application (7\%), but several (21\%) skipped typing by using a dictation application to save time. One such student reported feelings of happiness, and another, vindication, upon finding that her English pronunciation could be understood by the technology.

Microsoft Word itself provided the next step for 24 participants, who paid careful attention to the red/blue underlining in their compositions and tried to correct 
the spelling or grammatical errors that these pointed to. To aid in this, some $(30 \%)$ reported purchasing the app of the paper or electronic dictionary that they had used in high school. Four were surprised by how fast, for example, checking collocations had become using such an app. Others (42\%) embraced online translation websites to guide them in these corrections. Eleven participants (28\%) reported paraphrasing the resulting L2 sentences.

Many of the participants (58\%) then used MT to translate their entire essay as the final step in the writing process. Some (20\%) used it to translate their final L2 composition into L1, doing so to check content and nuance rather than linguistic accuracy. The remaining 15 participants (38\%) used MT to translate either a draft written in L1, or their own L1 approximations of what they had written directly in L2. This second group of participants described comparing their own writing with the MT-generated text, identifying differences and errors, and exploring the reasons for them using other trusted, often analogue, tools like dictionaries and textbooks kept from high school.

Whereas Lee (2020) reports improvements in both the number of her participants' lexico-grammatical errors, and in their understanding of L2 writing as a process rather than a final goal, the linguistic gains of participants in this project were not specifically assessed because the course aims to teach academic writing skills. Many (45\%) following this process described significant improvements in L2 writing confidence, stating for example, "I feel much better writing now" and "I know that I can do the assignments correctly". Another reported that "using DeepL shows me that my writing can be understood by native [speakers]". Others (28\%) described how their grades for assignments improved over the course of the semester. While these participants were not asked whether they felt their method of assignment task completion benefitted their L2 skills, it seems that they view it as having done so. This echoes the findings in Briggs (2018) that learners believe MT to be of significant value in language learning.

\section{Conclusions}

Many of the learners in this study have harnessed the power of technological tools to improve their L2 academic writing skills, including the use of MT to proofread and check assignments before submission. Participants not only identifying appropriate tools but also developing processes to use them effectively shows that learners are ready to embrace this level of technology usage. While some educators may hesitate to introduce such tools to students, and fear that they will simply be used to 
translate passages from L1 to L2, the independent development of these processes by the participants in this project show that technological tools can improve learner efficacy and satisfaction.

\section{References}

Briggs, N. (2018). Neural machine translation tools in the language learning classroom: students' use, perceptions, and analyses. JALT CALL Journal, 14(1), 3-24. https://doi.org/10.29140/ jaltcall.v14n1.221

Educational Testing Service TOEIC. (2018). 2018 report on test takers worldwide (TOEIC Listening and Reading Test). https://www.ets.org/s/toeic/pdf/2018-report-on-test-takersworldwide.pdf

Gubrium, A. C., Hill, A. L., \& Flicker, S. (2014). A situated practice of ethics for participatory visual and digital methods in public health research and practice: a focus on digital storytelling. American Journal of Public Health, 104(9), 1606-1614. https://doi.org/10.2105/ AJPH.2013.301310

Lee, S. 2020). The impact of using machine translation on EFL students' writing. Computer Assisted Language Learning, 33(3), 157-175. https://doi.org/10.1080/09588221.2018.1553 186

Nonaka, I., \& Konno, N. (1998). The concept of 'Ba': building a foundation for knowledge Creation. California Management Review. http://journals.sagepub.com/doi/pdf/10.2307/41165942

Otani, T. (2009). SCAT. A qualitative data analysis method by four-step coding: easy startable and small-scale data-applicable process of theorization. Nagoya University Bulletin of the Graduate School of Education and Human Development, 54, 27-44. 


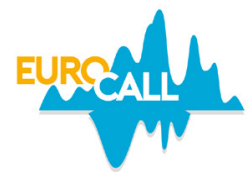

\title{
The use of MS Teams in ESP instruction during the COVID-19 pandemic: students' attitudes towards the e-learning environment
}

\author{
Ivana M. Krsmanović ${ }^{1}$ and Vesna M. Petrović ${ }^{2}$
}

\begin{abstract}
With the outbreak of COVID-19, universities worldwide were forced to quickly transition to online emergency teaching in order to secure the well-being of students and teachers. The paper analyses students' attitudes towards the use of the Microsoft Teams platform in the instruction of English for Specific Purposes (ESP) at the Faculty of Technical Sciences Čačak during the winter semester 2020. The study focuses on students' engagement with e-learning, their motivation, and overall satisfaction with ESP instruction during pandemic conditions. The study was conducted with first-year students of engineering $(\mathrm{N}=79)$ using an online survey as an exploratory, qualitative research instrument. The findings of the research revealed that students have positive attitudes towards the use of Microsoft Teams in ESP instruction as the e-learning environment. The results suggest that all the available features of the tool are perceived as beneficial and easy to adapt to, with the recorded sessions of online lectures and online testing rated the most useful segments of the online ESP instruction.
\end{abstract}

Keywords: Microsoft Teams, English for specific purposes, attitudes, COVID-19, emergency remote teaching.

\section{Introduction}

One and a half years after the COVID-19 outbreak, almost every learner in the world has experienced a forced transition to online learning at a certain point (emergency remote teaching). About 1.5 billion students worldwide have been affected by the abrupt transition to online schooling (Holzapfel, 2020), partially or

1. University of Kragujevac, Kragujevac, Serbia; ivana.krsmanovic@ftn.kg.ac.rs; https://orcid.org/0000-0003-4793-628X

2. University of Kragujevac, Kragujevac, Serbia; vesna.petrovic@ftn.kg.ac.rs; https://orcid.org/0000-0002-1321-3449

How to cite this article: Krsmanović, I. M., \& Petrović, V. M. (2021). The use of MS Teams in ESP instruction during the COVID-19 pandemic: students' attitudes towards the e-learning environment. In N. Zoghlami, C. Brudermann, C. Sarré, M. Grosbois, L. Bradley, \& S. Thouësny (Eds), CALL and professionalisation: short papers from EUROCALL 2021 (pp. 189-193). Research-publishing.net. https://doi.org/10.14705/rpnet.2021.54.1331 
fully, which represents $70 \%$ of the global student population (UNESCO, 2020). In such circumstances, online teaching of English as a foreign language as the only teaching method available has become a growing challenge for both teachers and students in tertiary education.

Students' attitudes and motivation are elements that play a pivotal role in language learning and are constantly in interaction (Martínez-Sáez, Sevilla-Pavón, \& Gimeno-Sanz, 2018; Radovan \& Markovec, 2015). Recent research suggests that positive attitudes towards the learning environment lead to higher learner satisfaction and confidence (Radovan \& Markovec, 2015), whereas students' attitudes toward CALL represent a key factor for predicting the success in CALL (Zhang, 2011). A significant focus was recently placed on the effects of students' attitudes in CALL in regular teaching conditions (e.g. Delibegović \& Hasanspahić, 2020), however, students' perceptions of Microsoft Teams as an e-environment in ESP have been under-researched (Keshtiarast \& Salehi, 2020).

This study aims at investigating students' attitudes towards the use of the MS Teams platform in the instruction of ESP at the Faculty of Technical Sciences Čačak during the winter semester of 2020. The main goal of the research is to assess how students perceive the e-environment and MS Teams as a learning tool, in the emergency remote teaching circumstances.

\section{Method and instrument}

Exploratory, qualitative research (non-experimental method) was applied. Upon completion of the spring semester, 79 students were selected by purposeful sampling, and they were asked to complete an online questionnaire. It consists of five sections: (1) demography, (2) general learning routine and equipment used, (3) motivation and overall course, (4) online tests, and (5) benefits and shortcomings of the ESP course held using Teams. Out of 38 questions, the first eight questions are multiple-choice questions, and Questions 9-38 are given as statements with a fivepoint Likert scale. The reliability of the data collection instrument was determined by the Cronbach Alpha's Coefficient, with a result of 0.83 .

\section{Results and discussion}

As for demography, $72.7 \%$ of the respondents are male, $26 \%$ are female, whereas $1.3 \%$ identify as 'other'. The majority of the respondents belong to the $18-20$ 
age group (75.3\%). Section 2 of the questionnaire was designed to investigate students' learning routine and the equipment used during the semester, reasons for skipping online classes and the MS Teams tools they used the most/least. In terms of equipment used, the respondents used: a laptop (35.1\%), a phone (27.3\%), a phone and a computer alternatively (27.3\%), and a desktop computer (10.4\%). As many as $32.5 \%$ of students reported to have attended all classes, whereas $41.6 \%$ confessed to having missed only one to three classes in the whole semester.

Reasons for skipping classes differed; 'insecure Wi-Fi connection' leads the reasons list with $44 \%$ of respondents, 'being absent due to being employed' with $27.3 \%$, 'classes timetable' with $22.7 \%$, and 'lack of skills in Teams' with $3 \%$. Finally, choices 'equipment issues' and 'my or someone else's illness' were chosen by $1.5 \%$ respondents respectively. As for the most frequently used MS Teams tools: 'video recordings of direct online lectures' was chosen by $45.5 \%$, respondents, 'teacher's video calls (direct online classes)' by $29.9 \%$, 'teaching materials in pdf, word' by $15.6 \%$, chat messages by $2.6 \%$, and finally, online tests by $6.5 \%$. The least frequently used MS Teams tools were: chat messages (61\%), teacher's direct video calls (direct online classes - 13\%), teaching materials in pdf, word $(11.7 \%)$, video recordings of direct online lectures $(10.4 \%)$, and online tests $(3.9 \%)$.

Section 3 of the questionnaire addressed students' motivation and overall course satisfaction. The results in Table 1 show that students evaluated both direct and recorded online classes positively (on a five-point Likert scale, one being 'disagree' and five being 'totally agree'). Direct online classes only moderately motivated them to attend the course (Item 9) and communicate with the teacher (Item 11), whereas the recorded classes were perceived as more motivating to better prepare for the exam (Item 16) or manage learning time effectively (Item 15). However, students gave the lowest evaluation to Statement $12(\mathrm{M}=3.5205)$ which refers to direct online classes as a motivator to communicate with their colleagues. The highest evaluation was given to Item $14(\mathrm{M}=4.3766)$ which measures whether the recorded classes motivated them to revise or study the chapters they had missed.

Table 1. Descriptive statistics on direct and recorded online classes

\begin{tabular}{|l|l|l|l|l|l|l|}
\hline \multicolumn{2}{|l|}{ Statement } & N & Min & Max & Mean & $\begin{array}{l}\text { Standard } \\
\text { deviation }\end{array}$ \\
\hline 9 & $\begin{array}{l}\text { Direct online classes motivated } \\
\text { me to attend the course fully. }\end{array}$ & 77 & 1.00 & 5.00 & 3.9870 & .97998 \\
\hline 10 & $\begin{array}{l}\text { Direct online classes motivated me } \\
\text { to actively participate in the course } \\
\text { (communicate, share, etc.). }\end{array}$ & 77 & 1.00 & 5.00 & 3.6753 & 1.10551 \\
\hline
\end{tabular}




\begin{tabular}{|c|c|c|c|c|c|c|}
\hline 11 & $\begin{array}{l}\text { Direct online classes motivated me } \\
\text { to communicate with the lecturer. }\end{array}$ & 77 & 1.00 & 5.00 & 3.7662 & 1.11090 \\
\hline 12 & $\begin{array}{l}\text { Direct online classes motivated } \\
\text { me to communicate with my } \\
\text { colleagues (fellow students). }\end{array}$ & 73 & 1.00 & 5.00 & 3.5205 & 1.28138 \\
\hline 13 & $\begin{array}{l}\text { Recorded online classes } \\
\text { motivated me to study more. }\end{array}$ & 77 & 1.00 & 5.00 & 3.9610 & 1.08144 \\
\hline 14 & $\begin{array}{l}\text { Recorded online classes motivated me } \\
\text { to revise/study the chapters I missed/ } \\
\text { go back to chapters I did not learn. }\end{array}$ & 77 & 1.00 & 5.00 & 4.3766 & 1.08869 \\
\hline 15 & $\begin{array}{l}\text { Recorded online classes motivated } \\
\text { me to better plan my studying time } \\
\text { (manage time more effectively). }\end{array}$ & 77 & 1.00 & 5.00 & 4.2727 & .94083 \\
\hline 16 & $\begin{array}{l}\text { Recorded online classes motivated me to } \\
\text { prepare better for the final examination. }\end{array}$ & 77 & 1.00 & 5.00 & 4.2857 & .98485 \\
\hline
\end{tabular}

Sections 4 and 5 investigated the benefits and shortcomings of the course and tests conducted via Teams, with the final five questions investigating future recommendations. After the descriptive statistical analysis was performed, the results showed that students expressed generally positive attitudes towards online tests and the overall course (all means $>4$ ). However, students gave the lowest estimation to Item $35(\mathrm{M}=2.4177)$ which reads 'I would like to have future English courses exclusively in the classroom'. This concurs with the result calculated for Item $37(\mathrm{M}=4.0909)$ which reads: 'I would like to have future tests and classes exclusively online'. Students highly rated the flexibility and easy access of Teams as a tool $(M=4.5769)$, but they gave the highest evaluation to the statement 'the Online Business English course in Teams was beneficial as I can replay the lectures and access the learning materials as many times as needed' $(\mathrm{M}=4.7722)$. Students also feel that a shortcoming of online classes in Teams is a lack of adequate home space to study and focus on learning $(M=4.0127)$.

\section{Conclusions}

The conducted study revealed that students perceive MS Teams as a supportive learning environment in ESP, which enhances engagement and serves as a convenient, although technically demanding, tool. The most valuable features of the tool were video recordings of direct online lectures, which motivated students to revise or re-access the teaching material. The study also showed that students prefer online testing to traditional and would also like to have other upcoming courses in ESP online. 


\section{References}

Delibegović, N., \& Hasanspahić, A. (2020). Computer-assisted language learning in English language classrooms in Bosnia and Herzegovina. ExELL (Explorations in English Language and Linguistics), 8(1), 14-46. https://doi.org/10.2478/exell-2020-0012

Holzapfel, B. (2020, December 15). The acceleration of hybrid learning for higher-ed students and faculty. Microsoft Education Blog. https://educationblog.microsoft.com/en-us/2020/12/ the-acceleration-of-hybrid-learning-for-higher-ed-students-and-faculty

Keshtiarast, B., \& Salehi, H. (2020). Investigating employing information communication technology for ESP learning: a case of Iranian EFL students' attitudes. International Online Journal of Education and Teaching, 7(2), 412-433. https:/eric.ed.gov/?id=EJ1250584

Martínez-Sáez, A., Sevilla-Pavón, A., \& Gimeno-Sanz, A. (2018). Analysing students' perceptions of two learning and evaluation modalities in the InGenio FCE Online Course and Tester. In P. Taalas, J. Jalkanen, L. Bradley \& S. Thouësny (Eds), Future-proof CALL: language learning as exploration and encounters - short papers from EUROCALL 2018 (pp. 193-199). Research-publishing.net. https://doi.org/10.14705/rpnet.2018.26.836

Radovan, M., \& Markovec, D. (2015). Adult learners' learning environment perceptions and satisfaction in formal education - case study of four East-European countries. International Education Studies, 8(2), 101-112. https://doi.org/10.5539/ies.v8n2p101

UNESCO. (2020). Global education monitoring report 2020: inclusion and education: all means all. https://unesdoc.unesco.org/ark:/48223/pf0000373718

Zhang, S. (2011). Attitudes of ESL students toward the use of computer-assisted language learning (call) in a university in China. Unpublished doctoral dissertation. A \& M UniversityCommerce. https://www.proquest.com/docview/884796731 


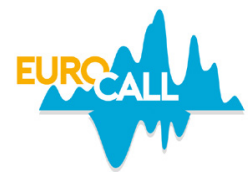

\title{
Experiences of using Unicam for asynchronous video assessment of the Irish language
}

\author{
Rob Lowney ${ }^{1}$, Gearóidín Uí Laighléis ${ }^{2}$, Seán Mac Risteaird ${ }^{3}$, \\ and Éadaoin Ní Mhuircheartaigh ${ }^{4}$
}

\begin{abstract}
Video is used widely in language education as a learning tool and a production tool for students to demonstrate oral competence. In response to the Covid-19 pandemic, Irish language lecturers at Dublin City University (DCU) set asynchronous video assessment tasks for students on teacher education programmes. Tasks were completed using the web-based Unicam platform, which streamlines video creation and submission, allowing students to focus on their task and not technical affairs. Students' and the teaching team's Unicam experiences were evaluated through anonymous surveys drawing on the Unified Theory of Acceptance and Use of Technology. Both parties were neutral to slightly positive in their attitudes towards the Unicam tool.
\end{abstract}

Keywords: Unicam, asynchronous video assessment, oral competence, online assessment.

\section{Introduction}

This paper will share findings from an evaluation of the video platform Unicam at DCU.

The use of video in language learning is nearly ubiquitous (Hockly \& Dudeney, 2018). As well as providing context and visual aids to language learners, video lends itself to assessment of language as learners can document their language

1. Dublin City University, Dublin, Ireland; rob.lowney@dcu.ie; https://orcid.org/0000-0002-8866-4367

2. Dublin City University, Dublin, Ireland; gearoidin.uilaighleis@dcu.ie; https://orcid.org/0000-0003-0651-8815

3. Dublin City University, Dublin, Ireland; sean.macristeaird@dcu.ie; https://orcid.org/0000-0002-7683-5456

4. Dublin City University, Dublin, Ireland; eadaoin.nimhuircheartaigh@dcu.ie

How to cite this article: Lowney, R., Uí Laighléis, G., Mac Risteaird, S., \& Ní Mhuircheartaigh, É. (2021). Experiences of using Unicam for asynchronous video assessment of the Irish language. In N. Zoghlami, C. Brudermann, C. Sarré, M. Grosbois, L. Bradley, \& S. Thouësny (Eds), CALL and professionalisation: short papers from EUROCALL 2021 (pp. 194-199). Research-publishing.net. https://doi.org/10.14705/rpnet.2021.54.1332 
production (Shrosbree, 2008). Producing their own videos is a form of multimodal active learning for students (Schultz \& Quinn, 2013) and also facilitates selfregulation (Glenn, 1996).

DCU Irish language lecturers participated in the Enhancing Digital Teaching and Learning project to explore options for technology-enhanced assessment. Led by learning technologists, they learned about Unicam, a web app which allows students to record audio, video, and screen sharing. Video files are stored in the student's own institutional Google Drive. It also facilitates one-click video submission to DCU's virtual learning environment 'Loop' for assessment and grading purposes. It aims to streamline video creation for students, allowing them to focus on their task and not the intricacies of creating, editing, and managing video. When grading submissions, educators do not need to manage video files locally as playback occurs online. Unicam is DCU's institutional video platform, created by a university spinout company.

DCU adopted remote teaching in 2020/21, which meant lecturers needed to create meaningful assessment tasks to support student learning online (Kelly, 2020). Aware of the above affordances of student-produced video, the lecturers designed asynchronous video tasks for students on teacher education programmes to demonstrate oral competence in the Irish language (e.g. reading a passage, delivering a school lesson). As an institutional tool, Unicam was chosen for this.

\section{Method}

In spring 2021 the authors evaluated students' and the teaching team's experiences through a quantitative study. One anonymous survey was circulated to students (913) and one to the teaching team (13).

Both surveys mostly comprised Likert-scale questions in which respondents indicated their level of agreement to statements, where one is equivalent to 'strongly disagree' and five is equivalent to 'strongly agree'. The statements largely drew on the Unified Theory of Acceptance and Use of Technology, or UTAUT (Venkatesh, Morris, Davis, \& Davis, 2003). This theory states that there are a number of factors that influence users to use a particular technology in the future. These factors include performance expectancy (does the tool perform in the way that you expect it to); effort expectancy (how much effort does it take to use the tool and is that effort level reasonable); attitude (what is a user's general attitude towards the tool); facilitating conditions (what support and resources are available); self-efficacy 
(how well can a user use the tool themselves); and anxiety (does the use of the tool cause any sort of anxiety, worry, or fear). The theory proposes additional factors (including age and gender) but these were excluded from the survey instruments because they constitute special categories of personal data under GDPR.

Two hundred and twenty eight students responded to their survey ( $\sim 25 \%$ response rate), and eight of the teaching team responded to theirs ( $\sim 50 \%$ response rate). The responses to each statement were averaged across both surveys.

\section{Results and discussion}

In most cases (with the exception of the anxiety factor), a higher score indicates a greater level of positivity and tendency towards using the tool in future (see Table 1). The student responses are almost medial, around the three mark. Although this does not indicate an overwhelmingly positive response towards Unicam, it would seem to suggest that there is a middling attitude towards it. Perhaps that is to be expected - the purpose of Unicam is simply to streamline the video creation and video submission workflow. It is not intended to be a revolutionary tool; it aims to be a simple, user-friendly tool to allow students to create video.

Table 1. Student survey responses $(n=228)$; note: ASV=Asynchronous Video Assessment

\begin{tabular}{|l|l|l|l|}
\hline Statement & $\begin{array}{l}\text { Average } \\
\text { agreement }\end{array}$ & Statement & $\begin{array}{l}\text { Average } \\
\text { agreement }\end{array}$ \\
\hline $\begin{array}{l}\text { PE: Unicam is useful } \\
\text { for creating ASV }\end{array}$ & 3.75 & $\begin{array}{l}\text { AT: Unicam ASV make } \\
\text { assessment more fun }\end{array}$ & 3.00 \\
\hline $\begin{array}{l}\text { PE: Unicam is useful for } \\
\text { submitting ASV to Loop }\end{array}$ & 3.76 & AT: I like using Unicam & 3.19 \\
\hline $\begin{array}{l}\text { PE: Using Unicam to create/ } \\
\text { submit ASV increases } \\
\text { my productivity }\end{array}$ & 3.11 & $\begin{array}{l}\text { AT: It is a good idea to } \\
\text { use Unicam for ASV }\end{array}$ & 3.71 \\
\hline $\begin{array}{l}\text { EE: } \text { It is clear and easy } \\
\text { to use Unicam }\end{array}$ & 3.72 & $\begin{array}{l}\text { FC: } \text { There are sufficient } \\
\text { resources/support to help me }\end{array}$ & 3.71 \\
\hline $\begin{array}{l}\text { EE: } \text { It is clear and easy } \\
\text { to submit Unicam ASV } \\
\text { to Loop for grading }\end{array}$ & 3.58 & $\begin{array}{l}\text { FC: I have sufficient } \\
\text { knowledge to use Unicam }\end{array}$ & 3.90 \\
\hline $\begin{array}{l}\text { EE: Using Unicam makes } \\
\text { it more efficient for me } \\
\text { to create and submit } \\
\text { ASV rather than creating/ } \\
\text { exporting/uploading files } \\
\text { from my computer }\end{array}$ & 3.69 & $\begin{array}{l}\text { FC:Unicam works well } \\
\text { with Google Drive }\end{array}$ & 3.61 \\
\hline
\end{tabular}




\begin{tabular}{|l|l|l|l|}
\hline $\begin{array}{l}\text { EE: From a technical point } \\
\text { of view, Unicam does not } \\
\text { take that much time to use }\end{array}$ & 3.48 & $\begin{array}{l}\text { FC: Unicam works } \\
\text { well with Loop }\end{array}$ & 3.64 \\
\hline $\begin{array}{l}\text { EE: Getting to know } \\
\text { Unicam was easy }\end{array}$ & 3.62 & $\begin{array}{l}\text { FC: Unicam works } \\
\text { well with other tools/ } \\
\text { processes for assessment }\end{array}$ & 3.34 \\
\hline $\begin{array}{l}\text { EE: Getting to know Unicam } \\
\text { did not take much time }\end{array}$ & 3.55 & $\begin{array}{l}\text { FC: There are specific } \\
\text { people to help with Unicam }\end{array}$ & 3.50 \\
\hline $\begin{array}{l}\text { EE: I am comfortable in } \\
\text { using Unicam technically }\end{array}$ & 3.72 & $\begin{array}{l}\text { AN: Unicam is } \\
\text { somewhat intimidating } \\
\text { to me technically }\end{array}$ & 2.81 \\
\hline $\begin{array}{l}\text { AT: Unicam ASV make } \\
\text { assessment more interesting }\end{array}$ & 3.26 & $\begin{array}{l}\text { AN: I hesitate to use Unicam } \\
\text { for fear of making a mistake }\end{array}$ & 2.93 \\
\hline
\end{tabular}

The teaching team's workflow is different to students (Table 2). They do not usually create Unicam videos - they grade them - so their survey largely relates to accessing submitted videos via Loop. Their responses show slightly more positivity compared to the students. In particular, statements around effort expectancy, performance expectancy, and some of the facilitating conditions received higher than medial responses.

Table 2. Teaching team survey responses $(n=8)$

\begin{tabular}{|l|l|l|l|}
\hline Statement & $\begin{array}{l}\text { Average } \\
\text { agreement }\end{array}$ & Statement & $\begin{array}{l}\text { Average } \\
\text { agreement }\end{array}$ \\
\hline PE: Unicam is useful for ASV & 4.25 & $\begin{array}{l}\text { AT: Unicam ASV make } \\
\text { assessment more fun }\end{array}$ & 3.38 \\
\hline $\begin{array}{l}\text { PE: It is clear and easy } \\
\text { to access students } \\
\text { submitted ASV }\end{array}$ & 3.75 & $\begin{array}{l}\text { AT: I like using Loop to } \\
\text { grade Unicam ASV }\end{array}$ & 3.63 \\
\hline $\begin{array}{l}\text { PE: Grading Unicam ASV } \\
\text { increases my productivity }\end{array}$ & 3.38 & $\begin{array}{l}\text { AT: It is a good idea to } \\
\text { use Unicam for ASV }\end{array}$ & 4.00 \\
\hline $\begin{array}{l}\text { PE: } \text { Students submitting } \\
\text { with Unicam enables me to } \\
\text { assess more efficiently than if } \\
\text { I were to download/upload/ } \\
\text { open video files locally }\end{array}$ & 4.13 & $\begin{array}{l}\text { FC: There are sufficient } \\
\text { resources/support to help me } \\
\text { use Loop grading features }\end{array}$ & 4.13 \\
\hline $\begin{array}{l}\text { EE: Grading Unicam } \\
\text { ASV on Loop is easy }\end{array}$ & 3.75 & $\begin{array}{l}\text { FC: I have sufficient } \\
\text { knowledge to use Loop } \\
\text { grading features }\end{array}$ & 4.38 \\
\hline $\begin{array}{l}\text { EE: It does not take too } \\
\text { much time to acces/ } \\
\text { playback Unicam ASV }\end{array}$ & 4.13 & $\begin{array}{l}\text { FC: Unicam works } \\
\text { well with Loop }\end{array}$ & 3.88 \\
\hline $\begin{array}{l}\text { EE: Getting to know Loop } \\
\text { grading features was easy }\end{array}$ & 3.88 & $\begin{array}{l}\text { FC: Unicam works well } \\
\text { with other tools/processes I } \\
\text { need to use for assessment }\end{array}$ & 3.88 \\
\hline
\end{tabular}




\begin{tabular}{|l|l|l|l|}
\hline $\begin{array}{l}\text { EE: Getting to know } \\
\text { Loop grading features } \\
\text { did not take much time }\end{array}$ & 4.28 & $\begin{array}{l}\text { FC: There are specific } \\
\text { people to help me } \\
\text { with Loop grading }\end{array}$ & 4.38 \\
\hline $\begin{array}{l}\text { EE: I am comfortable using } \\
\text { Loop grading features }\end{array}$ & 4.25 & $\begin{array}{l}\text { AN: Grading Unicam ASV } \\
\text { was somewhat intimidating } \\
\text { to me technically }\end{array}$ & 2.25 \\
\hline $\begin{array}{l}\text { AT: Unicam ASV make } \\
\text { assessment more interesting }\end{array}$ & 3.63 & $\begin{array}{l}\text { AN: I hesitate to use } \\
\text { Loop grading for fear } \\
\text { of making a mistake }\end{array}$ & 2.25 \\
\hline
\end{tabular}

\section{Conclusions}

As an institutional tool, the lecturers chose Unicam to facilitate students' production of videos in a streamlined way, and facilitate easy grading by the teaching team. The findings have shown a medial to slightly positive experience of Unicam asynchronous video assessments. The lecturers note that some minor administrative issues occurred at times, where slightly incorrect Loop submission settings were applied, but once resolved, a smooth workflow was experienced by students and the teaching team. The authors therefore believe that there is scope to continue Unicam asynchronous video assessments for future student cohorts. It has the potential to be positioned as a central Irish language assessment tool on DCU teacher education programmes. Creatively engaging students, through asynchronous video production such as this, could lead to the redevelopment of future approaches to oral assessment.

\section{References}

Glenn, R. J. (1996). Using video to enhance content and delivery skills in the basic oral communication course: summarizing the uses and benefits. Fall Conference of the Kentucky Communication Association, (Lake Cumberland, KY, September 20-21, 1996).

Hockly, N., \& Dudeney, G. (2018). Current and future digital trends in ELT. RELC Journal, 49(2), 164-178. https://doi.org/10.1177/0033688218777318

Kelly, B. (2020). Principles and guidelines related to hybrid delivery of academic programmes in 20/21. DCU Academic Affairs.

Schultz, P. L., \& Quinn, A. S. (2013). Lights, camera, action! Learning about management with student-produced video assignments. Journal of Management Education, 38(2), 234-258. https://doi.org/10.1177/1052562913488371

Shrosbree, M. (2008). Digital video in the language classroom. The JALT CALL Journal, 4(1), 75-84. https://doi.org/10.29140/jaltcall.v4n1.56 
Venkatesh, V., Morris, M. G., Davis, G., \& Davis, F. D. (2003). User acceptance of information technology: toward a unified view. MIS Quarterly, 27(3), 425-478. https:/doi. org/10.2307/30036540 


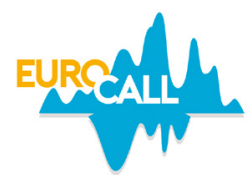

\title{
Developing intercultural communicative competence in the ClerKing telecollaborative project
}

\author{
Oneil Madden ${ }^{1}$ and Soyini Ashby ${ }^{2}$
}

\begin{abstract}
Living in the 21 st century means living in an era that is increasingly globalising where cross-cultural communication is essential; thus, students should be given opportunities to cultivate their Intercultural Communicative Competences (ICC). This paper reports on Phase 3 of ClerKing, a Franco-Jamaican telecollaborative project, which involved Applied Foreign Languages (AFL) students of English from Clermont Auvergne University (UCA), France, and students of French from the University of the West Indies (UWI), Mona, Jamaica. WhatsApp and videoconferencing were used to facilitate the interactions. Using the exploratory approach, we seek to identify different parameters of ICC, relying on Byram's (1997) and Deardorff's (2006) models. Preliminary findings show that students demonstrated and developed ICC such as openness and curiosity, culturespecific knowledge, an understanding of worldviews, sociolinguistic awareness, flexibility and adaptability, and negotiation of meaning. However, time difference, personal and academic schedules, connectivity issues, and misjudged/misinterpreted communication can lead to intercultural conflict.
\end{abstract}

Keywords: intercultural communicative competence, global competence, ClerKing, WhatsApp.

\section{Introduction}

The perpetual rise in globalisation, migration, and, more recently, an increase in constant online interactions across cultures, suggest that the education system needs to be more proactive and deliberate in introducing and implementing curricula that

\footnotetext{
1. University Clermont Auvergne, Clermont-Ferrand, France; oneil.madden@etu.uca.fr; https://orcid.org/0000-0002-9816-7444 2. University of the West Indies, Mona, Kingston, Jamaica; soyini.ashby@uwimona.edu.jm; https://orcid.org/0000-0003-3979-7689 telecollaborative project. In N. Zoghlami, C. Brudermann, C. Sarré, M. Grosbois, L. Bradley, \& S. Thouësny (Eds), CALL and professionalisation: short papers from EUROCALL 2021 (pp. 200-206). Research-publishing.net. https://doi.org/10.14705/ rpnet.2021.54.1333
} 
will help foster ICC of students - the current and future citizens. Telecollaboration offers the potential to cultivate these skills (O’Dowd, 2006).

Definitions of ICC vary, and alternative terms include cross-cultural adaptation, intercultural sensitivity, multicultural competence, etc. (Sinicrope, Norris, \& Watanabe, 2007). However, several experts in the field agreed that ICC involves communicating effectively in the foreign language and demonstrating specific skills, values, attitudes, and knowledge about a culture (Deardorff, 2006; Moeller \& Nugent, 2014).

Given the nature of ICC, understanding culture is of utmost importance, though this concept is equally complex. Nieto (1999) suggests that culture constitutes "the ever-changing values, traditions, social and political relationships, and worldview created, shared, and transformed by a group of people" (p. 48). It generally includes products, ideas, and behaviours that are all interrelated and vary based on family, generation, region, ethnic group, and industry, to name a few.

\section{Models of ICC}

Byram's (1997) model of ICC comprises five elements or savoirs: (1) savoirs (knowledge): knowledge of self and other and of interactions, individual and societal; (2) savoir-être: attitudes, relativising self, and valuing others; (3) savoir comprendre/communiquer: skills of interpreting and relating; (4) savoir apprendre/ faire: skills of discovering and/or interacting; and (5) savoir s'engager: political education and critical cultural awareness.

Deardorff's (2006) pyramid of ICC (see Figure 1) starts with the requisite attitudes (respect, openness, curiosity) that an individual needs to cultivate and demonstrate in order to communicate effectively in intercultural contexts. The next tier of the pyramid is shared between knowledge and comprehension and skills. The former encapsulates cultural self-awareness, deep understanding and knowledge of culture, culture-specific information, and sociolinguistic awareness, while the latter includes listening, observing, interpreting, analysing, evaluating, and relating. Both aspects are interdependent to achieve the desired internal and external outcomes that are the two final tiers of the pyramid. Internal outcome refers to being adaptable and flexible, engaging in ethnorelativism, and demonstrating empathy. External outcome entails comporting oneself appropriately to achieve one's goals to a certain degree. 
Figure 1. Deardorff's (2006, p. 254) Pyramid of ICC 3

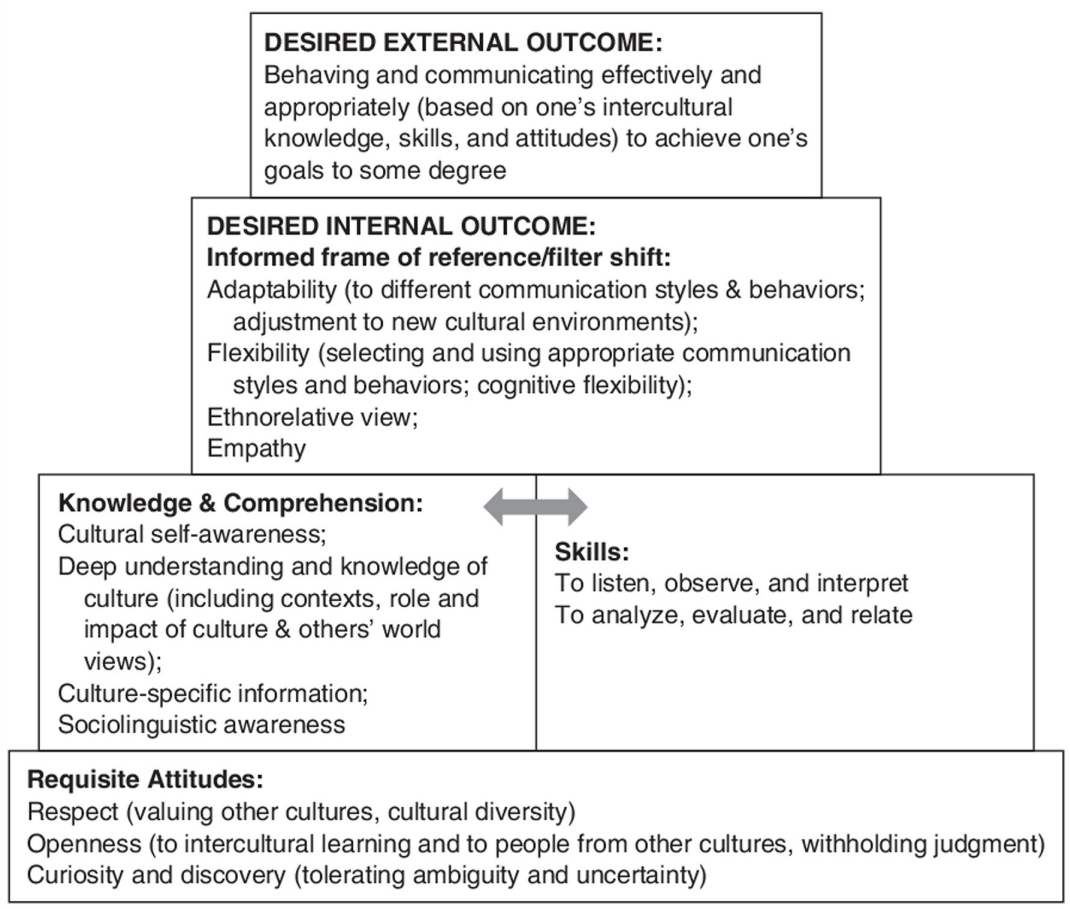

- Move from personal level (attitude) to interpersonal/interactive level (outcomes)

- Degree of intercultural competence depends on acquired degree of underlying elements

Both Byram's (1997) and Deardorff's (2006) models use such words as openness and curiosity to explain their belief that an individual must remain open to learning about new beliefs, values, and worldviews in order to participate in relationships of equality. Using the exploratory approach, we seek to identify and examine different parameters of ICC, specifically how students express these competences in Phase 3 of the ClerKing telecollaborative project.

\section{Method}

Building on the work of Madden and Foucher (2019, 2020), this study reports on Phase 3 of the Franco-Jamaican telecollaborative project, ClerKing (ClermontKingston), between AFL students of English from UCA and modern languages

3. Deardorff, D. K. Journal Studies in International Education, 10(3), pp. 241-266, copyright (C) 2006 by SAGE, Reprinted by Permission of SAGE Publications 
students of French from UWI, Mona. The project occurred during a ten-week period between 26 students ( 21 female, 5 male), who were paired equally (one Clermontois to one Jamaican), according to their profiles submitted prior to the start of the project. The main objectives of this project were for students to practise the target language studied and to develop and/or improve their linguistic (all skills), cultural, and intercultural competences in said language, based on their respective language levels. Clermontois students were B2-C2 in English on the Common European Framework of Reference for Languages, while Jamaican students were B1-B2 in French. Students discussed different intercultural topics weekly with the help of a discussion guide (for example, education systems, stereotypes, peer pressure, multiculturalism, cultural taboos) via WhatsApp and different videoconferencing platforms (Skype, Zoom).

The data collection for this study comprised all the interactions that occurred within ClerKing, including the individual tasks done, such as learning and reflective journals, as well as two questionnaires - one completed at the start of the project, and the other at the end. The former gathered data on the participants' biographies, linguistic competences, usage of communication tools, and elements related to intercultural communication, while the latter examined the same elements, but within the context of the project at the end.

\section{Preliminary findings and discussion}

In the post-project questionnaire, $68 \%$ of the respondents declared that they had gained linguistic knowledge, while everyone noted that they had obtained cultural knowledge (see Excerpt 1, supplementary materials). Both the linguistic and cultural gains mainly fall under two categories common to both Byram's (1997) and Deardorff's (2006) models of ICC: savoir-être/requisite attitude and savoir/ knowledge and comprehension. The examples cited are from the students' learning and reflective journals.

\subsection{Savoir-être: requisite attitude}

It was observed in the journal entries and WhatsApp interactions that having the right attitude, skills, and posture contributed to students demonstrating and cultivating ICC. Being open and curious has allowed students to embrace others' and develop their own perspectives of the world, show empathy, evolve in their personal development, and learn more about their own culture (see Excerpt 2, supplementary materials). 


\subsection{Savoir: knowledge and comprehension}

A brief analysis of the WhatsApp interactions and journal entries confirms the students' own statements in the post-questionnaire that they gained a lot of culture-specific information, thanks to the topics discussed, but also due to the fact that they were from distinctive cultural and linguistic backgrounds. The new insights garnered included information relating to mentality, traditions, celebrations, holidays, icons, geography, economy, cuisine, social behaviours, and religious beliefs, among others. There were also opportunities to confirm or clarify stereotypes (see Excerpt 3, supplementary materials).

Additionally, students gained more consciousness regarding cultural selfawareness and understood, to some extent, why people of the opposite culture behave how they do (see Excerpt 4, supplementary materials). Furthermore, there was the development of sociolinguistic awareness, in the form of slang expressions, exposure to regional language(s) and different language variations (Jamaican Creole and broken English) and specific vocabulary used in one's local culture. Moreover, there was also the struggle to use the appropriate language register (for example, 'vous' versus 'tu' in French) (see Excerpt 5, supplementary materials).

Additionally, we observed an interplay among the attitudes, knowledge, and the desired internal outcome displayed by some of the participants. For example, in Excerpt 3a, openness ("I found it very interesting to learn") seemed to lead to evaluating ("I knew very little") which apparently increased knowledge and produced some cognitive flexibility ("allowed me to remove the clichés").

There were also opportunities for students to negotiate meaning (see Excerpt 6, supplementary materials). However, the interactions also allowed for personal stereotypes of an individual's own culture to be transferred to interlocutors of the target culture (see Excerpt 7, supplementary materials). This could influence the latter's perception of the people and culture.

\subsection{Challenges}

Despite the gains declared by the students in their reflective journal entries and the post-project questionnaire, the project was affected by a six-hour time difference, personal and institutional timetables, and poor internet connectivity. Additionally, there were instances of misjudged/misinterpreted communication, which can lead to intercultural friction (see Figure 2). 
Figure 2. Example of misjudged communication

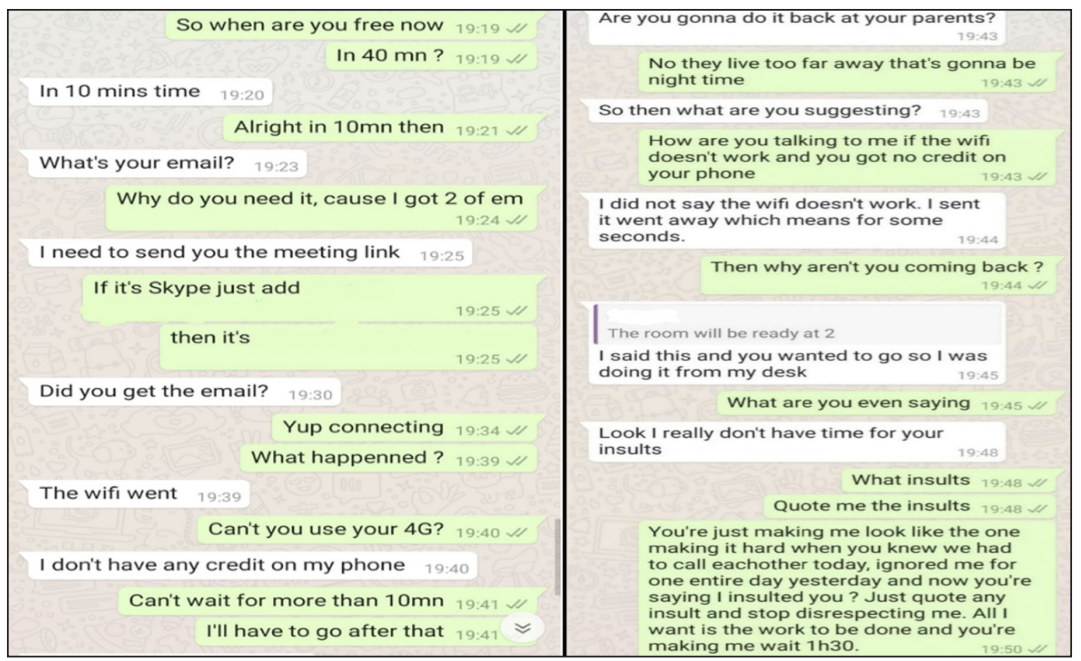

\section{Conclusions}

Our study suggests that there is an interconnection between students' attitudes and their engagement and takeaway from this intercultural project. Similarly, the attitudes and skills noted in both Byram's and Deardorff's models of ICC are interdependent to achieve meaningful output. Additionally, we have noted that the use of journaling helped the students to engage in metacognition, as they acquired new knowledge and experiences. Conversely, challenges related to the time difference, internet connectivity, schedules, and misunderstanding can negatively affect a telecollaborative project.

\section{Supplementary materials}

https://research-publishing.box.com/s/qmmgz12nignv7exevethwaa1bywzmwom

\section{Acknowledgements}

We would like to thank Open Learning Project students from UCA, and French students and staff from the Department of Modern Languages and Literatures from the UWI, Mona for their participation. 


\section{References}

Byram, M. (1997). Teaching and assessing intercultural communicative competence. Multilingual Matters.

Deardorff, D. K. (2006). Identification and assessment of intercultural competence as a student outcome of internationalization. Journal Studies in International Education, 10(3), 241-266. https://doi.org/10.1177/1028315306287002

Madden, O. N., \& Foucher, A.-L. (2019). Understanding the complexities associated with conceptualising pedagogical scenarios for online multimodal interaction between two languages and cultures. In F. Meunier, J. Van de Vyver, L. Bradley \& S. Thouësny (Eds), CALL and complexity - short papers from EUROCALL 2019 (pp. 263-269). Researchpublishing.net. https://doi.org/10.14705/rpnet.2019.38.1020

Madden, O., \& Foucher, A.-L. (2020). Connecting cultures and participation through WhatsApp: assessing students' perception in the ClerKing telecollaborative project. In K.-M. Frederiksen, S. Larsen, L. Bradley \& S. Thouësny (Eds), CALL for widening participation: short papers from EUROCALL 2020 (pp. 201-207). Research-publishing.net. https://doi.org/10.14705/ rpnet.2020.48.1189

Moeller, A. K., \& Nugent, K. (2014). Building intercultural competence in the language classroom. Faculty Publications: Department of Teaching, Learning and Teacher Education. 161. http://digitalcommons.unl.edu/teachlearnfacpub/161

Nieto, S. (1999). The light in their eyes: creating multicultural learning communities. Teachers College Press: Multicultural Education Series.

O'Dowd, R. (2006). Telecollaboration and the development of intercultural communicative competence. Langenscheidt.

Sinicrope, C., Norris, J., \& Watanabe, Y. (2007). Understanding and assessing intercultural competence: a summary of theory, research, and practice. Second Language Studies, 26 , $1-58$. 


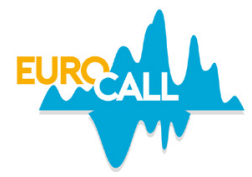

\title{
Capturing potential learning sequences in intercultural interactions through telecollaboration
}

\author{
Oneil Madden ${ }^{1}$, Trishana Nelson ${ }^{2}$, and Rona Barnett-Passard ${ }^{3}$
}

\begin{abstract}
Telecollaboration allows for students to develop foreign/second language competences linguistically, culturally, and interculturally. The use of platforms, such as WhatsApp and Zoom, is now more frequently exploited in foreign language education to ensure that a wider cross section of students, including Jamaicans, can develop global competences. This paper reports on Phase 4 of ClerKing, a six-week Franco-Jamaican telecollaborative project, which occurred between Applied Foreign Languages (AFL) students of English from University Clermont Auvergne (UCA), France, and students of various disciplines taking French courses in the Department of Modern Languages and Literatures at the University of the West Indies (UWI), Mona, Jamaica. Telecollaboration consisted in 45 participants of mixed ages and genders discussing different intercultural topics in groups. Using the exploratory approach, we seek to identify moments of Potential Learning Sequences (PLS). Preliminary findings show that PLS could be made apparent through vocabulary and syntax development, culture-specific knowledge, and negotiation of meaning.
\end{abstract}

Keywords: potential learning sequence, intercultural communication, ClerKing, WhatsApp, telecollaboration.

\section{Introduction}

Telecollaboration has become more widespread in the field of language sciences, and more and more universities and countries, including Jamaica, have come on board to explore the benefits that this pedagogical tool could bring to the teaching

\footnotetext{
1. Université Clermont Auvergne, Clermont-Ferrand, France; oneil.madden@etu.uca.fr; https://orcid.org/0000-0002-9816-7444 2. Université des Antilles Martinique, Schoelcher, Martinique; trishana.nelson@etu.univ-antilles.fr

3. University of the West Indies, Mona, Kingston, Jamaica; rona.barnettpassard@uwimona.edu.jm

How to cite this article: Madden, O., Nelson, T., \& Barnett-Passard, R. (2021). Capturing potential learning sequences in intercultural interactions through telecollaboration. In N. Zoghlami, C. Brudermann, C. Sarré, M. Grosbois, L. Bradley, \& S. Thouësny (Eds), CALL and professionalisation - short papers from EUROCALL 2021 (pp. 207-213). Research-publishing.net. https://oi.org/10.14705/rpnet.2021.54.1334
} 
and learning of modern foreign languages and cultures, as well as to the development of intercultural communicative competences. Telecollaboration provides authentic social interactions for students via Computer/Mobile-assisted Language Learning (CALL/MALL) platforms, such as desktop videoconferencing, and WhatsApp, which is increasingly being exploited, as it is considered to be popular, practical, and preferable among students (Madden \& Foucher, 2019, 2020).

Generally grounded in interactionist theories of second language acquisition, telecollaboration provides opportunities for negotiation of meaning and form, which in turn fosters language acquisition. Helm and Guth (2010) highlighted that through online collaboration, foreign language learners have a special environment for language development and cultural exchange, which allows them to reduce barriers and make connections between language and culture, while they communicate to negotiate meaning and reach mutual understanding. Helm (2015, p. 198) noted benefits such as increased motivation and linguistic output, gains in language development (accuracy, fluency), intercultural communicative competence, and pragmatic competence, etc.

Despite the numerous telecollaborative projects conducted over the past two decades, there is still a dearth in the literature concerning PLS. Defined by De Pietro, Matthey, and Py (1989), a PLS refers to the process through which the learner captures linguistic data in his/her interaction with a native speaker and makes them the object of internal cognitive activities. However, the notion of native speaker could be extended to include the more competent speaker in certain instances, especially as many online intercultural exchanges now include nonnative speakers. Similarly, Madden and Foucher (2020) suggest that PLS could also be demonstrated in the form of negotiation of meaning, reformulation, questioning, etc., as well as in developments in the learner's cultural and intercultural positioning; that is to say, the perspectives drawn during or after interacting with his/her interlocutor. From their study, the authors also cited examples such as new vocabulary and expressions, grammar acquisition, marked differences in cultures and social behaviours, and beliefs as PLS observed in the students' interactions (Madden \& Foucher, 2020).

Metacognition is a key process when it comes to PLS. This concept refers to 'thinking about one's thinking' (Flavell, 1979) and the different strategies and skills a learner employs to arrive at meaningful learning outcomes. Metacognition could be in the form of self-correcting and self-assessing, accommodating new knowledge through reflection, and examining how one processes thoughts and feelings. 
Using the exploratory approach, we seek to identify and examine different instances of PLS at varying degrees during telecollaboration.

\section{Method}

Building on the work of Madden and Foucher (2019, 2020), this study reports on Phase 4 of the Franco-Jamaican telecollaborative project, ClerKing (ClermontKingston), between AFL students of English from UCA and students of various disciplines taking French courses in the Department of Modern Languages and Literatures at the UWI, Jamaica. The project occurred during a six-week period, February to March 2021, between 45 students (36 females, 9 males) who were divided into nine groups of four and three groups of three (one Clermontois in each group), according to their profiles submitted prior ${ }^{4}$ to the start of the project. The main objectives of this project were for students to practise the target language studied and to develop and/or improve their linguistic, cultural, and intercultural competences in the target language, based on their respective language levels. Clermontois students were B2-C2 in English on the Common European Framework of Reference for Languages, while Jamaican students were A2-B1 in French. Students discussed different intercultural topics (food, music, education system) weekly with the help of a discussion guide ${ }^{5}$ via WhatsApp and/or different videoconferencing platforms (Skype, Zoom).

The data collection for this study was similar to the one mentioned in Madden and Foucher (2019, 2020), with the addition of reflective journals. The data for this study are from the pre- and post-intervention questionnaires but primarily the learning and reflective journal entries. Excerpts from WhatsApp interactions are also used for illustration.

\section{Preliminary findings and discussions}

Concerning the use of the different communication platforms, WhatsApp was used to facilitate more text-based interactions and, therefore, the development of writing skills (see below). In their answers to the post-intervention questionnaire, students noted that WhatsApp is convenient for telecollaborative projects, as it possesses all the features necessary to communicate and it allows them to make plans. It also facilitates bonding and allows participants to connect on a more personal level,

\footnotetext{
4. Students were grouped according to their language options and levels, as well as common interests 5. Conversation questions
} 
thus making the project seem less formal and scholarly.Similarly, most students noted that videoconferencing made the exchanges authentic, more engaging and convivial, and less academic. This is due to the fact that the conversations occurred in real time, thus making the participants more accustomed to each other and everyone could express him/herself. Additionally, videoconferencing is suitable, especially when cultures are very distinct, as well as when there is a significant time difference, as it helps to foster proximity, lower communication barriers, and authentic, synchronous exchanges.

\subsection{Linguistic gains}

Sixty-nine percent $(69 \%)$ of the respondents noted that they feel they have gained linguistic knowledge in the form of new vocabulary, slangs, expressions, abbreviations, and, for the Clermontois students, some Jamaican creole words. Students also reported improvement in pronunciation, thanks to the videoconferencing exchanges, as they were corrected by their partner/s. Additionally, some students compared the language studied in the formal classroom to the one used in general daily life, noting that the latter was less formal. Furthermore, the interactions provided opportunities for syntax and sociolinguistic development/ reinforcement and for students to be active learners in the construction of their own knowledge (see Figure 1 and Figure 2).

Figure 1. Screenshots of grammar development/reinforcement

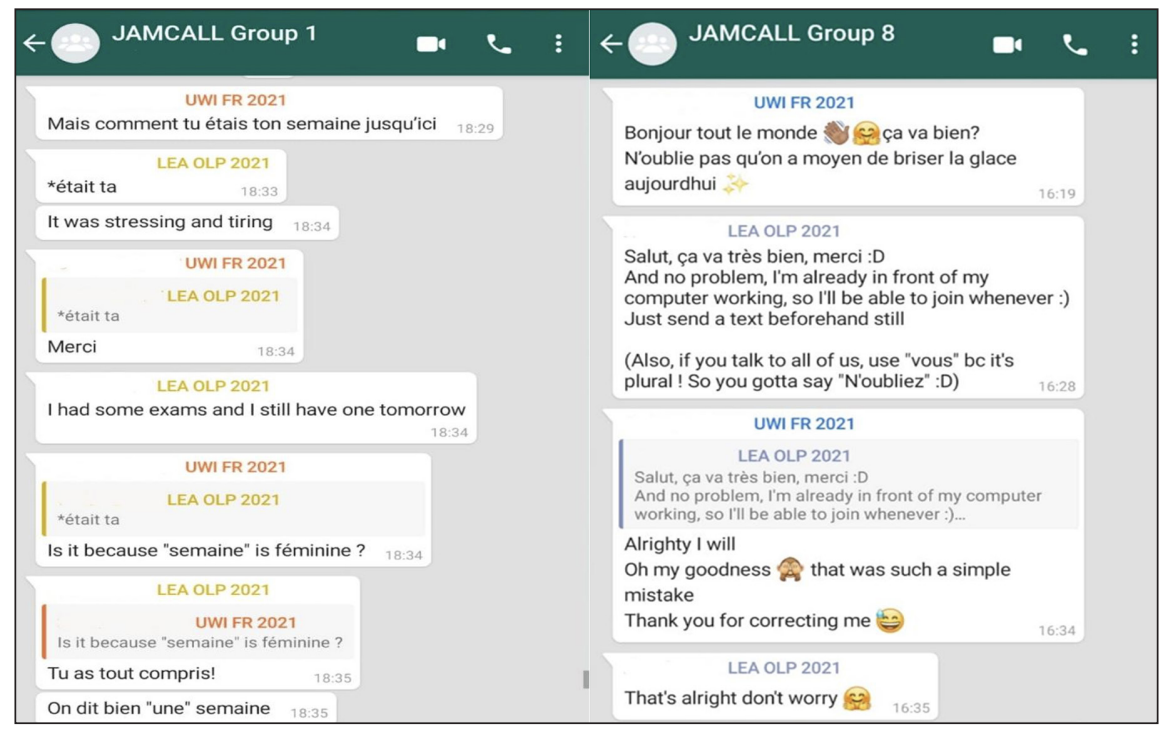


Figure 2. Screenshots of sociolinguistic awareness/development

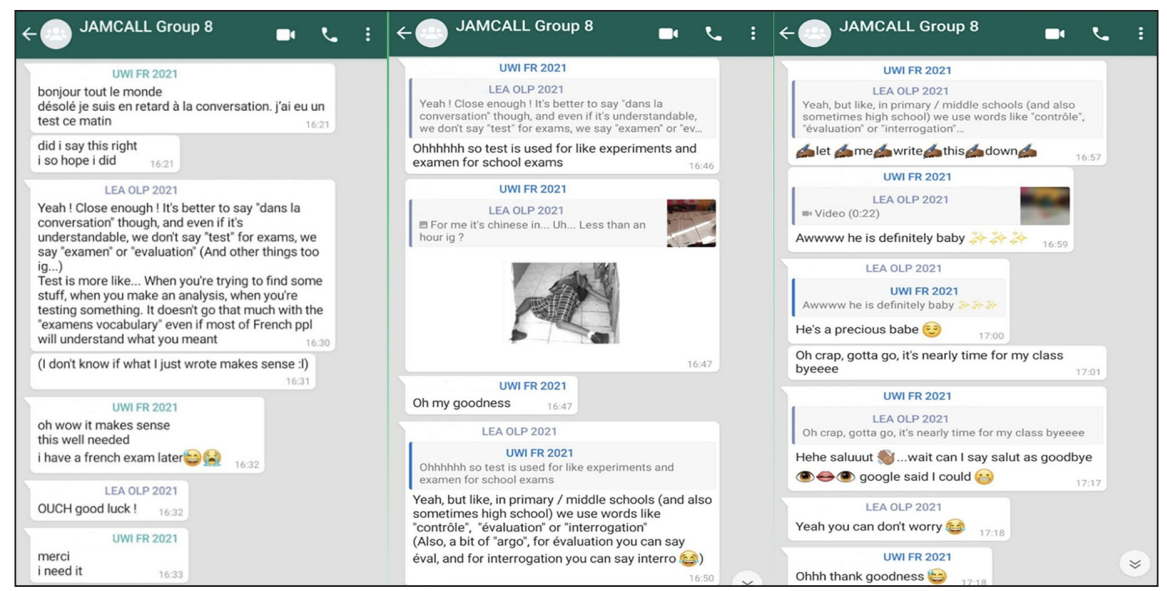

\subsection{Cultural and intercultural gains}

All the respondents declared that they have learned cultural information regarding the functioning of each country, with respect to the different topics discussed: cuisine, music, and education system, etc (see Figure 3).

Figure 3. Excerpts from students' self-reported cultural and intercultural gains

\section{Cultural and intercultural gains}

"I think it was one of the most complicated, if I may say so, because it was the one that I had the most trouble understanding. Indeed, [my partners] were telling me about dishes that I had never heard of before...The nutritional habits of Jamaica and Trinidad and Tobago are different from those in France. Indeed, the food is spicier and (more) exotic, and it seems that there is no real schedule to eat unlike in France."

"Food was interesting because I learned a bit more how Caribbean people eat their meals. For instance, I learned that they mostly eat savoury food, even at breakfast, and don't eat much sweet food, while we mostly eat sweet food for breakfast. I also discovered that soup was an important and frequent meal, even though I thought that a tropical country wouldn't rely much on stews, a meal being destined for more cold-inclined climate[s] in my mind."

"Furthermore, Jamaican people usually eat savoury breakfast when it's uncommon in France. The main cultural difference is about the place of religion. In France, the decline of believers and the concept of laïcité explain this discrepancy."
"The high value Jamaicans attach to religion is something I also noticed during the two calls we made in class. Indeed, many spoke about the fact that they rather not use curse words because it is something bad and that people actually pay attention to (unlike in France)."

"We had a chance during our exchanges to talk about religion and our relationship with it. I have to confess that I was surprised with what I learned. This is an establishment in Jamaica, and I think we can all agree on this point. I don't personally get it, but I had the chance to understand the place and the importance that it had in the life of the people that practice it."

"I learnt about the French culture and how different their culture is from Jamaica's like their culture is very secular. My Jamaican partner and I are Christians however, our French partner [is] not religious. Regardless, we were able to have a discussion on religion without any disputes or objections. [My French partner] was very willing and open to hearing about our opinions on said topics as well as on topics like abortion and homosexuality." 
Students noted that both cultures have distinct food practices and eating habits. Additionally, they discovered the place of religion in public schools and individual life. Jamaican students became aware of the concept of laicité. Interculturally, the interactions promoted tolerance and open-mindedness, and allowed for stereotypes and preconceived notions to be clarified (see supplementary materials).

\section{Conclusions}

Our study suggests that WhatsApp and videoconferencing platforms are suitable tools for telecollaborative projects, as they aid in the development of language skills, such as vocabulary and grammar development, as well as pronunciation. Correlation was noticed between students' self-reported linguistic gains and post-intervention questionnaire responses and our assessment of their WhatsApp and Skype interactions. We observed PLS on different levels and forms: (socio) linguistic, cultural, and intercultural, similar to Madden and Foucher (2020). It is sometimes difficult for researchers to determine if and how learning has occurred; however, we have noted that metacognition helps learners to actively engage in the processing and accommodating of new knowledge (Flavell, 1979).

\section{Supplementary materials}

\section{https://research-publishing.box.com/s/5xe7ty884b7ul358o3mmo111zcn9cx5p}

\section{Acknowledgements}

We would like to thank Open Learning Project students from UCA, and French students and staff from the Department of Modern Languages and Literatures from the UWI, Mona, for their participation.

\section{References}

De Pietro, J.-F., Matthey, M., \& Py, B. (1989). Acquisition et contrat didactique : les séquences potentiellement acquisitionnelles de la conversation exolingue. In D.Weil \& H. Fugier (Eds), Actes du troisième colloque régional de linguistique (pp. 99-124). Université des sciences humaines et Université Louis Pasteur. 
Flavell, J. H. (1979). Metacognition and cognitive monitoring: a new area of cognitivedevelopmental inquiry. American Psychologist, 34, 906-911. https://oi.org/10.1037/0003066X.34.10.906

Helm, F. (2015). The practices and challenges of telecollaboration in higher education in Europe. Language Learning \& Technology, 19(2), 197-217.

Helm, F., \& Guth, S. (2010). The multifarious goals of telecollaboration 2.0: theoretical and practical implications. In F, Helm \& S. Guth (Eds), Telecollaboration 2.0: language literacies and intercultural learning in the 21st century. Peter Lang

Madden, O. N., \& Foucher, A.-L. (2019). Understanding the complexities associated with conceptualising pedagogical scenarios for online multimodal interaction between two languages and cultures. In F. Meunier, J. Van de Vyver, L. Bradley \& S. Thouësny (Eds), CALL and complexity - short papers from EUROCALL 2019 (pp. 263-269). Researchpublishing.net. https://doi.org/10.14705/rpnet.2019.38.1020

Madden, O., \& Foucher, A.-L. (2020). Connecting cultures and participation through WhatsApp: assessing students' perception in the ClerKing telecollaborative project. In K.-M. Frederiksen, S. Larsen, L. Bradley \& S. Thouësny (Eds), CALL for widening participation: short papers from EUROCALL 2020 (pp. 201-207). Research-publishing.net. https://doi.org/10.14705/ rpnet.2020.48.1189 


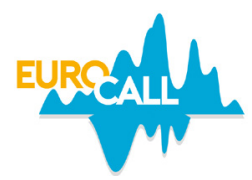

\title{
Facilitating L2 listening through automatic detection of speech and lexical difficulties
}

\author{
Maryam Sadat Mirzaei ${ }^{1}$ and Kourosh Meshgi ${ }^{2}$
}

\begin{abstract}
This paper focuses on Partial and Synchronized Caption (PSC) as a tool to train L2 listening and introduces new features to facilitate speech-related difficulties. PSC is an intelligent caption that extensively processes the audio and transcript to detect and present difficult words or phrases for L2 learners. With the new features, learners can benefit from repetition and slowdowns of particular audio segments that are automatically labeled difficult. When encountering high speech rates, the system slows down the audio to the standard rate of speech. For disfluencies in speech (e.g. breached boundaries), the system generates the caption and repeats that video segment. In our experiments, intermediate L2 learners of English watched videos with different captions and functionalities, provided feedback on new PSC features, and took a series of tests. Smart repetition and slowdown components received positive learner feedback and led to significant improvement in L2 listening recognition.
\end{abstract}

Keywords: captioned videos, listening, scaffold, repetition, slowdown, language learning.

\section{Introduction}

Training L2 listening skills has long been a challenge for L2 learners and teachers, however few tools are developed to foster this process. While listening, learners need to go through complicated procedures such as input decoding at syllablelevel, lexical search to find the right words, parsing to apply syntactic rules, and finally, meaning understanding (Field, 2019). Failures in understanding authentic materials can often be attributed not to the general comprehension process but

1. RIKEN AIP, Tokyo, Japan; maryam.mirzaei@riken.jp; https://orcid.org/0000-0002-0715-1624

2. RIKEN AIP, Tokyo, Japan; kourosh.meshgi@riken.jp; https://orcid.org/0000-0001-7734-6104

How to cite this article: Mirzaei, M. S., \& Meshgi, K. (2021). Facilitating L2 listening through automatic detection of speech and lexical difficulties. In N. Zoghlami, C. Brudermann, C. Sarré, M. Grosbois, L. Bradley, \& S. Thouësny (Eds), CALL and professionalisation: short papers from EUROCALL 2021 (pp. 214-219). Research-publishing.net. https://doi.org/10.14705/ rpnet.2021.54.1335 
to the recognition of individual words and their segmentation. Some difficulties arise from the listener's unfamiliarity with a word, while others lie in the learner's inability to segment the incoming speech stream into separate words (Salverda, Dahan, \& McQueen, 2003). A serious difficulty in L2 listening is caused by the increased number of activated lexical competitors and the challenge to find the right match between the activated candidates and what is just heard. It is more difficult to recognize words when the number of candidates that partially match the input is larger (Broersma, 2012). Given the transient nature of speech, many learners fail to quickly resolve this situation, which distorts subsequent understanding.

Captions can facilitate the listening process by making a phonological visualization of the aural cues (Bird \& Williams, 2002). However, matching the selected candidate against the intended input and modifying the hypothesis onthe-fly based on the evidence in the caption can be confusing and may lead to cognitive overload. Thus, learners may require more time to resolve the situation when there is a mismatch between the activated hypothesis and the evidence in the caption.

Apart from these, speakers often change their speaking rate to get the listener's attention or express excitement, anger, etc. Comprehension is impeded when L2 listeners listen to audios with fast speech rates (Renandya \& Farrell, 2011). Thus, increased speech rate exuberates the situation as the learners need to accelerate the recognition process and often fail to decode the speech signal. They may know the words in isolation, but fast speech rate often incurs connected speech and imperceptible boundaries, which impedes segmentation. In such cases, even captions may not help the listeners as the words disappear before they can read or recognize them. Thus, learners need another type of scaffold. Speed controllers allow learners to adjust the speech rate to a level they can tolerate. However, listening self-regulation may not assist all learners, especially lower-proficiency listeners, as they need to know when to pause (Roussel, 2011).

We leverage PSC which does word-level synchronization, and omits easy words from the caption to encourage more listening than reading. PSC automatically detects lexical difficulties and problematic speech segments, such as difficult word boundary detection (Mirzaei, Meshgi, \& Kawahara, 2018). We introduced a repetition function so that the identified hard segments are automatically replayed after a short pause (Figure 1). Another functionality is a smart and smooth slowdown. PSC calculates speech rate for individual words and finds excessively fast speech segments. It slows down these segments to maintain the average rate of the video but preserves naturalness by following standard speaking rate. Our study 
aims to provide a useful scaffold for L2 listeners by targeting specific areas that impede L2 listening.

Figure 1. PSC caption with smart slowdown and repetition functionalities

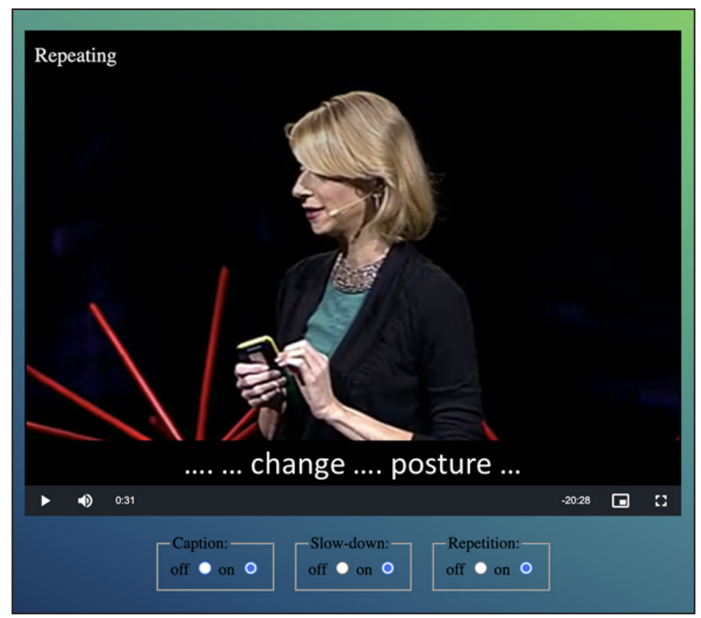

\section{Proposed method}

In PSC, we detect speech difficulties by using Automatic Speech Recognition (ASR) systems. Similar to L2 listeners, these systems produce recognition errors when encountering problematic speech segments and disfluencies. The generated errors of the ASR system can indicate cases of breached boundaries, minimal pairs, homophones, and acoustically similar words. Thus, it helps to identify where in the input learners may face perceptual difficulties. Using this, our system detects potentially challenging segments, shows them in the caption, and sets for repeating those segments automatically after a short pause (with adjustable number of repetitions and the default being one). Resolving such ambiguous segments requires a more complicated process. Therefore, through repetition, our system provides more time for processing the input and matching/readjusting the candidate words and the boundaries.

PSC uses a force-alignment procedure that matches the ASR-generated transcripts with human-annotated transcripts to find both the ASR errors and the time tag for each word. We used a TED corpus that provides human annotations to conduct the forced-alignment procedure. PSC calculates the speech rate of each word in syllables per second, then monitors the speech rate of the adjacent words to identify 
the segments with significantly faster rates of speech compared to the speaker's average speaking rate. This usually happens due to changes in the emotion of the speaker. The system smoothly lowers the speed of the video as far as it normally blends with the rest of the video without being too slow or unnatural. The reason is that we avoid over-simplification, as learners should be able to handle normal rates of speech. The system looks for instances of high speech rate and speech disfluencies to determine which facilitative strategy to use while allowing the learners to change the settings or turn it off if needed.

\section{Experiments and results}

We conducted experiments with 37 intermediate learners of English (university students) and asked them to watch a series of videos (1 2 minutes) with several target and random replays that they were not aware of. After each replay, learners chose whether the replay was useful or not. Figure 2 a shows their feedback for each video. Most participants found the target repetition more useful than random ones, indicating that our system could accurately detect the problematic segments, and the repetition was beneficial to the listeners (Figure 2b). However, we also noticed that some participants prefer not to have replays at all, whereas some welcome any extra scaffold and always choose to have repetition even for easy segments (random). Thus, it is important to allow learners to customize the system based on their preferences.

Figure 2. Learner feedback on random and target replays

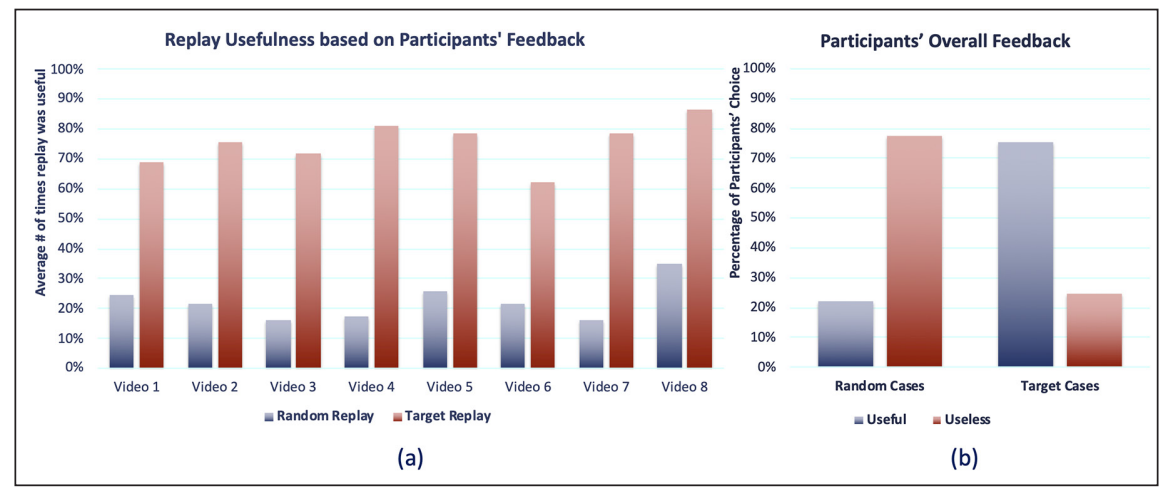

Next, the participants were divided into three groups: no-caption with repetition, PSC without repetition, and PSC with repetition. At the end of the videos, learners transcribed a target replay segment. Results in Figure $3 \mathrm{a}$ show that learners 
struggled in transcribing the target segments that involved perceptual difficulties. Their transcription included incorrect segmentation and boundary detection. Adding the repetition feature to PSC significantly improved the performance and better assisted the learners. A possible explanation is that learners may be unaware of alternative segmentation or stick to their guess and cannot abandon it (Field, 2019). However, repetition provides another chance to reidentify the boundaries, decode more accurately, and consider other hypotheses.

Finally, we maintained the same grouping but used paraphrasing tests for the slowdown: no-caption with slowdown, PSC without slowdown, and PSC with slowdown. Figure $3 \mathrm{~b}$ shows that without the slowdown functionality, PSC is not very helpful when the speech rate is considerably fast since the learners do not get a chance to follow the caption. However, we need to consider that speech rate may not be the only factor, and lexical difficulties can also cause problems.

Figure 3. Learners' performance when having replays (a) and slowdowns (b) as assistive features

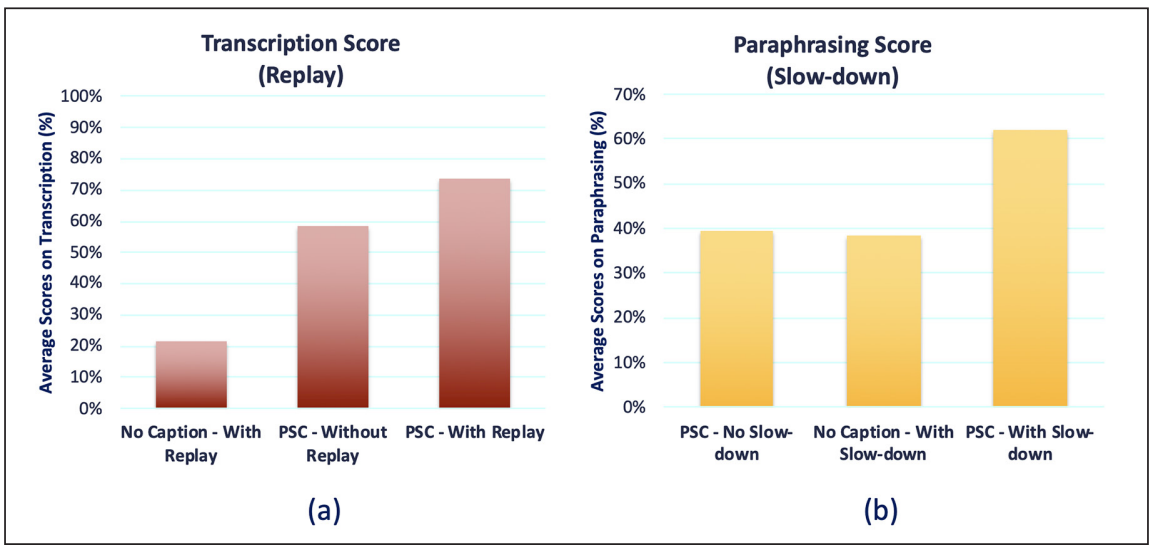

\section{Conclusions}

We used PSC as a tool to provide a timely scaffold for the L2 listeners. We detected L2 listeners' challenges in the input and enabled three forms of assistance: presenting difficult words/phrases in the caption, repeating potential breached boundary cases, and slowing down the parts with excessively fast speech rates. Learner feedback indicated that the system could successfully detect the hard-to-recognize segments and highlighted the usefulness of our assistive strategy. Moreover, with the replay function in PSC, learners could better transcribe the video and set the correct 
boundaries. Findings also revealed that the automatic detection of speed variation and slowing down the relative segment could assist learners to better comprehend the input. Since PSC's features are adjustable, learners can gradually decrease the amount of shown words or disable the scaffolding features to cope with real-life situations.

\section{References}

Bird, S. A., \& Williams, J. N.(2002). The effect of bimodal input on implicit and explicit memory: an investigation into the benefits of within-language subtitling. Applied Psycholinguistics, 23(4), 509-533. https://doi.org/10.1017/S0142716402004022

Broersma, M. (2012). Increased lexical activation and reduced competition in second-language listening. Language and cognitive processes, 27(7-8), 1205-1224. https://doi.org/10.1080/0 1690965.2012 .660170

Field, J. (2019). Second language listening: current ideas, current issues. In J. Schwieter \& A. Benati (Eds), The Cambridge handbook of language learning. Cambridge University Press. https://doi.org/10.1017/9781108333603.013

Mirzaei, M. S., Meshgi, K., \& Kawahara, T. (2018). Exploiting automatic speech recognition errors to enhance partial and synchronized caption for facilitating second language listening. Computer Speech \& Language, 49, 17-36. https://doi.org/10.1016/j.csl.2017.11.001

Renandya, W. A., \& Farrell, T. S. (2011). 'Teacher, the tape is too fast!' Extensive listening in ELT. ELT journal, 65(1), 52-59. https://doi.org/10.1093/elt/ccq015

Roussel, S. (2011). A computer assisted method to track listening strategies in second language learning. ReCALL, 23(2), 98-116. https://doi.org/10.1017/S0958344011000036

Salverda, A. P., Dahan, D., \& McQueen, J. M. (2003). The role of prosodic boundaries in the resolution of lexical embedding in speech comprehension. Cognition, 90(1), 51-89. https:// doi.org/10.1016/S0010-0277(03)00139-2 


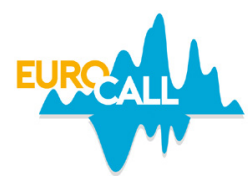

\title{
Promoting common ground building in $L 2$ cross-cultural conversations
}

\author{
Maryam Sadat Mirzaei ${ }^{1}$, Kourosh Meshgi ${ }^{2}$, and Toyoaki Nishida ${ }^{3}$
}

\begin{abstract}
Teaching culture out of context may not be the optimal approach, yet it could be achieved by immersive technologies. This study uses an immersive theme-based environment and focuses on cross-cultural interactions between learners of different cultures in goal-oriented scenarios. We collected interactions among learners with different cultural backgrounds and annotated common ground formation and conversation breakdowns in those interactions. Next, we recreated the scenarios in a 3D immersive environment using an in-house situation creation toolkit to enable experiencing the situation by using choices to navigate the conversation and observing the consequences. In case the conversation derails, we provide timely scaffolding by offering appropriate communication strategies to rebuild common ground. Learners can be the actors of the scenarios but can also be the observers by switching between roles and points of view. Preliminary experiments with 20 L2 learners of English from different cultures showed that practicing with immersive conversational game-play is effective for raising cultural awareness and learning to choose appropriate strategies for smooth interactions.
\end{abstract}

Keywords: cultural competence, 3D environment, virtual worlds, cross-cultural communication, second language.

\section{Introduction}

With new technologies, communication across borders has become a part of our life. Smooth intercultural conversation using L2 not only requires knowledge of the language and deft listening and speaking skills but also entails cultural

\footnotetext{
1. RIKEN AIP, Tokyo, Japan; maryam.mirzaei@riken.jp; https://orcid.org/0000-0002-0715-1624

2. RIKEN AIP, Tokyo, Japan; kourosh.meshgi@riken.jp; https://orcid.org/0000-0001-7734-6104

3. Fukuchiyama University, Kyoto, Japan; toyoaki.nishida@fukuchiyama.ac.jp
}

How to cite this article: Mirzaei, M. S., Meshgi, K., \& Nishida, T. (2021). Promoting common ground building in L2 crosscultural conversations. In N. Zoghlami, C. Brudermann, C. Sarré, M. Grosbois, L. Bradley, \& S. Thouësny (Eds), CALL and professionalisation: short papers from EUROCALL 2021 (pp. 220-225). Research-publishing.net. https://doi.org/10.14705/ rpnet.2021.54.1336 
awareness (Byram, 2012). Language and culture have intertwined relationships and are deeply connected, as culture forms language use, and language carries cultural meanings. At the conversation level, cultural differences may manifest through verbal and non-verbal interactions, where the lack of cultural competence leads to common ground breakdown, and the language barrier can exacerbate the situation (Stopniece, 2019). Achieving a higher level of intercultural awareness is not easy as learners often do not realize the deterioration of common ground until the conversation falls apart. Further, they may not notice what led to this result. Thus, attending to how common ground is developed and updated during the conversation and at what point the breakdowns become critical help determine when and how to assist the learners.

With new opportunities introduced by technologies such as virtual reality and 3D virtual worlds, researchers began to design platforms to foster the development of cross-cultural competence (Culbertson et al., 2016). These platforms allow for real-life experiences in another culture via a virtual environment. The interactions in these systems are carefully designed to teach discrete cultural points. However, actual interactions among learners from different cultural backgrounds can also improve cross-cultural competence and can even be more naturally internalized as these interactions are induced on-the-fly in a given situation. Moreover, virtual environments, especially virtual games, can offer access to a context for using target language and promote social interaction leading to the development of sociocultural competence (Peterson, 2012).

This paper focuses on learners' interactions and communication breakdowns in cross-cultural settings based on the participants' text-chat episodes in a themebased situation. We closely monitored common ground formation and updates during the conversation and looked for instances of breakdowns. We recreated the interactions in a $3 \mathrm{D}$ environment using our situation creation toolkit to allow the learners to experience the same situation from different viewpoints, thus realizing experiential learning (Mirzaei, Zhang, Meshgi, \& Nishida, 2019). We aim to improve cross-cultural competence and promote common ground building by immersing the participants in a given situation and asking them to fulfill goaloriented interactions by choosing suitable options while receiving assistance.

\section{Method}

In an attempt to raise cross-cultural awareness, we collected a series of conversations taking place between L2 learners interacting with people of other cultures. Following 
the grounding theories (Clark, 1996), we annotated common ground updates and defined four categories: (1) common ground is established, (2) common ground is maintained, (3) common ground is lost and both parties know, and (4) common ground is lost and only one party is aware of it. The annotations were used as indicators for the necessary scaffold and appropriate communication strategies to rebuild common ground when (3) or (4) happens. The fixing strategies were defined based on the situations derived from the interactions, including but not limited to: be flexible, use affirming responses, ask for/provide clarification, and make a polite request.

We developed a situation creation toolkit based on the Unity game engine that enables designing scenarios in a 3D environment for non-expert users. Such an environment can be explored with virtual reality headsets for a fully immersive experience or controlled by a keyboard or mouse. The system enables creating and collecting interactions plus having an embodied experience of the situation in which the interactions occur. We used this system to simulate the data derived from learner interactions in the form of a game tree made out of the conversations. We made a $3 \mathrm{D}$ visualization of those conversational situations so that other learners could engage in them as role-players or observers (Figure 1). We also designed non-player characters to act as a conversational partner, representing a target culture. Learners played a role by making decisions in a game-like conversation tree while benefiting from suggested strategies designed based on the annotations of common ground to repair the conversation.

Figure 1. Learners navigate the interactions by moving down the conversation tree in which $\left(^{*}\right)$ represents common ground breakdown

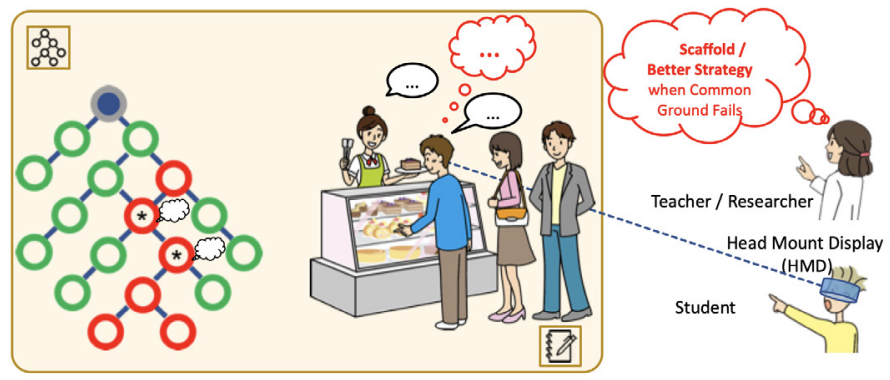

\section{Preliminary experiments}

We conducted a preliminary analysis with 20 learners of English from Europe, India, Japan, and China. Before the interactions started, participants received a 
preamble about the scenario, the goal, and the settings in which the interaction was going to occur. The conversational partners had a mutual goal that was evident to both, similar to fulfilling a quest or task (e.g. hiring/being employed) but also had some personal goals or received some explanation about a personal problem (e.g. having a financial deadline). They used our system by interchangeably contributing as a creator, a role-player, and observer to monitor conversations. At each step, the outcomes of the learners' choices unfolded as they moved down the conversation tree. They refined their choices by using the suggested repairing strategies. For something more challenging, we provided several strategies and asked if the learner could choose the best approach (given the situation) to improve the conversation's quality. In the end, we asked the learners to review their choices and explain the causes of common ground breakdowns or try other branches to see the outcomes.

We observed interesting common ground formation and breakdown and L1 culture transfer. Analysis of participants' strategy selections showed an improvement in the use of strategies through practicing, suggesting that our platform is effective in raising learners' awareness of common ground deformation in cross-cultural interactions. We received positive learner feedback on $3 \mathrm{D}$ environments, the usefulness of scaffolding, the importance of trying alternative branches, and the benefits of reviewing choices (Figure 2).

Figure 2. Participants' votes on the effectiveness of our system and its components

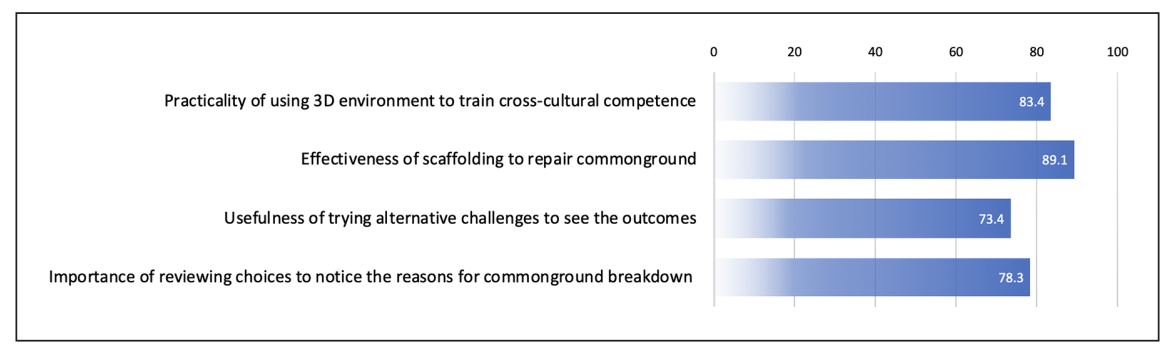

Data also suggested that when practicing cultural competence, learners need to understand the differences and similarities, avoid L1 culture transfer, and be able to take the perspective of the partner to select the appropriate choices. With annotations, we observed that in many cases, common ground breakdown was not noticeable to at least one of the conversational partners, indicating that they missed the viewpoint of their partner. This finding was confirmed by the participants during the review phase. Moreover, participants' feedback showed that the immersive experiences draw on the ability to be surrounded by a virtual environment that can stimulate language learning, as highlighted in other studies 
(Jeffery \& Collins, 2008). Participants claimed to have lower stress, and the use of avatars allowed them to be bold both in using the target language and in expressing their preferences which is in line with the findings of other studies on taking risks and engaging in language play when using virtual environments (Peterson, 2011). While L1 culture transfer was the main factor for common ground breakdowns, the finding on using avatars as an opportunity to take risks could also be accounted for and needs further analysis and confirmation.

\section{Conclusions}

Intercultural communication is imperative in today's global society for getting along with people whose beliefs and backgrounds are different. This study explored the instances of common ground breakdown in a cross-cultural setting to provide timely scaffolding in a theme-based conversation. We introduced an immersive environment for experiencing the situations, navigating the conversations, and observing the outcome. Using this system, participants began to learn to use appropriate strategies designed to rebuild and maintain common ground, thus practicing to improve cross-cultural competence.

\section{Acknowledgments}

This research was supported by KAKENHI Grant-in-Aid for Scientific Research (A), Grant No.19H01120.

\section{References}

Byram, M. (2012). Language awareness and (critical) cultural awareness-relationships, comparisons, and contrasts. Language awareness,21(1-2), 5-13. https://doi.org/10.1080/09 658416.2011 .639887

Clark, H. H. (1996). Using language. Cambridge University Press. https://doi.org/10.1017/ CBO9780511620539

Culbertson, G., Andersen, E., White, W., Zhang, D., \& Jung, M. (2016). Crystallize: an immersive, collaborative game for second language learning. In Proc. of the ACM Conference on Computer Supported Cooperative Work Social Computing (pp. 636-647). https://doi. org/10.1145/2818048.2820020

Jeffery, A., \& Collins, M. (2008). Immersive learning and role plays in Second Life. In Society for Information Technology Teacher Education International Conference, 2628-2632. 
Mirzaei, M. S., Zhang, Q., Meshgi, K., \& Nishida, T. (2019). Collaborative learning through story envisioning in virtual reality. In F. Meunier, J. Van de Vyver, L. Bradley \& S. Thouësny (Eds), CALL and complexity - short papers from EUROCALL 2019 (pp. 297-303). Researchpublishing.net. https://doi.org/10.14705/rpnet.2019.38.1026

Peterson, M. (2011). Towards a research agenda for the use of three dimensional virtual worlds in language learning. Calico Journal, 29(1), 67-80. https://oi.org/10.11139/cj.29.1.67-80

Peterson, M. (2012). Learner interaction in a massively multiplayer online role playing game (MMORPG): a sociocultural discourse analysis. ReCALL, 24(3), 361-380. https://doi. org/10.1017/S0958344012000195

Stopniece, S.(2019). Language as a site of search for common ground and power positioning in Chinese-Finnish negotiation. Journal of Intercultural Communication, 49. 


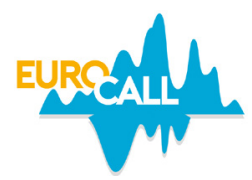

\title{
Intelligent personal assistants and $\mathrm{L} 2$ pronunciation development: focus on English past -ed
}

\author{
Souheila Moussalli ${ }^{1}$ and Walcir Cardoso ${ }^{2}$
}

\begin{abstract}
This study investigates an Intelligent Personal Assistant's (IPA) ability to assist English as a Second Language (ESL) learners in developing their phonological awareness, perception, and production of the allomorphy in regular past tense marking in English (e.g. talk[t], play[d] and add[Id]). The study addresses the following questions: Can the pedagogical use of IPAs improve learners' pronunciation of -ed allomorphy in terms of phonological awareness, perception, and production? What are learners' attitudes toward IPAs? The results suggest that participants improved in their ability to articulate their phonological awareness regarding the target form, and that their attitudes toward the technology was positive in terms of the four measures adopted to assess their experience (i.e. learnability, usability, motivation, and willingness to use). We discuss these findings and emphasize the pedagogical potential of IPAs for the development of L2 pronunciation, as well as their ability to personalize learning and consequently extend the reach of the language classroom.
\end{abstract}

Keywords: IPA, English past -ed, smart speakers.

\section{Introduction}

The use of technology in language learning provides learners with increased autonomy and opportunities to regulate their own learning, while offering easy access to information outside the language classroom (Braul, 2006). This study explores the pedagogical use of one such technology: IPAs, voice-controlled services that complete tasks by orally interacting with users. An example of a popular IPA is the Alexa App (Alexa henceforth), a virtual assistant developed by Amazon.

1. Concordia University, Montréal, Canada; souheilamoussally@hotmail.com

2. Concordia University, Montréal, Canada; walcir.cardoso@concordia.ca; https://orcid.org/0000-0001-6376-185X

How to cite this article: Moussalli, S., \& Cardoso, W. (2021). Intelligent personal assistants and L2 pronunciation development: focus on English past -ed. In N. Zoghlami, C. Brudermann, C. Sarré, M. Grosbois, L. Bradley, \& S. Thouësny (Eds), CALL and professionalisation: short papers from EUROCALL 2021 (pp. 226-231). Research-publishing.net. https://doi.org/10.14705/ rpnet.2021.54.1337 
This study examines whether Alexa can assist English learners in developing and/ or improving their phonological awareness, aural perception, and oral production of the allomorphy that characterizes regular past tense marking in English (e.g. -ed is pronounced talk[t], play[d] or add[Id]). The rationale for using IPAs is based on previous research with IPAs (Dizon, 2017; Moussalli \& Cardoso, 2016, 2020; Underwood, 2017) indicating that their use encourages repetition, improves listening and speaking, and can motivate learners to reformulate, self-correct, and persist in using the L2 (Moussalli \& Cardoso, 2020).

In its design, this study adopts Celce-Murcia, Brinton, Goodwin, and Griner (2010) recommendation for pronunciation instruction. The process starts with awareness raising (Phase 1), then with the development of perception or discrimination abilities (Phase 2), and controlled (Phase 3) and guided oral production (Phase 4), toward a more spontaneous and automatized use of the target feature (Phase 5). This study focuses on the first four stages. In addition, it examines the participants' attitudes toward the use of IPAs to assess the tool's potential to promote learning (learnability), its usability, and potential to increase motivation and willingness to use the technology. The following questions guided this study.

- Will the pedagogical use of an IPA (Alexa) assist in the learning of English past -ed allomorphy in terms of phonological/sound awareness, perception (or phonemic discrimination), and production?

- What are learners' attitudes toward the pedagogical use of Alexa?

\section{Method}

Eighteen ESL students (nine males, nine females) from different language backgrounds (CEFR ${ }^{3}$ scale: B1-C2) were divided into two groups: the Alexa and the non-Alexa group. This study consisted of five main phases: (1) pre-test, (2) explicit -ed instruction, (3) app familiarization (for the Alexa group only), (4) practice, and (5) post-test. Participants completed a questionnaire about their language learning history, then completed the pre-tests assessing their past -ed knowledge. Five preand post-tests were created (Figure 1) following Celce-Murcia et al.'s (2010) first four stages: (1) a five-item survey about the participants' phonological awareness; (2) two perception tests: while one assessed the participants ability to discriminate the three allomorphs in sentences, the other assessed the target allomorphs in

3. Common European Framework of Reference for languages 
words produced in isolation; and (3) two oral production tests: read-aloud tasks for controlled production, and a role-playing game for guided speech.

Figure 1. Perception and production tests: pre- and post-tests

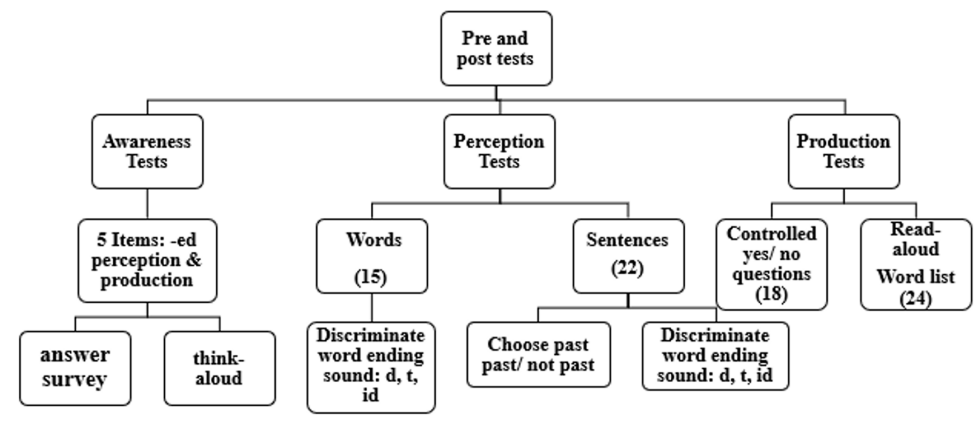

All participants underwent the five phases: pre-testing, explicit -ed instruction, and the practice phase (for both Alexa and non-Alexa group). In addition, the Alexa group was provided with an app familiarization phase. After the four-week pedagogical intervention, the participants completed the post-tests (modified versions of the pre-tests). At the end of the experiment, participants in the Alexa group were asked to complete a survey (using a nine-point Likert scale: $1=$ strongly disagree, 9=strongly agree) inquiring about their attitudes toward Alexa (learnability, motivation, willingness to use, and usability). They were also interviewed about their experience and attitudes toward the pedagogical use of Alexa to learn about English pronunciation. The participants in the non-Alexa group, on the other hand, were interviewed about their experience completing the assigned learning materials.

A mixed method design was used. Means and standard deviations were calculated for the five-item awareness test and nine-point Likert scale survey $(n=28)$. Between and within mixed ANOVAs were calculated for both sets of perception and production tests. Finally, the interview data were transcribed and analyzed according to the coding methods proposed by Saldaña (2009).

\section{Results and discussion}

To answer the first research question, we examined the participants' development across the three levels of testing: awareness, perception, and production. The results for the phonological awareness test revealed that participants improved 
between the pre- and post-test for the first test (survey). For example, for '-ed accurate' statements (e.g. "-ed in kissed and jumped sounds the same"), means increased from $M=5.56$ to $M=6.61$, while for '-ed inaccurate' statements (e.g. "-ed is pronounced the same in walked, lived, and invited") means decreased from $M=3.33$ to $M=2.56$, as hypothesized (see Table 1).

Table 1. Awareness test: means and standard deviation

\begin{tabular}{|l|l|l|l|l|}
\hline \multirow{2}{*}{} & \multicolumn{3}{l|}{ Pre-test } & \multicolumn{2}{l|}{ Post-test } \\
\cline { 2 - 5 } & Mean & SD & Mean & SD \\
\hline Stated knowledge of past -ed pronunciation. & 5.67 & 2.16 & 6.11 & 1.87 \\
\hline Kissed and jumped sound the same. & 5.56 & 3.24 & 6.61 & 3.12 \\
\hline -ed is pronounced the same in walked, lived, and invited. & 3.33 & 2.84 & 2.56 & 2.30 \\
\hline -ed in jumped and dreamed sound the same. & 4.11 & 2.90 & 3.56 & 2.97 \\
\hline -ed in printed and dreamed sound the same. & 3.89 & 3.32 & 3.22 & 3.20 \\
\hline
\end{tabular}

The results for the two perception tests revealed that there were no significant differences between the pre- and post-test for all measures (Figure 2). Similarly, also shown in Figure 2, the results for production were not deemed significant for any of the tests performed. Interestingly, the results of our qualitative analysis based on interviews revealed that participants in the Alexa group found it easier to produce the target [t], [d], and [Id] allomorphs than to perceive them.

Figure 2. Perception and production tests: results

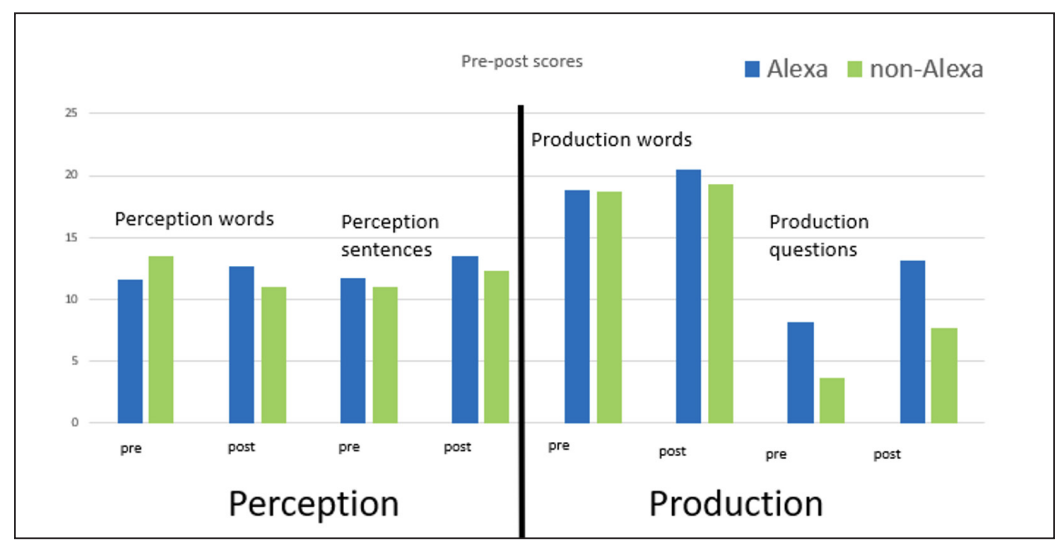

Regarding the second question, the results revealed that Alexa has great potential as a learning tool (learnability: $M=7.07 / 9$ ), it has high usability scores (usability: $M=6.77$ /9), it motivates the participants to learn and explore the language (motivation $(M=7.3 / 9)$, and it sparks their willingness to continue to use it in their 
future language learning endeavors (willingness to use: $M=7.73 / 9$, see Table 2, where Cronbach's Alpha values indicate satisfactory internal consistency between the items for each theme adopted). The participants also explained that the IPA was a great tool for use outside the language classroom, as a conversational partner (e.g. "is important because you sometimes don't have other person for speak so Alexa is a tool for this when you are alone [sic]").

Table 2. Four-theme survey: means and standard deviation

\begin{tabular}{|l|l|l|l|}
\hline & Mean & SD & Cronbach's Alpha \\
\hline Learnability $(\mathrm{n}=7)$ & 7.07 & .36 & .89 \\
\hline Usability $(\mathrm{n}=7)$ & 6.77 & .39 & .82 \\
\hline Motivation $(\mathrm{n}=7)$ & 7.36 & .41 & .92 \\
\hline Willingness to use $(\mathrm{n}=7)$ & 7.73 & .47 & .94 \\
\hline
\end{tabular}

In sum, the results revealed some improvements based on the phonological awareness tests but no significant differences between the pre- and post-tests for the perception and production, probably because of the study's limitations: the short duration of the treatment and the low number of participants. However, the participants did find Alexa a great tool for learning and motivating them to use the L2, as attested in quantitative (phonological awareness tests) and qualitative data (interviews), thus corroborating findings highlighting the potential of IPAs to support L2 development (Dizon, 2020; Moussalli \& Cardoso, 2020).

\section{Conclusions}

This study contributes to the computer assisted language learning literature by demonstrating that IPAs are valuable pedagogical tools that can extend the reach of the classroom by allowing language learners to autonomously improve aspects of their L2 phonological development (e.g. awareness of past tense marking). As far as L2 pronunciation is concerned, this study adds to the existing literature that explores the link between listening (perceptual) training and output practice on the acquisition of L2 morphophonemics.

\section{References}

Braul, B. (2006). ESL teacher perceptions and attitudes toward using computer-assisted language learning (CALL): recommendations for effective CALL practice [Master's thesis], University of Alberta]. ProQuest Dissertations Publishing. 
Celce-Murcia, M., Brinton, D. M., Goodwin, J. M., \& Griner, B. (2010). Teaching pronunciation: a course book and reference guide. Cambridge University Press.

Dizon, G. (2017). Using intelligent personal assistants for second language learning: a case study of Alexa. TESOL Journal, 8(4), 811-830. https://doi.org/10.1002/tesj.353

Dizon, G. (2020). Evaluating intelligent personal assistants for L2 listening and speaking development. Language Learning \& Technology, 24(1), 16-26. https://doi.org/10125/44705

Moussalli, S., \& Cardoso, W. (2016). Are commercial 'personal robots' ready for language learning? Focus on second language speech. In S. Papadima-Sophocleous, L. Bradley \& S. Thouësny (Eds), CALL communities and culture - short papers from EUROCALL 2016 (pp. 325-329). Research-publishing.net. https://doi.org/10.14705/rpnet.2016.eurocall2016.583

Moussalli, S., \& Cardoso, W. (2020). Intelligent personal assistants: can they understand and be understood by accented L2 learners? Computer Assisted Language Learning, 33(8), 865890. https://doi.org/10.1080/09588221.2019.1595664

Saldaña, J. (2009). The coding manual for qualitative researchers. Sage.

Underwood, J. (2017). Exploring AI language assistants with primary EFL students. In K. Borthwick, L. Bradley \& S. Thouësny (Eds), CALL in a climate of change: adapting to turbulent global conditions - short papers from EUROCALL 2017 (pp. 317-321). Research publishing.net. https://doi.org/10.14705/rpnet.2017.eurocall2017.733 


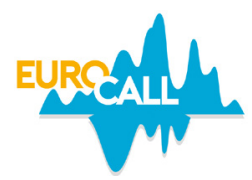

\title{
Promoting informal learning by integrating smartphones into the language classroom
}

\author{
Martin Mullen ${ }^{1}$
}

\begin{abstract}
Although smartphones have become normalised in people's everyday behaviours, they remain under-exploited from a language learning perspective. This paper describes a study in an Irish university which explored the nature and extent of language learners' existing use of smartphones for informal learning purposes through a survey, a case study, and a group interview. The results showed that firstly, smartphones played only a limited and tangential role in their language learning, and secondly, that learners had narrow perceptions of what 'actual, proper study' entails, demonstrated by their overwhelming preference for more traditional language learning resources and practices. The paper finishes by making suggestions regarding how smartphones can be integrated into the language classroom, at both third and second level, to help broaden learner perceptions of what language study is, and consequently, allow smartphones to play a more significant role in their learning practices.
\end{abstract}

Keywords: MALL, smartphones, informal learning, learner autonomy.

\section{Introduction}

Smartphones have been well-researched in terms of formal, teacher-led projects (Marek \& Wu, 2016), yet what learners actually choose to do on their devices outside of these projects remains relatively under-explored (Lai \& Zheng, 2018). Thus, while the ideal (or idealised) smartphone user is one who embraces the flexibility and convenience of mobile devices and takes an agentive role in developing and utilising a range of sources to create a beneficial personalised learning environment (Godwin-Jones, 2020), the extent to which language learners harness smartphones for "informal learning [which] is learner-controlled, not linked to any course

1. University of Limerick, Limerick, Ireland; martin.a.mullen@ul.ie; https://orcid.org/0000-0002-6183-7766

How to cite this article: Mullen, M. (2021). Promoting informal learning by integrating smartphones into the language classroom. In N. Zoghlami, C. Brudermann, C. Sarré, M. Grosbois, L. Bradley, \& S. Thouësny (Eds), CALL and professionalisation: short papers from EUROCALL 2021 (pp. 232-237). Research-publishing.net. https://doi.org/10.14705/rpnet.2021.54.1338 
or institution, and takes place outside the classroom" is not well documented (Trinder, 2017, p. 402). This study aimed to fill that research gap by exploring how students of modern languages at an Irish university both perceived and used their smartphones as language learning tools. This paper will briefly describe the methodology and results of the study, and conclude by making recommendations on how explicit in-classroom focus on smartphones can help learners become more informed, judicious users of smartphones outside the classroom.

\section{Method}

The methodology comprised three stages. Firstly, a survey was distributed to students of modern languages which garnered 84 responses. Secondly, a case study was conducted with 20 students of modern languages in which, over a two-week period, they were asked to complete seven reports on how they had encountered second languages on their smartphones in the previous 24 hours (the participants completed 133 of a possible 140 reports). The third stage was a group interview of the case study participants, which seven attended. This interview produced a transcript of 10,897 words, which was subjected to thematic analysis following the six-step procedure outlined by Braun and Clarke (2006) ${ }^{2}$. Themes identified during this stage were triangulated with data from both the survey and case study to ensure that any findings made were robustly supported across the data sets. Links to the survey, case study form, and interview schedule are provided in the supplementary materials.

\section{Results}

This section will offer key excerpts of the data collected. Figure 1 offers insight into the frequency with which language learners encountered second languages on their smartphone.

Case study data showed similar patterns regarding how often these students of modern languages actually encountered second-language content on their smartphones. As Table 1 indicates, across the 20 case study participants, who returned 133 of a possible 140 reports between them, instances of second-language encounters remained low when excluding university-related work and dictionary use.

2. Notably (1) familiarising yourself with the data; (2) generating initial codes; (3) searching for themes; (4) reviewing themes; (5) defining and naming themes; and (6) producing the report. 
Figure 1. Frequency of encounters with second languages on smartphones

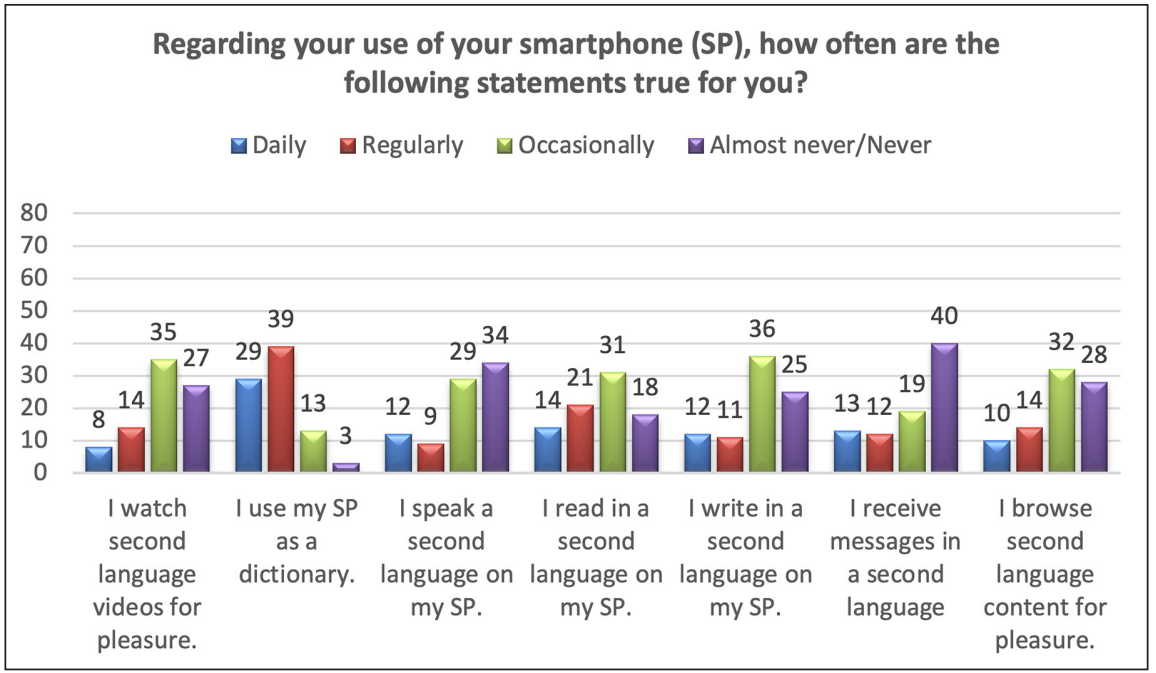

Table 1. Smartphone-mediated exposure to second-language content in case study

\begin{tabular}{l|l|}
\begin{tabular}{|l|l|}
\hline In what ways did you encounter your second language while using your \\
smartphone in the past 24 hours? (Please tick all that apply) \\
\hline doing university homework/coursework & $65 / 133$ \\
\hline doing other language study (unrelated to homework/coursework) & $23 / 133$ \\
\hline using a dictionary & $49 / 133$ \\
\hline using language learning apps (apart from dictionary) & $13 / 133$ \\
\hline spoken communication with friends & $17 / 133$ \\
\hline written communication with friends & $23 / 133$ \\
\hline reading social media content/posts & $46 / 133$ \\
\hline commenting on social media content/posts & $12 / 133$ \\
\hline listening to second-language music & $27 / 133$ \\
\hline watching second-language videos & $19 / 133$ \\
\hline
\end{tabular}
\end{tabular}

\section{Discussion}

Overall, data from all three strands revealed that while the participants were heavy smartphone users, and while the majority of their exposure to second-language content occurred on smartphones (such as the 46 instances of social media content in Table 1), this rarely translated into production of second-language content on their smartphones (only 12 instances of second-language comments on social 
media among 20 participants over a two-week period). Instead, learners were more likely to perceive smartphones and social media as separate from their studies, with $90.5 \%(n=76 / 84)$ agreeing that 'I use my smartphone to escape study' and $89.3 \%(n=75 / 84)$ expressing the same sentiment about social media. Across all data strands, the following themes emerged regarding the role of smartphones and social media in their learning practices.

- Learners held traditional, narrow perceptions of what 'actual, proper' language study entails, exemplified by one interview comment that "for actual like proper study, and schoolwork, I wouldn't use my phone at all really". This form of study involves traditional practices such as learning off lists of verbs, or writing target language items multiple times. This perception extended into having the right 'mentality' for study, with learners needing to be in study mode for encounters with second-language content to be beneficial.

- Learners also had clear perceptions of what smartphones are for communication, entertainment, and socialisation purposes. Beyond use as a dictionary, use of language learning apps was infrequent, with only a minority of students using smartphones for anything beyond their prescribed course/homework, instead displaying an overwhelming preference for laptops. As one participant commented, "you use your laptop for serious work, and not just for playing around", a sentiment which highlighted how smartphones were perceived. As survey data showed, smartphones and social media were viewed as ways to escape study, rather than study resources.

- While smartphones only played a limited role in the 'actual, proper study' described above, learners did value them for what this researcher terms 'study-lite' activities - a hybrid of study and entertainment similar to edutainment, but making more use of non-educational resources such as Netflix, YouTube, and various social media. Consumption of secondlanguage music or video content fit this categorisation, being described by one participant as "a positive break from study".

\section{Suggestions}

Despite the language learning affordances of smartphones outlined in the research (see Godwin-Jones, 2020), this study revealed that the participants 
remained unwilling or unready to meaningfully exploit the learning affordances of the devices. While smartphones possess real capabilities for computing, communication, and collaboration, "it is no easy task to harness [these capabilities] for the purpose of serious learning" (Godwin-Jones, 2017, p. 13), and the teacher's main role and challenge "is to provide to students the skills and knowledge to be informed and engaged online learners" (Godwin-Jones, 2017, p. 13). This paper concludes by making three suggestions as to how language teachers in Ireland can meet that challenge, at both second and third-level education.

\subsection{Dedicated periods of language learning on smartphones}

Students should be encouraged to use their smartphones in class to experiment with language learning apps (such as Duolingo or Memrise). Students can share their experiences with different apps, evaluate them individually and as a group with the help of their teacher, and identify which apps best suit individual learning preferences. Such explicit focus on smartphone use will both expose learners to a variety of resources and improve their ability to evaluate the merits of the resources they encounter.

\subsection{Use of smartphones to complement 'traditional' learning}

Smartphones can be used to support learning while engaged in other activities. For instance, using a smartphone to find collocations of a newly-learned word, or to quickly discover extra information about topics being discussed in textbooks, can help learners develop perceptions of smartphones as having value in complementing their general studies.

\subsection{Harnessing social media}

Teachers could create social media accounts for their class on one or more platforms (such as Facebook or Instagram), and 'follow' accounts which produce content relevant to students' interests (such as a Spanish-language football page, a French news organisation, a Japanese language learning page, etc.). Checking these accounts will reveal the steady drip-feed of authentic, relevant second-language content and opportunities for interaction with both native speakers and learners of target languages, which social media offer. This will help learners perceive social media as venues where they can encounter and use their target languages. 


\section{Conclusion}

While teachers understandably shy away from smartphones in the classroom, smartphones will continue to be used heavily by learners in their everyday lives, and they cannot be normalised as learning resources if they are always ignored or forbidden. Steps such as those suggested above can help learners to become more active, informed, and judicious users of smartphones as language learning resources, improving their learning journeys within and beyond the classroom.

\section{Supplementary materials}

- Link to survey

- Link to case study form

- Link to group interview schedule

\section{References}

Braun, V., \& Clarke, V. (2006). Using thematic analysis in psychology. Qualitative research in psychology, 3(2), 77-101. https://doi.org/10.1191/1478088706qp063oa

Godwin-Jones, R. (2017). Smartphones and language learning. Language Learning \& Technology, 21(2), 3-17. https://doi.org/10125/44607

Godwin-Jones, R. (2020). Building the porous classroom: an expanded model for blended language learning. Language Learning \& Technology, 24(3), 1-18. https://doi.org/10125/44731

Lai, C., \& Zheng, D. (2018). Self-directed use of mobile devices for language learning beyond the classroom. ReCALL, 30(3), 299-318. https://doi.org/10.1017/S0958344017000258

Marek, M., \& Wu, W. (2016). Educational Engineering for CALL and MALL. In Y. Leung (Ed.), Epoch making in English language teaching and learning (pp. 115-125). English Teachers' Association.

Trinder, R. (2017). Informal and deliberate learning with new technologies. ELT Journal, 71(4), 401-412. https://doi.org/10.1093/elt/ccw117 


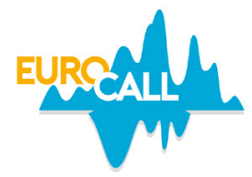

\title{
EFL learners and English email writing: developing a computerised diagnostic language assessment
}

\author{
Allan Nicholas ${ }^{1}$, John Blake², and Maxim Mozgovoy ${ }^{3}$
}

\begin{abstract}
Email remains a key mode of communication between faculty and students in higher education institutions. Composing appropriate email texts is an important skill for learners; however, little technological support is available for the pragmatic aspect of email communication - the ways in which social context influences language choices. Furthermore, pragmatics can be undertaught in the language classroom. One approach to providing support for learners while also addressing the issue of giving instruction to large class sizes is via computerisation. In this ongoing research project, we describe the development of a Computerised Diagnostic Language Assessment (C-DLA) of L2 English email writing for Japanese English as a Foreign Language (EFL) learners in Japanese higher education. The C-DLA provides automated feedback to learners on the pragmatic aspects of their draft email texts, with feedback adapting to learners' success in resolving identified issues. We report on the development phases of the project, challenges encountered, and implications for further research.
\end{abstract}

Keywords: pragmatics, assessment, email, computerised assessment.

\section{Introduction}

Email remains a key mode of communication between faculty and students in higher education institutions. In writing L2 English emails, students have access to a number of online tools that can help with the formal aspects of writing, such as grammar and spelling. There is little support, however, for the pragmatic aspect of email communication - the ways in which the surrounding social context of

\footnotetext{
1. University of Aizu, Aizu-wakamatsu, Japan; anich@u-aizu.ac.jp

2. University of Aizu, Aizu-wakamatsu, Japan; jblake@u-aizu.ac.jp

3. University of Aizu, Aizu-wakamatsu, Japan; mozgovoy@u-aizu.ac.jp

How to cite this article: Nicholas, A., Blake, J., \& Mozgovoy, M. (2021). EFL learners and English email writing: developing a computerised diagnostic language assessment. In N. Zoghlami, C. Brudermann, C. Sarré, M. Grosbois, L. Bradley, \& S. Thouësny (Eds), CALL and professionalisation: short papers from EUROCALL 2021 (pp. 238-242). Research-publishing.net. https://doi.org/10.14705/rpnet.2021.54.1339
} 
the communication influences our language choices. Furthermore, in comparison with other elements of language learning, pragmatics is often undertaught in the language classroom (McConachy \& Hata, 2013; Taguchi \& Roever, 2017). In the university English L2 learning context, there is also often the need to provide efficient - but still effective - feedback to large classes of learners, with each learner having their own particular strengths and weaknesses. The need to overcome these challenges is an important one, as failure to adhere to L2 community pragmatic norms in email communications may lead to negative consequences for learners and their relationships with English L1 faculty (Economidou-Kogetsidis, 2011, 2016; Savic, 2018). One approach to addressing these classroom challenges is via computerisation - allowing large classes of students to simultaneously receive individualised feedback.

In this study, we describe an ongoing work-in-progress research project: the development of a C-DLA of L2 English email writing for Japanese EFL learners at a Japanese computer science university. The purpose here is to describe the process of development to date and the challenges encountered. The purpose of the C-DLA is twofold: to simultaneously evaluate learner performance while promoting learning via automated, individualised feedback. This follows a dynamic assessment-type approach, in which learner potential is assessed via the principled, systematic use of mediation (Poehner, 2008). The C-DLA development comprises two main phases: corpus development and software development.

\section{Method}

In the initial corpus phase, approximately 1,300 English L2 learner emails were collected and annotated. Using Google Forms, email text data were elicited via the administration of a set of four tasks, based on the real-world needs of the learners, with varying social contexts. Task scenarios were based on the results of a questionnaire administered to a sample of the target student population, eliciting examples of common requesting scenarios in their academic and daily lives. High frequency scenarios were assigned + or - values for three variables: power (P), social distance (D) and imposition (R), based on Brown and Levinson (1987; see Table 1 for definitions). Text data were then imported to WebAnno, a web-based platform, and manually annotated for perceived instances of pragmatic failure by expert English users, using a tailor-made coding scheme. The coding scheme was adapted from the CCSARP project (Blum-Kulka \& Olshtain, 1984) and Economidou-Kogetsidis (2016) for use with email data specifically, and for identifying pragmatic failure, rather than pragmatic features. 
Table 1. P, D, R definitions (adapted from Hudson, Detmer, \& Brown, 1995, also published in Nicholas \& Blake, 2020, p. 2)

\begin{tabular}{|l|l|l|l|l|l|}
\hline P & Meaning & D & Meaning & R & Meaning \\
\hline+ & $\begin{array}{l}\text { Receiver has a } \\
\text { higher rank, title or } \\
\text { social position, e.g. } \\
\text { president, supervisor. }\end{array}$ & $+\begin{array}{l}\text { Sender and receiver do } \\
\text { not know, or identify } \\
\text { with, each other. }\end{array}$ & + & $\begin{array}{l}\text { Great expenditure of } \\
\text { goods or energy by } \\
\text { the receiver to carry } \\
\text { out the request. }\end{array}$ \\
\hline- & $\begin{array}{l}\text { Receiver has a lower } \\
\text { rank, title, or social } \\
\text { position, e.g. salesperson } \\
\text { serving a customer. }\end{array}$ & - & $\begin{array}{l}\text { Sender or receiver } \\
\text { know, or identify } \\
\text { with, each other. }\end{array}$ & - & $\begin{array}{l}\text { Small expenditure of } \\
\text { energy by the receiver } \\
\text { to carry out the request. }\end{array}$ \\
\hline
\end{tabular}

In the software development phase, a basic C-DLA prototype was created and tested. A user-friendly graphical user interface was created to enable learners to use the C-DLA without the need for detailed explanations. The C-DLA administers four email tasks for each assessment. For each task, students draft and submit an email in the input field. Instances of pragmatic failure in the student-created text are identified via rules-based parsing and string searching. Feedback messages are automatically displayed on detection of any instances of pragmatic failure. Learners then redraft their email, receiving feedback up to four times for each task. Feedback messages for each repeated specific instance of failure increase in explicitness. After all four tasks are completed, a summary report is generated for each learner, showing frequent instances of pragmatic failure across all four tasks, and the amount of feedback they required in order to complete the tasks successfully. Currently, the system is in the testing phase, being iterated and improved upon by the researchers, before beginning a piloting process with learner participants.

\section{Discussion and conclusion}

One challenge in developing the C-DLA relates to the corpus data collection. For the C-DLA to be useful, it was necessary to implement rules for identification of specific instances of pragmatic failure. The primary purpose of the corpus phase, therefore, was to analyse the data and identify patterns within them that could inform rule creation and enhance the accuracy of the C-DLA system. In this way, we sought to avoid reliance on researcher intuition. Typically, corpus data is authentic; however, authentic email data collection can be challenging, leading to the decision to elicit data via classroom-based tasks. A key benefit of this approach was the ability to control the contextual variables of the email task 
scenarios, as well as the ability to collect the data efficiently and systematically. Relatedly, automatic annotation of pragmatics-focused corpora is an ongoing challenge for researchers; therefore, the corpus was manually annotated - a timeintensive process.

An additional challenge in the software programming phase relates to automatic head act detection. The potential for there to be multiple request-type phrases in a given email text is problematic in terms of accurately identifying the head act of the request act. In response to this issue, the rules incorporated into the software are undergoing regular iteration and adjusting in response to researcher and pilot participant feedback with the aim of increasing accuracy. The fact that the texts are written by EFL learners increases the challenge of this task. With learners not necessarily aware of L2 pragmatic norms in email communication, head act placement within the body of an email may be less predictable than with an L1 English communicator.

As a work-in-progress, the next steps of the project involve further piloting with small groups of learner participants, with the aim of C-DLA administration to larger groups in classroom settings. This will allow for evaluation of the effectiveness of the feedback approach adopted, tracking learners across time as they engage with the C-DLA on multiple occasions.

\section{Acknowledgements}

This research project is supported by a JSPS KAKENHI (Grants-in-aid for Scientific Research), Grant number 19K00826, 'Developing a diagnostic language assessment of Japanese EFL learners' English email writing'.

\section{References}

Blum-Kulka, S., \& Olshtain, E. (1984). Requests and apologies: a cross-cultural study of speech act realization patterns (CCSARP ). Applied Linguistics, 5(3), 196-213. https://doi.org/10.1093/ applin/5.3.196

Brown, P., \& Levinson, S. C. (1987). Politeness: some universals in language use. Cambridge University Press.

Economidou-Kogetsidis, M. (2011). "Please answer me as soon as possible": pragmatic failure in non-native speakers' e-mail requests to faculty. Journal of Pragmatics, 43(13), 3193-3215. https://doi.org/10.1016/j.pragma.2011.06.006 
Economidou-Kogetsidis, M. (2016). Variation in evaluations of the (im)politeness of emails from L2 learners and perceptions of the personality of their senders. Journal of Pragmatics, 106, 1-19. https://doi.org/10.1016/j.pragma.2016.10.001

Hudson, T., Detmer, E., \& Brown, J. D. (1995). Developing prototypic measures of cross-cultural pragmatics (technical report 7). University of Hawai'i.

McConachy, T., \& Hata, K. (2013). Addressing textbook representations of pragmatics and culture. ELT Journal, 67(3), 294-301. https://doi.org/10.1093/elt/cct017

Nicholas, A., \& Blake, J. (2020). A failure mode and effects analysis of pragmatic errors in learner e-mails. SHS Web Conf, 77, 1-6. https://doi.org/10.1051/shsconf/20207702001

Poehner, M. (2008). Dynamic assessment - a Vygotskian approach to understanding and promoting L2 development. Springer Science \& Business Media.

Savic, M. (2018). Lecturer perceptions of $\mathrm{im} /$ politeness and in/appropriateness in student e-mail requests: a Norwegian perspective. Journal of Pragmatics 124, 52-72.

Taguchi, N., \& Roever, C. (2017). Second language pragmatics. Oxford University Press. 


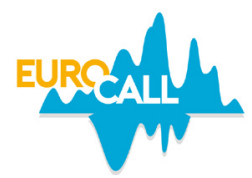

\title{
Using Moodle Quiz to respond to emergency: a case study with a tertiary $L 2$ French teacher
}

\author{
Salomi Papadima-Sophocleous ${ }^{1}$ and Savvi Antoniou ${ }^{2}$
}

\begin{abstract}
This short paper reports on the case of a tertiary level French language practitioner self-training in using Moodle Quiz during the Covid-19 pandemic online emergency remote teaching (Hodges et al., 2020). As no teacher training program included a topic such as 'how to deal with the pandemic', switching to online teaching was done under emergency conditions (MacIntyre, Gregersen, \& Mercer, 2020). The practitioner had taken advantage of the situation and explored ways of self-training. She took advantage of Moodle Quiz (MQ) affordances. She experimented with different ways MQ could be used to construct a diverse number of quiz activities, embedded with audio and video, infused with elements of constructivism, and aiming at catering for the aims and expected outcomes of the specific students and course. Self-training helped the practitioner face the challenges of online emergency teaching as she developed knowledge, skills, and experiences necessary for creating online interactive activities.
\end{abstract}

Keywords: tertiary level French, self-teacher training, online emergency teaching, Moodle Quiz.

\section{Introduction}

Since the beginning of the pandemic, many researchers have tried to record the shifting from classroom to emergency online teaching (Al-Maskari, Al-Riyami, \& Kunjumuhammed, 2021; Plutino \& Polisca, 2021; Reich et al., 2020). This case study describes the experience of a French language instructor who followed a 'do-it-yourself' method (Kessler, 2006) to train herself in the use of MQ during

\footnotetext{
1. Cyprus University of Technology, Limassol, Cyprus; salomi.papadima@cut.ac.cy; https://orcid.org/0000-0003-4444-4482 2. Cyprus University of Technology, Limassol, Cyprus; savvi_antoniou@cytanet.com.cy; https://orcid.org/0000-0002-3946-7076

How to cite this article: Papadima-Sophocleous, S., \& Antoniou, S. (2021). Using Moodle Quiz to respond to emergency: a case study with a tertiary L2 French teacher. In N. Zoghlami, C. Brudermann, C. Sarré, M. Grosbois, L. Bradley, \& S. Thouësny (Eds), CALL and professionalisation: short papers from EUROCALL 2021 (pp. 243-247). Research-publishing.net. https://doi.org/10.14705/rpnet.2021.54.1340
} 
the emergency remote teaching as defined by Hodges et al. (2020). This case study aims to shed light into emergency self-training practices, applied during the pandemic emergency online language teaching by an individual language instructor.

\subsection{Before the pandemic}

Before Covid-19, at the Cyprus University of Technology (CUT), French was taught face-to-face, in class, supported by technologically enhanced activities. Moodle Learning Management System (LMS), the CUT official e-platform, was used to deliver the course and share teaching materials. Many consolidating activities were provided in printed form while others were online ready-made activities retrieved from websites and available via Moodle. Other online materials such as YouTube videos and songs were also available via Moodle.

Learning French onsite was based on constructivism; a student-centered method, where students construct new knowledge from their own experience (Piaget, 1968). French language learning and assessment were enhanced by contextualized scenarios depicting real-life communicative situations.

\subsection{During the pandemic}

Because of the emergency situation created by the pandemic, the onsite French course had to be redesigned and turned into a full online one. The instructor searched the web to find ways to create online activities for the specific needs of the CUT French students and complement the teaching material delivered and shared on the Moodle platform. However, she discovered that most tutorials were generic; hardly any of them focused on languages.

\section{Method}

\subsection{Participant}

The study involved the case of a language instructor with 16 years of experience in French language teaching, and a very limited experience in Computer-Assisted Language Learning (CALL) at the beginning of this study. In particular, she had no experience in online teaching, and no experience in creating online activities. 


\subsection{Data collection}

In this paper, a case study descriptive design was adopted. The study was conducted in Spring 2020 during the pandemic outbreak. Following the particular research design, data were collected qualitatively in two forms: (1) the French instructor's reflective field notes (unstructured form) during the self-training and teaching process; these included in-action (during the activity) and on-action (after the activity) reflection (Schön, 1983); and (2) a semi-constructed interview, for a more in-depth view.

\section{Results and discussion}

Analysis of data revealed four aspects of self-training. The first was the types of self-training methods and techniques the French instructor came up with during the online emergency teaching. According to the data from both sources, the instructor first reviewed several online 'how-to' videos, then she explored different online software. Her findings led her to focus on exploring the affordances of the MQ on Moodle LMS, which seemed to be promising, and experiment constructing activities tailored to the course with that particular tool. The practitioner was learning by doing during her self-training: she adapted existing paper-based language activities and she created new interactive ones, making good use of the MQ features. She then tried them in class and refined them. She also received student feedback. Furthermore, she learned from others; sharing her MQ activities with a colleague provided her with valuable feedback and ideas concerning the pedagogical aspects of the activities.

The second aspect of this self-training examined was the knowledge, skills, and experiences the instructor felt she gained through her self-training. Her interview data supported in more depth the results of the analysis of her reflective notes and offered a more focused point of view of the instructor's self-training process. Initially, the practitioner had only basic knowledge of the Moodle platform. Through self-training, she moved beyond that and trained herself further, in other features of the platform. She experienced self-training in course redesign and MQ activities creation; in doing so, she became more aware of how to infiltrate elements of constructivism in her activities with the use of scenarios and roles from real-life communicative contexts. She practiced reflection and improvement. Her self-training included receiving feedback from the students as part of the process of course improvement. It also included collaboration, sharing, and receiving input 
from other colleagues, elements that she found valuable in her emergency selftraining process.

The third was about course redesign involvement and the reflective comparison of similarities and differences of the onsite and online courses version. According to the field notes and the interview, the course redesign firstly involved mainly the activities. Pre-pandemic activities used onsite were mainly in print form and were used for learning, consolidation, and formative and summative assessment. They covered a large part of the course; the redesign was primarily concerned with their transformation into online interactive activities. However, in the process of creating new activities that would be online, other changes needed to take place as well. The course structure was also modified, making it more coherent, neater, and easier to navigate, by restructuring the content and deleting any unnecessary items.

The fourth aspect dealt with the measurement of the practitioner's growth of confidence in creating online activities. The activities created were successful when implemented during the course, as expressed informally to the instructor by the students. They also formed a valuable resource for future use. The new knowledge, skills, and experiences acquired during the online activities' construction led to the collaborative sharing and dissemination to other colleagues, through the French instructor's collaboration with another colleague who taught Greek and went through a similar process of turning their classroom courses online for the emergency needs of teaching during Covid-19. Both courses were A1 CEFR level, they covered similar topics and contextualized situations, and were based on constructivism. This was in the form of an online in-service session, during which they shared their steps in creating different types of activities, in both French and Greek, and the learning theories and language teaching methods they were based on. The in-service participants gave positive feedback and expressed interest in putting into practice the knowledge they acquired during the in-service. All these contributed to her growth of confidence in online teaching, online course design and activity construction, and in collaborating and sharing with other colleagues. From a totally inexperienced instructor in online teaching and online activity development, the French teacher started becoming a trainer and researcher in the area.

\section{Conclusions}

The French instructor self-training case during the emergency online teaching indicated its many possibilities. She came up with a number of methods and 
techniques that enabled her to transform her onsite course, redesign it, and turn it into an online one, developing knowledge, skills, and experiences in creating MQ constructivist and contextualized activities, and eventually developing the ability to train others.

The findings of this case study may prove useful to both practitioners and researchers, who may want to further explore the potential of online teaching tools.

\section{References}

Al-Maskari, A., Al-Riyami, T., \& Kunjumuhammed, S. K. (2021). Students' academic and social concerns during COVID-19 pandemic. Education and Information Technologies. https://doi. org/10.1007/s10639-021-10592-2

Hodges, C. B., Moore, S., Lockee, B., Trust, T., \& Bond, A. (2020 March 20). The difference between emergency remote teaching and online learning. https://er.educause.edu/ articles/2020/3/the-difference-between-emergency-remote-teaching-and-online-learning

Kessler, G. (2006). Assessing CALL teacher training: what are we doing and what could we do better? In P. Hubbard \& M. Levy (Eds), Teacher Education in CALL (pp. 23-42). John Benjamins.

MacIntyre, P. D., Gregersen, T., \& Mercer, S. (2020). Language teachers' coping strategies during the Covid-19 conversion to online teaching: correlations with stress, wellbeing and negative emotions. System, 94, 102352. https://doi.org/10.1016/j.system.2020.102352

Piaget, J. (1968). Six psychological studies. Vintage Books.

Plutino, A., \& Polisca, E. (2021). (Eds). Languages at work, competent multilinguals and the pedagogical challenges of COVID-19. Research-publishing.net. https://doi.org/10.14705/ rpnet.2021.49.9782490057832

Reich, J., Buttimer, C., Fang, A., Hillaire, G., Hirsch, K., Larke, L., Littenberg-Tobias, J., Moussapour, R. M., Napier, A., Thompson, M., \& Slama, R. (2020). Remote learning guidance from state education agencies during the COVID-19 pandemic: a first look. Massachusetts Institute of Technology. https://doi.org/10.35542/osf.io/437e2

Schön, D. (1983). The reflective practitioner: how professionals think in action. Temple Smith. 


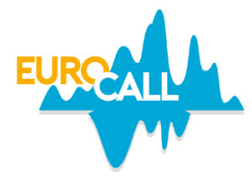

\title{
Face issues in second language teaching via videoconferencing: the role of the smile as a co-verbal semiotic resource
}

\author{
Agnès Pétillat ${ }^{1}$, Anne-Laure Foucher $^{2}$, and Ciara R. Wigham ${ }^{3}$
}

\begin{abstract}
Synchronous online language teaching involves the simultaneous employment of a range of techno-semio-pedagogical competences (Guichon, 2012). Indeed, given their flexibility and versatility, digital tools and the Internet can render teacher-student interactions dynamic. Among the necessary professional skills and strategies for online synchronous teaching, this paper focuses on the specific dimensions of affective competences and the social need to maintain a climate of comfort during one-to-one online tutoring interactions. We focus on a particular social phenomenon that is strongly linked to emotions - facework (Goffman, 1967). Applied to computer assisted language learning, we analyse how this social practice unfolds in an interactional environment where the perception of the other is mediated by a videoconferencing platform. We noted four different types of facework triggering situations: lexical breakdowns, private anecdote tellings, overlaps, and interruption of learner reflection time. Our multimodal analysis of facework reveals the frequent use of the smile as a mimicry semiotic resource and highlights the phenomenon of interactional synchrony.
\end{abstract}

Keywords: socio-affective skills, online language learning/teaching, facework multimodal analysis, smile.

\footnotetext{
1. Université Clermont Auvergne, Clermont-Ferrand, France; agnes.borrelli@etu.uca.fr

2. Université Clermont Auvergne, Clermont-Ferrand, France; a-laure.foucher@uca.fr

3. Université Clermont Auvergne, Clermont-Ferrand, France; ciara.wigham@uca.fr

How to cite this article: Pétillat, A., Foucher, A.-L., \& Wigham, C. R. (2021). Face issues in second language teaching via videoconferencing: the role of the smile as a co-verbal semiotic resource. In N. Zoghlami, C. Brudermann, C. Sarré, M. Grosbois, L. Bradley, \& S. Thouësny (Eds), CALL and professionalisation: short papers from EUROCALL 2021 (pp. 248-254). Researchpublishing.net. https://doi.org/10.14705/rpnet.2021.54.1341
} 


\section{Introduction}

This study examines the socio-affective competences of trainee-teachers of French as a foreign language during one-to-one online tutoring interactions. Our theoretical framework explores the competence of emotive communication (Arndt \& Janney, 1991) through the multimodal analysis of facework acts.

As a sociological concept, 'face' refers to "the positive social value a person effectively claims for himself by the line others assume he has taken during a particular contact" (Goffman, 1967, p. 213). Closely intertwined with face, 'territory' or 'negative face' is defined as the extension of identity that coincides with material and immaterial possessions. From an interactional perspective, facework refers to a set of regulations applied by interactants to protect faces (their own and their interlocutors') by avoiding face-threatening acts (Brown \& Levinson, 1978) or by completing face-flattering acts (Kerbrat-Orecchioni, 1992). Contextualised to our research area, diverse situations engage teachers and learners in facework phenomena. Cicurel (2011) argued that when a teacher avoids unjustified correction and depreciation of skills, he clearly attempts to protect the learner's face. Dausendschön-Gay (1995) observed, in a corpus of exolingual interactions, that native speakers avoided inconsistencies and restrictions of allowed speaking time to preserve interlocutors' knowledge and territories. Guichon (2017) noticed that self-territory disclosure helps teacher-learner relationships gain in connivance.

Facework is a complex multimodal process comprising a range of exchanged semiotic resources. In particular, the smile attracted our attention in the study corpus. Indeed, in their logbooks, trainees reported having observed learners smiling and associated this with different triggering situations including understanding and appreciating the activity, experiencing motivation, feeling encouraged by the tutor, and sharing with him/her a mutual trusting relationship. Relying on those declarations and given that smiling has been commonly considered as a softener, a listening backchannel, an affiliation, and a social inclusion marker (Crivelli \& Fridlund, 2018), our analysis focuses on this semiotic resource.

\section{Method}

Data for our study was collected within the telecollaborative project Vadim (videoconferencing for language learning, intercultural and multimodal project). The project formed part of a didactics of French as a foreign language Master's course at Université Clermont Auvergne (UCA). Thirty-three trainee-teachers 
from UCA tutored 33 learners of French who were based in Denmark and Italy. Their online synchronous interactions were conducted over a two-month period in Spring 2019 via the videoconferencing platform Adobe Connect and the virtual bulletin board Padlet. Vadim's aim was to help the learners practise and develop their oral communication, and their linguistic and interactional skills. From the trainee-teachers' perspective, it offered hands-on experience of online tutoring, allowing trainees to report upon and analyse their own practices.

Data collection included 76 questionnaires received from all participants, 383 pedagogical texts (including teachers logbooks and reflexive reports) and 132 video recordings ${ }^{4}$. Our analysis followed a four-step process:

- delineate a study corpus of seven tutorials that had in common a phraseological semantic activity dedicated to understanding some standard French fixed expressions;

- segment meetings into sequences using ELAN;

- create a facework acts categorisation tool based on models by Brown and Levinson (1978) and Kerbrat-Orecchioni (1992) and the concepts of 'learning territory' and 'conversational face' (Cicurel, 2011; Dausendschön-Gay, 1995) (Figure 1); and

- annotate facework communication modalities, referring to McNeill's (1992) model for gesture, the ICOR convention for verbal communication (ICAR, 2013) and the 'facial action coding system' (Ekman \& Friesen, 1978) for mimicry. From the latter, we created a four-level smile scale (Figure 2).

Figure 1. Facework categorisation

\begin{tabular}{|l|c|c|c|}
\hline \multicolumn{2}{|c|}{} & $\begin{array}{c}\text { Absence of threat } \\
\text { Consolidate faces } \\
\text { (positive politeness acts) }\end{array}$ & $\begin{array}{c}\text { Presence of threat } \\
\text { Repair faces } \\
\text { (negative politeness acts) }\end{array}$ \\
\hline $\begin{array}{l}\text { Conversational } \\
\text { face }\end{array}$ & Tutor's act & & \\
\cline { 2 - 4 } $\begin{array}{l}\text { Learning } \\
\text { territory }\end{array}$ & Learner's act & & \\
\cline { 2 - 4 } & Tutor's act & & \\
\hline
\end{tabular}

4. Ethical consent was obtained from all participants. The majority agreed for their images to appear unedited in scientific or pedagogical publications. 
Figure 2. Smile scale

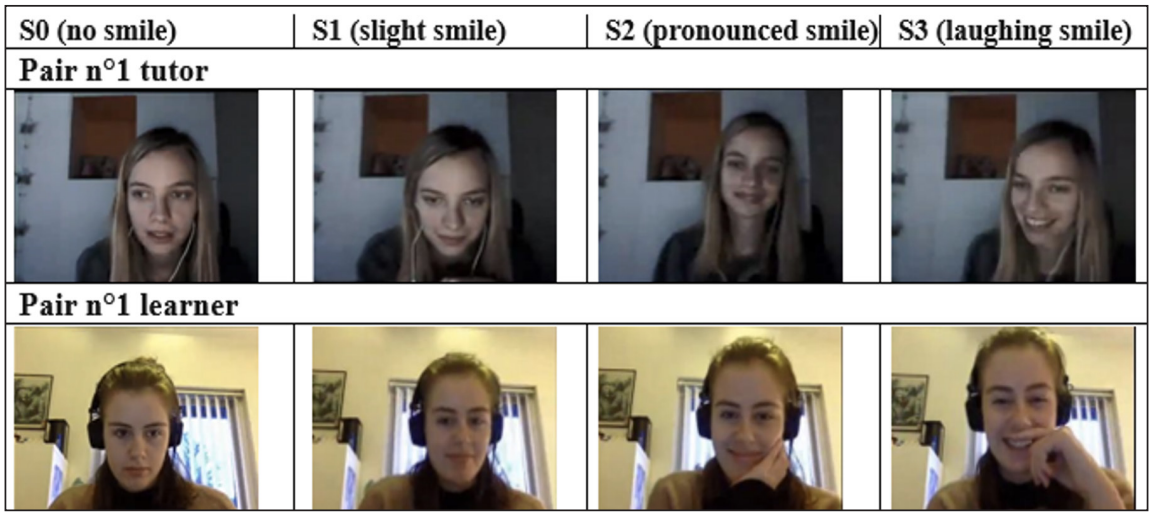

\section{Results and discussion}

From the annotation of the first 20 minutes of video recordings from the study corpus, four situations that trigger facework emerged:

- learners' lexical breakdowns that stop or slow down the activity's progress;

- private and personal anecdotes recounted by the learner or tutor;

- verbal overlaps between interactants; and

- learners' reflection time that is interrupted by the tutor.

We propose to illustrate two of these triggering situations.

In the first excerpt, the learner tries to guess the meaning of a non-contextualised idiomatic French expression. The learner takes time to think and formulate an initial idea in response to a solicitation. The tutor interrupts in the verbal mode, asking him to answer and offering a 'lexical hint'. This incursion in the learner's immaterial territory could be categorised as a face threat. To make it less intrusive, the tutor launches a softening multimodal support for his action: he intensifies his smile (Figure 3) then verbally minimises the fact that the learner does not have an answer before producing a forward-backward upper body movement (UBP).

In response, the learner smiles while saying "no, no, no". He also produces an intensified smile and then executes a forward-backward UBP similar to that of the tutor (Figure 4). Finally he attempts to answer without the proposed lexical hint. 
Considering the time ${ }^{5}$ that separates the tutor's smile and movement from those of the learner (Figure 5), we suggest this sequence is an example of interactional synchrony in which there is the expression of an affiliation want; an 'affective tuning process' (Cosnier, 1996).

Figure 3. Tutor smile's intensification (S1 to S2)

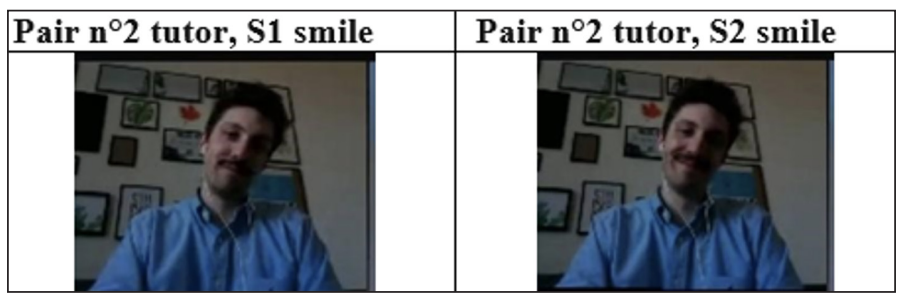

Figure 4. Interactional synchrony

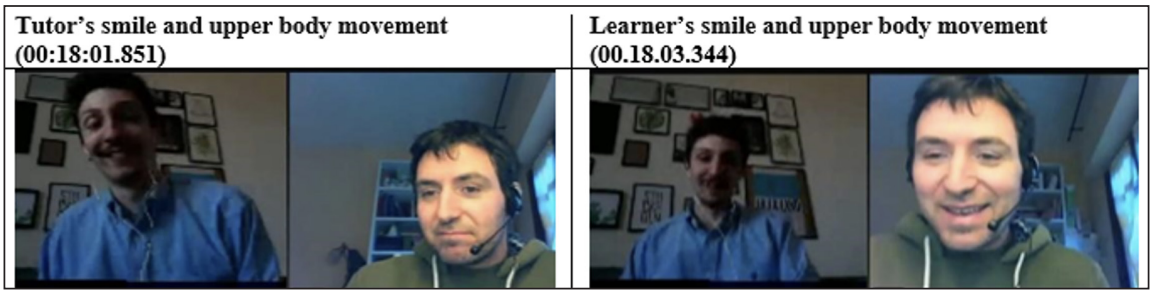

Figure 5. S1 and S2 smiles in red (up is tutor's smile, down learner's one) and UBP or 'repositionnements' in green (up is tutor's movement, down is learner's one), synchrony

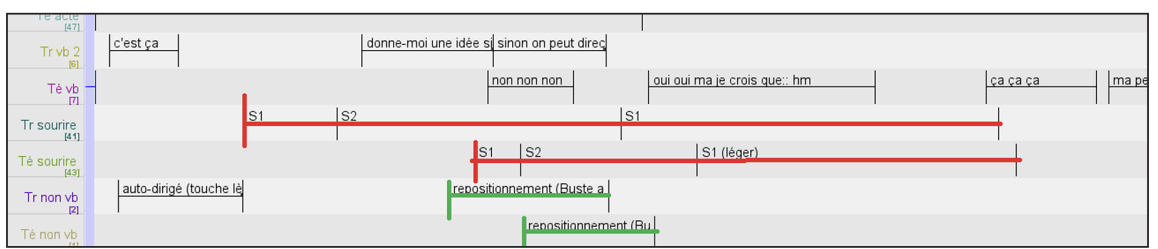

In a second excerpt from another pair, a learner's lexical breakdown initiates a facework episode structured as follows: the learner acknowledges that she forgot the word that could have helped her to give the right answer: "I am rather ashamed because we spoke about it last time". This verbal self-accusation is supported by an S3 smile combined with an auto contact gesture and upper body sways. Receiving

5. 643 milliseconds separate the learner's perception of the tutor's smile and his own. Regarding upper body movements, 1492 milliseconds separate the tutor's production from the learner's. 
this multimodal message, the tutor quickly minimises the self-accusation stating "never mind". The verbal modality is enhanced by an S3 smile and an upper body forward movement. Again, we notice mirroring regarding the multimodal density of the interaction (Figure 6).

Figure 6. Mirroring in tutor and learner's facework mimogestuality

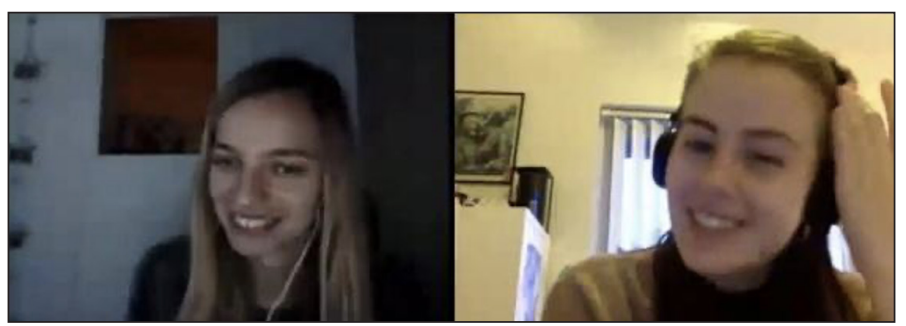

\section{Conclusion}

To conclude, our study suggests that facework comes into play in situations including overlaps, reflection time interruptions, lexical breakdowns, and disclosure acts. Smiling is a semiotic resource employed to introduce, soften, or enhance face-threatening and face-flattering acts. In the episodes studied, tutor and learner gaze at each other and their smile exchanges result in interactional multimodal synchronies. Concerning our short-term research perspectives, we intend to study facework episodes when tutor and/or learner attentions are polyfocused: in the online environment the participants must manage different windows simultaneously making gaze and smile exchanges difficult. It would be interesting to observe how facework is managed when tutors and learners do not pay continual visual attention to each other. Regarding long-term perspectives, our objective is to create pedagogical materials that could be used in teacher training and that would allow trainees to study and discuss face issues. This way, they could be motivated to reflect on their skills and their duties, and orient their own practices.

\section{References}

Arndt, H., \& Janney, R. W. (1991). Verbal, prosodic, and kinesic emotive contrasts in speech. Journal of Pragmatics, 15(6), 521-549. https://doi.org/10.1016/0378-2166(91)90110-J

Brown. P., \& Levinson. S. (1978). Universals in language usage: politeness phenomena. In E. N. Goody (Ed.), Questions and politeness: strategies in social interaction, 8, 56-289. Cambridge University Press. 
Cicurel, F. (2011). Les interactions dans l'enseignement des langues. Agir professoral et pratiques de classe. Didier.

Cosnier, J. (1996). Le geste et le co-pilotage interactionnel. Psychologie de La Motivation, 21, 129-138.

Crivelli, C., \& Fridlund, A. J. (2018). Facial displays are tools for social influence. Trends in Cognitive Sciences, 22(5), 388-399. https://doi.org/10.1016/j.tics.2018.02.006

Dausendschön-Gay, U. (1995). La gestion interactionnelle de la différence des compétences linguistiques : le cas des interactions exolingues. Cahiers de praxématique, 25, 31-52. https://doi.org/10.4000/praxematique.3081

Ekman, P., \& Friesen, W. V. (1978). Manual for the facial action coding system. Consulting Psychologists Press. https://doi.org/10.1037/t27734-000

Goffman, E. (1967). Interaction ritual: essays on face-to-face interaction. Aldine.

Guichon, N. (2012). Vers l'intégration des Tic dans l'enseignement des langues. Didier.

Guichon, N. (2017). Se construire une présence pédagogique en ligne. In N. Guichon \& M. Tellier (Eds), Enseigner l'oral en ligne - une approche multimodale (pp. 29-58). Didier.

ICAR. (2013). Convention de transcription ICOR. Interactions, Corpus, Apprentissages et Représentations.

Kerbrat-Orecchioni, C. (1992). Les interactions verbales 2. la relation interpersonnelle et la politesse dans les interactions verbales. Armand Colin.

McNeill, D. (1992). Hand and mind: what gestures reveal about thought. University of Chicago Press. 


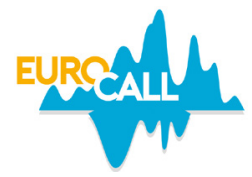

\title{
To Zoom or not to Zoom: Japanese and Ukrainian students' attitudes towards online language learning
}

\author{
Jaime Selwood $^{1}$ and Kateryna Nykytchenko ${ }^{2}$
}

\begin{abstract}
This paper reports on research that aimed to provide initial insight into how university students in two different countries, Japan and Ukraine, coped with greater use of videoconferencing software and whether this resulted in any issues surrounding their online privacy. To facilitate learning under the COVID-19 pandemic, instructors and learners had to speedily adapt to a 'new normal' of intense videoconferencing online learning. However, did this rapid implementation of online learning negatively impact students' privacy? The findings presented in this reflective paper suggest that despite initial concerns, students who participated in the research exhibited low-level concerns regarding the impact of videoconferencing software on their online privacy. Although, students' privacy concerns did grow when presented with long-term or permanent use of online learning as an integral part of a language learning structure.
\end{abstract}

Keywords: privacy, videoconferencing, online learning, COVID.

\section{Introduction}

Like almost every educational institution around the world, the universities in Japan and Ukraine where the authors taught had to rapidly adjust to the restrictions imposed by an unprecedented global pandemic. The immediate impact of the coronavirus on language learning was that face-to-face interaction between learners and educators became no longer viable (Schleicher, 2020). The response to classes migrating to an online format was necessary to reduce the potential spread of COVID (Sahu, 2020). Yet, issues relating to student welfare, and in particular their

\footnotetext{
1. Hiroshima University, Hiroshima, Japan; jselwood@hiroshima-u.ac.jp; https://orcid.org/0000-0002-0228-7581

2. Kyiv National Linguistic University, Kyiv, Ukraine; kateryna.nykytchenko@knlu.edu.ua; https://orcid.org/0000-0003-4938-5290

How to cite this article: Selwood, J., \& Nykytchenko, K. (2021). To Zoom or not to Zoom: Japanese and Ukrainian students' attitudes towards online language learning. In N. Zoghlami, C. Brudermann, C. Sarré, M. Grosbois, L. Bradley, \& S. Thouësny (Eds), CALL and professionalisation: short papers from EUROCALL 2021 (pp. 255-260). Research-publishing.net. https://doi.org/10.14705/rpnet.2021.54.1342
} 
privacy, were not afforded the amount of time that such a monumental alteration to a learning process would normally require.

The technology adopted for these online learning courses was dominated by two videoconferencing software platforms, Microsoft Teams and Zoom. Both offered similar online software capability - namely the ability to interact in real time with class members in different locations via live-stream video (Clopper, Baccei, \& Sel, 2020). The university in Japan allowed individual educators to select the technology they felt best served their requirements. In this regard, the author based in Japan chose Zoom as it offered the ability to show all participants' video screens simultaneously. Teams, initially at least, limited the number of participants' video screens that were displayed concurrently. Unlike in Japan, the university in Ukraine adopted Teams as the compulsory platform for all educators and students. Both programmes were free of cost for the students to use.

\section{Method}

The study was based around English language learning courses at two universities - one in Japan and one in Ukraine. The first sample involved 199 non-English majors from Hiroshima University enrolled in an exclusively online general English course focusing on oral communication. A 60 to 90 -minute class was held once a week in a 16-week semester. Japanese students possessed low-tohigh level ability with weak-to-low motivation and used etextbooks and podcasts. The other group was represented by 60 native Ukrainian-speaking English majors from Kyiv National Linguistic University, who, unlike the Japanese students, had integrated online and face-to-face classes. They had 80-minute classes once/twice a week in a 15/17-week semester focusing on oral communication and translation practices. Ukrainian students demonstrated mid-to-high level ability and mid-tolow motivation and used paper textbooks and handouts. The empirical research was carried out simultaneously at the end of the semester, namely in May and July.

The participants were requested to complete an anonymous Google Forms questionnaire consisting of nine questions - either multiple-choice or open-ended. In this respect the data was collected and analysed by adopting quantitative and qualitative research methods. Regarding the quantitative method, it enabled a statistical analysis approach to the usage of digital backgrounds, operating systems, and software platforms. A qualitative analysis (Mayring, 2015) focusing on content analyses was used in order to gauge the students' views on (1) the effectiveness of online classes over traditional ones, (2) the potential pitfalls of online learning, and 
To Zoom or not to Zoom: Japanese and Ukrainian students' attitudes...

(3) whether there exist any privacy concerns from the students relating to cameraon/camera-off during online classes when using a live-streaming camera.

\section{Results and discussion}

To receive the highest number of student answers, the feedback form was deliberately limited to nine questions; the four relevant to this paper are included below. Naturally, a potential negative aspect of such an approach is that fewer questions could limit the depth of the analysis. In total, 259 students responded, 60 from Ukraine, and 199 from Japan. The authors accept that this created a numerical imbalance but set out with the aim of acquiring as much student feedback as they could.

The initial questions (refer to Table 1), aimed at gaining a broad understanding of students' attitudes towards how their privacy might have been impacted by continued use of videoconferencing software. The first two questions concentrated on students' comfortability with the use of videoconferencing software and whether they took any measures to limit intrusion by others into their location. Question 1 focused on the live-streaming aspect of online learning and provided generally positive responses, from both Ukraine and Japan, with a 55\% $(n=142)$ favourability. In Question 2 only 20\% $(n=51)$ of students used a digital background to conceal their location backgrounds, which indicated that students were not unduly concerned by other class members being able to see from where they were joining the class.

Table 1. Videoconferencing usage

\begin{tabular}{|l|l|l|l|}
\hline \multicolumn{5}{|l|}{ 1: Are live-stream cameras comfortable for online learning? } \\
\hline & YES & NO & DO NOT KNOW \\
\hline UKRAINE & $57 \%$ & $33 \%$ & $10 \%$ \\
\hline JAPAN & $53 \%$ & $26 \%$ & $21 \%$ \\
\hline COMBINED & $55 \%$ & $30 \%$ & $15 \%$ \\
\hline $\begin{array}{l}\text { 2: Did you use a digital background to protect your privacy } \\
\text { when using videoconferencing software? }\end{array}$ \\
\hline \multicolumn{3}{|l|}{ NO } \\
\hline UKRAINE & 45 & YES \\
\hline JAPAN & 163 & 15 \\
\hline COMBINED & 208 & 36 \\
\hline
\end{tabular}

Table 2 shows two questions that focused on the depth of student concerns relating to online privacy. Question 3A centred primarily on students' privacy concerns 
when using videoconferencing as the main conduit of their language learning classes. The answers showed that respondents from both Japan and Ukraine were not unduly concerned by the use of such technology. When students were asked directly if they had online privacy concerns, $25 \%(n=66)$ expressed that they did hold some such reservations. This was an increase of 5\% from those that used digital backgrounds, but this figure still reflects that the majority of students in both countries did not express deep concern over how their privacy might be impacted through live-streaming.

Question 3B asked for further additional explanation from those 25\% who had expressed some privacy concerns during live-streaming online classes. When students were asked to elaborate on their answer in Question 3A, the three most popular responses revolved around students' lack of concern over what others could see of their location. This was due to either nothing revealing being in view or the ability to move their device around to restrict what others could view of their location. Further answers focused on students' confidence in the privacy settings of the videoconferencing software and the limited and regular number of participants in each class. What the answers from these questions indicated was that students were largely not concerned by others gaining insight into their location, and those that held some level of worry had faith in the in-built privacy settings.

Table 2. Online privacy concerns

\begin{tabular}{|l|l|l|}
\hline \multicolumn{3}{|l|}{ 3A: Are you worried about online privacy during class? } \\
\hline & NO & YES \\
\hline UKRAINE & 40 & 20 \\
\hline JAPAN & 153 & 46 \\
\hline COMBINED & 193 & 66 \\
\hline $3 B:$ f &
\end{tabular}

3B: If you answered 'no', what reasons did you have?

Examples of the most popular responses (ranked in order of frequency)

1. Nothing behind me.

2. I do not care.

3. Because there's no important information.

4. I don't care about my privacy unless my room is so messy.

5. Because it's only for certain people to see.

6. Because only me and the wall of the room are visible.

7. Because the background of the screen is blurred.

8. Because recording the class is limited.

9. In my case other student can see only wall.

10. It is because I trust the other students.

11. Students taking the class are limited.

12. I try not to show privacy-related things.

13. Because ZOOM/TEAMS have some functions to protect privacy such as mute and camera off. 
Finally, Question 4 (see Table 3) asked respondents whether they felt online classes offered less privacy protection than traditional classroom-based ones. This question provided the largest discrepancy between Japan and Ukraine, with 52\% $(n=31)$ of the former answering that online classes provided 'much worse' or 'little worse' privacy protection. In comparison, 29\% $(n=58)$ Japanese respondents agreed that online classes presented negative privacy obstacles. Focusing on potential positives, $42 \%$ of Japanese students $(n=103)$ answered they believed online classes were 'much better' or 'little better', more than that of their Ukrainian counterparts where only $25 \%(n=15)$ held the same opinion.

Table 3. Online vs traditional

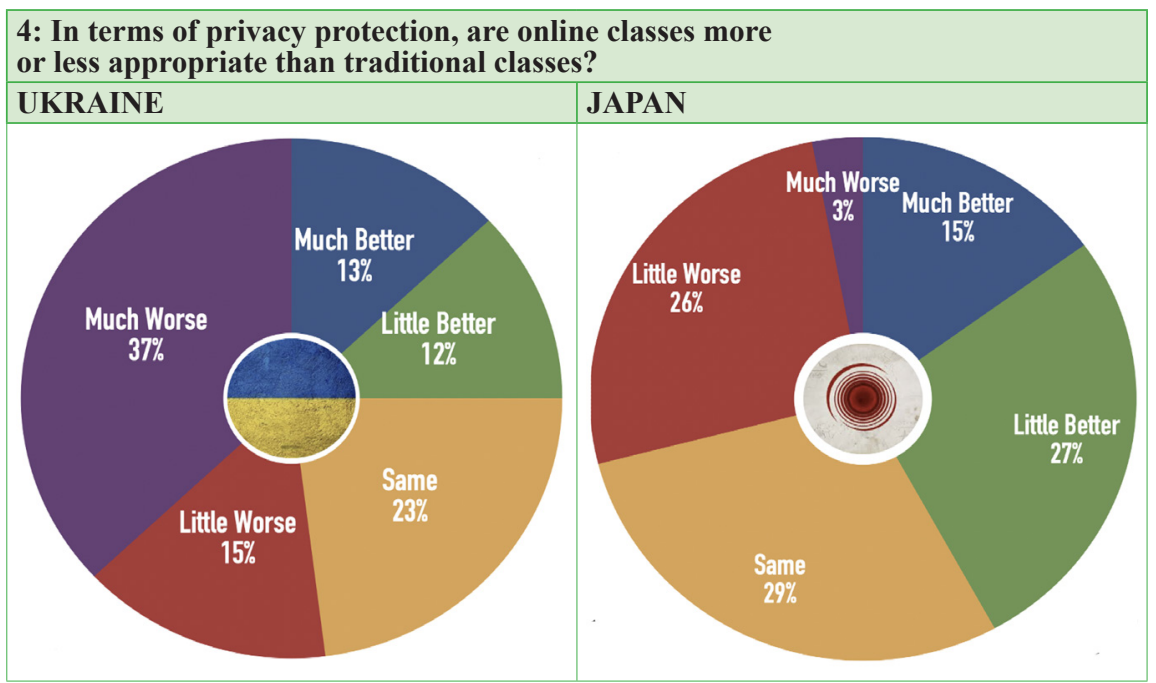

\section{Conclusions}

The reflective paper aimed to provide a snapshot into what privacy concerns, if any, students had whilst participating in online live-streaming classes taught during the COVID-19 pandemic. In truth, both authors were surprised by the results, as our unscientific observations of teaching online courses via videoconferencing software had indicated that privacy issues were a matter of some concern. Yet, the results showed that only a quarter of students in both countries held concerns over privacy, which, although far from conclusive, would seem to suggest that students are comfortable with the technology and were adaptable in how they used it during online classes. To achieve a wider and better understanding of students' privacy 
concerns, further research will be needed before any definitive conclusions can be reached.

\section{References}

Clopper, A. J., Baccei, E. C., \& Sel, T. J. (2020). An evaluation of Zoom and Microsoft Teams video conferencing software with network packet loss and latency. https://igitalcommons. wpi.edu/iqp-all/5687

Mayring, P. (2015). Qualitative Inhaltsanalyse: Grundlagen und Techniken. Beltz.

Sahu P. (2020). Closure of universities due to coronavirus disease 2019 (COVID-19): impact on education and mental health of students and academic staff. Cureus, 12(4):e7541. http://doi. org/10.7759/cureus. 7541

Schleicher, A. (2020). The impact of COVID-19 on education: insights from education at a glance 2020. OECD. https://www.oecd.org/education/the-impact-of-covid-19-on-educationinsights-education-at-a-glance-2020.pdf 


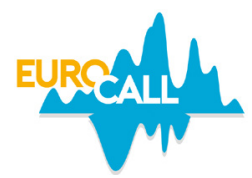

\title{
A world of differences: the role of individual differences in $L 2$ vocabulary learning with clickers
}

\author{
Anne-Marie Sénécal ${ }^{1}$ and Walcir Cardoso ${ }^{2}$
}

\begin{abstract}
This study examined the acquisition of L2 English vocabulary with clickers, focusing on the role of individual differences. Following a pretest-posttest design, we measured perception and performance among 61 English learners who took part in a vocabulary acquisition treatment, in which they answered MultipleChoice Questions (MCQs) via clickers (experimental group) or hand-raising (control group). Findings show that students have positive perceptions of clickers across all analytical measures adopted and that clickers promote vocabulary learning. However, the differences in learning gains between the two groups were not significant, indicating individual differences among learners. Four of the learners who exhibited 'extreme' (lowest/highest) perception and performance scores were selected for further analyses. The presence of individual differences in clickerenhanced learning suggests the technology should be carefully implemented to accommodate learners' individual differences.
\end{abstract}

Keywords: learner response systems, clickers, L2 pedagogy, individual differences.

\section{Introduction}

Clickers are handheld devices that wirelessly collect and transmit student input to a computer. During a lesson, instructors can display MCQs on a projector and open a polling session, during which student answers are computed. When the polling is closed, an answer distribution graphic is displayed on the board. This visual feedback informs the instructor of the students' understanding and gives students a sense of how they are performing in comparison with their peers. Other pedagogical affordances of clickers include the promotion of collaborative learning (via peer

\footnotetext{
1. Concordia University, Montreal, Canada; anne-marie.senecal@concordia.ca; https://orcid.org/0000-0001-8725-0413

2. Concordia University, Montreal, Canada; walcir.cardoso@concordia.ca; https://orcid.org/0000-0001-6376-185X

How to cite this article: Sénécal, A.-M., \& Cardoso, W. (2021). A world of differences: the role of individual differences in L2 vocabulary learning with clickers. In N. Zoghlami, C. Brudermann, C. Sarré, M. Grosbois, L. Bradley, \& S. Thouësny (Eds), CALL and professionalisation: short papers from EUROCALL 2021 (pp. 261-266). Research-publishing.net. https://doi.org/10.14705/rpnet.2021.54.1343
} 
instruction), immediate feedback, and user anonymity (to increase participation) (Cardoso, 2011).

There is a general agreement in the literature that students have positive perceptions of the use of clickers across the four measures predominantly explored: learning, self-assessment, engagement, and interactivity (e.g. Song, Oh, \& Glazewski, 2017). In terms of learning gains, the consensus is not as clear-cut. The literature agrees that clickers promote learning but is not definitive when comparing gains between groups: while some reveal a superiority for clickers (e.g. Agbatogun, 2014), others show comparable gains between the instructional approaches considered (e.g. Mays, Yeh, \& Chen, 2020). The literature suggests that these comparable gains may be associated with the role of individual differences (e.g. Landrum, 2015), an under-investigated phenomenon in CALL research (Foroozesh-nia, 2015).

The goal of this study is to examine L2 learners' perceptions of clickers and how the technology can affect their performance when learning vocabulary. In addition, it aims to explore the role of individual differences in the learning process. The following research questions were adopted.

- Perception: what are students' perceptions of the pedagogical potential of clickers?

- Performance: is the pedagogical use of clickers beneficial for the acquisition of L2 vocabulary?

- Individual differences: what is the role of individual differences (in perception and performance) in clicker-enhanced vocabulary learning?

\section{Method}

Sixty-one Grade 8 students (13-14 years old) in two intact groups were recruited to participate. The groups were randomly assigned to a treatment, in which MCQs were answered via clickers (Clicker Group, $\mathrm{CG}, n=31$ ) or via hand-raising (NonClicker Group, NCG, $n=30)$.

A six-week vocabulary instruction treatment targeted 30 low-frequency words (to minimize previous exposure to the words), extracted from Roald Dahl's novel James and the Giant Peach. The treatment was preceded by a pretest and followed by an immediate posttest, all measuring the students' knowledge of the 30 target 
words. In the tests, students were asked to demonstrate their understanding of the words by either defining them, creating a sentence using the word, drawing a picture representing the word, or translating the word into their first language, French. The data collected included the answers to the 30 words on each test, which were coded as either correct (1) or incorrect (0). An independent-samples $t$-test as well as mixed-model ANOVAs were run to analyze the data.

To measure learners' perceptions of clickers (CG only), surveys were administered after the treatment (CG: $n=29$ ). The five item Likert scale survey (adapted from Cardoso, 2011) included 13 statements related to four perception measures: learning, self-assessment, engagement, and interactivity. Internal reliability of the survey was confirmed via Cronbach's Alpha and further analyzed by a panel. Via descriptive statistics, the means and standard deviations for each survey item was calculated.

To explore individual differences, four participants from the CG were selected to represent deviations among the participants. They were selected because their perception and performance deviated from the mean in an extreme manner (i.e. they were considerably higher or lower). Perception and performance data were plotted on a graph (see forthcoming Figure 1) to visually represent the result deviations between the four participants.

\section{Results and discussion}

In Table 1, the results reveal that students in the CG had positive perceptions of clickers, as their perceptions were above the level of neutrality $(\geq 3)$ on all measures, particularly for engagement $(M=4.15, S D=0.65)$.

Table 1. Student perceptions of clicker technology

\begin{tabular}{|l|l|l|}
\hline \multirow{2}{*}{ Measures of perception } & \multicolumn{2}{|l|}{$\mathbf{C G}(\mathbf{n}=\mathbf{2 9})$} \\
\cline { 2 - 3 } & $\mathbf{M} / \mathbf{5}$ & SD \\
\hline Learning & 3.78 & .84 \\
\hline Self-assessment & 3.91 & .59 \\
\hline Engagement & 4.15 & .65 \\
\hline Interactivity & 3.14 & .88 \\
\hline
\end{tabular}

Table 2 illustrates the results for student performance, showing that both the CG and NCG improved in vocabulary learning between the pretest and posttest. An independent-samples $t$-test was run to compare the participants' level of vocabulary before the treatment in the CG $(M=1.29 ; S D=1.77)$ and NCG $(M=.93 ; S D=1.38)$, 
which revealed to be comparable, $t(59)=0.87, p=.39$. When looking at the learning gains, there was a significant improvement between the pretest and posttest results in the $\mathrm{CG}(M=6.61 ; S D=3.81)$ and the NCG $(M=4.97 ; S D=2.31), F(1.771$, $104.5)=159.53, p<.001$. However, when comparing the improvement between the groups, there was not a significant difference, $F(1.771,104.5)=3.031, p>.05$.

Table 2. Performance on vocabulary assessment tests

\begin{tabular}{|l|l|l|l|l|}
\hline \multirow{2}{*}{ Test } & \multicolumn{3}{|l|}{ CG (n=31) } & NCG (n=30) \\
\cline { 2 - 5 } & M/30 & SD & M/30 & SD \\
\hline Pretest & 1.29 & 1.77 & .93 & 1.38 \\
\hline Immediate posttest & 6.61 & 3.81 & 4.97 & 2.31 \\
\hline
\end{tabular}

Overall, the findings revealed that students have positive perceptions of clickers. These results corroborate the literature that shows similar evidence (e.g. Song et al., 2017). For performance, the learning gains shown in the CG support findings in the literature that indicate that the pedagogical use of clickers promotes learning (e.g. Agbatogun, 2014). The results also reveal that the improvements in the CG were not significantly higher than those in the control group. While this finding corroborates previous studies who found comparable learning gains (e.g. Mays et al., 2020), it contradicts others who found clicker-enhanced learning outperformed other instructional approaches (e.g. Agbatogun, 2014). The absence of significantly higher improvement in the $\mathrm{CG}$ may be explained by the interaction of individual differences in performance, which is highlighted by the high levels of standard deviation in the $\mathrm{CG}$ on the posttest $(M=6.61, S D=3.81)$.

The results of the four participants selected, shown in Figure 1, highlight 'extreme' scores (highest standard deviations). For one participant, Jordan, clicker-enhanced learning was particularly successful as he received one of the highest scores for perception (4.54/5) and vocabulary acquisition (10/30). On the opposite end of the spectrum, Alex did not greatly benefit from clickers as he scored among the five lowest in both measures (perception: 3.15/5; learning gains: 1/30). For other students, a discrepancy between measures was observed (e.g. high perception and low performance). For example, Sasha rated high perceptions $(4.69 / 5)$ but scored among the five lowest participants for learning gains $(2 / 30)$, indicating that high perceptions did not project to acquisition. Contrarily, while Cameron had lower perceptions $(2.85 / 5)$, she still benefited from the clicker-based treatment as she had high vocabulary acquisition (8/30). In sum, the presence of extremes in these results highlights the effects of individual differences (see also Landrum, 2015), indicating that the proposed clicker-enhanced learning was more beneficial for some students than others. 
Figure 1. Four potential scenarios: perception and performance quadrant

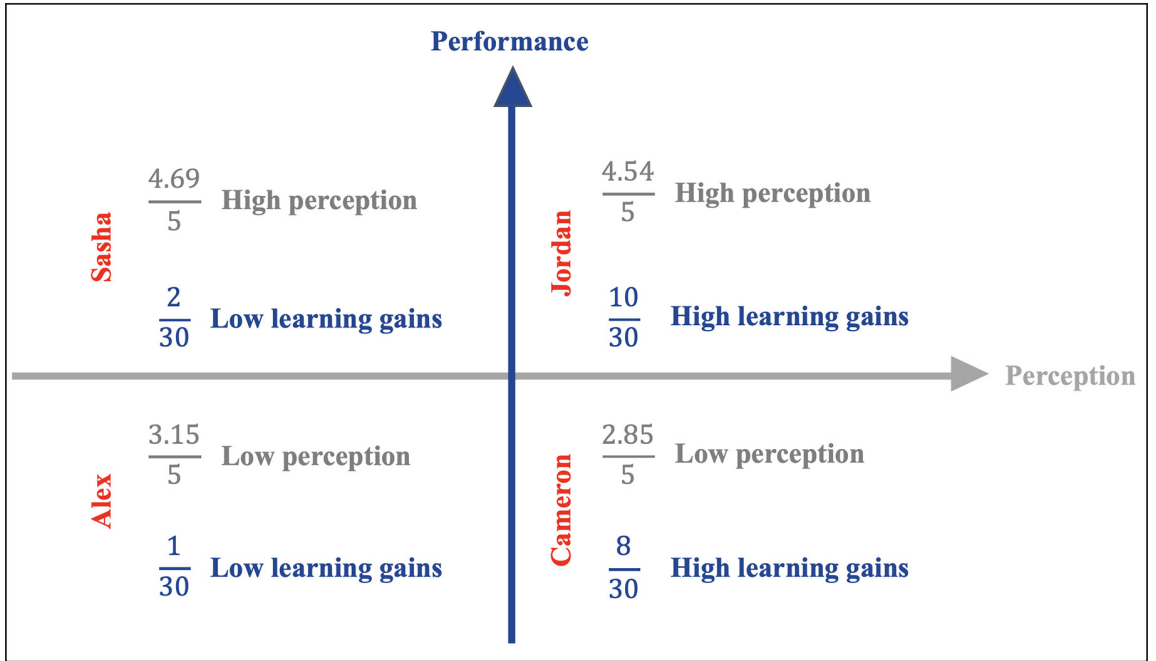

\section{Conclusions}

In conclusion, this project has shown that L2 students hold positive perceptions of the use of clickers and that the technology has the potential to aid vocabulary learning. However, the individual differences observed show that clickers are not a pedagogical panacea, and that the technology should be implemented in conjunction with other instructional approaches to accommodate the students' needs, interests, and individual differences.

\section{Acknowledgments}

We would like to thank Turning Point Canada and the participants from Collège Sainte-Anne. Funding for this study was provided by the Social Sciences and Humanities Research Council of Canada.

\section{References}

Agbatogun, A. (2014). Developing learners' second language communicative competence through active learning: clickers or communicative approach? Educational Technology \& Society, 17(2), 257-269. 
Cardoso, W. (2011). Learning a foreign language with a learner response system: the student's perspective. Computer Assisted Language Learning, 24, 393-417. https://doi.org/10.1080/0 9588221.2011 .567354

Foroozesh-nia, S. (2015). Overview of the significance of different learner characteristics in computer-based language learning environment. In M. Rahimi (Ed.), Handbook of research on individual differences in computer-assisted language learning (pp. 1-23). Information Science Reference. https://doi.org/10.4018/978-1-4666-8519-2

Landrum, R. (2015). Teacher-ready research review: clickers. Scholarship of Teaching and Learning in Psychology, 1(3), 250-254. https://doi.org/10.1037/st10000031

Mays, B., Yeh, H.-C., \& Chen, N.-S. (2020). The effects of using audience response systems incorporating student-generated questions on EFL students' reading comprehension. The Asia-Pacific Education Researcher, 29(6), 553-566. https://oi.org/10.1007/s40299-02000506-0

Song, D., Oh, E., \& Glazewski, K. (2017). Student-generated questioning activity in second language courses using a customized personal response system: a case study. Educational Technology Research and Development, 65(6), 1425-1449. https://doi.org/10.1007/s11423017-9520-7 


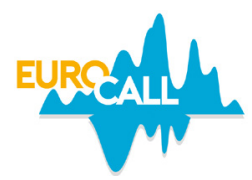

\title{
Assessing learners' needs for practising spoken Icelandic L2 with the mobile app TALAĐU!
}

\author{
Fanny Sissoko ${ }^{1}$ and Branislav Bédi ${ }^{2}$
}

\begin{abstract}
This article presents results from a human-centred approach study to designing a mobile app TALAĐU!, which aims at assisting learners of Icelandic as a second language (L2) with spoken language practice. The main goal of the app would be to encourage learners to have real-life conversations with Icelandic speakers by accomplishing conversational missions. In the first stage of development, a qualitative deep-method needs study in the form of interviews was conducted with 19 migrants from 14 different countries, who permanently live in Iceland. Results indicated that learners have five core needs for practising spoken language: connection, confidence, clarity, growth, and convenience. Based on different learning styles and confidence in speaking rather than language ability, three main learner profiles were indicated: 'diving in', 'learning with caution' and 'dipping a toe'. Both the learners' needs and the profiles would drive the design of the learning app to personalise and maximise the learner experience with practising spoken L2. This human-centred study approach suggests an innovative strategy in designing a learning app for practising L2 in a specific language and culture environment.
\end{abstract}

Keywords: human-centred design, L2 Icelandic, learner profiles, online app, spoken language.

\section{Introduction}

In Iceland, many migrants experience a lack of opportunities in practising the spoken language outside of their formal instruction for various reasons, often connected to working with other migrants who do not speak the target language,

\footnotetext{
1. Independent Designer and Researcher, Reykjavík, Iceland; fansissoko@gmail.com

2. The Árni Magnússon Institute for Icelandic Studies, Reykjavík, Iceland; branislav.bedi@arnastofnun.is; https://orcid. org/0000-0001-7637-8737

How to cite this article: Sissoko, F., \& Bédi, B. (2021). Assessing learners' needs for practising spoken Icelandic L2 with the mobile app TALAĐU!. In N. Zoghlami, C. Brudermann, C. Sarré, M. Grosbois, L. Bradley, \& S. Thouësny (Eds), CALL and professionalisation: short papers from EUROCALL 2021 (pp. 267-272). Research-publishing.net. https://doi.org/10.14705/ rpnet.2021.54.1344
} 
and the segregation of the labour market (Skaptadóttir \& Innes, 2017, p. 25). The tendency of native Icelandic speakers to switch into English when encountering foreign speakers also minimises the exposure to spoken Icelandic and therefore L2 language practice with locals (Kristinsson, 2020). This may influence L2 Icelandic practice of both short-term visitors such as exchange students, seasonal workers, and long-term immigrants from various fields such as education and industry. Several other attempts have been made to increase learners' exposure to spoken Icelandic. This includes courses provided by private language schools or at universities, the project The Icelandic Village 3 that involves locals in different businesses speaking Icelandic to foreigners, and also new online technologies such as the prototype of an L2 learning computer game Virtual Reykjavik (Bédi et al., 2016) that should enable a simulation of a real-life conversation with locals in a virtual environment. Although there are many other apps on the market that support enhancing language skills, e.g. Babbel, Busuu, Duolingo, Lingoda, Mondly, uTalk, none of them offer Icelandic language neither are they tailor-made for the needs of L2 Icelandic learners in Iceland. This article presents another attempt to help foreign speakers to practise spoken L2 Icelandic through an online app, which is designed to be used locally in a real-life environment.

TALAĐU!, which translates to English as 'SPEAK!', is a work-in-progress mobile application aiming to assist with spoken language practice in L2 Icelandic. The main goal is to encourage learners to have real-life conversations with Icelandic speakers by accomplishing conversational missions. The aim of this article is to present results from a human-centred study about learners' needs for practising L2 Icelandic. The results would drive the design of the app so that the learner would be able to personalise their journey by choosing a level, setting a daily time for practising, and selecting topics they want to grow their confidence in while using the app. Each day, the app would push notifications to learners with new vocabulary, common phrases, and cultural cues relevant to the topics they had preselected. The learners would be moreover encouraged to practise the language in their real-life environment by interacting with locals face-to-face using this app. The communicative approach, task-based learning, and role-play are the main learning approaches used in the app. Gamification elements would consist of rewards that learners will receive for completing individual tasks. The design strategy for teaching spoken language skills in a real-life environment with TALAĐU! considers both the needs and the different learning profiles of non-native speakers of Icelandic for practising spoken language with other native speakers in a real-life environment. Its methodology is presented here below.

3. https://languagelearninginthewild.com/project/the-icelandic-village/ 


\section{Understanding the needs of learners}

The development of this app follows a human-centred methodology (Buchanan, 2001) whereby potential users take part in the research and design of the solution. When designing information systems, a human-centred approach considers aspects of context and socio-cultural significance to make the system 'humancentred' rather than only 'user-centred' (Gasson, 2003, p. 42). This means that gathering knowledge about problems and offering solutions for the real word are the main goal of this approach. Guided by human feedback, systems can then better serve the needs of their potential users (Schnepp et al., 2020, p. 2). Here, the first stage involved a qualitative deep-method human-centred needs study conducted with 19 participants located within and outside of the capital region from 14 different countries, who came to Iceland for different purposes and under different conditions.

In-depth interviews about informants' ways of learning and needs for practising spoken L2 Icelandic were conducted. Four of the participants did not speak any English but had a considerable level of Icelandic to be interviewed in Icelandic language. Selective sampling method was used to collect data.

Thematic analysis was used for analysis, which indicated five core needs that will drive the design of the app: connection, confidence, clarity, growth, and convenience (Figure 1). These are based on five reoccurring themes from informants' interviews. The purpose is to find a meaningful connection in a conversation, to break the first barrier in speaking the target language, and to move beyond a superficial interaction with speakers of Icelandic.

Figure 1. Five core needs for achieving a successful conversation with local speakers of Icelandic

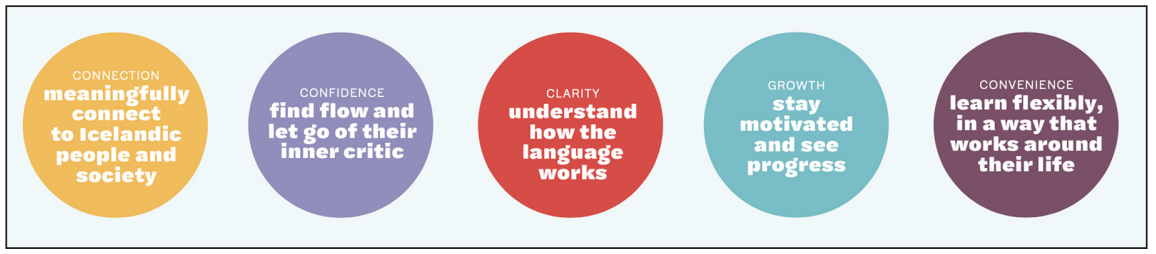

The informants' different learning styles and their level of confidence in speaking rather than language ability helped to indicate three main learner profiles for personalising and maximising the learner experience when using the app (Figure 2). 
Figure 2. The app design features three main user profiles

\begin{tabular}{|c|c|c|c|c|c|}
\hline \multicolumn{2}{|c|}{ DIVING IN } & \multicolumn{2}{|c|}{ WITH GAUTION } & \multicolumn{2}{|c|}{ DIPPING A TOE } \\
\hline \multicolumn{2}{|l|}{ MINDSET } & \multicolumn{2}{|l|}{ MINDSET } & \multicolumn{2}{|l|}{ MINDSET } \\
\hline \multicolumn{2}{|c|}{$\begin{array}{l}\text { Itry, even if I don't speak } \\
\text { perfectly, lve learned to be } \\
\text { ok with making mistakes. }\end{array}$} & \multicolumn{2}{|c|}{$\begin{array}{l}\text { I have a solid base, but } \\
\text { don't have the confidence } \\
\text { to speak uniess Inowl } \\
\text { can handle it perfectly. }\end{array}$} & \multicolumn{2}{|c|}{$\begin{array}{l}\text { Ifeet like } l^{\prime} m \text { right at the } \\
\text { start of a long and hard } \\
\text { journey! }\end{array}$} \\
\hline \multicolumn{2}{|c|}{$\begin{array}{l}\text { I need a real motivation so } \\
\text { clive into situations where I } \\
\text { have no choice but speaking } \\
\text { lcelandic. }\end{array}$} & \multirow{3}{*}{\multicolumn{2}{|c|}{$\begin{array}{l}\text { The grammar overwhelms } \\
\text { me if I'm not taught in a } \\
\text { structured, step-by-step } \\
\text { way. } \\
\text { - I don't feel I can be my full } \\
\text { self when I speak Icelandic } \\
\text {-I want people to see me } \\
\text { for who I am. }\end{array}$}} & \multirow{2}{*}{\multicolumn{2}{|c|}{$\begin{array}{l}\text { Pm quite isolated and } \\
\text { don't have many lcelandic } \\
\text { connections to practise } \\
\text { with, so l feel completely } \\
\text { overwhelmed. }\end{array}$}} \\
\hline \multicolumn{2}{|c|}{$\begin{array}{l}\text { Grammar is boring so don't } \\
\text { talk to me too much about it, } \\
\text { PIl pick it up. }\end{array}$} & & & & \\
\hline \multicolumn{2}{|c|}{$\begin{array}{l}\text { like to absorb the language } \\
\text { through various mediums - } \\
\text { everything is an opportunity } \\
\text { to learn books, radio, tv, } \\
\text { youtube ads, groceries, etc. }\end{array}$} & & & & \\
\hline $\begin{array}{l}\text { FEELINGS TO } \\
\text { AVOID }\end{array}$ & $\begin{array}{l}\text { FEELINGS TO } \\
\text { RE-CREATE }\end{array}$ & $\begin{array}{l}\text { FEELINGS TO } \\
\text { AVOID }\end{array}$ & $\begin{array}{l}\text { FEELINGS TO } \\
\text { RE-CREATE }\end{array}$ & $\begin{array}{l}\text { FEELINGS } \\
\text { TOAVOID }\end{array}$ & $\begin{array}{l}\text { FEELINGS TO } \\
\text { RE-CREATE }\end{array}$ \\
\hline $\begin{array}{l}\text { Boredom } \\
\text { Stagination }\end{array}$ & $\begin{array}{l}\text { Curiousity } \\
\text { Immersion }\end{array}$ & $\begin{array}{l}\text { Anxiety } \\
\text { Frustration }\end{array}$ & $\begin{array}{l}\text { Achievement } \\
\text { Clarity }\end{array}$ & $\begin{array}{l}\text { Lonetiness } \\
\text { Overwhelm }\end{array}$ & $\begin{array}{l}\text { Connection } \\
\text { Encouragement }\end{array}$ \\
\hline
\end{tabular}

\section{Key design features and user journey}

Based on our study, key features are personalisation, selecting useful conversational topics with respective learning materials, choosing from a menu of suggested missions for a conversation practice in real life, and gamification to mark progress to unlock the next level. These features will help the learners immerse themselves into the language through real-world missions, provide feedback, and motivate them to complete individual tasks. The app will be personalised based on the learner profiles and needs for conversation practice.

The learners would set their own time and goals for each mission and receive tips on the type of conversations, vocabulary, and memory exercises around each of the selected topics for conversation in a real-life environment. The missions will help learners put into practice what they have learned on simple or more complicated topics, for example, ordering a coffee or asking older family members about their childhood, by simply speaking to local people. The next level can be unlocked only by completing each mission. The app will support real person-toperson conversation among other things by suggesting phrases and sentences that learners can read and listen to, repeat, and then use in real life. This will help foreign speakers to connect with the local speaking community. 


\section{Conclusion}

The design approach taken in this human-centred needs study sheds light on the necessity to investigate what kind of needs L2 learners have in the local environment of a specific target language to help them make real-time conversations. The learners would select conversational topics, get help with starting and finishing a conversation, and review vocabulary that they need to use. Although still a work-inprogress, once ready the app would use conversational tasks encouraging learners to complete them in real-life environments. This approach could be applied to design other L2 learning apps because it would shed light on the needs of learners in different language and culture contexts of other countries. The development of this application has three main stages: research about learners' needs, design of the app and the implementation of learning tasks, and the production of a prototype. This article presented findings from the first stage.

\section{Acknowledgements}

This research was funded by Hönnunarsjóður (Design Fund) in Iceland.

\section{References}

Bédi, B., Arnbjörnsdóttir, B., Vilhjálmsson, H. H., Helgadóttir, H. E., Ólafsson, S., \& Björgvinsson, E. (2016). Learning Icelandic language and culture in Virtual Reykjavik: starting to talk. In S. Papadima-Sophocleous, L. Bradley \& S. Thouësny (Eds), CALL communities and culture - short papers from EUROCALL 2016 (pp. 37-43). Research-publishing.net. https://doi. org/10.14705/rpnet.2016.eurocall2016.535

Buchanan, R. (2001). Human dignity and human rights: thoughts on the principles of humancentered design. Design Issues, 17(3), 35-39. https://doi.org/10.1162/074793601750357178

Gasson, S. (2003). Human-centered vs. user-centered approaches to information system design. The Journal of Information Technology Theory and Application (JITTA), 5(2), 29-46. https:// aisel.aisnet.org/cgi/viewcontent.cgi?article $=1153 \&$ context=jitta

Kristinsson, A. P. (2020). Between Scylla and Charybdis: on language situation and language policy in contemporary Iceland. Bendrine Kalba, 93, 1-19. https://doi.org/10.35321/ bkalba.2020.93.02

Schnepp, J., Wolfe, R., Brionez, G., Baowidan, S., Johnson, R., \& McDonald, J. (2020). Humancentered design for a sign language learning application. In Proceedings of the 13th ACM International Conference on PErvasive Technologies Related to Assistive Environments (PETRA '20). Association for Computing Machinery. https://doi.org/10.1145/3389189.3398007 
Skaptadóttir, U. D., \& Innes, P. (2017). Immigrant experiences of learning Icelandic and connecting with the speaking community. Nordic Journal of Migration Research, 7(1), 2027. https://doi.org/10.1515/njmr-2017-0001 


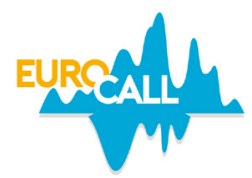

\title{
The HERO project: language training for migrants' professional career as caregivers through blended learning
}

\author{
María-Victoria Soulé 1 Kostas Stylianou ${ }^{2}$, Christina Yerou ${ }^{3}$, \\ Eftychia Xerou ${ }^{4}$, Theologia Tsitsi ${ }^{5}$, and Andreas Charalambous ${ }^{6}$
}

\begin{abstract}
The HERO project aims to develop a training program for caregivers to be working in the elderly care sector. The program is particularly addressed to caregivers from Middle Eastern and African countries as refugees and intends to help them integrate into European society. This paper seeks to offer an overview of the project, including its objectives, underlying principles, and deliverables. The paper particularly portrays the second intellectual output (O2) of the project, namely the 'On the job' training in language and terminology curriculum, which has been developed as the end product of O2. Initially, the methodology adopted to create learning material for language learning in a specific-purpose context is analyzed. Based on this, the paper provides a description of the content development by justifying and showcasing the learning material and laying out the logic behind this, through the trainers' guide. E-learning tools have been integrated in the course material, which also justifies the methodology applied for the purpose of this project.
\end{abstract}

Keywords: professionalization, migration, languages for specific purposes, blended learning.

\footnotetext{
1. Cyprus University of Technology, Limassol, Cyprus; mariavictoria.soule@cut.ac.cy; https://orcid.org/0000-0001-7798-2426

2. Cyprus University of Technology, Limassol, Cyprus; kostas.stylianou@cut.ac.cy

3. Cyprus University of Technology, Limassol, Cyprus; christina.yerou@cut.ac.cy; https://orcid.org/0000-0002-5730-3905

4. Cyprus University of Technology, Limassol, Cyprus; eftychia.xerou@cut.ac.cy

5. Cyprus University of Technology, Limassol, Cyprus; theologia.tsitsi@cut.ac.cy

6. Cyprus University of Technology, Limassol, Cyprus; andreas.charalambous@cut.ac.cy; https://orcid.org/0000-0003-4050-031X

How to cite this article: Soulé, M.-V., Stylianou, K., Yerou, C., Xerou, E., Tsitsi, T., \& Charalambous, A. (2021). The HERO project: language training for migrants' professional career as caregivers through blended learning. In N. Zoghlami, C. Brudermann, C. Sarré, M. Grosbois, L. Bradley, \& S. Thouësny (Eds), CALL and professionalisation: short papers from EUROCALL 2021 (pp. 273-278). Research-publishing.net. https://doi.org/10.14705/rpnet.2021.54.1345
} 


\section{Introduction}

With the continuous incoming of refugees from African and Middle Eastern countries which are under non-stop war conflicts, the EU is trying to integrate them in the labor market (European Commission, 2019), particularly in the field of elderly care. However, due to the migrants' lack of language and communication skills along with the fact that their knowledge in the workplace is only experiencebased (i.e. in most cases without qualifications), the migrant/refugee integration to the labor market does not seem to be adequate.

The $\mathrm{HERO}^{7}$ project aims to fill this gap by both providing training in the profession of a caregiver, as well as developing language and communication skills vital to such a professional setting and society in general. The HERO program is an Erasmus + Key Actions training program, which focuses on elderly care and infectious disease prevention. The project involves four countries: Cyprus, Greece, Italy, and Portugal, and includes English along with the language of the country of residence and training.

The HERO project is being funded for four Intellectual Outputs (IO). This paper reports on the second IO curriculum called 'On the job' training in language and terminology which designed the curriculum for the language courses focusing on Specific Purposes (SP) courses (Connor \& Upton, 2012) at A1-A2 level of the CEFR, the Common European Framework of Reference for languages (Council of Europe, 2001).

\section{Insight on content development}

\subsection{Context}

The context of this research involves the learning material in languages for SP and the trainers' guide, which were created as part of the HERO project. For its development, a task-based needs analysis was employed (Malicka, Gilabert, \& Norris, 2019), along with document analysis (Frey, 2018). More specifically, caregiver duties and responsibilities in the protocols of the four partner institutions were systematically examined and compared, with the aim of

7. HERO is the acronym for the project Training program in elderly care and infectious disease prevention for the integration of refugees from the Middle Eastern and African countries in western society. 
establishing the most significant tasks and duties in the elderly care area. Cultural and social differences, various educational and social backgrounds were also considered, as well as different learning styles to embrace the diversity of the target audience (McNamara et al., 2018). The approach for the language courses incorporates a blended methodology conceptualized as a combination of onsite with online experiences to produce effective, efficient, and flexible learning (Stein \& Graham, 2014).

\subsection{Learning material}

The content material was built on language learning at a basic level and the care terminology, more specifically, at the A1-A2 CEFR level. The language course material was created and translated into four languages: English, Greek, Italian, and Portuguese. The material was slightly adapted to meet the linguistic and cultural necessities of the four countries. The curriculum for the language course was designed so that it focuses on SP courses within the elderly care area. The language course material starts with an outline where the topic of each unit is described as well as the scenarios (context of situation), language needed, key terminology, and learning hours. The material includes nine units. The topics of Units 0 to 8 are displayed in Table 1 .

Table 1. HERO learning material: Units 0 to 8

\begin{tabular}{|l|l|}
\hline Unit & Content \\
\hline 0 & The Alphabet and Numbers 0 to 100 \\
\hline 1 & A New Client \\
\hline 2 & A Day in the Elderly Care Unit \\
\hline 3 & Everyday Duties of a Carer: Nursing Interventions \\
\hline 4 & Everyday Duties of a Carer: Hygiene duties \\
\hline 5 & Everyday Duties of a Carer: Feeding \\
\hline 6 & Hospital Infection \\
\hline 7 & Reporting an Incident \\
\hline 8 & Physical Health: Problems and Aids \\
\hline
\end{tabular}

Unit 0 was designed as an introductory/optional unit for learners who are not aware of the alphabet or the numbers up to 100 in the target language. This unit consists of three sections and includes activities where the content presented in its sections is put into practice with the use of Quizlet (see Figure 1). Quizlet is both an online learning environment, and a mobile application that permits the creation of vocabulary, flashcards, games, and quizzes. 
Figure 1. Example of a Quizlet 'Match' activity for the alphabet in ESP

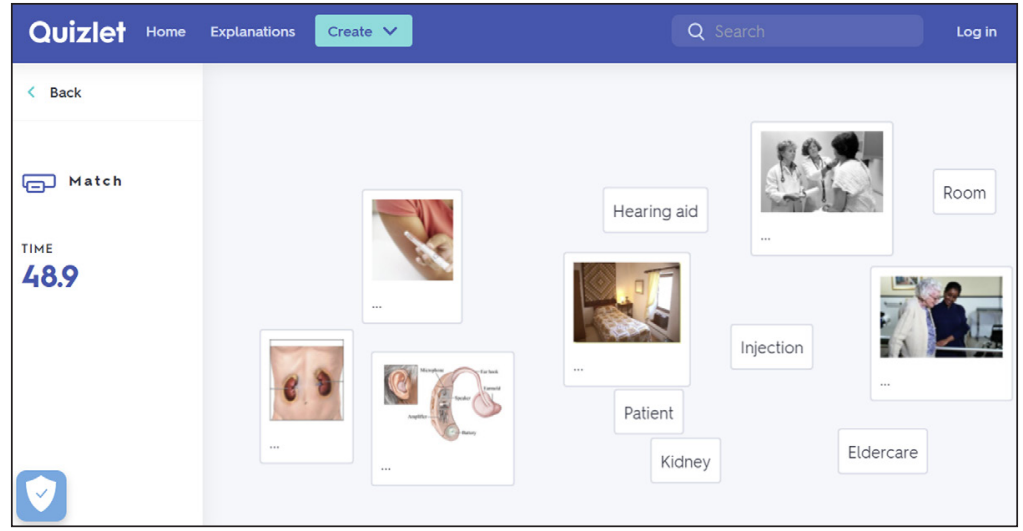

Figure 2. Example of a matching activity designed for the HERO Moodle course

\begin{tabular}{|l|l|}
$\begin{array}{l}\text { Match these following common musculoskeletal disorders with their } \\
\text { definitions. }\end{array}$ \\
Tendinopathy \\
alters the joints biochemically, \\
structurally, and physiologically.
\end{tabular}

Units 1 to 8 were designed following a structure of five sections. Section 1 includes texts in the form of dialogues, schedules, instructions, and reports. Section 2 consists of introductory vocabulary related to the topic of each unit. Section 3 
provides the learners with useful phrases from the texts as well as other phrases that could be used in similar contexts. Section 4 explains the grammar/function of the language used in the texts by introducing tables, grammar rules, as well as examples of language in use. Section 5, the last one, contains practice activities based on the previous sections. The activities were designed as part of a Moodle course, which includes assignment activities, multiple-choice quizzes, cloze questions, matching questions, drag-and-drop matching, and self-assessment tasks with detailed feedback (see Figure 2 above).

\subsection{Trainers' guide}

The guide proposes different steps to help the language instructors implement the language course material. Each unit of the course material is accompanied by suggestions that include: guidelines on how to read the texts (i.e. role-plays, brainstorming), as well as different approaches for the vocabulary section (i.e. pronunciation, use of digital devices in class), the useful phrases section (i.e. explanation of phrases in context), the language spot section (i.e. interaction between the instructor and learners), and the activities section (i.e. individual, peer, and group work, feedback to learners).

The trainers' guide also provides the keys for the activities of the language course material, from Section 1 to 5 of each unit. The guide is also available in all four languages.

\section{Conclusions}

The aim of the HERO project is to provide content development for the training of refugee or migrant caregivers who work in elderly care units in European countries. The content was developed following a specific training methodology, considering cultural and social differences, various education and social backgrounds, and different learning styles, to be used as a multicultural training tool for professionals (Brotman, 2003). The content was also translated in four different languages. Apart from developing the necessary language skills, the project also aimed at raising awareness of the proper language use both in the working field and in everyday life. Additionally, considering that language is more effectively learned when using authentic course materials (Guariento \& Morley, 2001), the content was designed in such a way as to help target learners to build up their acquired knowledge through role-plays and focus-groups, as they increase student motivation and involvement. 
For a more successful delivery of the training sessions, a trainers' guide was also developed. Finally, the evaluation of course material, the trainers' guide, together with the methodology selected for the course implementation will be conducted in the next phases of the project.

\section{References}

Brotman, S. (2003). The limits of multiculturalism in elder care services. Journal of Aging Studies, 17(2), 209-229. https://doi.org/10.1016/S0890-4065(03)00003-3

Connor, U., \& Upton, T. (2012). Language for specific purposes: overview. The Encyclopaedia of Applied Linguistics. https://doi.org/10.1002/9781405198431.wbeal0891

Council of Europe. (2001). Common European framework of reference for languages: learning, teaching, assessment. Press Syndicate of the University of Cambridge.

European Commission. (2019). Statistics on migration to Europe. https://ec.europa.eu/info/ strategy/priorities-2019-2024/promoting-our-european-way-life/statistics-migrationeurope en\#overall-figures-of-immigrants-in-european-society

Frey, B. (2018). The SAGE encyclopaedia of educational research, measurement, and evaluation (vols 1-4). Sage. https://doi.org/10.4135/9781506326139.n209

Guariento, W., \& Morley, J. (2001). Text and task authenticity in the EFL classroom. ELT Journal, 55(4), 347-353. https://doi.org/10.1093/elt/55.4.347

Malicka, A., Gilabert, R., \& Norris, J. M. (2019). From needs analysis to task design: insights from an English for specific purposes context. Language Teaching Research, 23(1),78-106. https://doi.org/10.1177/1362168817714278

McNamara, T., Elder, C., Flynn, E., Knoch, U., Manias, E., Woodward-Kron, R., \& Yahalom, S. (2018). Cross-disciplinary collaboration in research on a specific-purpose language test in the healthcare setting. Journal of Applied Linguistics and Professional Practice, 13(1-3), 189-210. https://doi.org/10.1558/japl.31857

Stein, J., \& Graham, C. (2014). Essentials for blended learning. A standards-base guide. Routledge. https://doi.org/10.4324/9780203075258 


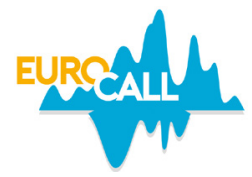

\title{
Students' intercultural sensitivity development through telecollaborative Chinese language learning on Zoom: a case study of Irish students at the beginning-level of Chinese language
}

\author{
Mengdi Wang ${ }^{1}$, Ann Devitt ${ }^{2}$, Garreth Hodgins ${ }^{3}$, and Ciarán Bauer ${ }^{4}$
}

\begin{abstract}
This descriptive study presents the first research cycle with four synchronous telecollaborative language learning sessions on Zoom between Irish and Chinese teenagers. Intercultural Sensitivity Scale (ISS) post-questionnaire results show that the mean of interaction enjoyment scale is the highest compared to the other four categories, which implies that telecollaboration provides an enjoyable and authentic environment for Irish adolescent learners to experience communication with native speakers. However, low averages of ISS categories indicate some factors are at play such as short telecollaboration duration and potential technological issues. The gap between the previous needs analysis and current findings demonstrates that participants probably underestimated the challenge of engaging with Chinese native speakers, which would suggest that more scaffoldings and preparations are required for beginning-level learners before and during telecollaborations.
\end{abstract}

Keywords: telecollaboration, intercultural sensitivity, Chinese as a foreign language learning.

\section{Introduction}

Computer Mediated Communication (CMC) is a sub-field of computer assisted language learning. Telecollaboration projects are recognized as one of CMC types

\footnotetext{
1. Trinity College Dublin, Dublin, Ireland; wangm3@tcd.ie; https://orcid.org/0000-0002-1113-2821

2. Trinity College Dublin, Dublin, Ireland; devittan@tcd.ie; https://orcid.org/0000-0003-4572-0362

3. Stepaside Educate Together Secondary School, Dublin, Ireland; garryhodgins@outlook.ie

4. Trinity College Dublin, Dublin, Ireland; ciaran@bridge21.ie
}

How to cite this article: Wang, M., Devitt, A., Hodgins, G., \& Bauer, C. (2021). Students' intercultural sensitivity development through telecollaborative Chinese language learning on Zoom: a case study of Irish students at the beginning-level of Chinese language. In N. Zoghlami, C. Brudermann, C. Sarré, M. Grosbois, L. Bradley, \& S. Thouësny (Eds), CALL and professionalisation: short papers from EUROCALL 2021 (pp. 279-284). Research-publishing.net. https://doi.org/10.14705/ rpnet.2021.54.1346 
by some researchers (Çiftçi \& Savaş, 2018) concerning distance collaborative learning and exchange through technology with a group of people speaking the target language. In recent years, many researchers have raised interest in exploring learners' intercultural communication competence development (Chun, 2011; O'Dowd \& Dooly, 2020). Intercultural communication competence as an 'umbrella' concept (Chen \& Starosta, 1996) includes three dimensions - intercultural awareness (cognitive), intercultural adroitness (behavioral), and intercultural sensitivity (affective). With regards to the last aspect, ISS was created by Chen and Starosta (2000) to measure partners" "active desire to motivate themselves to understand, appreciate, and accept differences" (p. 3) during intercultural communications.

This study aims to present preliminary findings about young Irish learners' intercultural sensitivity in a telecollaborative learning environment with Chinese native speakers by addressing the following research question: What kind of role does telecollaborative learning play in developing intercultural sensitivity among young Irish learners?

\section{Method}

\subsection{Participants}

The whole project applies a design-based research approach which includes two cycles of problem identifications, telecollaborative intervention designs, implementations, reflections, and revisions (supplementary materials, Appendix 1). This study followed by a needs analysis with the same group of Irish participants in 2019 goes forward to Cycle 1 implementation phase, which contains four synchronous telecollaborative sessions within four weeks in spring 2021. Twentyfour students (12 Irish at beginning-level of Chinese language, 12 Chinese) with ages ranging from 13 to 15 years old and three teachers (one from Ireland, two from China) participated in this study.

\subsection{ISS survey}

The ISS uses a five-point Likert scale (1=strongly disagree, 2=disagree, $3=$ uncertain, $4=$ agree, $5=$ strongly agree). It consists of 24 items categorized into five factors: interaction engagement, respect for cultural differences, interaction confidence, interaction enjoyment, and interaction attentiveness (supplementary materials, Appendix 2). The scales are calculated as set out in Chen and Starosta 
(2000). This paper reports a detailed analysis of ISS survey results received from seven Irish respondents after four telecollaborative sessions.

\section{Results and discussion}

In the previous needs analysis, Irish participants reported a keen interest in "engaging with China through native speaker contact" (Wang, Bauer, \& Devitt, 2019, p. 394). However, they were more negative about the actual interaction engagement with native speakers along with low averages of interaction confidence and attentiveness (Table 1). This result can be explained by the fact that one participant had very negative responses to this survey. Besides, there may have been other factors at play including short telecollaboration duration, technological issues, and participants' limited Chinese proficiency. The highest average score in interaction enjoyment (3.76) implies that Irish learners enjoy communicating with native speakers through telecollaborations.

Table 1. Descriptive statistics of ISS items

\begin{tabular}{|c|c|c|c|c|c|c|}
\hline & & $\begin{array}{l}\text { Interaction } \\
\text { Engagement }\end{array}$ & $\begin{array}{l}\text { Interaction } \\
\text { Enjoyment }\end{array}$ & $\begin{array}{l}\text { Respect for } \\
\text { Cultural } \\
\text { Differences }\end{array}$ & $\begin{array}{l}\text { Interaction } \\
\text { Confidence }\end{array}$ & $\begin{array}{l}\text { Interaction } \\
\text { Attentiveness }\end{array}$ \\
\hline $\mathrm{N}$ & Valid & 7 & 7 & 7 & 7 & 7 \\
\hline $\mathrm{Me}$ & & 2.24 & 3.76 & 3.19 & 2.43 & 2.24 \\
\hline Std & viation & .65 & 1.37 & .80 & .62 & .69 \\
\hline Mi & & 1.00 & 1.00 & 1.50 & 1.40 & 1.00 \\
\hline & um & 3.00 & 5.00 & 3.83 & 3.00 & 3.00 \\
\hline
\end{tabular}

Appendix 3 (supplementary materials) summarizes responses to all ISS items. A detailed analysis of each category is provided below.

\subsection{Interaction engagement}

This factor refers to participants' feelings in intercultural communications. Figures of Item 1 show that most of the respondents enjoy interacting with people from different cultures. Responses to Items 13 and 24 indicate that more than half of participants step into different cultures with an open mind. In terms of openmindedness, Chen and Starosta (2000) precisely explained it as a willingness “to explain themselves and accept their counterparts' explanation in intercultural interaction" (p. 5), which would suggest that Irish participants hold positive attitudes toward different cultures (Item 21). 


\subsection{Respect for cultural differences}

This factor deals with participants' reactions to their counterparts' culture and opinions, either respective or tolerant. The majority of responses to Items 2, 18, and 20 suggests that participants are more culturally relativized than ethnocentric. Five of seven participants show their disagreement with Item 7 and hence that they like to be with people from different cultures. In addition, this item along with Items $2,8,18$, and 20 are connected with the concept of non-judgment discussed by Chen and Starosta (2000), which "reflects the quality of a sensitive person by allowing oneself to sincerely listen to one's culturally different counterparts" (p. 5). This is a significant step for young generations to be more objective and neutral toward cultural differences and enjoy themselves in intercultural communications with others (Okumura, 2020). The uncertain responses in Item 16 can be explained by the fact that sometimes people cannot provide a specific response regarding unforeseen circumstances.

\subsection{Interaction confidence}

Interaction confidence presents the extent of participants' confidence in intercultural communications. Figures of Items 4 and 10 show that respondents feel confident during telecollaborations. However, five uncertain responses (Item 5) may be caused by the paucity of specific communicative situations given to participants. Their individual differences regarding personalities and language proficiency levels might have also been the reason. The influence of these affective factors on young generations cannot be neglected.

\subsection{Interaction enjoyment and attentiveness}

While interaction enjoyment is self-explanatory, interaction attentiveness reflects the endeavors and attempts that participants make in intercultural interactions. Overall, the majority of responses to Items 9, 12, and 15 indicate that participants enjoy collaborations with Chinese peers through Zoom. Figures of Items 14 and 17 reflect the degree of participants' adroitness to intercultural differences, which assist them to better understand and capture different information during intercultural interactions.

\subsection{Limitations}

Findings have to be seen in light of two major limitations. The primary limitation is related to the issue of a small sample size. It may affect the reliability of ISS 
results due to responses bias, e.g. one participant had very negative responses to the ISS survey. The second limitation is concerned with time constraints (four weeks) in the process of this study. We would consider recruiting more participants in Cycle 2 with a more extended project duration (if possible) and optimizing the telecollaborative task design to fill in these gaps.

\section{Conclusions}

Despite the limited number of participants, our telecollaboration experiment seems to have provided an enjoyable and authentic environment for Irish adolescent learners. The issue of low averages for ISS categories implies that other factors such as a short telecollaboration period and potential technological problems cannot be neglected. The disconnection between the needs analysis (Wang et al., 2019) and findings in this study demonstrates that learners probably underestimated the challenge of engaging with native speakers, which would suggest that more scaffoldings and preparations are required for beginning-level learners before and during telecollaborations. More in-depth analysis to compare the pre and post changes of intercultural sensitivity among this group and the differences between Irish and Chinese participants will be discussed in an upcoming study.

\section{Supplementary materials}

https://research-publishing.box.com/s/pt4m9jisjqgc8tqntytb3oboxr90m1ku

\section{Acknowledgments}

This study is funded by the China Scholarship Council. The authors also wish to thank all participants for their time and support.

\section{References}

Chen, G.-M., \& Starosta, W. J. (1996). Intercultural communication competence: a synthesis. Annals of the International Communication Association, 19(1), 353-383. https://oi.org/10. 1080/23808985.1996.11678935

Chen, G.-M., \& Starosta, W. J. (2000). The development and validation of the intercultural sensitivity scale [Data set]. Human Communication, 3, 1-15. https://doi.org/10.1037/t61546-000 
Chun, D. (2011). Developing intercultural communicative competence through online exchanges. CALICO Journal, 28(2), 392-419. https://doi.org/10.11139/cj.28.2.392-419

Çiftçi, E. Y., \& Savaş, P. (2018). The role of telecollaboration in language and intercultural learning: a synthesis of studies published between 2010 and 2015. ReCALL, 30(3), 278-298. https://doi.org/10.1017/S0958344017000313

O'Dowd, R., \& Dooly, M. (2020). Intercultural communicative competence development through telecollaboration and virtual exchange. In J. Jackson (Ed.), The Routledge handbook of language and intercultural communication (2nd ed.). Routledge. https://doi. org/10.4324/9781003036210-28

Okumura, S. (2020). Design and implementation of a telecollaboration project for primary school students to trigger intercultural understanding. Intercultural Education, 31(4), 377-389. https://doi.org/10.1080/14675986.2020.1752546

Wang, M., Bauer, C., \& Devitt, A. (2019). Computer-mediated communication in Chinese as a second language learning: needs analysis of adolescent learners of Chinese at beginner level in Ireland. In F. Meunier, J. Van de Vyver, L. Bradley \& S. Thouësny (Eds), CALL and complexity - short papers from EUROCALL 2019 (pp. 391-396). Research-publishing.net. https://doi.org/10.14705/rpnet.2019.38.1042 


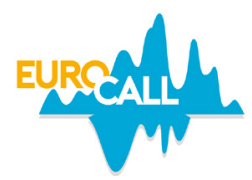

\title{
Less commonly taught languages at EUROCALL: what has changed over the years?
}

\author{
Monica Ward ${ }^{1}$
}

\begin{abstract}
The world of Computer Assisted Language Learning (CALL) is dominated by English, and to a lesser extent, French, Spanish, and German. While these languages are the main focus of EUROCALL conferences, there has always been a presence of Less Commonly Taught Languages (LCTLs) at these conferences. Most of the official languages of the EU and European languages more generally have been discussed by CALL researchers at EUROCALL conferences, but some languages have yet to make an appearance. There have also been presentations on other LCLTs outside of Europe, including Mandarin, Arabic, Japanese, and less widely spoken languages such as Thai and Nahuatl. This paper looks at the presence of LCTLs at EUROCALL conferences since 1993 and reflects on what has changed over the years. It notes the importance of the conference location on the languages discussed at the conference and the role of EU projects in supporting LCTLs.
\end{abstract}

Keywords: less commonly taught languages, CALL, EUROCALL.

\section{Introduction}

The Ethnologue (2021) estimates that there are over 7,000 languages in the world, ranging from widely spoken languages such as Mandarin, English, and Spanish to less commonly spoken languages like Czech and Greek, and endangered languages like Karaim and Erromintxela. There are 24 official languages of the European Union (EU, 2020) but there are many other official, regional, minority, and endangered languages spoken across Europe. EUROCALL is the European association for CALL and a multilingual Europe is important for EUROCALL (Chesters, 1999; Kingscott, 1996). Languages from other parts of the world have made appearances at EUROCALL conferences. EUROCALL gatherings took

1. Dublin City University, Dublin, Ireland; monica.ward@dcu.ie

How to cite this article: Ward, M. (2021). Less commonly taught languages at EUROCALL: what has changed over the years? In N. Zoghlami, C. Brudermann, C. Sarré, M. Grosbois, L. Bradley, \& S. Thouësny (Eds), CALL and professionalisation: short papers from EUROCALL 2021 (pp. 285-289). Research-publishing.net. https://doi.org/10.14705/rpnet.2021.54.1347 
place before 1993 (Davies, 2001) and have been hosted in 17 different countries, including majority speaking LCTLs. The list of conferences is available from the EUROCALL past conferences website (EUROCALL, 2021a).

This paper looks at LCTLs at EUROCALL since the early days of CALL, with a focus on papers since 2012 and explores what trends have emerged. The term LCTL has other related but different terms, such as less widely used languages, minority languages, heritage languages in some, but not all, contexts, amongst others (see Ward, 2018 for details). As the name suggests, LCTL refers to languages that have fewer students than other languages. It does not refer to the number of L1 speakers of the language, nor is it a reflection of the importance, intrinsic beauty, or difficulty of the language. The term is also relative and depends on location. For example, Japanese is an LCTL in Europe, but not so in Asia - see Ostler and Reyhner (2002) and Ward (2018) for more details on LCTLs.

Unsurprisingly, the focus at EUROCALL conferences has been the Most Commonly Taught Languages (MCTLs) - English, Spanish, French, and German. There are fewer L2 learners of other European languages, but this situation can change. For example, until recently, Swedish would have been mainly studied as an L2 in other Nordic countries only. However, the arrival of migrants to the country in recent years who do not speak English has meant that there is a need for general language and CALL resources for Swedish (Lindström, Hashemi, Bartram, \& Bradley, 2017).

\section{Method}

Information on each EUROCALL conference from 1993 to 2021 was reviewed to determine which languages were discussed in an L2 context at the conference. This paper only reviews papers from 2012-2020 as the information is more comprehensive than for pre-2012 conferences. From 2012, selected papers were published by Research-publishing.net and links are available on the EUROCALL conference short papers site (EUROCALL, 2021b). This short review of the presence of LCTLs at EUROCALL does not refer to all languages presented at each EUROCALL conference - only those reported in the short papers publications. There have been presentations on LCTLs (2012-2020) but no corresponding accounts were written for the short paper proceedings.

In some cases, the language being studied was explicitly stated in the abstract, in other cases it was not stated. If the language was not stated but the paper referred 
to students in a non-English speaking country (e.g. Japan), English was assumed to be the L2. If a specific approach was being described (e.g. MALL), the (naïve) assumption was language independence. For this paper for simplicity purposes, a LCTL is defined as a European language other than English, French, German, and Spanish, while noting the presence of other LCTLs from other continents.

\section{Results and discussion}

Presentations featuring Spanish, French, and German can be found at almost all EUROCALL conferences. Table 1 shows a list of LCTLs reported on in EUROCALL conferences short papers from 2012-2020.

Table 1. List of LCTLs reported in EUROCALL short papers 2012-2020

\begin{tabular}{|c|c|c|c|c|}
\hline Year & Location & Home L1 & LCTLs & Comment \\
\hline 2012 & Sweden & Yes & $\begin{array}{l}\text { Greek, Italian, } \\
\text { Norwegian, Polish, } \\
\text { Russian, Swedish, Welsh }\end{array}$ & Other: Arabic, Chinese \\
\hline 2013 & Portugal & Yes & $\begin{array}{l}\text { Italian, Swedish, } \\
\text { Portuguese }\end{array}$ & $\begin{array}{l}\text { Other: Chinese, Igbo } \\
\text { Note: special interest } \\
\text { group for Portuguese } \\
\text { teachers in Portuguese }\end{array}$ \\
\hline 2014 & Netherlands & Yes & $\begin{array}{l}\text { Albanian, Catalan, } \\
\text { Estonian, Irish, } \\
\text { Polish, Russian }\end{array}$ & \\
\hline 2015 & Italy & Yes & $\begin{array}{l}\text { Danish, Dutch, Greek, } \\
\text { Icelandic, Irish, Russian }\end{array}$ & $\begin{array}{l}\text { Other: LCTL mentioned } \\
\text { EU project: TLC }\end{array}$ \\
\hline 2016 & Cyprus & Yes & $\begin{array}{l}\text { Croatian, Finnish, Greek, } \\
\text { Icelandic, Italian, Polish, } \\
\text { Portuguese, Turkish }\end{array}$ & $\begin{array}{l}\text { Other: Arabic, } \\
\text { Nahuatl, Nawat } \\
\text { Note: LCTL special } \\
\text { interest group formed }\end{array}$ \\
\hline 2017 & UK & Yes & $\begin{array}{l}\text { Finnish, Irish, } \\
\text { Italian, Polish }\end{array}$ & $\begin{array}{l}\text { Other: Japanese } \\
\text { Note: LCTL workshop }\end{array}$ \\
\hline 2018 & Finland & Yes & Finnish, Irish & $\begin{array}{l}\text { Other: Japanese, Korean } \\
\text { Note: LCTL symposium }\end{array}$ \\
\hline 2019 & Belgium & Yes & $\begin{array}{l}\text { Ancient Greek, Dutch, } \\
\text { Finnish, Icelandic, Irish, } \\
\text { Italian, Portuguese, } \\
\text { Russian, Slavic, } \\
\text { Slovak, Swedish }\end{array}$ & $\begin{array}{l}\text { Other: Chinese; } \\
\text { LCTL mentioned } \\
\text { Note: LCTL symposium }\end{array}$ \\
\hline 2020 & Denmark & No & $\begin{array}{l}\text { Estonian, Finnish, Finish } \\
\text { Sign Language, Icelandic, } \\
\text { Italian, Old Norse, } \\
\text { Portuguese, Russian }\end{array}$ & $\begin{array}{l}\text { Other: Japanese, Korean } \\
\text { Note: LCTL symposium; } \\
\text { EU project: iRead }\end{array}$ \\
\hline
\end{tabular}


There are two main themes from this analysis of past EUROCALL conferences. The first is that the location of the conference has an impact on which LCTL languages are spoken about at the conference; Swedish, Finnish, and other Nordic languages at conferences in the Nordic countries (Sweden, Finland, Denmark) and Greek and Turkish at the conference in Cyprus (2016). The only recent exception is Danish, which was not reported on in 2020 (but this may be partly Covid-19 related). The 2018 conference had a LCTL symposium at which several LCTLs were discussed, but not reported on in the short papers. The second observation is that many LCTLs have a presence at EUROCALL conferences as they are part of a larger EU project. The languages are sometimes mentioned only in the context of the project, rather than standalone presentations on the language itself - e.g. Dutch in the context of the TLC project (Oberhofer \& Colpaert, 2015).

Reflecting on changes, English, Spanish, French, and German continue to be the languages with the most focus, but there are usually at least a few presentations on LCTLs at each conference. There are many reasons why LCTLs have a limited presence at EUROCALL, including the fact that less students study them and LCTL teachers may work in precarious positions and may have CALL skills. The LCTL special interest group was formed at the 2016 conference in Cyprus. A group of EUROCALL members working with LCTLs recognised the need for CALL researchers to work together on common problems and to share knowledge and expertise. There have been LCTL symposiums at EUROCALL since then and this has provided a forum for LCTL CALL researchers to learn from each other. The special interest group also has contacts with CALICO members and this is mutually beneficial for both parties. A final observation is that holding a EUROCALL conference at a location where there are LCTLs spoken provides an opportunity for LCTL CALL researchers to present their work.

\section{Conclusions}

There has been great variety among the languages discussed at EUROCALL conferences. Almost all of the official languages of the EU have had a presence (including at pre-2012 conferences), with the possible exception of Bulgarian, Maltese, Latvian, and Slovenian. Other non-EU European languages have appeared at EUROCALL conferences as well as languages from other parts of the world, most notably Japanese and Mandarin (referred to as Chinese in the short papers). It is worthwhile and important for EUROCALL to continue to provide a welcoming environment for LCTLs at its conferences. 


\section{Acknowledgements}

The author welcomes corrections, particularly if a language is missing from Table 1.

\section{References}

Chesters, G. (1999). On the politics of CALL. ReCALL, 11(1), 7-12. https://doi.org/10.1017/ S0958344000002032

Davies, G. (2001). History of EUROCALL. https://www.eurocall-languages.org/about/history

Ethnologue. (2021). Ethnologue: languages of the world. https://www.ethnologue.com/guides/ how-many-languages

EU. (2020). European Union official languages. https://europa.eu/european-union/about-eu/eulanguages_en

EUROCALL. (2021a). Past conferences. https://www.eurocall-languages.org/conferences/pastconferences

EUROCALL. (2021b). Conference short papers. https://www.eurocall-languages.org/ publications/conference-proceedings

Kingscott, G. (1996). The impact of technology and the implications for teaching. Teaching Translation and Interpreting 3. John Benjamins. https://doi.org/10.1075/btl.16.38kin

Lindström, N. B., Hashemi, S. S., Bartram, L., \& Bradley, L. (2017). Mobile resources for integration: how availability meets the needs of newly arrived Arabic-speaking migrants in Sweden. In K. Borthwick, L. Bradley \& S. Thouësny (Eds), CALL in a climate of change: adapting to turbulent global conditions - short papers from EUROCALL 2017 (pp. 40-45). Research-publishing.net. https://doi.org/10.14705/rpnet.2017.eurocall2017.686

Oberhofer, M., \& Colpaert, J. (2015). TLC Pack unpacked. In F. Helm, L. Bradley, M. Guarda, \& S. Thouësny (Eds), Critical CALL - proceedings of the 2015 EUROCALL conference, Padova, Italy (pp. 439-443). Research-publishing.net. https://doi.org/10.14705/rpnet.2015.000372

Ostler, N., \& Reyhner, J. (2002). From the special issue editors. Language Learning \& Technology, 6(2), 2-3. https://doi.org/10125/25151

Ward, M. (2018). Qualitative research in less commonly taught and endangered language CALL. Language Learning \& Technology, 22(2), 116-132. https://doi.org/10125/44639 


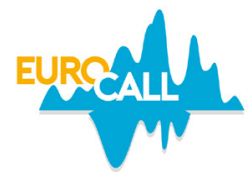

\title{
Reflections on 21st century skill development using interactive posters and virtual reality presentations
}

\author{
Andrew Warrick ${ }^{1}$ and Heather Woodward ${ }^{2}$
}

\begin{abstract}
In this preliminary research study, Japanese university students created two dimensional (2D) interactive posters and $360^{\circ}$ Virtual Reality (VR) presentations using Thinglink software. Students can use Thinglink software to annotate images with photos, videos, and descriptions. Researchers explore the extent to which students believed that creating and presenting their VR and interactive poster presentations improved their 21 st century skills of critical thinking, communication, collaboration, and creativity. They thought that creating them helped to develop their communication and creativity skills, and to a lesser extent, their collaboration and critical thinking skills. Researchers consider other avenues and recommend improvements for task design to help students develop collaboration and critical thinking skills.
\end{abstract}

Keywords: CALL, 21st century skills, Thinglink, presentation, virtual reality.

\section{Introduction}

As the economic prosperity of countries relies increasingly on technological innovations and globalization, developing students' 21 st century skills becomes essential for future success in the workforce. The National Education Association (2015) outlines four 21 st century skills to help students navigate the challenges of today's globalized world. These 21 st century skills comprise critical thinking, communication, collaboration, and creativity (4Cs). Budhai and Taddei (2015) recommend that teachers foster the 4C's development by utilizing technology. As such, there is a need to further investigate the extent to which students believe that the technology utilized develops the 4Cs. Project-Based Language Learning

1. Rikkyo University, Tokyo, Japan; andrewwarrick@rikkyo.ac.jp; https://orcid.org/0000-0001-6399-2519

2. Rikkyo University, Tokyo, Japan; heather.woodward@rikkyo.ac.jp; https://orcid.org/0000-0002-2840-9305

How to cite this article: Warrick, A., \& Woodward, H. (2021). Reflections on 21st century skill development using interactive posters and virtual reality presentations. In N. Zoghlami, C. Brudermann, C. Sarré, M. Grosbois, L. Bradley, \& S. Thouësny (Eds), CALL and professionalisation: short papers from EUROCALL 2021 (pp. 290-295). Research-publishing.net. https://doi.org/10.14705/rpnet.2021.54.1348 
(PBLL) can be used to develop the 4Cs, with Farouck (2016) noting that PBLL creates an environment for students to learn the skills of collaboration, negotiation, doing research with technology, and creating presentations - essential skills for business success. PBLL entails use of projects (i.e. a series of tasks planned to achieve a specific aim) to learn language. For example, one project consists of planning and presenting interactive posters and VR presentations using Thinglink software.

Teachers have utilized VR technology mainly to improve students' vocabulary and presentation quality (Papin \& Kaplan-Rokowski, 2020; Xie, Chen, \& Ryder, 2019); however, Hu-Au and Lee (2017) write that employing VR technology tasks can help foster student creativity, and students become eager to share their own content with others. Additionally, Lin, Wang, Kuo, and Luo (2017) find that students can improve their communication and cooperation among peers as they work together to complete VR tasks. Therefore, our research question is to what extent do students believe that VR and interactive poster software in a presentation course can contribute to the development of their 21 st century skills?

\section{Method}

\subsection{Participants}

Ninety first-year Japanese students at Rikkyo University, a private university in Tokyo, were enrolled in a mandatory English presentation course for 14 weeks. They had TOEIC scores between 280 and 680 with at least six years of formal English education in junior and senior high school.

\subsection{Thinglink}

Thinglink is a subscription-based software that allows users to upload $2 \mathrm{D}$ or $360^{\circ}$ photos, annotate them, and add voice recordings, photos, videos, notes, or pictures to those annotations (Thinglink, 2020). Students can create 2D posters or link a series of $360^{\circ}$ photos to create VR tours. Posters and presentations are interactive insofar as audience members can click on the annotations while they watch and listen to the presentations. We selected Thinglink because VR software can nurture creativity (Hu-Au \& Lee, 2017) and improve communication and collaboration (Lin et al., 2017). We therefore thought it suitable for enhancing students' 21 st century skills. 


\subsection{Procedures}

Researchers assigned two Thinglink individual presentation tasks. For each task, students used Thinglink to create 3D tours or interactive posters. Participants presented online using Zoom, an online conferencing application. Afterwards, they completed a survey.

\subsection{Survey and analysis}

At the end of the course, we administered a 20-item survey with a seven-point Likert scale. Survey questions were posed in English and Japanese, and asked students how they felt Thinglink helped to develop their creativity, collaboration, communication, and critical thinking. Descriptive statistics were used to analyze these results. Researchers also made observations from students' presentations, then discussed their observations to confirm any similar experiences.

\section{Results}

Table 1 below shows the number of students and percentage of students who answered to what extent the projects helped to develop their creativity, collaboration, critical thinking, and communication skills. For example, one student $(1.1 \%)$ strongly disagreed that the projects helped creativity whereas 22 students $(24.4 \%)$ strongly agreed.

Table 1. Students' perceptions of Thinglink fostering 21 st century skills

\begin{tabular}{|l|l|l|l|l|}
\hline & Creativity & Collaboration & $\begin{array}{l}\text { Critical } \\
\text { Thinking }\end{array}$ & Communication \\
\hline Strongly Disagree & $1(1.1 \%)$ & $10(11.1 \%)$ & $2(2.2 \%)$ & $1(1.1 \%)$ \\
\hline Disagree & $5(5.6)$ & $14(15.5)$ & $12(13.3)$ & $7(7.8)$ \\
\hline Slightly Disagree & $2(2.2)$ & $7(7.8)$ & $7(7.8)$ & $6(6.7)$ \\
\hline Neutral & $7(7.8)$ & $17(18.9)$ & $21(23.3)$ & $16(17.8)$ \\
\hline Slightly Agree & $21(23.3)$ & $17(18.9)$ & $23(25.6)$ & $27(30)$ \\
\hline Agree & $32(35.6)$ & $15(16.7)$ & $12(13.3)$ & $23(25.6)$ \\
\hline Strongly Agree & $22(24.4)$ & $10(11.1)$ & $12(13.3)$ & $10(11.1)$ \\
\hline
\end{tabular}

When asked if using Thinglink to create interactive posters and VR presentations developed their creativity, $83.3 \%$ of participants slightly agreed, agreed, or strongly agreed, and $66.7 \%$ believed the projects developed their communication skills, 
while $52.2 \%$ participants believed that the projects helped develop their critical thinking skills, and $46.7 \%$ believed it developed collaboration skills.

\section{Discussion}

Researchers noticed differences when students used Thinglink software compared to traditional software such as PowerPoint. During their presentations, participants needed to direct audience members, such as lead them on a tour of a city in VR, so they took on the communicative role of not just presenting information but guiding their audience as they interacted with their VR presentations and posters. Students might believe that their communication skills were developing because they were using different communicative functions such as directing audience members to turn to the left or right to view a particular scene; $2 \mathrm{D}$ presentations also have photos that presenters can point to and explain, while the 3D presenters did not have a pointer. As $360^{\circ} \mathrm{VR}$ allows users to 'move' from one place to another, it can provide a more authentic experience than $2 \mathrm{D}$ photos which might be better for encouraging more realistic language use (Xie et al., 2019).

Regarding creativity, participants had almost unlimited choices for creating their VR presentations and posters using Thinglink. They could tell whichever story they wished, present any place, and add any types of multimedia. We believe that the degree of freedom afforded by projects fostered their creativity, and perhaps as Wen (2020) found, the students were motivated to explore the full extent of what was possible knowing their work would be shared with peers.

For collaboration, projects were individual assignments; yet, 46.7\% of students reported that the projects helped foster collaboration. Some participants might have sought help from their classmates. Wen (2020) found that learning new technology promotes this type of cooperation as students rely on each other for assistance. If cooperative elements had been designed into projects, such as group work projects, more participants might have experienced increased collaboration as other studies such as Reinders and Bonner (2018) and Lin et al. (2017) have shown. However, results cast doubt on the reliability of students' perceptions as researchers anticipated a lower percentage of agreement.

Creating a VR tour might have been less conducive to improving critical thinking than, for example, presenting the advantages and disadvantages of solar energy. We believe students who agreed that Thinglink helped develop their critical thinking skills might have thought that the process of learning a new software or technology 
requires critical thinking skills, or that some students reflected carefully on the Thinglink task itself in creating their presentations, but more research must be conducted to confirm this rationale.

\section{Conclusion}

As technological innovations and globalization help to further economic prosperity, one of the most important tasks for teachers is fostering the development of students' 21 st century skills. More research into how effective VR and interactive poster technology is for improving the 4Cs is needed, as we only considered students' impressions of the software in furthering these skills. After our preliminary research, we consider ways to adapt VR and interactive poster tasks in the future to help students develop these skills. We realize that technology alone might fail to build these skills, so teachers should consider task design to achieve desired results.

\section{References}

Budhai, S. S., \& Taddei, L. M. L. (2015). Teaching the 4CS with technology: how do I use 21st century tools to teach 21 st century skills? ASCD.

Farouck, I. (2016). A project-based language learning model for improving the willingness to communicate of EFL students. Proceedings of IMCIC - ICSIT (pp. 145-150). https://www. iiis.org/CDs2016/CD2016Spring/papers/EB193TO.pdf

$\mathrm{Hu}-\mathrm{Au}, \mathrm{E} .$, \& Lee, J. (2017). Virtual reality in education: a tool for learning in the experience age. International Journal of Innovation in Education, 4(4), 215-226. https://doi.org/10.1504/ IJIIE.2017.10012691

Lin, M. T. Y., Wang, J. S., Kuo, H. M., \& Luo, Y. (2017). A study on the effect of virtual reality $3 \mathrm{~d}$ exploratory education on students' creativity and leadership. EURASIA Journal of Mathematics, Science and Technology Education, 13(7), 3151-3161. https://doi. org/10.12973/eurasia.2017.00709a

National Education Association. (2015). Preparing 21st century students for a global society: an educator's guide to the "Four Cs". https://www.academia.edu/36311252/Preparing_21st Century_Students_for_a_Global_Society_An_Educators_Guide_to_the_Four_Cs_Great_ Public_Schools_for_Every_Student

Papin, K., \& Kaplan-Rokowski, R. (2020). An exploratory analysis of the impact of learners' first language on vocabulary recall using immersive technologies. In K. M. Frederiksen, S. Larsen, L. Bradley \& S. Thouësny (Eds), CALL for widening participation: short papers from EUROCALL 2020 (pp. 266-271). Research-publishing.net. https://doi.org/10.14705/ rpnet.2020.48.1199 
Reinders, H., \& Bonner, E. (2018). Augmented and virtual reality in the language classroom: practical ideas. Teaching English with Technology, 18(3), 33-53.

Thinglink. (2020). Create unique experiences with interactive images, videos \& $360^{\circ}$ media. https://www.thinglink.com/

Wen, Y. (2020). Augmented reality enhanced cognitive engagement: designing classroombased collaborative learning activities for young language learners. Educational Technology Research and Development, 69(2), 843-860. https://doi.org/10.1007/s11423-020-09893-Z

Xie, Y., Chen, Y., \& Ryder, L. H. (2019). Effects of using mobile-based virtual reality on Chinese 12 students' oral proficiency. Computer Assisted Language Learning, 34(3), 225-245. https:// doi.org/10.1080/09588221.2019.1604551 


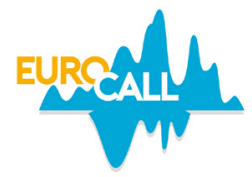

\title{
Digital language teaching after COVID-19: what can we learn from the crisis?
}

\author{
Sina Werner ${ }^{1}$ and Can Küplüce ${ }^{2}$
}

\begin{abstract}
The COVID-19 pandemic and resulting school closures have confronted the educational sector with numerous challenges. This study focuses on how teachers faced these challenges and examines what we can learn from the crisis for prospective digitally-enhanced English language teaching (ELT) and teacher education. It follows a qualitative research design and is based on semi-structured interviews with 20 foreign language teachers. The transcripts were analysed using qualitative content analysis to investigate teachers' perspectives on their work during the pandemic and to describe needs concerning their professionalisation. First results suggest that Computer Assisted Language Learning (CALL) needs to be integrated better in teacher education to foster teachers' competences for teaching languages online.
\end{abstract}

Keywords: emergency remote teaching, COVID-19, English language teaching, teacher education.

\section{Introduction}

The developments during the COVID-19 pandemic led to an unprecedented shift of learning and teaching: the related school closures forced teachers to transfer their teaching online at short notice. In Germany this meant teachers had to deal with many pre-existing challenges such as a missing infrastructure or educational inequalities regarding the integration of digital technologies in the educational system (Eickelmann et al., 2019). To distinguish this process from carefully planned concepts such as distance or blended learning, the term Emergency Remote Teaching (ERT) has emerged, which relates to

1. Ruhr-University, Bochum, Germany; sina.werner@rub.de; https://orcid.org/0000-0002-3473-1595

2. Ruhr-University, Bochum, Germany; can.kuepluece@rub.de; https://orcid.org/0000-0002-9558-9609

How to cite this article: Werner, S., \& Küplüce, C. (2021). Digital language teaching after COVID-19: what can we learn from the crisis? In N. Zoghlami, C. Brudermann, C. Sarré, M. Grosbois, L. Bradley, \& S. Thouësny (Eds), CALL and professionalisation - short papers from EUROCALL 2021 (pp. 296-301). Research-publishing.net. https://doi.org/10.14705/ rpnet.2021.54.1349 
"a temporary shift of instructional delivery to an alternate delivery mode due to crisis circumstances. It involves the use of fully remote teaching solutions for instruction or education that would otherwise be delivered face-to-face" (Hodges et al., 2020, p. 7).

This study aims to focus on the experiences of language teachers to investigate how they dealt with this exceptional situation and what happened in digital language classrooms during the pandemic. Based on the teachers' perspectives we would like to bring the needs and challenges of ERT into focus. Further, we would like to examine which competences teachers found most important and what we can learn from this time for teaching languages online. It is our understanding that we can use lessons from the COVID-19 pandemic to bring teacher education closer to the needs of prospective digital teaching practice. Following this goal, we aim to answer the following Research Questions (RQs).

RQ1: What challenges do teachers describe as most prevalent while teaching during the pandemic?

RQ2: Which competences are described as most important in dealing with the arising challenges?

\section{Method}

Due to the novelty of ERT implementation during the COVID-19 pandemic, we decided on a qualitative approach to answer the research questions. From the beginning of May 2021 to the end of July 2021, shortly after schools in Germany were reopened, we conducted semi-structured interviews with 20 secondary-school English as a foreign language teachers. The interviews lasted between 17 and 45 minutes and totalled 508 minutes of recorded material. We then transcribed all interviews to prepare them for qualitative content analysis (Kuckartz, 2014).

With the help of the data analysis software MAXQDA2020, we coded and categorised the transcribed material. To ensure intercoder reliability we first coded one of the interviews independently with our initial coding system. After comparing results and testing for Cohen's (1960) Kappa we found the intercoder reliability to be satisfactory $(\mathrm{K}=0.68)$ and continued by coding the remaining 19 transcripts. 


\section{Results and discussion}

The initial coding process produced a total of 1,127 codes which comprised 17 (main) categories (Figure 1). By far the most prominent category was 'challenges' with 402 codes. Additional salient categories identified in the initial coding process were the general description of 'ERT teaching practice' (88 codes), 'needs' regarding educational policies (74 codes), and 'technical infrastructure' (73 codes).

Further examination of the two categories most closely related to our research questions - 'challenges' and 'competences' (82 codes) - revealed additional subcategories which we will present in more detail below. Additionally, the category 'potential for prospective ELT' (57 codes) emerged as a point of interest for the overarching question of what we can learn from the crisis and thus will be discussed briefly.

Figure 1. Distribution main categories (1,127 total codes)

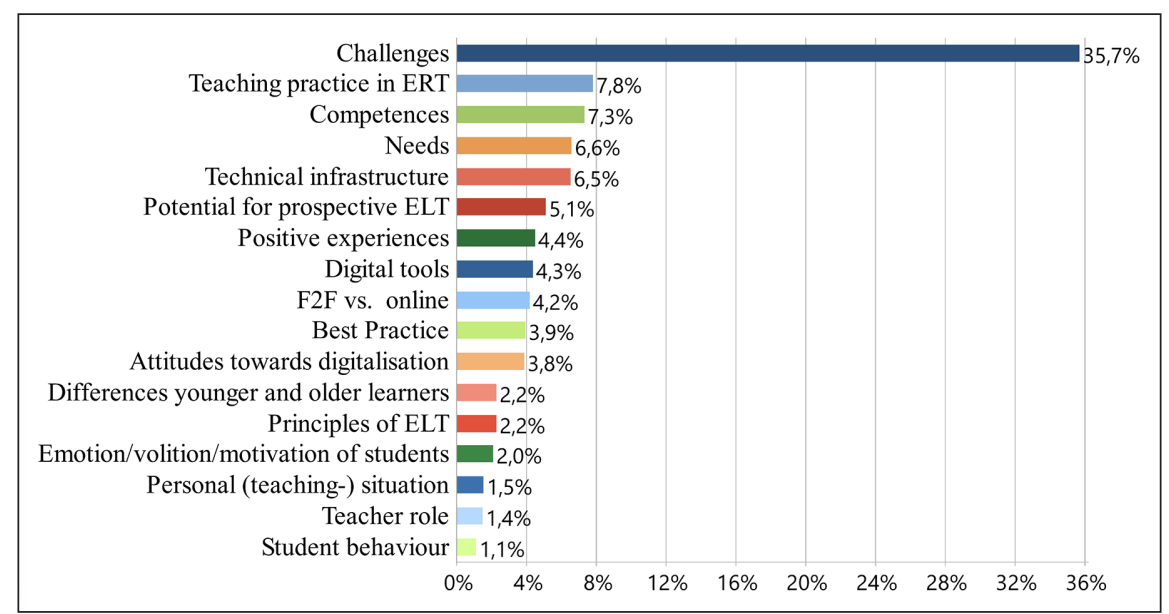

Closer analysis of the category 'challenges' produced 137 codes containing interdisciplinary challenges and 67 ELT-specific codes. Interdisciplinary challenges included issues of (a lack of) social interaction, increased workload, and less control of student output. According to the teachers, ELT-specific challenges particularly arose regarding the fostering of speaking competences and the progression in grammar and vocabulary learning due to organisational problems and/or the teachers not knowing any suitable online tools.

When being asked what competences teachers found most relevant for teaching languages during the pandemic they again mainly focused on interdisciplinary 
aspects. The most frequently mentioned competence was the ability to integrate digital tools into language teaching. The participants also recurrently considered open-mindedness and frustration tolerance as fundamental. Other interdisciplinary skills that were highlighted included the ability to organise and structure workload in ERT.

The integration of digital tools was the most frequently mentioned aspect in the category 'potential for prospective ELT'. Teachers also described the new setting as beneficial for individualising learning since students could decide on their own how much time they would spend on tasks. The analysis further showed that the mixture of asynchronous and synchronous teaching was considered a positive aspect of ERT. Some of the participants observed that individual students were more active in video-conferences than in class. Due to more flexibility in structuring their teaching, teachers saw more opportunities to integrate (international) projects as well.

Considering the 17 main categories, we believe that the prominence of the category 'challenges' can be in part explained by the experiences of ERT. Had the shift to distance teaching been planned out more sufficiently, the category would have been less outstanding since problems such as inconsistent organisation and a sudden increase of workload could have been less severe. However, the prominence of the category 'challenges' appears to also be connected to general issues in infrastructure as well as a lack of expertise when it comes to using digital tools. Following previous CALL research, at least issues of grammar and vocabulary progression as well as giving feedback could have been improved by adequate usage of digital potential (e.g. Fang, Yeh, Luo, \& Chen, 2021; Sarré, Grosbois, \& Brudermann, 2019). An additional result, especially of the three categories analysed, is the general focus on interdisciplinary aspects across categories as compared to subject-specific ones. This suggests the importance of transferable skills, such as digital literacy, media competences, as well as soft skills such as frustration tolerance and organisational talent in distance teaching scenarios.

Due to the qualitative nature of the study, results can only be seen as first impressions that could be investigated further with quantitative data. While the approach allowed us to generate in-depth, data-driven categories and subcategories, the sample of $n=20$ is not representative for language teachers at secondary schools. This could be an opportunity for additional quantitative studies that follow-up on categories identified to further explore whether the findings can be transferred to other contexts. 


\section{Conclusions}

Given the initial results, RQ1 can preliminarily be answered with a focus on interdisciplinary challenges that may be organised in two broad categories. On the one hand challenges that arose from the unique situation of the pandemic and the resulting emergency shift to online learning, such as inconsistent organisation and social isolation. On the other hand, we can identify challenges that arose from a lack of digital expertise, which resulted in an overwhelming workload, difficulties to engage students in speaking activities, and problems to provide students with feedback. This might indicate a need for better integration of CALL-related competences (e.g. using automated feedback, teacher dashboards, and learning platforms) into ELT school practice in Germany.

RQ2 can be answered by highlighting the teachers' emphasis on interdisciplinary skills and competences required. We believe that this might suggest the need for an even stronger integration of transferable soft skills such as organisational talent and frustration tolerance into language teacher education.

\section{Acknowledgements}

This project is part of the 'Qualitätsoffensive Lehrerbildung', a joint initiative of the Federal Government and the Länder which aims to improve the quality of teacher training. The programme is funded by the Federal Ministry of Education and Research. The authors are responsible for the content of this publication.

\section{References}

Cohen, J. (1960). A coefficient of agreement for nominal scales. Educational and psychological measurement, 20(1), 37-46. https://doi.org/10.1177/001316446002000104

Eickelmann, B., Bos, W., Gerick, J., Goldhammer, F., Schaumburg, H., Schwippert, K., Senkbeil, M., \& Vahrenhold, J. (2019). (Eds). ICILS 2018 \#Deutschland: Computer- und informationsbezogene Kompetenzen von Schülerinnen und Schülern im zweiten internationalen Vergleich und Kompetenzen im Bereich Computational Thinking (1st ed.). Waxmann.

Fang, W., Yeh, H., Luo, B., \& Chen, N. (2021). Effects of mobile-supported task-based language teaching on EFL students' linguistic achievement and conversational interaction. ReCALL, 33(1), 71-87. https://doi.org/10.1017/S0958344020000208

Hodges, C., Moore, S., Lockee, B., Trust, T., \& Bond, A. (2020). The difference between emergency remote teaching and online learning. Educause review, 27(1), 1-9. 
Digital language teaching after COVID-19: what can we learn from the crisis?

Kuckartz, U. (2014). Qualitative text analysis: a guide to methods, practice and using software (1st ed.). SAGE Publications Ltd.

Sarré, C., Grosbois, M., \& Brudermann, C. (2019). Fostering accuracy in L2 writing: impact of different types of corrective feedback in an experimental blended learning EFL course. Computer Assisted Language Learning, 34(5-6), 707-729. https://doi.org/10.1080/0958822 1.2019 .1635164 


\title{
Professionalization tools: impact of the game-based website 'Check your Smile' on specialized terminology acquisition
}

\author{
Nadia Yassine-Diab ${ }^{1}$, Laura M. Hartwell², and Sébastien Dejean ${ }^{3}$
}

\begin{abstract}
Computer assisted vocabulary learning, i.e. specialized terminology acquisition, is a major tool to learning Languages for Specific Purposes (LSP) necessary to students' professionalization. One current area of research is digital game-based language learning because of its motivating qualities. This paper discusses electronics students' acquisition of specific vocabulary as related to the free game-based collaborative platform Check Your Smile (CYS), which is entirely devoted to learning LSP terminology. CYS aggregates various types of games that automatically generate individualized game plays, drawing upon a collaboratively constructed multilingual dictionary. The study focuses on multiple variables including attending a selective engineering course taught in English and the language used to teach the mandatory electronics class. Empirical data shows that students having used CYS tend to obtain better vocabulary test scores than students who did not.
\end{abstract}

Keywords: serious games, terminology acquisition, English for specific purposes.

\section{Introduction}

Digital serious games remain a popular area of research as these learner-centered activities, similar to a language learning 'task' (Cornillie, Thorne, \& Desmet, 2012), have long been considered both fun and motivating (Oblinger, 2004),

\footnotetext{
1. Lairdil, Université Toulouse 3 - Paul Sabatier, Toulouse, France; nadia.yassine-diab@univ-tlse3.fr; https://orcid.org/0000-0003$3129-4075$

2. Lairdil, Université Toulouse 1 - Capitole, Toulouse, France; laura.hartwell@ut-capitole.fr; https://orcid.org/0000-0002-8601-4176 3. IMT, UMR 5219 CNRS and Université de Toulouse, Université Toulouse 3 - Paul Sabatier, Toulouse, France; sebastien. dejean@math.univ-toulouse.fr; https://orcid.org/0000-0001-9610-5306

How to cite this article: Yassine-Diab, N., Hartwell, L. M., \& Dejean, S. (2021). Professionalization tools: impact of the game-based website 'Check your Smile' on specialized terminology acquisition. In N. Zoghlami, C. Brudermann, C. Sarré, M. Grosbois, L. Bradley, \& S. Thouësny (Eds), CALL and professionalisation: short papers from EUROCALL 2021 (pp. 302-306). Research-publishing.net. https://oi.org/10.14705/rpnet.2021.54.1350
} 
bringing attraction to the chore of vocabulary acquisition. According to Hung et al. (2018), a learning game, often focused on vocabulary acquisition, can be defined as "a playful activity that is structured by rules for the pursuit of quantifiable outcomes (e.g. win states and points), and incorporates educational objectives (e.g. knowledge acquisition) as its own end" (p. 89). These games thus help to place learners in a positive state of mind (Papastergiou, 2009) as they actively evolve in a social dimension (Oblinger, 2004). The setting implies that mistakes are treated in a different way, while risk-taking is encouraged (Mariais, 2012, p. 48). However, according to the review by Benini and Thomas (2021), "empirical research is still limited when it comes to analyzing the effectiveness of gamification in educational and [second language acquisition] settings and practices" (p. 32).

In response to that gap, this paper examines the empirical data related to the technical English terminology acquisition by French electronics students with access to the platform CYS, which is a collaborative digital game-based language learning web platform targeting specific English vocabulary. The data covers three variables of the cohort: the participation in an optional selective engineering course taught in English, the language of the primary electronics class that may be either English or French, and finally the use or not of the CYS platform. We hypothesize that student use of serious games targeting specific lexical needs correlates with greater technical vocabulary acquisition while the addition of multiple sources of English will increase lexical acquisition. This paper is part of a larger three year quantitative (user tests) and qualitative (surveys) study analyzing the data of 441 engineering and medical students' consultations of CYS (Yassine-Diab et al., 2016).

Drawing upon a collaboratively constructed multilingual dictionary, CYS aggregates a bouquet of games. Individualized user game plays are automatically generated to target the user's field of study. The first experimentations originated following a needs' analysis in 2011-2014 for a 'Content and Language Integrated Learning' course in computing at the University Toulouse 3 - Paul Sabatier. It benefited from a French IDEX grant in 2016-2018 for increased research and development. The data presented here is from the 2016-2018 cohorts in preparation of a platform redesign and conception of a secondary premium access. It currently consists of seven games ranging from crossword puzzles to oral games requiring attention to syllable stress, as well as a collaborative dictionary organized according to academic field aimed at supporting vocabulary acquisition of English for specific purposes. For this, any user can submit a pair of new terms (word, translation and definitions), before users vote on the submission to validate or reject the entry. 


\section{Method}

The variables examined here relate to the specificities of 248 engineering students. Among these, 39 high-performing students, called $\mathrm{CMI}^{4}$ students, were selected to participate in an intensive engineering course taught in English. All students attended a regular English class and an electronics class, which was taught either in English (60 students) or in French (188 students), while approximately 40\% of students had access to CYS.

Data was collected during a 30-minute summative evaluation (pre-test) before classes began and again at the end of the semester (post-test). The short answer evaluation questions, formulated by English and electronics teachers, included technical illustrations and instructions such as responding in a short answer to the questions 'find the band-rejection filter' or 'describe the following graph'. The objective was to determine whether students knew and could use the necessary professional English vocabulary for electronics.

The evolution between the two tests was assessed by the computation of a progression rate determined as: (post-test - pre-test) / pre-test. The resulting percentage corresponds to the difference between the two scores in relation to (divided by) the pre-test score. This median gives a central tendency indicator of progression, which tends to be robust despite potential outliers.

\section{Results and discussion}

Students did better on the post-test than on the pre-test as demonstrated by the median progression rates. Of the 248 students, 210 increased their score, the median rate being $45 \%$ (see Table 1, subsets do not equal 248 as only available data is used per subset). The highest progression rates are for students who used CYS and were not selected for the CMI course (52\%) or whose electronics course was taught in French. The difference of progression between students attending electronics class in French and using CYS (50\%) or not using CYS (29\%) is notable.

Table 1. Student progression rates for various subsets

\begin{tabular}{|l|l|l|}
\hline Progression Rate (S2 - S1) / S1 & $\#$ & Median \\
\hline Global & 248 & $45 \%$ \\
\hline CYS No & 170 & $50 \%$ \\
\hline
\end{tabular}

4. CMI stands for Cursus Master en Ingénierie 
Professionalization tools: impact of the game-based website 'Check your Smile'...

\begin{tabular}{|l|l|l|}
\hline CYS Yes & 65 & $36 \%$ \\
\hline Electronics in French / CYS No / CMI No & 109 & $29 \%$ \\
\hline Electronics in French / CYS Yes / CMI No & 24 & $50 \%$ \\
\hline Selective CMI No / CYS No & 111 & $29 \%$ \\
\hline Selective CMI No / CYS Yes & 42 & $52 \%$ \\
\hline Electronics in English / CYS No & 19 & $39 \%$ \\
\hline Electronics in English / CYS Yes & 41 & $35 \%$ \\
\hline Selective CMI Yes / CYS No / Elec. in English (Yes) & 18 & $43 \%$ \\
\hline Selective CMI Yes / CYS Yes / Elec. in English (Yes) & 21 & $22 \%$ \\
\hline
\end{tabular}

Every CMI student ( $n=18+21$ i.e. 39) attended electronics classes in English, although some students in the English-based electronics class $(n=19+41$, i.e. 60) did not attend the CMI course. Thus, there is considerable overlap of these two subsets, both of which had rates lower than the global median $(45 \%)$. The combination of these two in-class variables may explain a lower global progression rate for students using CYS (36\%), as these students benefited from much more intensive in-class English attention. The data on the smaller cohort of attending both CMI and electronics in English $(n=39)$ is insufficient to explain the lower level of progression by CYS users $(22 \%)$. Thus, CYS appears to correlate with greater gains for students with less in-class access to English.

\section{Conclusions}

An analysis of the empirical data demonstrates that completing activities on CYS, a serious game targeting specific lexical needs, does correlate with greater technical vocabulary acquisition, especially for students not benefiting from selective courses in English. Variables are interrelated. This suggests that vocabulary acquisition can be supported by offering multiple sources of access to English. Serious games may offer an important source for students motivated by this type of task, especially for those who do not have the opportunity to attend courses in the target language.

In the future, we intend to examine the effect of student practices such as the amount of time spent on CYS and the chosen game. Other studies have found (Hartwell, 2010) that on-line users of similar activities may avoid words that are more difficult and that time spent is not dependent on lexical knowledge. Further studies might look at the impact of time and game choice on vocabulary or language tests, be they written or oral. 


\section{Acknowledgments}

We thank the students Corentin Leroyer (2019), Viet Minh Thong Le (2020), and Dinh Triem Phan (2020) for their contribution to the statistical analysis of the data.

\section{References}

Benini, S., \& Thomas, M. (2021). A critical review of research on gamification and second language acquisition. In M. Peterson, K. Yamazaki \& M. Thomas (Eds), Digital games and language learning (pp. 9-46). Bloomsbury Academic. https://doi.org/10.5040/9781350133037.ch-002

Cornillie, F., Thorne, S., \& Desmet, P. (2012). Editorial. Digital games for language learning: challenges and opportunities. ReCALL, 24(3), 243-256. https://doi.org/10.1017/ S0958344012000134

Hartwell, L. M. (2010). Impact of software design on on-line text reconstruction. System, 38(3), 370-378. https://doi.org/10.1016/j.system.2010.06.009

Hung, H.-T., Yang, J. C., Hwang, G.-J., Chu, H.-C., \& Wang, C.-C. (2018). A scoping review of research on digital game-based language learning. Computers \& Education, 126, 89-104. https://doi.org/10.1016/j.compedu.2018.07.001

Mariais, C. (2012). Modèles pour la conception de learning role-playing games en formation professionnelle. Thèse de Doctorat. Université de Grenoble. tel.archives-ouvertes.fr/tel00702237

Oblinger, D. G. (2004). The next generation of educational engagement. Journal of Interactive Media in Education, 2004(1). https://doi.org/10.5334/2004-8-oblinger

Papastergiou, M. (2009). Digital game-based learning in high school computer science education: impact on educational effectiveness and student motivation. Computers and Education, 52(1), 1-12. https://doi.org/10.1016/j.compedu.2008.06.004

Yassine-Diab, N., Alazard-Guiu, C., Loiseau, M., Sorin, L., \& Orliac, C. (2016). Check your Smile, prototype of a collaborative LSP website for technical vocabulary. In S. PapadimaSophocleous, L. Bradley \& S. Thouësny (Eds), CALL communities and culture - short papers from EuroCALL (pp. 496-501). Research-publishing.net. https://doi.org/10.14705/ rpnet.2016.eurocall2016.613 


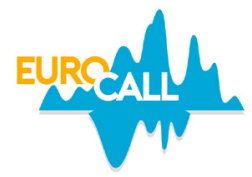

\title{
Addressing the impact of informal language learning practices in digital wilds on the development of $\mathrm{L} 2$ digital literacies
}

\author{
Artem Zadorozhnyy ${ }^{1}$ and Baohua $\mathrm{Yu}^{2}$
}

\begin{abstract}
An extensive number of studies acknowledge the transformed nature of literacies by building on the complexity of multimodal semiotic repertoires and available digital resources (Reinhardt \& Thorne, 2019; Toffoli, 2020). The exposure to such resources and tools makes digital literacies dynamic as environments provide students with opportunities to apply their skills in praxis through trial and failure. Among the existing conceptual constructs that might help discuss the complex nature of online digital informal learning practices and their connection to L2 digital literacies, the framework of dynamic systems theory (Larsen-Freeman, 2019) is implemented. Qualitative methodology was employed to explain whether informal language learning practices are conducive to constructing L2 digital literacies among pre-service language teachers. Relevant pedagogical implications are discussed.
\end{abstract}

Keywords: informal language learning, L2 digital literacies, pre-service teachers, online digital environments.

\section{Introduction}

The development of digital information and communication systems established appropriate circumstances for a wide range of literacy practices to coexist. While in a traditional sense, the capacity to read and encode written language was understood as literacy, the term 'digital literacies' extended an existing notion for embracing the affordances of digital environments by building on the concepts of

\footnotetext{
1. The Education University of Hong Kong, Hong Kong SAR, China; s1130750@s.eduhk.hk; https://orcid.org/0000-00029434-6971

2. The Education University of Hong Kong, Hong Kong SAR, China; baohuayu@eduhk.hk; https://orcid.org/0000-00020321-7374

How to cite this article: Zadorozhnyy, A., \& Yu, B. (2021). Addressing the impact of informal language learning practices in digital wilds on the development of L2 digital literacies. In N. Zoghlami, C. Brudermann, C. Sarré, M. Grosbois, L. Bradley, \& S. Thouësny (Eds), CALL and professionalisation: short papers from EUROCALL 2021 (pp. 307-311). Research-publishing.net. https://doi.org/10.14705/rpnet.2021.54.1351
} 
computer literacy, multimedia literacy, and information literacy (Scribner \& Cole, 2013). To a great extent, the Internet and Web 2.0 technologies were the primary driving forces in reshaping literacy by adding ontological shifts in connection to emerging modalities which are reflected in the usage of emojis, voice and video messages, and the integration of images for transmitting and receiving messages through different modes.

Reinhardt and Thorne (2019) characterise the change in interpretation of L2 digital literacies in connection to their "participatory, multifarious, and informal" features and the engagement in digital wilds that shifted from being extensively consumption-oriented towards being more interactive and producible (p. 9). In supporting this point, Chen (2020) claims that being digitally literate means knowing how to operate specific digital tools and recognising the situated nature of literacies for establishing meaningful communication. As one of the most challenging contemporary issues for language instructors is to effectively educate students for successful and meaningful engagement in a social universe composed of many literacies, many of which exist outside traditional academic realms, researchers argue that the concept of L2 digital literacies should be addressed through bridging informal and formal learning practices (Reinhardt \& Thorne, 2019). Hence, this study depicts the reported experience of developing L2 digital literacies in informal online spaces and of underlining possible pedagogical implications by building on the example of undergraduate pre-service language teachers.

\section{Conceptual framework}

Among the existing conceptual constructs that might help discuss the complex nature of online digital informal learning practices and their connection to L2 digital literacies, the framework of Complex Dynamic Systems (CDS) theory (LarsenFreeman, 2019) seems central. Complex systems framework acknowledges the plurality of individual, socio-political, and socio-cultural levels that occur across spatial and temporal scales and function by exerting influence on each other. Prior studies support its relevance and applicability in encompassing the non-linearity and dynamism of language acquisition, which could be observed when considering language development phases and affecting determinants (Larsen-Freeman, 2019; Toffoli, 2020).

The application of CDS theory to empirical investigations about informal language learning practices remains scarce. Among existing studies, Jurkovič (2019) distinguished four pivotal components in digital learning practices that interact 
together, namely: online users, online environments, social context, and formal language instruction framework. Integrating this conceptualisation to informal language learning practices allows depicting the 'habitat' of contemporary informal language learners with online users as key actors, online environments that provide multitudinous digital affordances, broader contextual peculiarities (e.g. language status, contextual language policies), and formal language instruction framework. By adopting the stance of analysing the perceived impact of students' informal language learning practices, this work aims at addressing perceptions about the L2 digital literacies development in formal and informal learning spaces with a research question that stands as follows: to what extent are informal language learning practices conducive in constructing students L2 digital literacies?

\section{Method}

To address perceptions of student teachers related to the perceived development of L2 digital literacies, we employed face-to-face and online semi-structured interviews with 32 pre-service English language teachers ( 25 female; 7 male) enrolled in undergraduate degrees at six different higher education institutions in Kazakhstan. The interviews were conducted as part of a doctoral research project, lasted from 60 to 90 minutes, and consisted of questions addressing experiential beliefs regarding the engagement in informal learning activities and its perceived associated impact. The choice of participants was guided by the need to select individuals whose level of English proficiency was considered higher than average in the context of Kazakhstan. Hence, the study sample was represented by students majoring in Foreign Languages programme dedicated to training future foreign language teachers with 7 male and 25 female students representing six different institutions.

\section{Results and discussion}

To begin, availability of open access resources and awareness about digital affordances were reported to impact students' engagement in social-oriented technological experiences that occur within global social media platforms (i.e. Instagram, Facebook, TikTok). Interviewees, who indicated their frequent engagement in informal learning $(\mathrm{N}=12)$, considered themselves part of a global community of L2 learners that allows them to be exposed to authentic language content, thus, impacting their L2 digital literacies. Although all interviewees reported being more engaged in receptive informal learning practices (e.g. 
reading and listening-centred activities), all informants noted positive influence on L2 digital literacies associated with their engagement in productive informal language learning practices. Participants with insignificant and limited experience in informal productive language learning practices $(\mathrm{N}=7)$ were found to have a lower willingness to communicate with unfamiliar people. Several interviewees considered online discussions as unsafe environments. In particular, two female participants seemed to be intimidated by the idea of participating in online discussions.

Another crucial finding was that the development of L2 digital literacies is reported to be linked to critical thinking skills. Rephrasing Chen (2020), students involved in practices of making sense of texts in online environments are more prone to learn the features and mechanisms of the language used online such as sarcasm, everyday slang, and any other non-academic language structures. In other words, students learn how to differentiate their discoursal identities, choose appropriate words, grammar, and other language devices to sound natural. Our findings confirmed this stance as experienced informal language users $(\mathrm{N}=12)$ reported learning about different language functions and forms of language through their engagement or mere observations of online communicative practices (e.g. on forum discussions, blog posts, or comments in social media). However, what is more, exposure to different views and opinions was found to facilitate critical reflection of the content by considering and juxtaposing different perspectives stated by people of different origins and cultural backgrounds.

The analysis of interviews demonstrated that approximately half of participants $(\mathrm{N}=14)$ expect language instructors to acknowledge the affordances of digital environments by not simply adapting communicative approaches but, more importantly, conventions related to digital genres. In comparison to traditional language forms, which are usually covered within the frameworks of university sessions, this study's participants seem to believe that contemporary classroom practices should be constructed to bridge formal and informal environments. Participants, who reported being frequent informal language users, state that assignments should go beyond conventional language structures and more time should be dedicated to introducing different language forms.

Finally, four participants from different universities were found to have surprisingly low levels of L2 digital literacy and limited awareness of online social media spaces in comparison to most interviewees. Interestingly, several experienced informal language learners also acknowledged their initial unpreparedness to web-based interactions and urged language instructors to allow students to experiment with 
unconventional genres at both school and university levels. Such findings support prior findings of Reinhardt and Thorne (2019) and Yu and Zadorozhnyy (2021) who emphasised the importance of altering 'anachronistic' conventional language teaching approaches and recommended L2 instructors to consider integrating multimodal composition and digital storytelling projects to expose students to nonstandard language forms (Yu \& Zadorozhnyy, 2021).

\section{Conclusions}

Although we can refer to current generations of learners as digital natives, they still need to learn how to effectively exploit existing digital affordances to pursue language learning objectives. In alignment with prior studies, Kazakhstan interviewees recognise the need to address L2 digital literacies through purposefully planned activities in structured environments to learn about existing differences between colloquial and academic English(es). Therefore, with the augmented exposure of L2 learners to authentic language patterns in digital wilds, Kazakhstan language instructors need to acknowledge the importance of bridging informal and formal learning and consider the role of student L2 digital literacies in this process.

\section{References}

Chen, C. W.-Y. (2020). Analysing online comments: a language-awareness approach to cultivating digital literacies. Computer Assisted Language Learning, 33(4), 435-454. https:// doi.org/10.1080/09588221.2019.1569068

Jurkovič, V. (2019). Online informal learning of English through smartphones in Slovenia. System, 80, 27-37. https://doi.org/10.1016/j.system.2018.10.007

Larsen-Freeman, D. (2019). On language learner agency: a complex dynamic systems theory perspective. The Modern Language Journal, 103(S1), 61-79. https://doi.org/10.1111/modl.12536

Reinhardt, J., \& Thorne, S. L. (2019). Digital literacies as emergent multifarious literacies. In N. Arnold \& L. Ducate (Eds), Engaging language learners through CALL (pp. 208-239). Equinox.

Scribner, S., \& Cole, M. (2013). The psychology of literacy. Harvard University Press.

Toffoli, D. (2020). Informal learning and institution-wide language provision: university language learners in the 21st century. Palgrave Macmillan. https://doi.org/10.1007/978-3030-37876-9

Yu, B., \& Zadorozhnyy, A. (2021). Developing students' linguistic and digital literacy skills through the use of multimedia presentations. ReCALL, 1-15. https://doi.org/10.1017/ S0958344021000136 


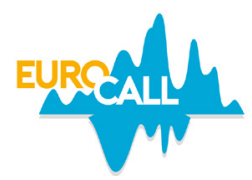

\title{
Developing pedagogically appropriate language corpora through crowdsourcing and gamification
}

\author{
Rina Zviel-Girshin ${ }^{1}$, Tanara Zingano Kuhn², Ana R. Luís³, \\ Kristina Koppel ${ }^{4}$, Branislava Šandrih Todorovićs \\ Špela Arhar Holdt ${ }^{6}$, Carole Tiberius ${ }^{7}$, and Iztok Kosem ${ }^{8}$
}

\begin{abstract}
Despite the unquestionable academic interest on corpus-based approaches to language education, the use of corpora by teachers in their everyday practice is still not very widespread. One way to promote usage of corpora in language teaching is by making pedagogically appropriate corpora, labelled with different types of problems (for instance, sensitive content, offensive language, structural problems), so that teachers can select authentic examples according to their needs. Because manually labelling corpora is extremely time-consuming, we propose to use crowdsourcing for this task. After a first exploratory phase, we are currently developing a multimode, multilanguage game in which players first identify problematic sentences and then classify them.
\end{abstract}

Keywords: crowdsourcing, gamification, language teaching, pedagogical corpora.

\section{Introduction and background}

Research on corpus-based approaches to language education has been receiving increasing interest and attention in the literature, as can be seen by the growing number of publications on the subject (e.g. Callies, 2019) as well as by the

\footnotetext{
1. Ruppin Academic Center, Emek Hefer, Israel; rinazg@ruppin.ac.il; https://orcid.org/0000-0002-7926-4476

2. CELGA-ILTEC/University of Coimbra, Coimbra, Portugal; tanarazingano@outlook.com; https://orcid.org/0000-0003-2640-5500

3. CELGA-ILTEC/University of Coimbra, Coimbra, Portugal; aluis@fl.uc.pt; https://orcid.org/0000-0002-7869-7835

4. Institute of the Estonian Language, Tallinn, Estonia; kristina.koppel@eki.ee; https://orcid.org/0000-0003-3194-9801

5. University of Belgrade, Belgrade, Serbia; branislava.sandrih@fil.bg.ac.rs; https://orcid.org/0000-0002-2714-427X

6. University of Ljubljana, Ljubljana, Slovenia; spela.arhar@cjvt.si; https://orcid.org/0000-0003-0565-0531

7. Dutch Language Institute, Leiden, Netherlands; carole.tiberius@ivdnt.org; https://orcid.org/0000-0002-7860-5427

8. University of Ljubljana \& Jožef Stefan Institute, Ljubljana, Slovenia; iztok.kosem@cjvt.si; https://orcid.org/0000-00024282-9031

How to cite this article: Zviel-Girshin, R., Kuhn, T. Z., Luís, A. R., Koppel, K., Todorović, B. Š., Holdt, Š. A., Tiberius, C., \& Kosem, I. (2021). Developing pedagogically appropriate language corpora through crowdsourcing and gamification. In N. Zoghlami, C. Brudermann, C. Sarré, M. Grosbois, L. Bradley, \& S. Thouësny (Eds), CALL and professionalisation: short papers from EUROCALL 2021 (pp. 312-317). Research-publishing.net. https://doi.org/10.14705/rpnet.2021.54.1352
} 
organisation of a highly successful conference especially dedicated to the topic (i.e. Teaching and Learning Corpora - TaLC). Overall, much current research has been jointly contributing to the continuous development of education-driven corpus tools and corpus-based teaching materials. However, it is widely known that the use of corpora by teachers is still not very widespread (e.g. Callies, 2019) due to a series of reasons, among which are lack of appropriate training and scepticism about the quality and appropriateness of the data (Kilgarriff, 2009).

There is no doubt that not all corpora are equally useful for pedagogical purposes. Authentic texts may contain inappropriate and offensive language, as well as non-standard elements, which might be problematic when presented to learners without the mediation of the teacher. Therefore, before using corpora in education, a combination of different actions must be taken, including close monitoring of the corpus content to identify possible structural (grammar and spelling) problems, and sensitive, offensive, or other inappropriate content. The creation of such a contentcontrolled corpus, however, is time-consuming, and often requires consulting large teams of linguists and educational experts. We thus decided to start a research and innovation project to compile pedagogical corpora through crowdsourcing. The objective of this paper is to report on the second phase of this project, i.e. the development of a multimode game, which is organised in three stages, namely, data preparation, game preparation, and training of machine learning models. In this paper, we focus on game preparation.

\section{Crowdsourcing: an alternative approach to creating corpora}

A much-used method to automatically remove inappropriate content from corpora is the rule-based method, e.g. by using a blacklist of words that are considered inappropriate for learners, usually taboo words, swear words, and vulgarisms. This approach has, for instance, been employed for the creation of the SkeLL corpora (Sketch Engine for Language Learning) ${ }^{9}$. Although this method is fast, the main disadvantage is that it relies on quantifiable heuristics that are applied to ALL sentences in the corpus regardless of their meaning. For example, a sentence containing a word such as 'pussy' may be considered inappropriate for learners when it refers to a woman's vagina, but by adding 'pussy' to the blacklist, sentences where it occurs in its neutral sense of 'cat' will also be removed from the corpus, which is undesirable. Moreover, teachers might want to work with

9. https://skell.sketchengine.eu/ 
offensive language or sensitive content in their classroom, depending on the unit topic and the characteristics of their students in terms of proficiency level, cultural background, and age.

Taking these two factors together - word polysemy and freedom of choice for teachers concerning the real-world examples they want to use in their classroom - we propose an alternative solution for creating corpora for pedagogical purposes. Instead of deleting sentences containing inappropriate words or sensitive content, our aim is to create problem-labelled corpora, thus allowing teachers and material developers to select the sentences according to their needs and purposes. Since this is an extremely laborious endeavour if done manually, we propose to apply crowdsourcing techniques.

Crowdsourcing (or citizen science) is a practice where members of a wider community contribute to content creation, problem solving, or even to some aspect of research. Crowdsourcing is often based on the framework of collective intelligence (Lévy, 1997) and can be thus defined as a tool to gather collective intelligence for certain tasks. Crowdsourcing in education is defined as "a type of (a) (online) activity in which (b) an educator, or an educational organization (c) proposes to a group of individuals via a flexible open call (d) to directly help learning or teaching" (Jiang, Schlagwein, \& Benatallah, 2018, n.p.). Within this context, crowdsourcing activities may (1) benefit education by content, (2) provide practical experience for the participants, (3) contribute to the exchange of complementary knowledge, and (4) augment abundant feedback (evaluations) for learners (Jiang et al., 2018).

Given the clear advantages of applying crowdsourcing for the creation of languagerelated resources for educational purposes, we as a group of researchers within the COST Action enetCollect ${ }^{10}$ have set up a research and innovation project entitled Crowdsourcing Corpus Filtering for Pedagogical Purposes. The main goal is to have the crowd contribute to the creation of pedagogically appropriate corpora by indicating offensive sentences in data extracted from corpora. In the first phase of this project, we ran a multilanguage crowdsourcing experiment in Pybossa ${ }^{11}$ (Kuhn et al., 2021). Although participants' engagement was rather low and the feedback received was that the task was quite dull, analysis of the answers revealed some interesting results. We found that participants did not necessarily consider sentences with explicitly rude content inappropriate for language learners, and that

10. https://enetcollect.eurac.edu

11. Pybossa is a free, open-source crowdsourcing and microtasking platform that allows i.e. to design the crowdsourcing task, control the number of participants and save the collected data; https://pybossa.com/ 
although they only had to mark what was strictly 'offensive', participants often did more than this. They also marked the sentences that they found problematic, such as incomplete sentences, complex sentences, sentences containing spelling and grammar errors, or even sentences containing too many foreign terms.

Based on the modest results of and the lessons learned from this previous experiment, it was concluded that motivation for participation should be improved, as well as a more specific task should be presented, including the possibility for the participants to point out structural problems. Thus, in the second phase of this project, we have decided to follow Von Ahn (2006) and develop a 'Game with a Purpose' (GWAP), i.e. a game that is fun to play and at the same time collects useful data for tasks that computers cannot yet perform (Hacker \& Von Ahn, 2009, p. 1208). Consequently, a multimode and multilanguage (Dutch, Estonian, Serbian, Slovene, and Portuguese) game is currently under development. In this game, players will first select the sentences they consider to be inappropriate for language learning purposes, and then provide the reasons for their choice by indicating in which category or categories the selected example fits, ranging from sensitivityrelated content to structural problems. Figure 1 illustrates the type of questions players will encounter in a single-player mode, however, it should be highlighted that gamification elements such as a scoring system and other engagement and motivation-enhancing features will still be added to the game. From the output of this game, i.e. the labelled sentences, corpora will be compiled that can be used by teachers, material developers, and lexicographers.

Figure 1. Illustration of one of the game modes

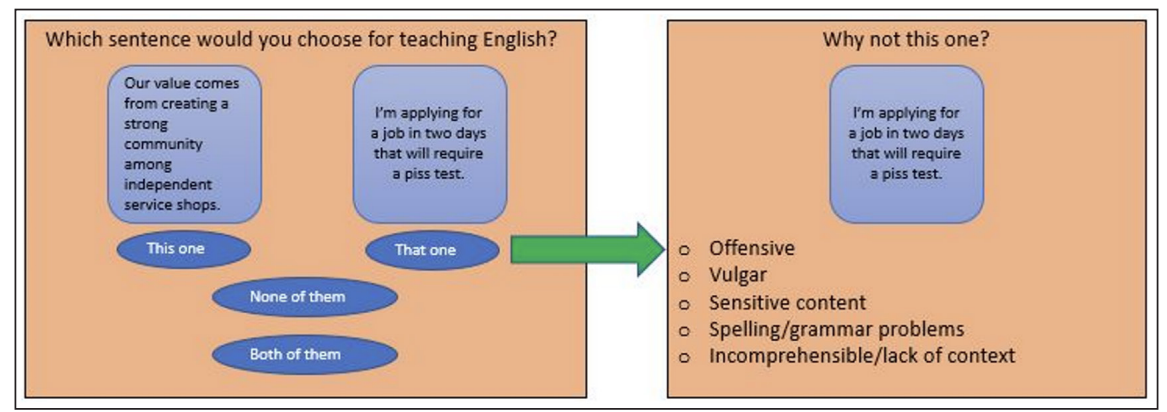

The game development has three stages. In the first stage, the datasets for the game have been prepared. In order to create datasets of potentially good example candidates and 'bad' example candidates, the web corpora have been automatically filtered for each language with some common and some language-related heuristics 
using the GDEX function ${ }^{12}$ in the Sketch Engine. The second stage involves game preparation, i.e. the development of varied game modes, implementation of gamification aspects such as scoring and motivation, and the design of the interface. As part of future work, the third stage will be concerned with training of machine learning models for each language based on the identification and categorisation of problematic content by the players.

\section{Concluding remarks}

Our work, compiling pedagogical corpora through crowdsourcing, will provide examples of good practice and a benchmark methodology, both for the preparation of corpus resources that can be more easily and freely used in the classroom as well as for the preparation of pedagogical language resources and materials. Ultimately, we would like to support teachers' awareness and usage of corpora in their teaching practice by providing them with user-friendly corpora.

\section{Acknowledgements}

The authors have been funded by the Horizon 2020 Framework Programme of the European Union under the enetCollect CA16105 COST Action, the Slovenian Research Agency (research core funding No. P6-0411, Language Resources and Technologies for Slovene), and the Portuguese national funding agency, FCT Foundation for Science and Technology, I.P. (grant number UIDP/04887/2020).

\section{References}

Callies, M. (2019). Integrating corpus literacy into language teacher education. In S. Götz \& J. Mukherjee (Eds), Learner corpora and language teaching (pp. 245-263). John Benjamins. https://doi.org/10.1075/slcs.201.12cal

Hacker, S., \& Von Ahn, L. (2009). Matchin: eliciting user preferences with an online game. In Proceedings of the SIGCHI Conference on Human Factors in Computing Systems (pp. 12071216). https://doi.org/10.1145/1518701.1518882

12. GDEX stands for Good Dictionary EXamples (Kilgarriff et al., 2008). It is a system for evaluation of sentences with respect to their suitability to serve as good examples for e.g. teaching purposes. Sentences are evaluated with respect to their length, use of complicated vocabulary, presence of controversial topics (e.g., politics, religion...), among others. 
Jiang, Y., Schlagwein, D., \& Benatallah, B. (2018). A review on crowdsourcing for education: state of the art of literature and practice. In Proceedings of the 22nd Pacific Asia Conference on Information Systems. PACIS 2018 Proceedings.

Kilgarriff, A. (2009). Corpora in the classroom without scaring the students. In Proceedings of the 18th International Symposium on English Teaching and Learning in the Republic of China. National Taiwan Normal University. http://www.kilgarriff.co.uk/Publications/2009K-ETA-Taiwan-scaring.doc

Kilgarriff, A., Husák, M., McAdam, K., Rundell, M., \& Rychlý, P. (2008). GDEX: automatically finding good dictionary examples in a corpus. In Proceedings of the XIII EURALEX international congress (pp. 425-432). Universitat Pompeu Fabra.

Kuhn, T. Z., Todorović, B. Š., Holdt, Š. A., Zviel-Girshin, R., Koppel, K., Luís, A. R., \& Kosem, I. (2021). Crowdsourcing pedagogical corpora for lexicographical purposes. In Proceedings of XIX EURALEX Congress: Lexicography for Inclusion, Vol. II, Democritus University of Thrace (pp. 771-779).

Lévy, P. (1997). Collective intelligence: mankind's emerging world in cyberspace (R. Bononno. Trans.) Helix Books.

Von Ahn, L. (2006). Games with a purpose. Computer, 39(6), 92-94. https://doi.org/10.1109/ MC.2006.196 


\section{Author index}

A

Akhlaghi, Elham 1

Albertson, Brendon 6

Alharbi, Amera 12

Allen, Christopher 18

Alm, Antonie 23

Antoniou, Savvi 243

Ashby, Soyini 200

B

Bączkowska, Anna 1

Barnett-Passard, Rona 207

Bauer, Ciarán 279

Bédi, Branislav 1, 29, 143, 267

Berthelsen, Harald 1

Blake, John 238

Borthwick, Kate 12

Boulton, Alex 52

Brudermann, Cédric xiii

C

Canollari-Baze, Albana 35

Canto, Silvia 41, 155

Cardoso, Walcir 126, 167, 226, 261

Charalambous, Andreas 273

Cheng, Li 46

Choubsaz, Yazdan 52

Chua, Cathy 1

Chujo, Junko 57

Combe, Christelle 112

Connolly, Ronan 63

Cotelli Kureth, Sara 80

Cucchiarini, Catia 1
D

David, Gaby 35

Dejean, Sébastien 302

Delforge, Carole 75

Delibegović Džanić, Nihada 119

De Lima Guedes, Karla K. 69

Delorme Benites, Alice 80

Devitt, Ann 279

Dey-Plissonneau, Aparajita 88

Di Sarno-García, Sofia 94

$\mathbf{E}$

Eardley, Annie 112

F

Foucher, Anne-Laure 172, 248

G

Gajek, Elżbieta 119

Godefridi, Isabelle 100

Grosbois, Muriel xiii

Gruber, Alice 155

H

Habibi, Hanieh 1

Hadjistassou, Stella 18, 106

Hartwell, Laura M. 302

Hassan, Xavière 112

Hatipoğlu, Çiler 119

Healy, Sandra 132

Herrera, Borja 137

He, Yue 126

Hodgins, Garreth 279

Holdt, Špela Arhar 312

Hopkins, Kelsey P. 143

Horváthová, Ivana 1

Hvalsøe, Pernille 1 


\section{I}

Iino, Atsushi 149

\section{J}

Jalilifar, Alireza 52

Jauregi-Ondarra, Kristi 41, 155

Joannidou, Shaunna 106, 161

Johnson, Carol 167

K

Kaome, Boingotlo Winnie 172

Kasami, Naoko 177

Kennedy, Olivia 184

Koppel, Kristina 312

Kosem, Iztok 312

Krsmanović, Ivana M. 189

Kuhn, Tanara Zingano 312

Küplüce, Can 296

L

Leblanc, Cécile 100

Lee, Hyowon 88

Lehr, Caroline 80

Lotz, Roy 1

Louca, Petros 106

Lowney, Rob 194

Luís, Ana R. 312

\section{M}

Mac Risteaird, Seán 194

Madden, Oneil 200, 207

Maizonniaux, Christèle 1

Mar-Molinero, Vanessa 69

Meshgi, Kourosh 214, 220

Meunier, Fanny 100

Milosewska, Lina 119

Mirzaei, Maryam Sadat 214, 220

Molina Muñoz, Pedro Jesus 106

Moussalli, Souheila 226

Mozgovoy, Maxim 238
Mullen, Martin 232

$\mathbf{N}$

Nelson, Trishana 207

Ní Chiaráin, Neasa 1

Nicholas, Allan 238

Ní Mhuircheartaigh, Éadaoin 194

Nishida, Toyoaki 220

Nykytchenko, Kateryna 255

$\mathbf{P}$

Papadima-Sophocleous, Salomi 243

Pétillat, Agnès 248

Petrović, Vesna M. 189

Pradier, Vincent 88

$\mathbf{R}$

Rayner, Manny 1

Riaz, Hamza 88

Richardson, David 18

Roje, Lara 29

$\mathbf{S}$

Sarré, Cédric xiii

Scriney, Michael 88

Selwood, Jaime 255

Sénécal, Anne-Marie 261

Sime, Julie-Ann 161

Sissoko, Fanny 267

Smeaton, Alan F. 88

Soulé, María-Victoria 273

Steele, Elizabeth 80

Stylianou, Kostas 273

Suñer, Ferran 100

$\mathbf{T}$

Tiberius, Carole 312

Todorović, Branislava Šandrih 312

Tsitsi, Theologia 273

Tsourakis, Nikos 1 
$\mathbf{U}$

Uí Laighléis, Gearóidín 194

W

Waldman, Tina 18

Wang, Mengdi 279

Ward, Monica 285

Warrick, Andrew 290

Watanabe, Yuki 23

Werner, Sina 296

Wigham, Ciara R. 248

Wistner, Brian 149

Woodward, Heather 290

Wright, Vicky 12

$\mathbf{X}$

Xerou, Eftychia 273

Y

Yao, Chunlin 1

Yassine-Diab, Nadia 302

Yerou, Christina 273

Yu, Baohua 307

$\mathbf{Z}$

Zadorozhnyy, Artem 307

Zoghlami, Naouel xiii

Zviel-Girshin, Rina 312 


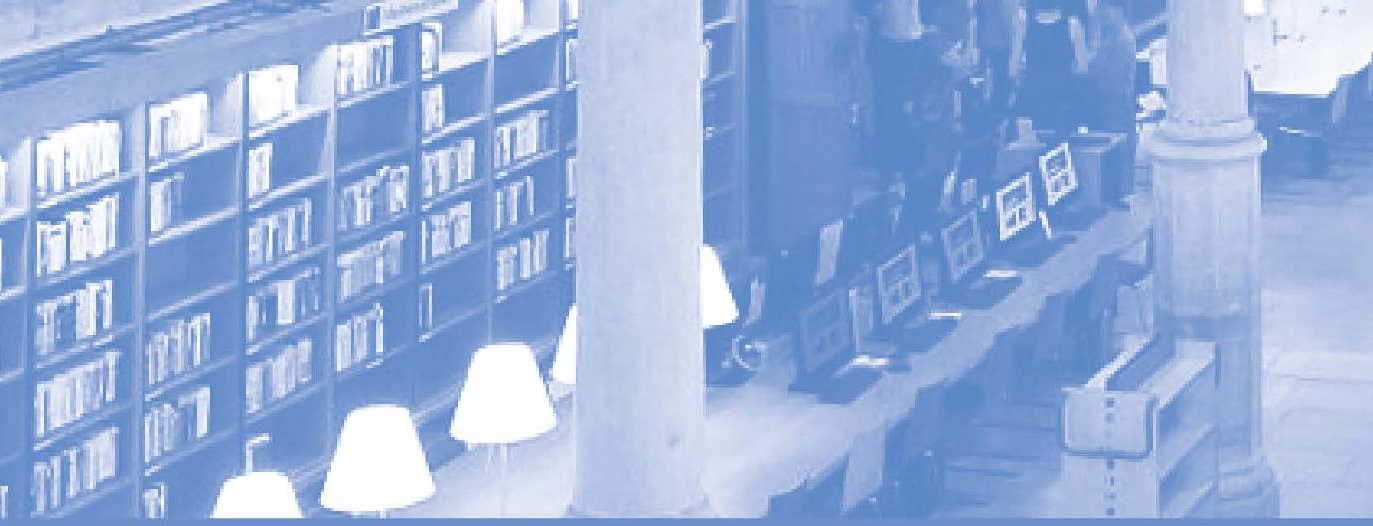

The 2021 EUROCALL conference engaged just under 250 speakers from 40 different countries. Cnam Paris and Sorbonne Université joined forces to host and organise the event despite the challenging context due to the Covid-19 pandemic. Originally programmed to be held on site in the heart of Paris, France, the EUROCALL organising team and executive committee agreed to opt for a blended and then for a fully online conference. The theme of the 2021 EUROCALL conference was "CALL \& Professionalisation".

This volume, a selection of 54 short papers by some of the EUROCALL 2021 presenters, offers a combination of research studies as well as practical examples fairly representative of the theme of the conference.

$\mathbf{R}_{\text {search-publishing.net }}$

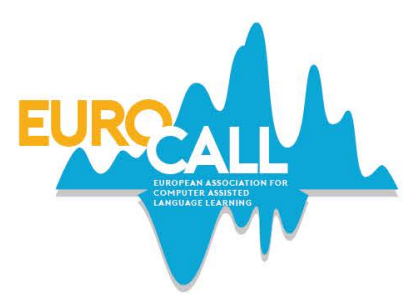

